Portland State University

PDXScholar

\title{
The status in 1980 of the Toulmin model of argument in the area of speech communication
}

Jeffrey Robert Sweeney

Portland State University

Follow this and additional works at: https://pdxscholar.library.pdx.edu/open_access_etds

Part of the Intellectual History Commons, Speech and Hearing Science Commons, and the Speech and Rhetorical Studies Commons

Let us know how access to this document benefits you.

\section{Recommended Citation}

Sweeney, Jeffrey Robert, "The status in 1980 of the Toulmin model of argument in the area of speech communication" (1980). Dissertations and Theses. Paper 3164.

https://doi.org/10.15760/etd.3155

This Thesis is brought to you for free and open access. It has been accepted for inclusion in Dissertations and Theses by an authorized administrator of PDXScholar. Please contact us if we can make this document more accessible: pdxscholar@pdx.edu. 
AN ABSTRACT OF THE THESIS OF Jeffrey Robert Sweeney for the Master of Science in Speech Communication presented November $17,1980$.

Title: The Status in 1980 of the Toulmin Model of Argument in the Area of Speech Communication.

APPROVED BY MEMBERS OF THE THESIS COMMITTEE:

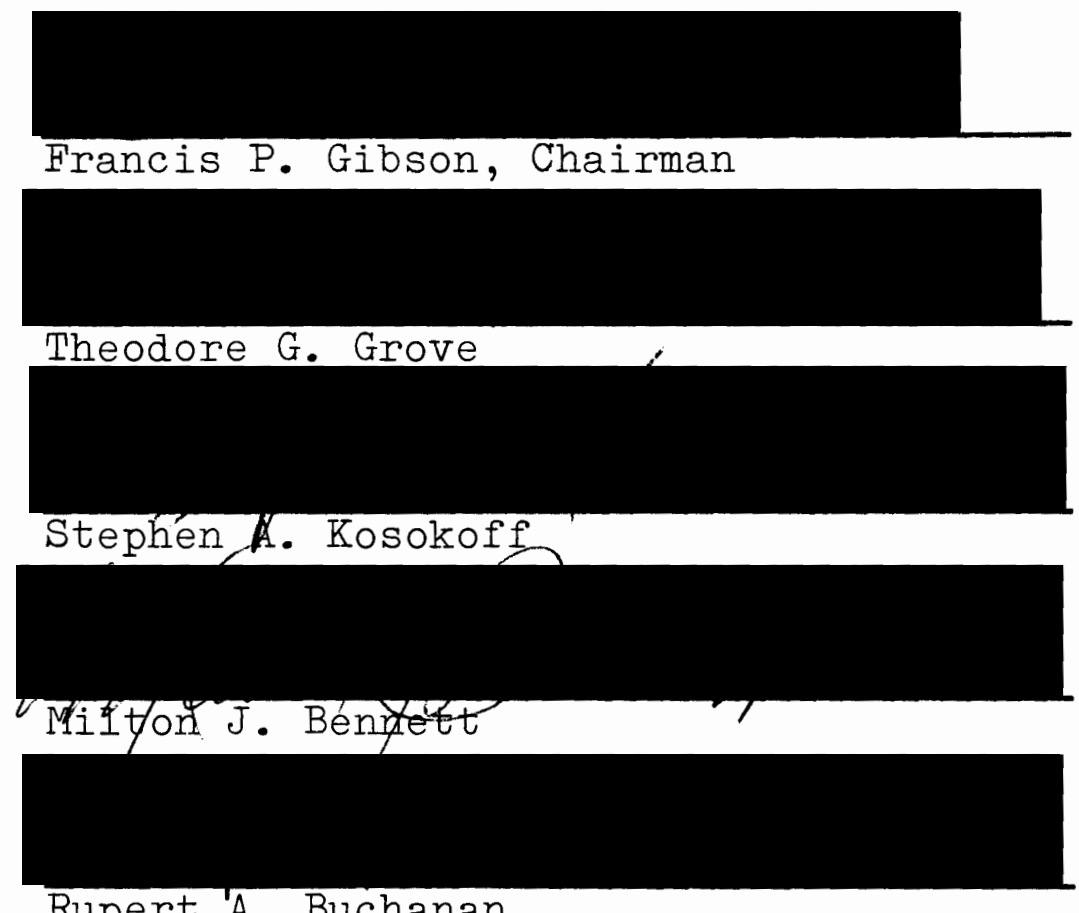

Rupert A. Buchanan

In 1958 Stephen E. Toulmin wrote of inadequacies of formal logic and proposed a new field-dependent approach to the analysis of arguments. Despite a generally negative response to his proposal from formal logicians, Toulmin's model for the laying out of arguments for analysis was 
subsequently appropriated by several speech communication textbook writers. In some textbooks, the Toulmin model has become successor to the syllogism as the paradigm of logical argument. Yet, perhaps due to their seemingly uncritical acceptance of Toulmin's approach there appears to be serious disagreement and confusion among speech communication professionals about the nature and applications of the Toulmin model. Towards a resolution of this problem, this study provides a descriptive analysis and assessment of the history of the Toulmin model and its proposed applications to speech communication.

Data were collected from two sources: (1) articles about the Toulmin approach from professional journals of philosophy and speech communication, and (2) selected speech communication textbook presentations of the Toulmin model or some variation of it. In order to determine the degree to which speech communication professionals appear to apprehend the limitations and strengths of the Toulmin approach relative to formal logic, major themes of criticism found in professional journals were used as points of departure for observations made of textbook presentations of the model. Various interpretations and applications of the Toulmin model presented in textbooks were compared, and critically assessed in order that specific issues suitable for subsequent investigation could be identified. 
Formal logicians' general criticisms of Toulmin's approach were judged to be inconsequential to potential applications of his model to speech communication. However, their criticisms specific to the model itself were judged to be salient and may be summarized as follows:

(1) many of the elements are difficult if not impossible to distinguish, (2) the backing element is inadequate to provide the kind of justification for arguments which Toulmin expects of it, (3) the data element is unclearly defined and is therefore questionable, and (4) the nature of warrantestablishing arguments is not clearly explained. The substance of these criticisms is that formal logicians object to nearly every innovative feature of the Toulmin model. It is hypothesized that this conflict between formal logicians and Toulmin may be explained as a difference of theoretical perspectives--linear vs. systems.

Apparently with little regard for crucial-differences between formal logic and Toulmin's approach, speech communication textbook writers have introduced diverse modifications of the model. Theoretical bases of Toulmin's approach such as "field-dependence" are seldom even tacitly acknowledged. Diagrammatic models have been severely altered. Modified definitions and poor exemplification have resulted in reduced clarity and consistency. There is also disagreement as to whether the model is usefully applied to field-invariant categories of argument, specific 
fields relevant to speech communication or rhetorical discourse in general.

Further research should be aimed towards a clarification of the epistemological implications of alternative theoretical perspectives, the nature of argument fields, and the nature of the elements and uses of the Toulmin model. Investigation of these issues should facilitate the judicious appraisal of the relative values of alternative approaches to argument analysis, the usefulness of proposed modifications of the Toulmin model, and the limits of its potential applications. 
THE STATUS IN 1980 OF THE TOULMIN MODEL OF ARGUMENT IN THE AREA OF SPEECH COMMUNICATION

\author{
by \\ JEFFREY ROBERT SWEENEY
}

A thesis submitted in partial fulfillment of the requirements for the degree of

MASTER OF SCIENCE
SPEECH COMMUNICATION

Portland State University

1981 
TO THE OFFICE OF GRADUATE STUDIES AND RESEARCH:

The members of the Committee approve the thesis of Jeffrey Robert Sweeney presented November 17, 1980.

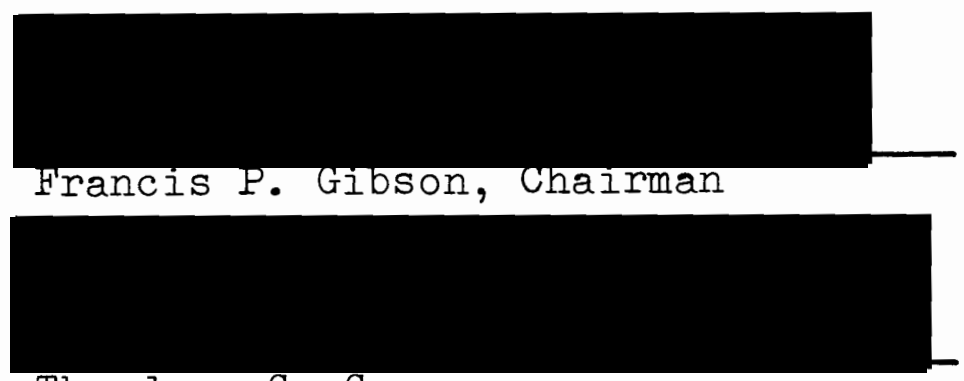

Theodore G. Grove

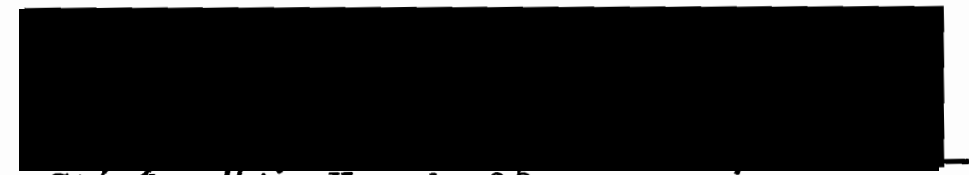

StephendA: Kosokoff

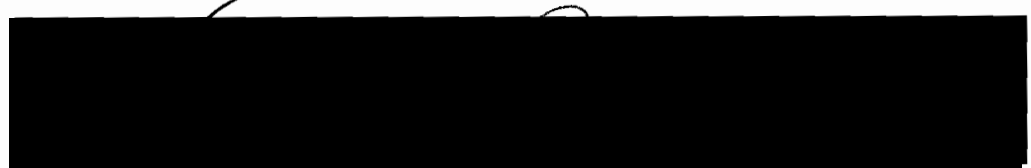

Wiltion J. Behnфtt

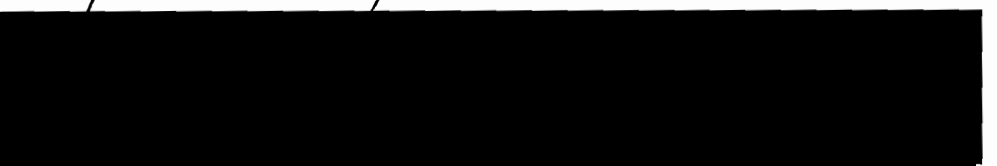

Rupert A. Buchanan

APPROVED:

Frayk Roberts, Acting Head, Department of Speech

Communication

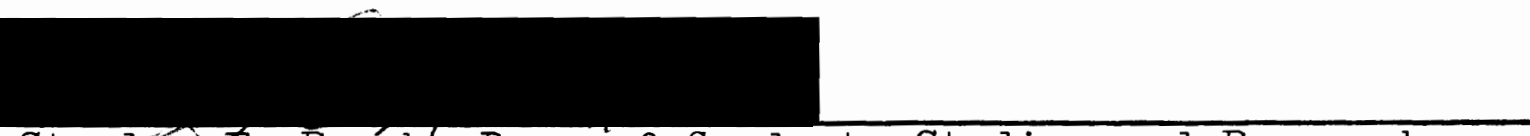

Stanley E. Rauch, Dean of Graduate Studies and Research 


\section{ACKNOWLED GMENTS}

I wish to express my deepest appreciation to all whose generous assistance and unqualified support have contributed to the success of this project. Listed below are those to whom I am especially indebted.

Francis P. Gibson. It has been my privjlege to have Dr. Gibson as thesis advisor. The initial impetus for this project was an idea suggested by him in his outstanding seminar, "Reason in Oral Discourse." Once I embarked on my research, he willingly shared with me insights born of his nearly two decades of careful and creative investigation of the Toulmin model. During the eighteen months this thesis took to write, we spent hundreds of stimulating hours together conferring, exploring, and sometimes debating. For me, these discussions were the most impactful aspect of my research. Without the benefit of his considerable experience, sure-handed guidance, and unflagging support, this project could not have been completed.

Dr. Gibson has helped me mold this work into a greater, more useful thesis than I had ever envisioned. For this I shall always be grateful. More generally, his enthusiasm for ideas and selfless devotion to the art of teaching are inspirational to me. 
Ted Grove, Milton Bennett, Steve Kosokoff, and Rupert

Buchanan deserve special thanks for serving as members of my final oral examination committee. Each of them surpassed my highest expectations by dedicating an extraordinary amount of time and care to the reading of my manuscript. Through detailed suggestions regarding style and substance, I benefited from the excellent scholarship of each member. To the extent that I responded to their suggestions, this thesis is unquestionably richer, clearer, and more readable. Most of all I appreciate the encouragement they offered me during those inevitable moments of panic and desperation.

\section{The faculty and staff of the Department of Speech}

Communication made an invaluable contribution by conspiring to create a uniquely warm and supportive environment for learning and working.

Barbara Vogelsang lent her superior expertise to the preparation and typing of the manuscript. Her assistance was a pleasure and a blessing.

Innis Bowers, whose sacrifices on behalf of this project were many, helped me more than any other with her love, laughter, patience, perspective, and companionship. In addition, my gratitude extends to the treasured members of my physical and spiritual families whose large and small contributions made the work seem less difficult and the goal, more worthwhile. The following is a partial list. 
Ben and Dora Sweeney

Dominic A. LaRusso

David J. Pegg

William G. Sweeney

Rick and Candace Rudge

Debbie Sullivan and Dan O'Shea

Richard D'Arcey

Marion Murray

Cheryl and Ted Haller

Mark Bergman

William J. Bowers

Janet Bennett

Bill and Francie Anton

Hiro and Ann Teguchi

Rick and Iucy Leffler

Don Levi

Stephen Toulmin and of course,

The Immortal Socrates. 
TABLE OF CONTENTS

PAGE

ACKNOWLEDGMENTS . . . . . . . . . . .

LIST OF FIGURES .............. ix

CHAPTER

I INTRODUCTION ................. I

Statement of the Problem ..... . 4

Methods of Research . . . . . 6

II FORMAL LOGIC AND THE TOULMIN MODEL:

ORIGINS OF A NEW APPROACH ....... 21

Formal Logic and the Syllogism ... 23

The Toulmin Model....... 38

Toulmin's Criticisms of Formal

Logic . . . . . . . . 55

Summary . . . . . . . . 68

III CRITICISM OF THE TOULMIN MODEL FROM THE PERSPECTIVE OF FORMAL LOGIC: A CONFLICT OF THEORETICAL PERSPECTIVES

General Criticisms of the Toulmin Approach ......... 82

Specific Criticisms of the Toulmin

Model........... 93

Differences of Theoretical

Perspectives ....... 122

Summary . . . . . . . . 140 
IV TEXTBOOK REPRESENTATIONS OF THE TOULMIN

APPROACH: INTERPRETATIONS OF SPEECH COMMUNICATION PROFESSIONAIS • • • • • • • 150

Theoretical Bases of the Toulmin

Approach as Reflected in Speech

Communication Textbooks . . . . 151

The Toulmin Diagrammatic Model as

Represented in Speech Communication

Textbooks

Terminology and Definitions of the

Toulmin Model as Represented in

Speech Communication Textbooks

191

The Toulmin Model as Represented by

Illustrative Examples in Speech

Communication Textbooks . . . . .

Discussion of the Syllogism in Speech

Communication Textbooks Presenting

the Toulmin Model

Summary . • . . . . . . . . . 214

$V$ APPIICATIONS OF THE TOULMIN MODEL:

UTILIZATION BY SPEECH COMMUNICATION

PROFESSIONALS

Applications of the Toulmin Model to

Field-Invariant Categories of

Argument

Applications of the Toulmin Model to

Specific Fields Relevant to Speech

Communication

256

Applications of the Toulmin Model to

Rhetorical Discourse in General . 266

Summary . • . • . . . . . . 273

VI CONCLUSION •. • . . . . . . . . 283

Summary of Major Findings . . . . 283 


$$
\begin{aligned}
& \text { Suggestions for Further Research . • • } 307 \\
& \text { Limitations of the Present Study . • • } 315
\end{aligned}
$$

A SELECTED BIBLIOGRAPHY • • • • • • • . • • • 317 


\section{IIST OF FIGURES}

FIGURE

PAGE

1. Use of Venn Diagrams to Illustrate the

Relationship Among the Elements of the

Syllogism in Example 3 . . . . . .

2. Schema of a Syllogism Showing Valid

Distribution of Terms . . . . . . 29

3. The Toulmin Diagrammatic Model . . . . . 41

4. An Example of a Simple Argument Diagrammed

with the Toulmin Model . . . . . . .

5. An Example of an Argument Diagrammed with the

Toulmin Model, Showing all Elements . •

6. One Approach to the Analysis of a Warrant-

Establishing Argument . . . . . . 118

7. A Second Approach to the Analysis of a

Warrant-Establishing Argument . . . . 119

8. The Toulmin Model According to Brockriede and

Ehninger, 1960 . . . . . . . . 167

9. The Toulmin Model According to Minnick ... 168

10. An Illustration of an Argument Analyzed in

Terms of the Toulmin Model According to

Toulmin, Rieke, and Janik . . . . . 170 
11. The Toulmin Model According to Bettinghaus in Miller and Nilsen . . . . . . . 173

12. The Toulmin Model According to Freeley . • . 173

13. The Toulmin Model According to Bradley . • . 174

14. The Toulmin Model According to Ehringer and Brockriede, 1978 . . . . . . 177

15. Two Extended Diagrams of the Toulmin Model Appearing in Bettinghaus and Book et al . . . . . . . . . 181

16. Extension of the Toulmin Diagrammatic Model to Chains of Reasoning According to Ehninger and Brockriede, 1963 . . . . 183

17. An Illustration of a Chain Argument Analyzed in Terms of an Extended Toulmin Diagram According to Book et al . . . . . . 184

18. Two Versions of the Extended Toulmin Diagram Proposed by McCroskey as a Model of the Enthymeme . . . . . . 186

19. An Extended Toulmin Diagram Proposed by Cronkhite as a Model of Persuasion and Attitude Change . . . . . . . . 190 20. An Illustrative Example of the Toulmin Model Presented by Ehninger and Brockriede, 1978 . . . . . . . . . 208 
21. An Illustrative Example of the Toulmin

Model Presented by Bryant and Wallace . . . . . . . . . . 210

22. An Illustrative Example of the Toulmin

Model Presented by Ehninger and

Brockriede, 1963 . . . . . . . 211

23. An Illustrative Example of Proof by

Generalization According to Ehninger

and Brockriede, 1963 . . . . . . . 240

24. An Illustrative Example of Proof by

Generalization According to

Blankenship . . . . . . . . . 241

25. An Illustrative Example of Effect-Cause

Proof According to Ehninger and

Brockriede, 1963 . . . . . . . . 243

26. An Illustrative Example of Sign Proof

According to Blankenship . . . . . . 244

27. Gottlieb's Extended Version of Toulmin's

Diagrammatic Model . . . . . . 261 


\section{CHAPTER I}

\section{INTRODUCT ION}

Stephen Toulmin's controversial attack on traditional approaches to logic was first published over twenty years ago in The Uses of Argument. ${ }^{1}$ Immediate response to his concepts came from formal logicians and philosophers and was largely negative. 2 Some years later, some speech communication professionals discovered Toulmin's work and enthusiastically embraced his pattern for laying out an argument according to the functions of its parts. 3 Most speech communication students have since been exposed to this pattern, otherwise known as the "Toulmin model." 4 In some speech communication textbooks the syllogism has been replaced by the Toulmin model as a paradigm of valid argument. 5 It is true that these textbook discussions of Toulmin's concepts vary in depth and significance, but that they are fairly common is evidence of the influence these concepts have had upon speech communication. 6

It is ironic that textbook writers in speech communication have found so much of immediate value in Toulmin's book, while the audience to whom it was addressed, scholars and students of philosophy, has remained largely unmoved by it. Indeed, unless he meant only to be modest, even Toulmin 
seemed to have reservations about the specific and immediate applicability of his ideas, for he introduces his book in part with these words:

The purpose of these studies is to raise problems not to solve them; to draw attention to a field of inquiry, rather than survey it fully; and to provoke discussion rather than to serve as a systematic treatise.? [Emphasis added.]

He goes on to typify his essays as "experimental incursions" and "trial balloons designed to draw fire."8 From the outset, Toulmin appears to have hoped that exposure to the fire would help forge his broady sketched themes of The Uses of Argument into a more applicable systematic treatise. This is one of the ways theories are developed and made more useful; they are subjected to the scrutiny of experts in the field and, when appropriate, empirically probed until they are subsequently rejected or refined. 9

In light of its dissemination in textbooks throughout our field, surprisingly few reports of research are found which aim at verifying Toulmin's claims or developing his concepts. As widely referenced as it is in speech communication textbooks, the Toulmin model has been the primary subject of only a dozen or so discussions in our professional journals. 10 Fewer than half of these acknowledge the attention Toulmin's ideas have attracted in philosophical literature. ${ }^{11}$ The recent publication of an introductory reasoning textbook by Stephen Toulmin, Richard Rieke, and Allan Janik may represent a refinement and more 
thorough presentation of the Toulmin model than is available elsewhere, yet it too fails to address many issues raised by critics or to suggest modifications which might improve the applicability of the Toulmin model. 12 At best, this reconfirmation of the Toulmin approach to argument provides some clarification and exemplification absent from The Uses of Argument while it ignores many fundamental questions. 13

Thus, the Toulmin model has advanced from its supportive role in exploratory essays to weather the severe and as yet unanswered criticism of formal logicians and has finally become the modern day successor to the syllogism in many speech communication textbooks. In the process the Toulmin model has undergone a diversity of diagrammatic and conceptual transformations which have for the most part gone unexplained. Considering Toulmin's apparent intent in proposing a new approach, it is ironic that the Toulmin model has infiltrated speech communication textbooks with relatively few published critical appraisals and a near absence of published empirical evaluations. Perhaps as a consequence of this apparent adoption on the basis of intuition rather than investigation, the state of the art of the Toulmin model in speech communication is diverse, diffuse, and somewhat diluted. In short, it is unclear to what extent and in what ways the Toulmin model has been developed by those who have interpreted it in speech 
communication. Further, it is unclear what effect such development may have had upon the potential applicability of the Toulmin model in our discipline.

\section{STATEMENT OF THE PROBLEM}

It appears to this writer that the time is ripe to reassess Toulmin's contributions to speech communication; to examine some of the interpretations, modifications, and applications of the Toulmin model suggested in speech communication textbooks in light of the relevant criticisms of formal logicians; and to identify specific issues towards which further investigation of the Toulmin model may usefully be directed. It is the purpose of this study to provide such an assessment in the form of a descriptive analysis of the history of the Toulmin model and its applications to speech communication. To this end it would appear that several questions need to be addressed. First, in what ways may the Toulmin approach be viewed as an innovation in the field of logic? Specifically, what assumptions, aims, and model represent the field of formal logic prior to the introduction of Toulmin's approach to the analysis of argument and how do these differ from formal logic? What problems or limitations of formal logic is the Toulmin approach intended to resolve or circumvent? These questions are the foci of chapter II. 
Second, on what basis do formal logicians criticize Toulmin's concepts? Specifically, which of these criticisms of the Toulmin approach in general and the Toulmin model in particular have implications for the application of Toulmin's concepts in speech communication? To what extent are differences in the approaches of Toulmin and formal logicians attributable to a conflict in their theoretical perspectives? These questions are the foci of chapter III.

Third, how is the Toulmin model represented in speech communication textbooks? Specifically, to what extent are innovative features of the Toulmin approach represented in speech communication textbooks? What variations or modifications are presented of the Toulmin model in its diagrammatic features, terminology, and elemental concepts? How is it exemplified in illustrations? How is the syllogism presented in relation to the Toulmin model? These questions are the foci of chapter IV.

What applications have been suggested in textbooks for the Toulmin model and what may be their implications? Specifically, how has it been utilized by some authors in the analysis and exemplification of general categories and what questions does this development raise? What applications have been suggested regarding specific fields relevant to communication? How do speech communication textbook writers suggest the Toulmin model be applied 
to rhetorical discourse in general? These questions are the foci of chapter $V$.

This study involves description, analysis, and evaluation pertaining to the above questions. Conclusions are intended to function heuristically, giving form to issues which may provide useful directions for further research. In sum, the problem which this study addresses is an apparent lack of critical evaluation in the process of adoption, adaptation, and development of the Toulmin model by speech communication professionals. By examining the history of the Toulmin model in its various stages of development and application to speech communication, issues critical to the applicability of the Toulmin model in our discipline may be identified with the intention of bringing them into clearer focus. With this study as a point of departure, subsequent research may proceed to clearly define the boundaries of applicability of the Toulmin model to speech communication theories and practices.

\section{METHODS OF RESEARCH}

According to Abraham Kaplan in The Conduct of Inquiry, "the aim of methodology is to help us to understand, in the broadest possible terms, not the products of scientific inquiry but the process itself."14 The product of the present research is the survey of a particular literature with analysis and commentary aimed to draw attention to 
inadequately explored issues which may require further investigation. This has resulted from a process involving a variety of interrelated activities all directed toward answering the questions which guided this research. This included the examination of a variety of print resources, the selection of primary sources for study, the discovery of relevant concepts within these primary sources, and the analysis, classification, organization, comparison, and contrasting of these concepts in a manner intended to best reveal feasible answers to the research questions.

Many of the procedures involved in this study are no different from those of any other research project: reading to collect data, analysis, and organization to provide clear explanation and support for a hypothesis. ${ }^{15}$ Two special problems were encountered, however, which merit discussion here because the methods of attacking them involved several techniques less typical than those already mentioned. These problems were: first, how to arrive at a clear and comprehensive analysis of the major criticisms which have been directed at the Toulmin model and are potentially pertinent to its applicability to speech communication; and second, how to select and evaluate discussions of the Toulmin model from the literature of speech communication. The solution developed for dealing with the first problem turned out to have direct bearing on the solution for dealing with the second. 
Work towards a comprehensive treatment of criticisms of the Toulmin model was needed because none was available in the literature at the time of writing. It is a supportable assumption that a deeper understanding of strengths and weaknesses of the Toulmin model would be promoted by the development of such an analysis. There may be hundreds of various references to the Toulmin model, some of them critical evaluations, in books, articles, and research reports written over the past twenty years. The location, collection, and analysis of these publications would be a supremely difficult task. Therefore, only articles devoted entirely to the evaluation of Toulmin's approach to argument were considered for study. References to such articles are found in several speech communication discussions of Toulmin. 16

By checking each reference as well as several indexes in communication, the social sciences, and philosophy, thirteen major articles devoted to an assessment of Toulmin's approach were located. 17 Nine of these were written by scholars whose expertise is in philosophy, especially formal logic. 18 Four others were authored by speech communication professionals, all but one of whom relied heavily upon some of the previously published philosophical criticisms representative of the perspective of formal logicians. 19 These articles, then, served as data which provided the basis for the presentation in chapter III. 
The analysis of the articles was performed in the following manner. First, all articles were examined carefully with an eye toward identifying contentions regarding the Toulmin model. Second, identified claims were organized into groups according to their content, while allowing for the membership of a single claim in more than one category when appropriate. Third, the resulting categories were themselves organized into a pattern representative of their relatedness or opposition to one another. The number of claims grouped in each category were taken to be indicative of force of the criticisms represented. Fourth, some categories of claim were excluded because they had more to do with the nature of Toulmin's character or his proficiency as a philosopher than with the qualities of his approach to argument. Finally, the resulting pattern of evolved categories was restructured to improve the overall comprehensibility of the presentation in chapter III. This provided a systematic method for handing the analysis of a variety of complexly related materials.

The categories derived from this analysis proved to be useful also in providing the criteria for treating the contents of the textbook survey materials obtained in the present study. In other words, identified areas of critical concern within Toulmin's approach were viewed here as significant points of presentation which may or may not be present in speech communication textbooks. The assumption 
is that those speech communication professionals who have traditionally used the syllogism in the analysis and evaluation of arguments are likely to have many of the same concerns as formal logicians who criticize the Toulmin approach. Consequently the degree to which speech communication professionals appear to apprehend the relative limitations as well as strengths of the Toulmin approach to argument may help to explain their various interpretations and suggested applications for the Toulmin model.

Textbooks were singled out for study here. There are two reasons. First, some limitation had to be placed on the materials for study for the project to be feasible. In the past twenty years numerous references to Toulmin have appeared in speech communication doctoral dissertations, masters theses, scholarly journal articles, and textbooks. Any and all of these sources might provide information relevant to the goals of this study. However, to survey them all would be inefficient if not impossible. Therefore, some limitation on the scope of materials to be considered had to be imposed.

Dissertations and theses, while they can provide valuable in-depth discussions, were ruled out because they often involve specialized concerns not representative of the field as a whole. On the other hand, articles in scholarly journals can be taken to be better representative of ideas widely known within the field because they have 
competed with other articles for publication and are circulated among members of professional organizations and university libraries. The difficulty is that surprisingly few journal articles in speech communication have been devoted to the Toulmin model since it was first introduced to our discipline in 1960.20 In the process of setting these criteria for the selection of source materials, incidental references to Toulmin in other articles on subjects of related interest were sampled and found to include few concepts salient to the research questions of this study. Thus, while there are references to several doctoral dissertations, masters theses, and a number of articles from professional journals of speech communication, none of these provide a primary data base for this study. Speech communication textbooks were selected for study because textbooks represent what Toulmin himself, incidently, calls the "transmit" of a field of knowledge, that is, the collectively validated concepts which are thought to make up a discipline and are passed on from scholar to student. 21 often included in textbooks alongside of more established ideas, innovations become part of an integrated exposition of publicly acknowledged concepts. The manner in which an innovation like the Toulmin model is incorporated into textbook presentations of a growing field like speech communication may indicate professional attitudes as to the purposes and practical values of the model. 
In addition, and perhaps more importantly, textbook presentations provide a clue as to how the next generation of speech communication theorists is likely to view the Toulmin model and its role or roles within our discipline. Thus, it is appropriate that textbook presentations of the Toulmin approach were selected for examination and analysis. The selection problem was to obtain a sample with high content validity. It was judged that the sample should include textbooks with different foci, from general surveys of the discipline to works devoted to specialized interest areas. Further, it was judged that selections should also represent changes over time in the treatment of the Toulmin model and therefore must include some older, out-of-print books as well as some of those currently available for use. Several criteria were used to ensure that the limited number of textbooks selected are appropriate to the goals of this study.

First, and most importantly, only textbooks designed for use in speech communication classrooms which present an identifiable Toulmin model were selected for study. With one exception to be discussed later, this ruled out textbooks in English, philosophy, and other fields external to speech communication.

Second, to limit the overall number of textbooks to be examined by focusing on those most likely to have influenced the greatest number of students over time, 
textbooks which had been in print at least seven years, had included the Toulmin model in at least two editions, or whose author or co-author had been associated with at least two textbooks which treat the Toulmin approach were selected for study. For example, Ehninger and Brockriede's Decision by Debate qualified for inclusion in this study on three different grounds: it remained in print well over seven years in its first edition, a second edition is currently in publication, and Ehninger is the author of another textbook in which the Toulmin model is presented. 22 Third, to allow for the inclusion of textbooks which represent special areas of interest within speech communication, five other textbooks were selected for limited analysis whether or not they met the second selection criterion. These books represent areas of interest less commonly associated with the Toulmin model: rhetorical theory, persuasion theory, rhetorical criticism, small group communication, and intercultural communication. 23 These three selection criteria provided a rational basis for limiting study to certain textbooks representing various interests within speech communication as well as changes over time. Twenty-seven textbooks discovered which met these criteria were included for study (see chapter IV).

One textbook selected for inclusion in this study meets the first criterion less directly than the others 
and its inclusion requires some explanation. The textbook is An Introduction to Reasoning by Stephen Toulmin, Richard Rieke, and Allan Janik. Because of the limited scope of the work, having to do with practical reasoning only, and perhaps because of Toulmin's association with it, this book might be mistaken for a philosophy textbook which offers an alternative to formal logic texts. Toulmin is, after all, a philosopher and courses in reasoning at many universities are taught through philosophy departments. While it is used in philosophy courses, the authors of this textbook have explicitly named several fields other than philosophy for which their book is applicable; first on their list is "departments of communication."24 Perhaps following this lead, Macmillan company has marketed the text to departments of speech communication. 25 In addition, Introduction to Reasoning has been reviewed in professional journals of speech communication and the reviewers consider the textbook well suited to undergraduate students in speech communication. 26 Finally, one of Toulmin's co-authors, Richard Rieke, is a recognized speech communication scholar with expertise in argumentation. 27 Therefore, this work is appropriately included in the sample.

The following procedures were used in the analysis of the selections. First, the textbooks were classified for purposes of comparison according to their pedagogical aims as stated in prefaces and introductions or as implied in 
their content, organization, and suggested activities or exercises. As mentioned above, five textbooks were admitted for study under the third criterion as a result of their special foci. These were temporarily set aside and not used for comparisons and contrasts developed from this part of the analysis. Of the remaining twenty-two texts, twelve were found to have as a pedagogical objective the improvement of students' oral communication skills; ten others aim instead at increasing students' understanding of and ability to engage effectively in the argumentation process. In other words, the selected textbooks are divided roughly by half into those which purport to improve a student's ability to deliver some kind of speech and those which purport to help a student cope with arguments either in debates or discourse in general. While this classification is not absolute or final in any sense, it was a useful aid in organizing materials for analysis. 28 Second, each textbook was examined, its references to formal logic and the Toulmin model located and these sections analyzed in terms of several categories derived from the initial analysis of criticisms of the Toulmin approach. This latter analysis resulted in the comparison and contrasting of critical features of the selected textbook presentations. 
Finally, patterns of similarity, difference, or change over time were noted and organized for presentation in chapters IV and $V$.

In summary, the methodology for this study involved description, analysis, and evaluation with respect to questions about how the Toulmin model has been and may potentially be further developed and applied in speech communication. Particular techniques used include:

(1) the categorization of critical claims representing issues regarding the theoretical usefulness and applicability of the Toulmin model; (2) the selection according to criteria of a limited number of textbooks which present the Toulmin model for study; and (3) the classification according to pedagogical intent and analysis in terms of predefined categories of the selected textbooks. Each of these specialized techniques was developed to suit the purposes of the present study. 
Chapter 1--Notes

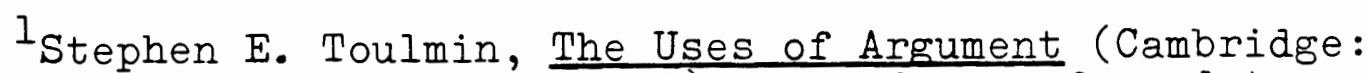
Cambridge University Press, 1958), hereafter referred to as Uses.

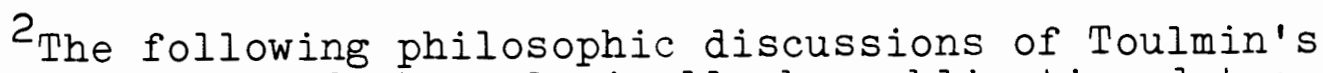
concepts are listed chronologically by publication dates: $\mathrm{J}$. Ch. Simopoulos, review of Uses, Hibbert Journal, 57 (1958), 96-98; L. C. Cooley, "On Mr. Toulmin's Revolution in Logic," Journal of Philosophy, 55 (March 26, 1959), 297-319; C. I. Hardin, review of Uses, Philosophy of Science, 26 (April, 1959), 160-163; S. Korner, review of Uses, Mind, 68 (July, 1959), 425-427; H. N. Casteneda, "On a Proposed Revolution in Logic," Philosophy of Science, 27 (July, 1960), 279-292; F. Will, review of Uses, The Philosophical Review, 69 (1960), 399-403; 0. Bird, "The Re-discovery of the Topics: Professor Toulmin's Inference-Warrants, "Mind, 70 (October, 1961), 534-539; and J. I. Cowan, "The Uses of Argument--An Apology for Logic," Mind, 73 (January, 1964), 27-54.

3 The first authors to exploit the potential applications of Toulmin's concepts to speech communication were Douglas Ehninger and Wayne Brockriede. Beginning with "Toulmin on Argument: An Interpretation and Application," Quarterly Journal of Speech, 46. (March, 1960), 44-53, and a subsequent textbook, Decision by Debate (New York: Doda, Mead and Company, 1963), these authors may be credited with having introduced the Toulmin model to speech communication professionals. Hereafter, Decision by Debate is cited as Decision (1963) for the first edition.

${ }^{4}$ Toulmin does not refer to his "pattern for analyzing arguments" as the Toulmin model (Uses, 99). However, some authors of speech communication textbooks use the phrase "Toulmin model," among them Ehninger and Brockriede, Decision (1963), and James C. McCroskey, An Introduction to Rhetorical Communication, 2nd ed. (Englewood Cliffs: Prentice-Hall, Inc., 1972). Throughout this study the pattern for the laying out of arguments for analysis will be referred to as the Toulmin model.

5 Four notable examples are Ehninger and Brockriede, Decision (1963); Erwin P. Bettinghaus, Message Preparation: The Nature of Proof (Indianapolis: Bobbs-Merrill Co., Inc. 1966); McCroskey, An Introduction to Rhetorical Communication; and John Wilson and Carroll Arnold, Public Speaking as a Liberal Art (Boston: Allyn and Bacon, Inc., 1964). 
6 This writer has observed a "streamlining" of some discussions of the Toulmin model in speech communication textbooks over the past fifteen years. For instance, Ehninger and Brockriede in Decision (1963) discuss all of the elements introduced by Toulmin in Uses. However, in a more recent edition of Decision (1978), these authors delete "backing for the warrant" entirely. Similar alterations in other textbooks are noted in chapter IV of this study.

7 Toulmin, p. 1. 8 Ibid.

${ }^{9}$ For a brief discussion of Toulmin's view of this process of theory development, see Stephen E. Toulmin, Reason in Ethics (Cambridge: Cambridge University Press, 1950), 91-95.

$10_{\text {Many more citations might be listed of articles }}$ relating to or referring to the Toulmin model. These ten are explicitly devoted to the subject of the Toulmin model or some aspect of it: (listed alphabetically by author) Wayne Brockriede and Douglas Ehninger, "Toulmin on Argument: An Interpretation and Application," Quarterly Journal of Speech, 46 (February, 1960), 46-55; Gary D'Angelo, "A Schema for the Utilization of Attitude Theory within the Toulmin Model of Argument," Central States Speech Journal, 22 (Summer, 1971), 100-109; Jerry Feezel, "A Qualified Certainty: Verbal Probability in Arguments," Communication Monographs, 41 (November, 1974), 348-356; Dale Hample, "The Toulmin Model and the Syllogism," Journal of the American Forensic Association, 14 (Summer, 1977), 1-9; Al Lewis, "Stephen Toulmin: A Re-appraisal," Central States Speech Journal, 23 (Spring, 1972), 48-55; Peter Manicas, "On Toulmin's Contribution to Logic and Argumentation," Journal of the American Forensic Association, 3 (September, 1966), 83-94; Pat Marsh, "A Model for Arguing Directive Propositions," JAFA, 6 (Winter, 1969), 1-11; James McCroskey, "Toulmin and the Basic Course," Speech Teacher, 14 (March, 1965), 91-100; Jerie Pratt, "The Appropriateness of a Toulmin Analysis of Legal Argumentation," Speaker and Gavel, 7, No. 4 (May, 1970), 133-137; and James Trent, "Toulmin's Model of Argument: An Examination and Extension," Quarterly Journal of Speech, 54 (October, 1968), 252-259.

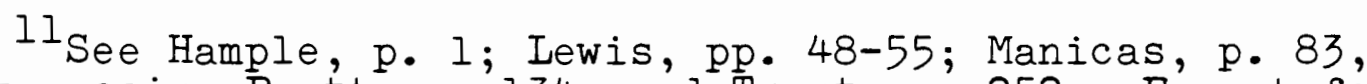
91 et passim; Pratt, p. 134; and Trent, p. 252. Except for Lewis and Manicas, these authors merely cite the philosophical criticism without any amplification or detail. 
12 Stephen E. Toulmin, Richard Rieke, and Allan Janik, An Introduction to Reasoning (New York: Macmillan Publishing Company, Inc., 1979), hereafter referred to as Reasoning.

13 Gerald Cox, review of Reasoning, by Toulin et al., Southern Speech Communication Journal, 45, No. 1 (Fall, 1979), 104-106; and Donn Parson, review of Reasoning, Journal of the American Forensic Association, 16 (Fail, 1979), 145-147.

14 Abraham Kaplan, The Conduct of Inquiry (San Francisco: Chandler Publishing Co., 1964), 23-24.

${ }^{15} \mathrm{~A}$ reference which provided useful insight into the mechanics of research is Jacques Barzun and Henry Graff, The Modern Researcher (New York: Harcourt, Brace and World, Inc., 1957).

16 of those previously cited in note 1l, Hample's references are the most complete and up-to-date.

17 The thirteen articles are these: Simopoulos; Cooley; Hardin; Korner; Casteneda; Will; Bird; Cowan; Manicas; Hample; Lewis; Trent; and Winston Brembeck, review of Uses, Quarterly Journal of Speech, 44 (April, 1958), $325-326$.

18 This includes the eight referred to in note 2 as well as Peter Manicas who, while published in Journal of the American Forensic Association, is a philosopher and formal logician.

${ }^{19}$ The exception is Brembeck whose review preceded most of the criticism published in philosophical journals.

$2 \mathrm{O}_{\text {Brockriede and Ehninger. }}$

${ }^{21}$ Stephen E. Toulmin, Human Understanding: The Collective Use and Evolution of Concepts (Princeton: Princeton University Press, 1972), 158-161.

22 Douglas Ehninger, Influence, Belief and Argument (Glenview: Scott, Foresman and Company, 1974).

${ }^{23}$ Respectively: James Golden, Goodwin Berquist, and William Coleman, The Rhetoric of Western Thought (Dubuque: Kendall/Hunt Publishing Company, 1976); Gary Cronkhite, Persuasion: Speech and Behavioral Change (Indianapolis: Bobbs-Merrill Company, Inc., 1969); 
Carroll Arnold, Criticism of Oral Rhetoric (Columbus:

Charles E. Merrill Pub. Inc., 1974); H. E. Gulley,

Discussion. Conference and Group Process, 2nd ed.

(New York: Holt, Rinehart and Winston, Inc., 1968);

John Condon and Fathi Yousef, An Introduction to Inter-

cultural Communication (Indianapolis: Bobbs-Merrill Company Inc., 1975).

24 Toulmin et al., Reasoning, p. v. Indeed, this text is apparently popular in some college philosophy courses. A recent college survey lists it among the most popular textbooks currently in use in courses in practical or informal logic. Informal Logic Newsletter, 2 (June, 1980), 19.

25 Personal interview with Stephen Kosokoff, Portland State University, Portland, Oregon, Il June 1980.

${ }^{26}$ Cox, review of Reasoning, by Toulmin et al., Southern Speech Communication Journal, 45, No. 1 (Fáll, 1979), 104-106; Daniel 0'Keefe, review of Reasoning, Journal of the American Forensic Association, 16 (Fall, 1979), 143-145; Donn Parson, review of Reasoning, JAFA, 16 (Fall, 1979), 145-147.

27 "Editor's Note," JAFA, 16 (Fall, 1979), 143.

28 No attempt was made to distinguish textbooks devoted to persuasion or rhetoric from those concerned with speech generally. Such distinctions are difficult to maintain as both persuasion and rhetoric are broadly defined by some theorists to include effective informative speaking. Regardless of the implications of titles, the books in this study were found to be clearly divided in their pedagogical objectives. 


\section{CHAPTER II}

\section{FORMAL IOGIC AND THE TOUTMIN MODEL: ORIGINS OF A NEW APPROACH}

To understand how Toulmin's model represents an innovation in the field of logic, examination must be made of the problems Toulmin adaresses in The Uses of Argument. 1 The purpose of this chapter is to explain Toulmin's concepts of reasoning in the context of a theory of formal logic based upon the classical syllogism. Specifically, attention will be focused on three topics: first, basic principles of formal logic and its paradigm, the categorical syllogism; second, the structure of the model proposed by Toulmin as a more candid tool for the laying out of arguments for analysis; and third, the chief criticisms aimed at the syllogism and formal logic which led to the development of Toulmin's approach. It should be stressed here that the following discussion is limited to main features and lines of thought which are prerequisite to the understanding of any rational criticism or practical applications of the Toulmin model. No attempt will be made to fully explain the theory of formal logic because such discussions are widely available and not germane to the current discussion. 
Even critics of the Toulmin approach consider his proposals "revolutionary" in their intent if not in their force. 2 Toulmin admits that much of what he presents in The Uses of Argument does not originate with him but has been discussed by various logicians for some time. 3 Drawing freely from others, Toulmin synthesizes some criticisms and suggestions in the hope that it will lead formal logicians into more fruitful, practicable areas of research and debate. 4 Conceptual development in the field of logic is Toulmin's stated objective. ${ }^{5}$ He summarizes his general thesis as follows:

In science and philosophy alike, an exclusive preoccupation with logical systematicity has been destructive of both historical understanding and rational criticism. Men demonstrate their rationality, not by ordering their concepts and beliefs in tidy formal structures, but by their preparedness to respond to novel situations with open minds-acknowledging the shortcomings of their formal procedures and moving beyond them. 6

To understand the "movement beyond" which Toulmin's approach to argument is taken to be, we must determine what the term "logic" has meant historically, how it is related to "formal validity" and finally how the "syllogism" is constructed to test or illustrate the properties of formal validity. These concepts are the basic components of prevailing thought in the field of logic prior to Toulmin. While logic has a rich history, our comments are limited to these fundamental concepts without which any discussion of logic cannot proceed.? 


\section{FORMAL IOGIC AND THE SYLLOGISM}

The term "logic" is drawn from the Greek root-word logos for which there is no English equivalent, although it has been roughly translated to mean everything from "order," in the universal sense, to "discourse," "imagination," and "humane nature of man." 8 The element of logos which survives in the modern concept of logic is that of order or organization, referring to the connections or relationships which can be understood to exist among things or ideas. 9 Iogic is a branch of philosophy concerned with the study of rational thought or reasoning. It is sometimes called an art, other times a science; with either interpretation, its chief concern is the development of principles of valid inference. 10 In other words, logicians have been devoted to devising formal standards for the assessment of the soundness, truth-value, correctness, or acceptability of the conclusions in argument.

"Logic, as I conceive it," writes John Stuart Mill, "is the entire theory of the ascertainment of reasoned or inferred truth. Formal logic, therefore, . . is really a very subordinate part of it."ll This distinction between logic and formal logic has never reached wide currency among philosophers, perhaps because it complicates the notion of formal validity which has been central to the concept of formal logic since it was first conceived. 
Principles and procedures have varied widely through the centuries, and yet the general dimensions of formal validity and its relation to truth have been maintained. ${ }^{12}$ Validity refers to "the consistency with which we use whatever language we have, and such consistency means that our words must faithfully follow the order and connections denoted by them."13 In other words, validity has to do with the kinds of statements that can be properly inferred from related statements without need for any further information. The chief application of logic is in the determination of the truth-value of conclusions which are the product of inference. However, truth itself is not the province of formal logic; formal validity and specific standards by which it can be determined are the subject of formal logic. As Mill states, "the end aimed at by formal logic... is not truth, but consistency."14

The systematic search for logical consistency began with the invention of the syllogism. Introduced by Aristotle in the six treatises of his Organon, the syllogism provided a firm basis for the development of a science of formal logic and served as the centerpiece to his concepts of scientific, dialectical, and rhetorical proof. 15 Later, the Megarian and Stoic philosophers added new forms and figures to the categorical premises of Aristotle, but it remained for more recent philosophers to diverge significantly from Aristotle's methods. ${ }^{16}$ It is appropriate, 
then, to focus attention on the syllogism--its function, components, and principles of application.

Aristotle developed the syllogism as a tool of scientific demonstration and dialectic. ${ }^{17}$ It was his opinion that "all instruction given or received by way of argument proceeds from pre-existent knowledge."18 To correctly draw less familiar conclusions from more familiar ones was the problem Aristotle faced which led to the development of the syllogism. ${ }^{19}$ By analyzing the way in which people name things and then classify them under more general terms according to their shared attributes, Aristotle made explicit the habits of consistency of thought which characterized the work of philosophers of his day. ${ }^{20}$ The advent of the syllogism, then, was only tangentially related to the problem of truth and the source of knowledge; it was directly concerned with the "clarification of exposition and thought."2l Through the recasting of an argument in syllogistic form, the validity of a conclusion drawn from the stated evidence becomes discoverable.

A syllogism consists of three related statements termed "propositions." These are examples of syllogistic propositions:

(1) All life is animated. No rock is animated. Therefore, no rock is life (alive). 
(2) All logicians are philosophers.

Stephen Toulmin is a logician.

Therefore, Stephen Toulmin is a philosopher.

(3) All $\mathrm{y}$ is $\mathrm{z}$.

Some $\mathrm{x}$ is $\mathrm{y}$.

So, some $\mathrm{x}$ is $\mathrm{z}$.

The final proposition in each of the above examples is the "conclusion," or statement to be affirmed. The other two propositions in each triad are termed "premises" which, when taken together as true, amount to proof of the conclusion. It is unavoidable in example three that if all of $y$, including some $x$, can be taken to be part of $z$, then some $x$ is also part of $z$. This relationship can be graphically demonstrated through the use of geometric diagrams as shown in Figure 1.22 This abstract sort of demonstration of the relationship between arbitrary symbols $x$ and $z$ is unsurprising. 
A11 $y$ is $z$.

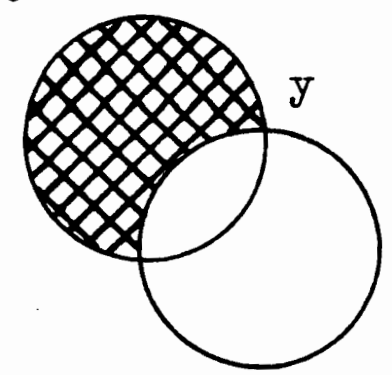

Some $x$ is $y$.

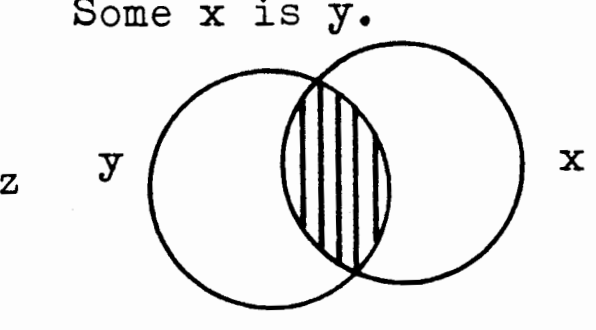

So, some $\mathrm{x}$ is $\mathrm{z}$.

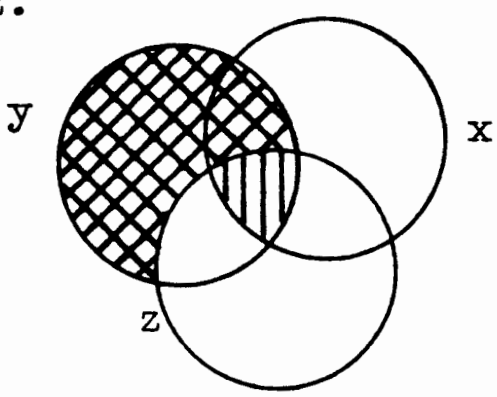

Figure 1. Use of Venn diagrams to illustrate the relationships among the elements of the syllogism in example 3 .

However, in example two the value of a syllogistic demonstration is more apparent; a person who is well aware of Toulmin the logician might express surprise at the assertion of his status as a philosopher, at least until it is pointed out that a logician is by definition a philosopher. It is this sort of demonstration which Aristotle had in mind for his syllogism to perform: to clarify thought and avoid confusion of terminology, especially in cases where several related terms are involved in the analysis of a scientific question. 
Not every three statements will qualify as a syllogism. More significantly, not every syllogistic form will qualify as "perfect" or formally valid. Medieval philosophers analyzed and summarized Aristotle's doctrine of the syllogism and developed it into a set of rules or principles that have since come into general use due to their comparative simplicity. 23 These rules are used to test a syllogism to see if it meets the requirements for formal validity. 24

The rules of the syllogism which represent standards of formal validity may be stated as follows: 25 (1) a valid syllogism must contain exactly three terms, each is used in the same sense throughout an argument; (2) in a valid syllogism, the middle term must be distributed at least once in the premises; (3) in a valid syllogism, either term which is distributed in the conclusion must also be distributed in the premise of the same name; (4) no valid conclusion can be drawn from two negative premises; (5) in a valid syllogism, if one of the premises is negative, so must the conclusion be negative; (6) in a valid syllogism, if one of the premises is particular, so also must the conclusion be particular--in other words, no valid particular conclusion may be drawn from two universal premises. The term "universal" refers to premises which have as their subject all of the members of a class; "particular," some determinate portion of a class. 
"Affirmative" refers to premises asserting the inclusion of one class in another, "negative" the exclusion of the same. Examples and explanations as to how these rules in combination may be used to certify the validity of any argument presented in syllogistic form follow. The syllogistic form itself is illustrated in Figure 2.

Major Premise: (middle term) is/are MAJOR TERM. Minor Premise: minor term is/are (middle term). Conclusion: so, minor term is/are MAJOR TERM. Figure 2. Schema of a syllogism showing valid distribution of terms.

Rule 1. In a valid syllogism, the conclusion is necessarily true if its terms hold a particular relationship to the terms of the premises. In other words, a valid syllogism is characterized by consistency in the relative inclusiveness and exclusiveness of its terms to each other as expressed in the premises and asserted in the conclusion. The first aspect of that valid relationship is that the entire syllogism may contain only three terms. By "term" is meant each noun or noun-phrase in the subject and predicate of a proposition. These terms are definable according to the formal role each plays in the syllogism. The predicate term of the conclusion is referred to as the "major term" and the premise in which it appears is a "major premise." Similarly, the subject term of the conclusion is 
referred to as the "minor term" and the premise in which it appears is a "minor premise." The third term appearing in both premises but not in the conclusion is referred to as the "middle term." So the syllogism is defined by the two terms of its conclusion and a third term shared by its premises. When these structural requirements are not met, a collection of three premises is judged to be just that and not a syllogism. Thus, equivocation in the use of terms will result in an unsound argument.

To illustrate the first rule of the syllogism, the following example is presented. While these three propositions may appear to constitute a syllogism, they may not because of ambiguity in the meaning and the number of terms: (1) physical conditioning is helpful in reducing the chances of heart attack; (2) running is good exercise; and (3) jogging is helpful in reducing the chances of heart attack. In these three propositions there are a total of five terms. While it may be argued that two of these terms refer to the same kind of activity, there is still one more term in the propositions than is permissible in a valid syllogism. "Good exercise" cannot be equated with "physical conditioning" which is sometimes its result. By this test, many syllogism-candidates may be eliminated by inserting abstract symbols in place of verbal terms as in "b is $c$, a is $d$; so, a is c." The particular referents of the terms are irrelevant to the formal validity of a 
syllogism; truth or the meaning of the terms is not at issue, just the number and relationship of terms.

Rules 2 and 3. The second and third rules of the syllogism have to do with the distribution of the terms. "Distribution" refers to the specification of the quantity of a term through the use of a quantifier, generally one of the following: "all," "some," "no," and "some. . not - . ." A syllogism will not be judged valid if the terms are not properly distributed, that is, if the conclusion goes beyond the information contained in the premises. 26 Consider the following examples of syllogism which are judged invalid because of faulty distribution of terms:

(1) All politicians are liars.

All criminals are liars. Therefore, all politicians are criminals.

(2) All medical doctors are greedy. No chiropractors are medical doctors. Therefore, no chiropractors are greedy.

(3) All feminists support the Equal Rights Amendment. All feminists are well-educated women.

(4) So, all well-educated women support E.R.A. The difficulty with example one is that there is no quantifier for the middle term; it is undistributed and so there is no information on the size of the class of "liars" relative to its subordinate classes, "politicians" and "criminals." While the conclusion cannot be excluded from 
among the logical possibilities, the premises do not assert that any overlap exists between the major and minor terms. Even if the premises are true, the conclusion goes further than is valid given the form of the premises. The second and third examples have the same problem except that they involve faulty distribution not of the midale term but the major and minor terms respectively. The major term "greedy" is distributed in the conclusion but not in the major premise of the second example; the minor term "well-educated woman" refers to a quantifiable class in the conclusion but an unspecified class in the minor premise. Clearly in each of the above examples it could never be certain that a distributed term refers precisely to the same thing when it is not distributed, a problem tantamount to having a fourth term in the syllogism. Such syllogisms are, therefore, invalid. It is worth emphasizing here that the meaning of the terms cannot affect the invalidity of a syllogism even if the conclusion can be taken as generally true in practice. The form makes all of the difference.

Rules 4 and 5. All of the rules of validity are the result of experimentation and analysis by Aristotle and his followers. They combined various forms of proposition to see which would result in valid conclusions and which would not. 27 In this way it was discovered that two negative premises result in an invalid conclusion, and that if either premise is negative then only a negative conclusion can be 
valid. To demonstrate this, consider this set of related propositions from which syllogisms may be constructed.

(1) All smoking is a bad habit (universal-affirmative).

(2) All smoking is a pleasant thing (universal-affirmative).

(3) Some pleasant things are bad habits (particularaffirmative). (4) Some bad habits are not dangerous (particular-negative). (5) Nothing dangerous is a pleasant thing (universal-negative). The combination of propositions four and five as premises in a syllogism can produce no valid or even meaningful conclusion. One might conclude either that bad habits are or are not pleasant, but there is no way to tell which conclusion is more consistent with the premises because of the ungrammatical double-negative they produce in combination. On the other hand, combining the affirmative propositions one and two as premises produces a valid affirmative conclusion with no confusion of terms: either "some pleasant things are bad habits" or "some bad habits are pleasant things." Only one combination remains to be tested, that of propositions three and five. When the negative proposition, five, serves as major premise to the affirmative proposition, three, a meaningful negative conclusion results, to the effect that "some bad habits are not dangerous." No affirmative proposition makes sense as a conclusion in this case. With regard to whether a conclusion is appropriately affirmative or negative, the invalid answer is generally an implausible 
sounding one. However, it is not the plain-sense, truthvalue, or practical consequence of a conclusion which are at issue; formal validity is, and it depends upon the abstract relationship of terms.

Rule 6. The rule regarding whether the propositions of a syllogism are properly universal or particular applies only in a few special cases and again involves the conclusion going beyond what is contained in the premises, albeit in a somewhat underhanded way. Even though the distribution requirements are met, a conclusion which implies or assumes the existence of entities which are only hypothetical in the premises cannot be accepted as valid. Consider this case-in-point:

All Transylvanians are kindly people.

No vampires are kindly people.

So, some vampires are not Transylvanian.

Because a "weaker" particular conclusion is used where a "stronger" universal one is proper, the implication is made that there are vampires somewhere in existence. Syllogisms of this form are judged invalid by modern logicians. 28

Any categorical syllogism found to violate one of the rules of formal validity is disregarded by formal logicians as inconsequential or meaningless because its conclusion is not completely "entailed by" or contained within the premises. The value of these rules, according to formal logicians, is their universal applicability; any argument 
which can be put into syllogistic form can be judged valid or invalid according to these rules. If valid, the truth of the conclusion rests only on the truth of the premises; the inference is certified by the rules of validity. Toulmin's criticisms of this system of argument analysis is the topic of the final section of this chapter.

While formal validity of syllogisms is of primary interest in formal logic, there are other, related concepts which are a significant part of the field. Some of these are considered in the following discussion.

Deduction and Induction

Since Aristotle, the field of logic has been divided along the lines of inductive and deductive reasoning procedures. Induction and deduction were viewed by Aristotle as the two sources of belief by syllogistic reasoning. 29 A deductive argument is one "in which certain things being laid down, something other than these things necessarily comes through them."30 Induction is different, less scientific according to Aristotle, but not without its advantages.

Induction is a passage from individuals to universals, e.g. the argument that supposing the skilled pilot is the most effective, and likewise the skilled charioteer, then in general the skilled man is the best at his particular task. Induction is the more convincing and clear: it is more readily learnt by the use of the senses, and is applicable generally to the mass of men, though Reasoning is more forcible and effective against contradictious people. 31 
He explains elsewhere the syllogistic mechanisms of inductive reasoning which involve establishing the connectedness of a doubtful middle term to the major or minor terms when the conclusion is known from experience. 32 The key distinction, however, involves the source of implication. In deduction "it is inferred that what is true for all members of a class is true of some members of that class"; in induction, "it is inferred that what is true of some members of a class is true for all, or some determinate portion of all, members of that class." 33

Another important distinction between induction and deduction is discussed by logicians. Whereas the truth of the conclusion of a syllogism necessarily follows if its premises are themselves true, inductive generalizations are always subject to later revision and can never be necessary. 34

Enthymeme and Epicheireme

The enthymeme and epicheireme are two forms used in practical argumentation and related to the syllogism. Of the enthymeme, much has been written by scholars in rhetoric who have puzzled over Aristotle's various references to a "rhetorical syllogism." 35 Drawing from these scattered references to the enthymeme, several definitions have been proposed. Most features of this one are representative:

The enthymeme is a syllogism based on probabilities, signs, and examples, whose function is 
rhetorical persuasion. Its successful construction is accomplished through the joint efforts of a speaker and audience. 36

Unlike the syllogism, the enthymeme is not used in the demonstration of scientific truths. Instead it is concerned with probable truths, conclusions inferred from the possible premises believed by a particular audience. The involvement of an audience in supplying or inferring some of the propositions appears to be one of the basic distinctions between argument by syllogism and argument by enthymeme. "In the Aristotilian system, the apodeictic syllogism is used to demonstrate the necessary truths of certain knowledge; the rhetorical syllogism or enthymeme is used to demonstrate the dialectical truth of opinions in the areas of uncertain knowledge such as ethics and politics." 37 However, both the enthymeme and the syllogism must conform to the usual requirements of formal validity; their differences lie in the degree of confidence one can place in their conclusions and in the fields of argument in which each is appropriately used. The enthymeme applies in fields where certainty is not easily attainable; its conclusions, while they may be universal, are generally less absolute than those of the syllogism.

About the epicheireme there is even more mystery and controversy than in the theory of the enthymeme. 38 In the Roman rhetorics of Psuedo-Cicero, Cicero, and Quintilian, the epicheireme appears to have replaced the enthymeme in 
its application as a "rhetorical syllogism." 39 An epicheireme resembles an expanded syllogism and, according to Quintilian, has been characterized as having anywhere from three to six parts. ${ }^{40}$ Generally, five parts are mentioned, "the major premise and its reason, the minor premise and its proof, and fifthly the conclusion." 41 The elements of support for the major and minor premises are included because of what the epicheireme holds in common with the enthymeme:

There is no difference between the epicheireme and the syllogism, except that the latter has a number of forms and infers truth from truth, whereas the epicheireme is more frequently concerned with arguments that are no more than credible. For if it were always possible to prove controversial points from admitted premises, the orator would have little to do in this connexion. 42

What the epicheireme and the enthymeme have in common, then, is one of the qualities which differentiates them both from the syllogism: probability in the premises and conclusion. 43 Whatever their differences, it is significant that all three are syllogistic forms subject to the same principles of formal validity.

Before moving to a consideration of the defects which Toulmin finds in formal logic, the model which Toulmin proposes as an alternative to the syllogism is examined.

\section{THE TOULMIN MODEL}

In chapter III of The Uses of Argument, Toulmin introduces a schema of argument which he believes to be 
more candid and practicable than the categorical syllogism. ${ }^{44}$ Here the Toulmin model will be described, its functional elements distinguished, their roles defined, and other salient concepts discussed. Comparative practical advantages of the Toulmin model to the syllogistic approach of formal logic as asserted in The Uses of Argument are discussed later in this chapter. 45

\section{"Argument," "Logic," and \\ the Toulmin Model}

The Toulmin model is "a pattern for analysing arguments" which, according to Toulmin, may be taken to reflect the form or micro-structure of arguments in various fields. 46 In order to comprehend what Toulmin means by "a logically candid layout of arguments" or "logical form of a valid argument" it is important to understand the special senses in which Toulmin uses the terms "argument" and "logic."47 The term "argument" is used by Toulmin in two senses: generically, to refer to the process by which justifications for statements of assertion are made explicit, and specifically, to refer to the products of reasoning, that is, statements produced in support of assertions. Thus, Toulmin implies a general distinction between argument, conceived as a public, linguistic, justificatory "business of making good claims," and reasoning, conceived as a private, psychological, cognitive activity involving "people's actual habits of inference." 48 Further, Toulmin 
draws no conclusions about reasoning in The Uses of Argument because he believes that "one can discuss arguments and inferences. . without having to refer in any way to the particular men doing the asserting and adducing. "49 Toulmin's subject is strictly argument as both process and product.

To Toulmin, logic refers to a procedure according to which the rationality or soundness of arguments may be assessed. 50 While Toulmin's interest in the justificatory potential of arguments diverges from the interests of formal logicians, his characterization of logic as representative of standards for use in the rational criticism of arguments is in general consistent with formal logic. 51 However, Toulmin claims to deliberately avoid terms like "logic" and "logical" which might confuse his approach with that of formal logicians. 52 Thus, by "validity" Toulmin clearly means the soundness of an argument and not its formal validity; by the "form" of an argument, Toulmin means to refer to his model of argument and not the syllogism. Toulmin's unique conception of logic as a sort of generalized jurisprudence is one subject of discussion in the final section of this chapter.

In short, Toulmin's approach to the process of rationality involves the logic of arguments or, in other words, the assessment of justificatory statements offered in support of assertions according to appropriate standards 
of criticism. The tool of analysis with which such an assessment may be performed is the Toulmin model.

\section{Functionally-Defined Elements}

\section{of the Toulmin Model}

Toulmin distinguishes six functional elements of argument: "claim" (C), "data" (D), "warrant" (W), "qualifier" (Q), "rebuttal" ( $R)$, and "backing" (B). These elements and their relationships are symbolized in Figure 3.53

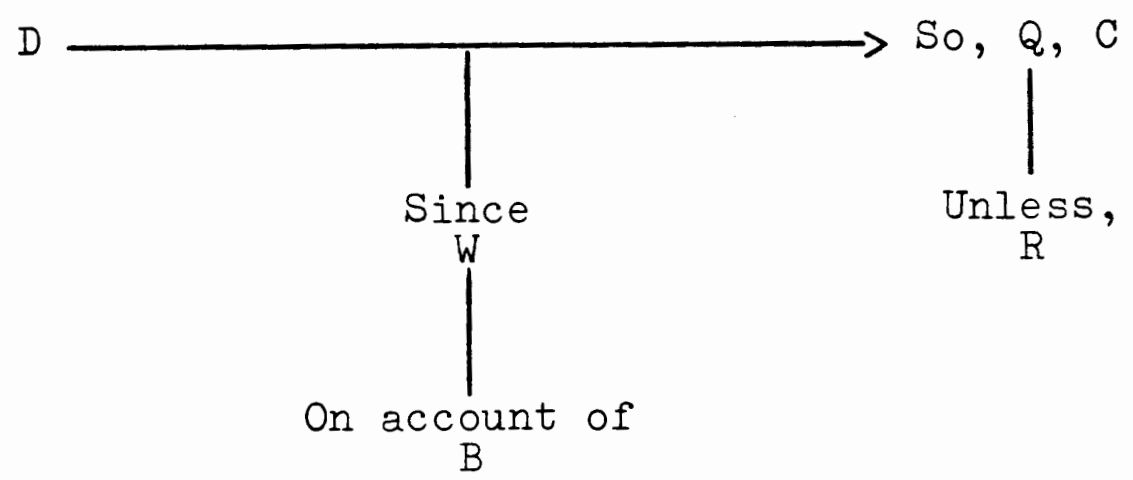

Figure 3. The Toulmin diagrammatic model.

The direction of the arrow between $D$ and $C$ is meant to symbolize the direction of movement of inference from the familiar, as in known, accepted, assumed or certain, to the less familiar, as in unknown, controversial or uncertain. In other words, to Toulmin argument is an epistemic process aimed at the establishment, disestablishment, or evaluation of claims of knowledge. 54 The Toulmin model is intended to provide a candid layout of the elements of practical argument as recognizable at the level of individual sentences. 55 
Claim. The statement of assertion or conclusion in an argument, because it represents a claim upon the attention and belief of others, is termed a "claim" in the Toulmin model. 56 In a developing argument, it is the establishment of a claim which is aimed at. In a completed argument, a claim is viewed as the product of inference founded upon data. The claim-statement answers such questions as "What are you getting at?," "What is your contention?," or, simply, "What is it you are saying?" Arguments are constructed around claims; without an explicit claim, a rational argument cannot be inferred. Therefore, Toulmin considers this element a necessary component of argument. A claim specifies what an argument is about as well as providing a starting point for rational considerations. 5 ?

Data. Categorical statements of fact which specify the information on which a particular claim is founded are referred to as "data." Data answer such questions as "What have you got to go on?," "On what grounds can you make this assertion?," "What makes you think so?," or "How do you know?"58 For an argument to proceed, the data produced in defense of a claim cannot be controversial. Data represent established concepts assumed to be acceptable to and shared by all parties to the claim. ${ }^{59}$ Data are taken to represent a second necessary component of argument since rational discussion of the merits of a claim can only proceed with an explicit reference to potentially relevant established facts. 
These shared facts function as the foundation for the claim in question.

Warrant. The term "warrant" refers to the inferencelicences, legitimizing rules or principles which authorize the movement from data to claim in an argument. 60 To rationally connect data to claim, an act of inference is required. The acceptability of an act of inference depends upon the warrant which may certify or endorse such a move. Warrants may answer such questions as "How did you get there?," "What is the connection?," or "On what authority are you permitted to infer such a claim from this kind of data?"6I According to Toulmin, warrants are general "hypothetical bridge-like statements" appealed to as justification for the types of inferences made in arguments. 62 No particular inference is defensible without reference to some warrant of broader applicability than the inference itself. 63 Therefore, the warrant represents Toulmin's third necessary component of argument because it supplies justification for the act of inference required to move from data to claim.

A warrant is used to justify the movement from data to claim in an argument. For a warrant to serve this function effectively, it must at some point become "established." This means that each warrant goes through a period in which it is only tentatively applied, in much the same way as an experimental hypothesis is entertained until 
and unless it becomes untenable. If a warrant can be successively applied with effectiveness and without contradicting other useful and well-established warrants, then the novel warrant becomes established within its field of application. 64 While such warrants are becoming established, the arguments in which they are used are classified as "warrant-establishing arguments."65 Once they have become established, then they may be used in the justification of arguments. Such arguments are termed "warrantusing arguments" by Toulmin. 66

For instance, until recently the following warrant was not known to be reliable and was therefore not established: "If harmonic seismic tremors occur together with certain gas emissions in an active volcano, then an eruption is imminent." This hypothesis could not be established as a warrant because volcanic eruptions were unpredictable and difficult to study. However, careful monitoring of Mt. St. Helens in Washington state during its recent activity has allowed scientists to successively measure the changes in seismic activity and gas emissions which occurred prior to each eruption. The data (measurements of changes) and claim (subsequent eruptions) were found to occur together with such regularity that the scientific community is now more confident about predicting volcanic eruptions where the circumstances are similar to 
Mt. St. Helens. To use Toulmin's terms, the warrant has become established in the field of volcanology.

Claim, data, and warrant represent the minimum essentials of argument. A collection of statements may be classified as meaningless, irrational, intuitive, precognitive, divine, dogmatic, etc. but it will not qualify as argument unless the functions of claim, data, and warrant are clearly distinguishable amongst its parts. Qualifier, rebuttal, and backing are other elements which, though not considered by Toulmin to be always essential to the analysis of an argument, are frequently present and significant in their functions.

Qualifier. Modal terms are frequently used to modify the force of a claim, that is, to specify the power of a warrant in light of exceptions, completeness of the data, strength of the warrant in general, and its applicability in the particular case. Such modal modifiers are termed "qualifiers" by Toulmin. 68 Some warrants may be taken to be conclusive, others only tentative. Sometimes a warrant is only partially suited to the available data or may be subject to special conditions in which its force will be altered. When any of these is the case, the claim should be modified with a modal qualifier, for example, "necessarily" or "certainly," "probably" or "presumably," or any number of other such adjectives. In some fields of argument a qualifier is appropriately expressed as a 
mathematical quantity; however, according to Toulmin, the qualifier is usually a general adjective indicating the degree of confidence or tentativeness with which the claim is asserted. 69

Rebuttal. This element refers to the specification of conditions under which the applicability of the warrant to the particular claim and data may be questioned. Rebuttals consist of hypothetical statements regarding specific data which, if discovered, would either modify the force of a warrant or negate its applicability entirely. 70 The potential for exceptions to or modifications of the force of a warrant is indicated by the qualifier and specifically described in the rebuttal. The function of rebuttals, then, according to Toulmin, is to comment on the justificatory potential of warrants in light of possible data. 71 In other words, conditions in which a qualifier must be adjusted if the warrant is to succeed as justification for the movement from data to claim may be specified in a rebuttal.

Backing. While the rebuttal represents an answer to questions about the specific applicability of a warrant to a particular situation, "backing" represents answers to questions about the general applicability of a warrant. Backing refers to the specification of assurances of the established general applicability of a warrant within its field of argument. Backing may consist of statements of 
fact offered in support of a warrant without regard to the particular argument to which the warrant is appealed. 72 Backing, therefore, amounts to one or more subordinate arguments consisting of established facts offered in support of a warrant.

An example may be helpful here to illustrate the functional roles played by the various elements and how they interrelate in an argument. A warehouseman who is smoking in an area where gasoline containers are stored might defend his actions with the following argument: "It's O.K. to smoke here now; I saw these containers emptied this morning." If pressed, he might make his warrant explicit as well: "If there's no gas in the cans, then there is no cause for caution near them." This simple argument is diagrammed in Figure 4.

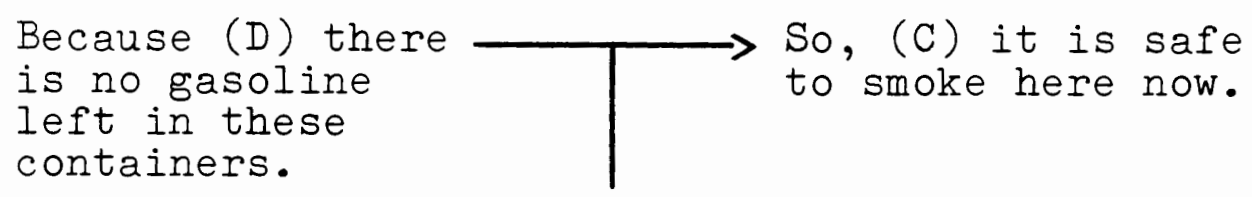

Since (W), if there is no gasoline in the cans then there is no cause for caution near them.

Figure 4. An example of a simple argument diagrammed with the Toulmin model.

Of course, someone might object to the warehouseman that he must not smoke because "It'Il ruin your health!" or "The sign says 'no smoking in this area." "But such objections 
present no challenge to the warehouseman's argument;

because their warrants are completely different, these counter-arguments are not germane to the warehouseman's justification for smoking. Still, the warehouseman must be prepared to defend his claim against reasonable objections having to do with how confident he is of his conclusion, whether his warrant is entirely applicable in this case or if it is subject to some exceptions or modifications, and whether his warrant is generally reliable or not. A consideration of these issues complicates the warehouseman's argument, yet by supplying the elements necessary to meet such challenges the candidness of the argument is increased, as shown in Figure 5 .

\begin{tabular}{|c|c|}
\hline \multicolumn{2}{|r|}{$\begin{array}{l}\text { (Q) presumably, } \\
\text { (C) it is } \\
\text { safe to smoke } \\
\text { here now. }\end{array}$} \\
\hline $\begin{array}{l}\text { Since (W) if there is } \\
\text { no gasoline in the cans } \\
\text { then there is no cause } \\
\text { for caution near them. } \\
\text { On account of (B) the } \\
\text { fact that nothing comes } \\
\text { out of nothing, (princi- } \\
\text { ple of energy conserva- } \\
\text { tion and its converse) } \\
\text { and the warehouseman's } \\
\text { experiences of smoking } \\
\text { near empty containers, etc. }\end{array}$ & $\begin{array}{l}\text { ( } \mathrm{R} \text { ) Unless vapor } \\
\text { from the gasoline } \\
\text { that was once in } \\
\text { the cans remains, } \\
\text { or the cans have } \\
\text { since been refilled } \\
\text { with a volatile } \\
\text { substance without } \\
\text { the warehouseman's } \\
\text { knowledge. }\end{array}$ \\
\hline
\end{tabular}


The warrant-using argument illustrated in Figure 4 is considered valid in Toulmin's terms first, because its warrant authorizes exactly the sort of inference which connects this kind of datum to that kind of claim, and second, because the warrant is explicit. 73 The soundness of the argument, however, depends not solely upon the explicitness and suitability of the warrant, because there may be weaknesses and faults contained within the warrant, or it may be completely wrong. The simple argument in Figure 4, though it has an explicit and appropriate warrant, is less sound than the more candid argument in Figure 5 which features the backing, rebuttal, and qualifier missing in Figure 4. Thus, the Toulmin model draws attention to the various functions of statements given in arguments and the ways they interrelate to provide some degree of justification and soundness for the claims they support.

\section{Distinctions Salient to}

the Toulmin Model

Three distinctions presented by Toulmin are germane to his model and its differences from the categorical syl$\log$ ism.

Force vs. Criteria. In considering the modal terms used in logic, Toulmin distinguishes two kinds of meaning they have in an argument. The "force" of a modal term refers to the practical impact it has on that which it modifies; "criteria," on the other hand, represent 
standards or reasons for the use of the modal term. In other words, force has to do with effect, criteria with appropriateness of a particular modal term. For example, according to Toulmin, the force of these modal terms may be defined as follows: "must" limits consideration to one; "possibly" includes something within consideration; and "cannot" excludes something from consideration. 74

However, the criteria for the application of these terms in an argument cannot be generalized in the same way because of differences in the situations which give rise to their appropriate use. For instance, in the case of the term "cannot," the reasons why a finite number for the quantity "pi" cannot be computed are nothing like those which explain why little Jimmy cannot stay up past midnight, or why I cannot fly an airplane. While the force of the term "cannot" is the same in each of the above cases, the specific criteria for using it meaningfully in an argument are in Toulmin's view unlimited. 75 Thus, while the force of an argument may be denoted by a modal qualifier which has the same meaning regardless of the field in which it is used, the criteria for its use, as indicated by backing and rebuttal, may vary from field to field.

Through its candid display of various functional elements of argument, the Toulmin model is intended to draw attention to the differences between those aspects of argument which, like force, are the same regardless of the field 
in which they are applied and those aspects of argument which, like criteria, vary according to the field of application.

\section{Field-invariant vs. Field-dependent Aspects of Argu-}

ment. Toulmin observes that justificatory argument is practiced in any number of different "fields," for instance, ethics, aesthetics, law, religion, each of the social and physical sciences as well as philosophy. ${ }^{76}$ In terms of the Toulmin model, fields are operationally defined as follows:

Two arguments will be said to belong to the same field when the data and conclusions in each of the two arguments are, respectively, of the same logical type: they will be said to come from different fields when the backing or the conclusions in each of the two arguments are not of the same logical type. 7 ?

Some aspects of an argument are "field-invariant" according to Toulmin; that is, they are the same regardless of the field in which the argument is made. Others are "fielddependent," specific to a particular school of thought and not necessarily meaningful anywhere else. ${ }^{78}$ In addition to the force of an argument, as indicated by the combination of claim, data, warrant, and qualifier, the overall form or structure of an argument is field-invariant. 79 These features do not change from field to field but are the same for all arguments. The criteria which are represented by the backing offered in general justification of a warrant as well as rebuttals which limit the applicability of a warrant are field-dependent features of an argument. 80 
Different logical types are represented by the backings used in different fields of argument. 81 It is significant that formal logicians define validity in field-invariant terms, Toulmin, in field-dependent terms.

Toulmin stresses the role of field-dependence in the rational assessment of argument. 82 He contends that "the standards for judging the soundness, validity, cogency or strength of arguments are in practice field-dependent" and therefore that attempts to analyze arguments in fieldinvariant terms are doomed to irrelevance. 83 Other than critiquing the procedures used by logicians to determine formal validity, Toulmin does not present an analysis of field-invariance in The Uses of Argument. However, in a more recent book, Toulmin, Rieke, and Janik present a classification of warrants based upon their field-invariant features. 84 Several classifications are discussed, including reasoning from analogy, generalization, sign, and cause. 85 While this list is not intended to be taken as "an exhaustive or formal account of all the possible types of argument," certain features of this explanation are of interest because of their implications for the applicability of the Toulmin model in speech communication. 86 First, the concept of field-invariant assumptions which underlie warrants is introduced:

All warrants share certain common functions, and over the years, students of reasoning have discovered that regardess of the field in which they 
occur, many of our warrants tend to share certain other features also. So specific warrants may be alike in resting on certain deeper assumptions or rules.87 [Emphasis added.]

Thus, a warrant in an argument classified as reasoning from analogy is based on the assumption that "there are enough similarities between two things to support the claim that what is true of one is also true of the other." 88 Similar assumptions provide arguments of each general classification with a field-invariant basis for their warrants. Second, according to Toulmin, Rieke, and Janik, while such basic assumptions may be useful in the classification of warrants, they are not important enough to be considered a seventh diagrammatic element of the Toulmin model of argument. This is because, as field-invariant aspects of argument, they are considered largely irrelevant to the assessment of arguments. 89 As Toulmin, Rieke, and Janik state:

- . [A] classification of general types of argument - . must be used with caution. Nothing said here will undermine our earlier conclusion that arguments need to be examined with an eye to the context and field in which they occur. Nor shall we be suggesting that there are any fixed rules for determining the gorrectness of arguments of one type or another. $90^{\circ}$

Thus, the "familiar general assumptions in terms of which claims can be justified" are not particularly useful because they are field-invariant; attention to assumptions is not advised because it may distract from the more important field-dependent features of argument. 91 
Analytic vs. Substantial Arguments. According to

Toulmin, when the backing for a warrant is included implicitly or explicitly in the claim, that argument is termed "analytic." 92 For example, the exemplary classical syllogism "Socrates is a man, all men are mortal, therefore Socrates is mortal" is analytic because to back the warrant implicit in the major premise one would have to check the man named Socrates for mortality. To do this would be to confirm the conclusion while circumventing the movement from data to claim.

When the backing of an argument contains information other than that which is asserted in the claim, the argument is termed "substantial." More often than not, according to Toulmin, practical arguments will be substantial, not analytic. 93 while acknowledging the mathematical applications of analytic arguments, Toulmin emphasizes their "peculiarities": 94

If the purpose of argument is to establish conclusions about which we are not entirely confident by relating them back to other information about which we have greater assurance, it begins to be a little doubtful whether any genuine, practical argument could ever be analytic. 95

Clearly Toulmin is interested in argument as it is usefully practiced in the various fields of human understanding. His model is presented as a structure which candidly displays the functions of elements of argument as it is practiced. He contends that such a model is sorely needed 
because of the limitations inherent in formal logic and the syllogism which make the traditional approach to argument inadequate at best. Toulmin's criticisms of formal logic are the topic of the remainder of this chapter.

TOUIMIN'S CRITICISMS OF FORMAL LOGIC

In The Uses of Argument, Toulmin suggests that a different, more flexible, and broader logic is needed if our understanding of how concepts develop, compete, change, and become established through argument is ever to reflect the practices of concept-users in the diverse fields of human thought. 96 Says Toulmin of his objectives:

If all were well (and clearly well) in philosophic logic, there would be no point in embarking on these investigations: our excuse lies in the conviction that a radical re-ordering of logical theory is needed to bring it more nearly into line with critical practice, and our justification will come only if the distinctions and objections insisted on here bring such a re-ordering nearer.

The Toulmin model incorporates the distinctions that may bring about such a re-ordering. The objections to formal logic discussed by Toulmin may be summarized as follows: (1) the mathematical-geometric assumptions adopted by formal logicians reflect the misdirectedness of their aims; (2) formal logic is far too limited in its scope to be of much practical significance or applicability; and (3) the distinctions to which formal logicians adhere are overly simplistic, tending to obscure the functional elements 
involved in practical argument. Toulmin's rationale for each of these objections is explained in the discussion which follows.

Mathematical-Geometric Assumptions of Formal Logicians Reflect

Misdirected Aims

It is a matter of history that the development of a theory of logic followed closely the advent by the ancient Greeks of the science of geometry. Formal logic, like geometry, is founded on a priori assumptions: that "perfect truths" or universals exist but are perceptible only to the intellect and not the senses; that propositions are derivable from these truths and not vice versa; and most importantly, only propositions that can be related through geometric demonstration to a primitive proposition or universal can be taken to be valid or true. In other words, in terms of logic, only those assertions that are convertible to a proper form derived from a universal are recognized as logically meaningful. 98

Like a system of mathematical axioms and propositions, the proof of which depends upon the internal relationships of elements and not any application to a particular time, place, or purpose, formal logic developed out of the analysis of "tenseless" terms combined in propositions in a search for absolute principles of thought. 99 The mathematical concept of logical relations has influenced 
developments in formal logic to the point that, in the past century, a school of thought has emerged called "symbolic logic" in which propositions are systematically stripped of all linguistic-referential qualities until what remains is a special language of semantic relations resembling a system of algebraic formulae. ${ }^{100}$ Toulmin concedes that this mathematical approach has some uses in certain fields of argument (for example, in generating hypotheses or quantifying the force of a claim); however, such approaches are irrelevant to the criteria, and therefore to the practical implications of argument. ${ }^{101}$ As Toulmin states, "Unfortunately an idealized logic, such as the mathematical model leads us to, cannot keep in serious contact with its practical application." 102

The significance of the mathematical nature of formal logic is in the way formal validity is determined. To say that an argument is in proper form is to assert something "quasi-geometrical" about its structure, according to Toulmin. 103 Indeed, the formal logician determines validity simply by applying the rules of the syllogism to a likely candidate to see if it has the correct number of terms properly placed in related propositions. There need be no comprehension of what the terms refer to or what consequences the argument will have within its field of application; such matters are considered extraneous or even potentially problematic to good logical criticism of 
argument. Toulmin asserts that this kind of validity is nothing more than a "shuffling [of] the parts of the premises and rearranging them in a new pattern," something which can be done with nearly any argument. 104 He insists that the field-dependent criteria of argument must be a consideration in any practical analysis.

Toulmin contends that an analogy with jurisprudence provides a more useful basis for a consideration of practical argument than does a mathematical-geometric approach. 105 He asserts that:

Logic is concerned with the soundness of the claims we make--with the solidity of the grounds we produce to support them, the firmenss of the backing we provide for them--or, to change the metaphor, with the sort of case we present in defence of our claims . . . Logic (we may say) is generalized jurisprudence. A main task of jurisprudence is to characterise the essentials of the legal process: the procedures by which claims-at-law are put forward, disputed and determined, and the categories in terms of which this is done. . . We shall aim, in a similar way, to characterize what may be called "the rational process," the procedures and categories by using which claims-in-general can be
argued for and settled. 106

Unlike formal logic which asks how nearly an argument corresponds to an ideal form, a jurisprudential logic asks how conclusions are justified through the production of arguments. 107 The formal logician compares every argument to a universal absolute standard; the Toulmin model is designed to organize arguments within a field to determine the relative soundness of claims and warrants. 108 Formal logic presumes the superiority of a particular field of 
argument, mathematics, while the Toulmin model is intended to facilitate the comparison and contrasting of argumentative structures within and among conceptual fields. ${ }^{109}$

In short, formal logic aims at an ideal for proper reasoning, in a sense, the purification of rational procedures. The Toulmin model, on the other hand, aims at practical procedures for establishing the soundness of conclusions in various fields of human understanding as well as providing a language for the explanation of conceptual diversification and change--how concepts are introduced, developed, changed, extended, or rejected over time. 110

\section{Formal Iogic is Too Limited in} Scope to be of Much Practical

\section{Significance or}

Applicability

In formal logic the analytic syllogism has been elevated to paradigmatic status. 111 Because they have, according to Toulmin, preoccupied themselves with analytic arguments, formal logicians' attentions have been diverted from practical considerations having to do with the criteria by which substantial arguments are justified. Formal logic has failed to recognize field-dependence as relevant to the consideration of the validity of an argument, while Toulmin believes field-dependence to be an unavoidable consideration. What is accomplished by applying analytic criteria to arguments of all fields is nothing more than an assessment of the comprehensibility of the argument; nothing of substance 
is learned at this stage of analysis. Says Toulmin, "Logical considerations are nothing more than formal considerations, that is, they are considerations having to do with the preliminary formalities of argument-stating, and not with the actual merits of any argument or proposition."112 Only in the limited field of a closed mathematical system is consistency alone the criterion for determining the soundness of a principle; "there is not justification for applying analytic criteria in all fields of argument indiscriminately."113

In short, according to Toulmin, most of the arguments used in practice are substantial, not analytic. While analytic arguments are perhaps simpler and more elegant than most, to Toulmin they are largely irrelevant. 114 Formal logicians' preoccupation with analytic arguments has resulted in a limited applicability for formal logic. Toulmin contends that a jurisprudential approach, as represented by the Toulmin model, can provide a stronger paradigm for a practical logic.

Formal Logicians' Distinctions are

Overly Simplistic, Tending to

Obscure the Functions of

Elements Involved in

Practical Argument

Toulmin claims that formal logicians' overreliance, bordering on dogmatic dependence, on the simplistic dichotomy between inductive and deductive reasoning has resulted in ambiguity about the functions of statements given in 
argument. His model is intended to clear up this ambiguity which he believes to be especially apparent in the syllogism. 115 Toulmin distinguishes four components to the distinction between induction and deduction and he discusses the consequences of overlooking these components. 116 According to Toulmin, unless one is solely concerned with analytic arguments, the distinction between inductive and deductive argument is inadequate. Analytic argument is well described by the principles of deduction. But to lump together all other arguments under the term induction is to gloss over a number of important distinctions among substantial arguments. 117 Thus, Toulmin argues that the classical distinction between deduction and induction ought not be upheld if we are to understand how argument is practiced in various fields. Instead, Toulmin contends that attention is due four variables by which arguments are distinguishable: (l) whether or not an argument is a candidate for validity; (2) whether an argument is warrantusing or warrant-establishing; (3) whether the conclusion of an argument is taken to be necessary or probable; and (4) whether the propositions rely on standard logical quantifiers or other sorts of connectives. 118

According to Toulmin, deductive or analytic arguments are, as a class, unique in a number of ways. First, deductive arguments alone are candidates for formal validity; their conclusions are the only ones which may be 
entailed by the premises. Second, because deductive conclusions cannot go beyond what is contained in their premises, they are always warrant-using--relying on previously established principles. They cannot be warrantestablishing. Third, conclusions of valid deductive arguments can only be necessary, never probable. Fourth, related to the absolute certainty of deductive valid conclusions is the lexical limitation of their premises. In a categorical syllogism, there are but four standard terms of logical quantification: "all," "no," "some," and "some . . not . . ." Analytic arguments alone meet these criteria of valid deductive argument. Other arguments are classified inductive, substantial, or inconclusive.

The Toulmin model is intended to make explicit the previously discussed distinctions overlooked by formal logicians. First, regarding validity, Toulmin presumes that matters of formal validity are prerequisite to comprehending an argument and are therefore not represented by any particular element of the layout; a critic must first understand what an argument means before any determination can begin to be made of its justificatory qualities. 119 second, once the meaning of an argument is recognized, the laying out of parts, that is, the distinguishing of claim, data, warrant, and backing, allows the critic to determine whether the argument is aimed at 
the justification of a claim or the establishment of a new warrant. 120 Third, the modal qualifier in conjunction with any explicit rebuttal statements will define the degree of probability conferred upon the claim by the warrant. Fourth, regarding standard terms of quantification, the Toulmin model is not limited by any specific linguistic classifiers; on the contrary, the model is adaptable to any meaningful expression language can provide. ${ }^{121}$ In addition, the Toulmin model goes beyond the syllogism in providing a critic with a means of assessing the justificatory potential of an argument, first by checking the degree to which the warrant fits the inference in question, and second, by examining the backing to discover the credentials of the warrant within the field of argument in which it is operating.

Because the syllogism fails to distinguish the variables of argument with which the Toulmin model is designed to cope, Toulmin considers it inherently inadequate to deal with practical argument. The syllogism has two defects according to Toulmin. First, it fails to clearly distinguish the functions of the major premise which may serve as warrant, backing, rebuttal, qualifier, or data. Second, it obscures differences in various fields of argument and the varieties of warrant-backings required to justify claims in these fields. 
The propositions of a syllogism may serve any of the functions of argument identified by Toulmin. In most cases, the minor premise can be taken as a statement of data and the conclusion, as a claim. The major premise, however, is marked by a "hidden complexity" in which may be combined the functions of warrant, backing, rebuttal, qualifier, or data. ${ }^{122}$ Unless an argument turns out to be analytic, in which case the distinction between backing and warrant is by definition of no practical consequence, the syllogism is inherently ambiguous in differentiating force from criteria. The syllogism cannot provide a critic with a candid analysis of argument because, according to Toulmin, the major premise is subject to interpretation as serving any or several of four functions.

To demonstrate the ambiguity of the major premise, the following syllogism is offered as an instance: "All Harvard Business School graduates are successful in their careers within two years of graduation (major premise); Smitty is a graduate of Harvard Business School (minor premise); so, Smitty will be successful within two years of her graduation (conclusion)." In this syllogism, the functions of the minor premise as data and conclusion as claim are clear enough. But whether the major premise functions here as backing or warrant cannot be determined. It seems equally plausible taken as a statement of fact meant as backing, as in "All Harvard Business School graduates have 
been found to be successful after two years in surveys $\mathrm{x}$, $y$, and $z$," or as warrant for an inference, as in "If a person graduates from Harvard Business School, then success is certain within two years." Notice also that a restatement of the major premise as warrant for an inference specifies the degree of confidence it confers upon the claim, in this case, certainty. So, the modal qualifier may also be taken to be part of what may be packaged in a major premise. As Toulmin concludes, "when they are stated in the form 'all A's are B's' it will often be entirely obscure just which function [universal premises] are to be understood as performing." 123

If a major premise is particular instead of universal, it may be mistaken for another statement of data. Some logicians claim that the principle of the syllogism may serve as "the ultimate foundation for the validity of all syllogistic arguments."124 In this sense every syllogism is seen as an argument from data contained in two premises to a conclusion. Toulmin objects to this interpretation on the grounds that it ignores all field-dependent aspects of argument. Either premise, if particular and interpreted as data, may also include an element of rebuttal. For example, the minor premise in a quasi-syllogism based on the previous illustration might be stated as "Smitty is a typical graduate of Harvard Business School. "12.5 The word "typical" is not, in itself, data; it is according to Toulmin a second- 
order comment on the data. ${ }^{126}$ It addresses the issue of rebuttal, commenting as it does on the degree to which the warrant-backing are applicable to the particular data and claim. In short, the premises of the syllogism fail to distinguish the six functional elements of argument identified by Toulmin.

Toulmin claims that the most candid layout of practical argument cannot be performed with the syllogism because its rigidly simple format does not allow for all necessary and useful distinctions. The consequences of this inadequacy are, for Toulmin, reflected in the general faults of the logic constructed upon the syllogism: by limiting the concerns of formal logic to those fieldinvariant aspects which can be simple and elegantly displayed in the syllogism, formal logicians overlook the rich differences among ways conclusions are justified in the various fields of argument. The syllogism, and the idealized logic it serves, simplifies argument at the expense of practicality. 127

Formal logicians generally look upon differences between substantial and analytic arguments as "deficiencies to be remedied, gulfs to be bridged."128 Toulmin believes that logicians have focused upon field-invariant standards for argument because of their wariness of transitions of logical type, "type-jumps" as Toulmin refers to them, between propositions asserted and the data and warrant- 
backing offered in justification of them. ${ }^{129}$ Where typejumps are involved in inferring a conclusion, analytic form is impossible.

Toulmin claims that logicians who find justification only in those arguments whose conclusions are entailed by their premises can make no logically acceptable assertion about the future based on past experience, about the distant past based on current trends, about life in general based on limited observations and controlled experiments, or about the minds of others based on personal artifacts, discourse, or the observations and opinions of friends and relatives. ${ }^{130}$ Formal logic systematically excludes these kinds of assertions from its province on the grounds that each involves a type-jump and therefore cannot be a candidate for formal validity. According to Toulmin, then, formal logic is neither equipped nor intended to deal directly with arguments used to justify or attack concepts typical of natural sciences like physics and biology, social sciences like history and psychology, or the discourse of everyday life.

Toulmin believes that the type-jumps of which formal logicians are so suspicious are the very stuff of practical argument. He claims "type-jumps and field differences are what we start with, and we can never properly get away from them . . [they] are not gulfs or deficiencies, but characteristic features of our very fields of argument."131 
Rather than attempt to change this fact, apologize for it, or ignore it entirely, Toulmin believes logicians should be working towards an applied logic which promotes the study of differences in criteria for justification specific to each field of thought. It is with this end in mind that he proposes his new approach to logic: that logicians should broaden their scope and recognize, that in argument as practiced, "validity is an intra-field, not an inter-field notion." 132

\section{SUMMARY}

Three topics have been examined in this chapter:

(1) formal logic and its primary tool, the categorical syllogism; (2) Toulmin's jurisprudential approach and functional model; and (3) Toulmin's criticisms of formal logic and the syllogism. Logic, rooted in the ancient Greek assumptions of a universal order, has to do with principles of formally valid inference. Its essential aim is the determination of consistency in the relationship of terms and its primary tool is the analytic syllogism. In a valid syllogism, consisting of a major premise, minor premise, and conclusion, the terms of the conclusion are inferred to be related because each of them is related to the same middle term according to the assertions made in the premises. There are rules for the positioning or "distribution" of terms in the propositions of a syllogism by which 
validity is determined. The rules of formal validity are concerned with consistency in the form in which an argument is stated: that is, a lack of equivocation in the use of terms, a lack of inconsistency among the premises, and the clear involvement of a contradiction in the negation of the asserted conclusion. They have nothing to do with the meaning of terms, consequence of a conclusion, soundness, or truth-value of an argument in practice. Enthymemes and epicheiremes, argument forms related to the syllogism, are subject to the same rules of formal validity. Only inductive arguments escape the requirements of formal validity. Toulmin proposes a model for the layout and analysis of arguments which he claims is more sophisticated and candid, and therefore more practical than the syllogism. His approach is drawn from an analogy with jurisprudence which seeks to establish the soundness or justifiability of argumentative claims. Toulmin distinguishes six functional elements in argument: "claim" or assertion; "data" or factual support; "warrant" or inference-license; "qualifier" or modal modifier specifying the degree of certainty associated with a claim; "rebuttal" or comment upon the particular suitability of the warrant to the data and claim; and "backing" or factual support for the warrant in general.

Further, Toulmin notes that some arguments are used to establish novel warrants, others to establish novel 
claims; within this latter group there is a limited class of arguments in which both the claim and the warrant are acceptable dependent upon the same facts found in the backing. Such arguments are termed "analytic" and are thought to be unusual in most fields of argument; all others, the most common kinds of argument, are termed "substantial." It is these substantial arguments with which the model is intended to deal. Another distinction central to Toulmin's approach is that between the "force" of a claim, a field-invariant aspect of argument, and the "criteria" represented by warrant-backing, a field-dependent aspect of argument. Both aspects are incorporated in the model.

Toulmin contends that his model would solve some problems or inadequacies he believes are inherent in formal logic and the syllogism. Specifically: first, he claims that the mathematical-geometric assumptions on which formal logic has been historically constructed are out of touch with the applications to which practical argument is put. To abstract one aspect of argument, namely the form of its expression, for analysis is to focus only on matters of force and to deny criteria. The formal consistency of argumentative statements is only a prerequisite, according to Toulmin, to any determination of the validity of an argument in a particular field. Second, he criticizes the limited scope of formal logic. Logicians have concentrated 
too much on the ideal form, the analytic syllogism, and viewed all other arguments as being by degrees substandard. Toulmin believes that other arguments are not substandard, but they rely on other, field-dependent standards. Finally, he attacks logicians for adhering to the overly-simple distinctions of the syllogism without recognizing the other functions served by parts of argument. For instance, the major premise in a syllogism may serve most any or all of the functions defined by Toulmin; but without distinguishing these functions, the field-dependent sources of validity become obscured.

Toulmin proposes his jurisprudential model to deal with substantial arguments, to draw attention to the different ways arguments function in different fields of thought, and to provide a tool for the determination of validity according to the field-dependent criteria which typify practical argument. By expanding the aims and scope of logic, and providing a critical tool more sophisticated than the classical syllogism, Toulmin believes he has laid the foundation for the development of an approach to argument which is at once consistent with epistemology and also relevant to the sciences, history, philosophy in general, and everyday discourse. 


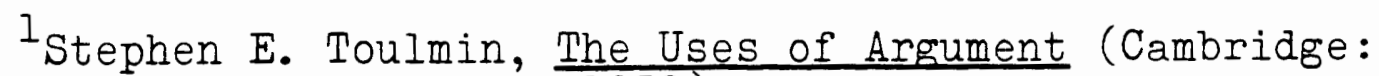
Cambridge University Press, 1958).

$2^{2}$ See for example I. C. Cooley, "On Mr. Toulmin's Revolution in Logic," Journal of Philosophy, 55 (1959), 297; also Hector Neri Casteneda, "On a Proposed Revolution in Logic," Philosophy of Science, 27 (July, 1960), 399.

${ }^{3}$ See especially the writings of Gilbert Ryle, J. I. Austin, J. C. Urmson, H. I. A. Hart, and A. N. Prior. Specific citations and other references are found in Uses, pp. 260-26l.

$$
{ }^{4} \text { Uses, p. 1. } \quad{ }^{5} \text { Ibia., p. } 253 .
$$

${ }^{6}$ Stephen E. Toulmin, Human Understanding: The Collective Use and Evolution of Concepts (Princeton: Princeton University Press, 1972), vii-viii.

7 The history of logic is surveyed in William Kneale and Martha Kneale, The Development of Logic (Iondon: Oxford University Press, 1962).

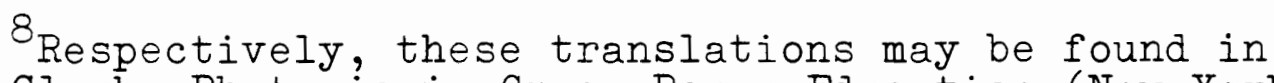
D. I. Clark, Rhetoric in Greco-Roman Education (New York: Columbia University Press, 1957), 53; E. P. J. Corbett, Classical Rhetoric for the Modern Student (New York: Oxford University Press, 1971), 50; Gregory Bateson, Mind and Nature (New York: E. P. Dutton Publishing Company, 1979), 18.

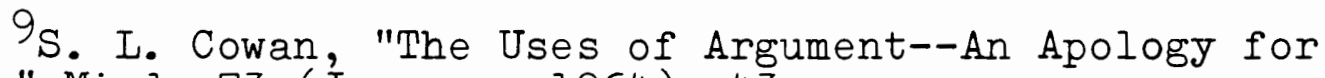
Logic," Mind, 73 (January, 1964), 43.

${ }^{10}$ Max Black, Critical Thinking (Englewood Cliffs: Prentice-Hall Publishing Company, 1942), 9, 37. "Inference" is used here to refer to the psychological activity through which an individual privately derives a new belief from a consideration of older beliefs. See Wesley Salmon, Iogic, (Englewood Cliffs: Prentice-Hall, Inc., 1963), 7-10.

Il John Stuart Mill, A System of Logic (1843; reprint. ed., New York: Longmans, Green and Co., 1941 impression), $136-137$. 
12 Kneale and Kneale, p. 1. See also C. D. Mortenson and R. I. Anderson, "The Limits of Logic," Journal of the American Forensic Association, 7, No. 2 (1970), 72.

13 M. R. Cohen and Ernest Nagel, An Introduction to Iogic and Scientific Method (New York: Harcourt, Brace and World, Inc., 1934), 17 .

14Mill, p. 137. The term "consistency" here and elsewhere in this study is used to refer to three characteristics of a valid syllogism: (1) the lack of equivocation in the terms, (2) lack of inconsistency among the premises, and (3) entailment of the conclusion by the premises--in other words, the denial of the conclusion involves a contradiction of the premises.

${ }^{15}$ Richard McKeon, ed., The Basic Works of Aristotle (New York: Random House, 1941), xvi.

16 Symbolic logic, a school of thought which has blossomed from concepts of Alfred North Whitehead and Bertrand Russell, Principia Mathematica (Cambridge: Cambridge University Press, 1927), is not treated in this study since it represents an extreme development of the mathematical aspects of formal logic against which Toulmin argues. Toulmin's approach represents a divergence from formal logic in another direction. However, many of Toulmin's objections to formal logic are directly applicable to symbolic logic as well.

17 McKeon, pp. xvi-xvii. In rhetoric, the counterpart of the syllogism is the enthymeme, to be discussed later in this chapter.

${ }^{18}$ Aristotle, Posterior Analytics, I.1.71a.1-2, trans. G. R. G. Mure in The Basic Works of Aristotle, ed. Richard McKeon (New York: Random House, 1941), 110.

${ }^{19}$ Ibid., I.2.71b,8-72b,4, pp. 111-113.

${ }^{20}$ Kneale and Kneale, pp. 1-22.

${ }^{21}$ Will Durant, The Story of Philosophy (New York: Simon and Schuster Publishing Co., 1926; reprint. ed., $1961), 50$.

22 The Venn diagram technique for testing syllogisms is discussed in Irving Copi, Introduction to Logic, 4 th ed. (New York: Macmillan Publishing Co., Inc., 1972), 188-197, as well as many other introductory logic textbooks. 
23w. V. O. Quine, Methods of Logic, 3rd ed. (London: Routledge Publishing Co., 1952), 91.

24 The rules presented here are drawn from three sources and represent a summary and synthesis. For comparative treatments, see Black, pp. 139-142; Copi, pp. 198203; and Stephen Barker, The Elements of Logic (New York: McGraw-Hill Publishing Co., 1965), 69-71.

25 These rules are sometimes referred to by the following titles: (1) "rule of terms," (2) and (3) having to do with the distribution of terms are referred to as "rules of quantity," (4) and (5) having to do with the effects of negative premises are referred to as "rules of quality," and (6) "rule of existential import." Material validity, the determination of truth of the premises, is not here discussed because it receives little if any attention in the logic textbooks cited in this study and Toulmin does not discuss it. For a treatment of informal fallacies, see Copi, pp. 72-107.

26 These corollary rules are used to determine whether a term is distributed or not: in a universal proposition, containing the quantifiers "all" or "no," the subject term is distributed; in a particular proposition, containing the quantifiers "some" or "some.. . not...", the subject term is not distributed; in a negative proposition, containing the quantifiers "no" or "some . . . not . . .", the predicate term is distributed; in a positive proposition, containing the quantifiers "all" or "some," the predicate term is not distributed. The following grid illustrates these corollary rules. See also, Barker, p. 45.

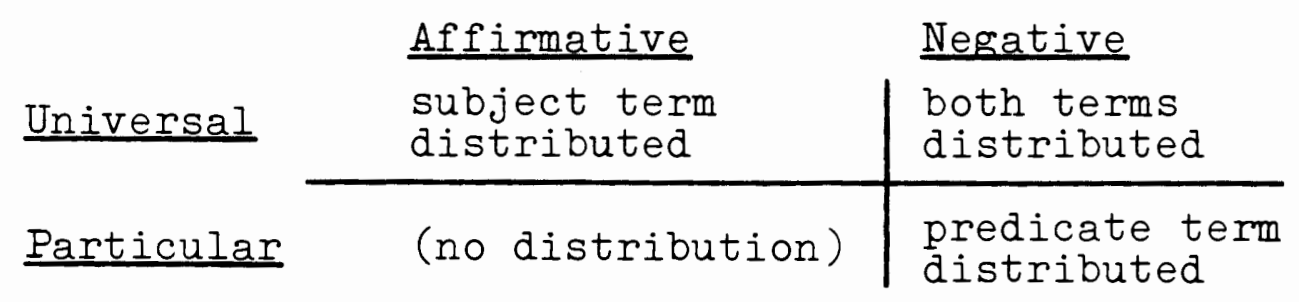

27 Aristotle's figures, moods, and rules for the conversion of propositions of syllogisms are not considered here because they have no bearing upon Toulmin's discussion of formal logic. For more complete discussions, see Aristotle's Organon, especially the Interpretation, Prior Analytics, and Posterior Analytics, Mill, or any number of introductory logic texts.

$$
{ }^{28} \text { Copi, p. } 171 \text {. }
$$


${ }^{29}$ Aristotle, Prior Analytics, II.23.68b.14, trans. A. J. Jenkinson in The Basic Works of Aristotle, ed. Richard McKeon, p. 102 .

30 Aristotle, Topics, I.1.100a.25-27, trans. W. A. Pickard-Cambridge, in McKeon, p. 188.

31

Ibid., I.2.105a.13-19, p. 198.

32 Prior Analytics, II.22.68b.15-29, p. 102.

33 Arthur Kruger, Modern Debate: Its Logic and Strategy (New York: McGraw-Hill Co., 1960), 148-149.

34 See Black, pp. 304-305; Cohen and Nagel, pp. 12-13. Aristotle also comments on the impossibility of complete enumeration as a justification in Posterior Analytics, I.19.81b,10-82a,20, pp. 136-137.

35 Aristotle, The Rhetoric of Aristotle, trans. Iane Cooper (New York: Appleton-Century-Crofts, Inc., 1960), 10 .

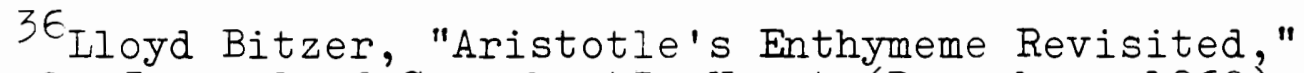
Quarterly Journal of Speech, 45, No. 4 (December, 1960), 408. For other perspectives on the nature of the enthymeme, see Gary Cronkhite, "The Enthymeme as Deductive Rhetorical Argument," Western Speech, 30, No. 2 (Spring, 1966), 129-134.

37 Charles Mudd, "Enthymeme and Logical Validity," QJS, 45, No. 4 (December, 1959), 413. There is scholarly disagreement over the degree to which the enthymeme was viewed as an instrument of pathetic as well as logical proof by Aristotle. For a discussion of this controversy, see Walter Fisher, "Uses of the Enthymeme," Speech Teacher, 8, No. 3 (September, 1964), 197-203.

38 Jerry Feezel, "The Mystery of the Epicheireme," WS, 31, No. 2 (Spring, 1967), 109.

39 Ibid., p. 112 .

40 Quintilian, Institutes of Oratory, trans. H. Butler (Cambridge: Harvard University Press, Loeb Classical Library, 1921), II, 351-353.

${ }^{41}$ Tbid., p. 357. In this remark, he claims to be following Cicero.

42 Ibid. 
43 According to Toulmin, such a structure may be termed quasi-syllogistic or a quasi-syllogism. It is this form of syllogism, presumed to be more practical and germane to argument in human affairs, which Toulmin uses to illustrate the usefulness of field-dependent sources of soundness. See Uses, pp. 109-111, 131-134, 139-141. A formal logician's view of quasi-syllogisms may be found in Salmon, pp. 45-47.

$$
{ }^{44} \text { Uses, pp. 94-145. }
$$

45 Toulmin's diagrammatic model appears to be a means to an end in its role in the Uses of Argument. The structure for the analysis of arguments appears to be less important in itself to Toulmin than the distinctions and perspective on argument which it represents. This interpretation is supported by the fact that Toulmin makes a single indirect reference to the micro-structure of arguments in his conclusion ( $p .256)$. In spite of the relative unimportance Toulmin appears to believe the model to have independent of his overall presentation, it is the model which has received the greatest attention by speech communication professionals. Thus, the model is presented in detail here.

$$
\begin{aligned}
& 46_{\text {Uses }}, \text { p. 99, 256, 103. } \\
& 47 \text { Ibid., pp. 94-95. }{ }^{48} \text { Ibid., p. 12, } 5 .
\end{aligned}
$$

${ }^{49}$ Tbid. p. 12. Toulmin and others have recently addressed the subject of reasoning and its relation to argument. See Reasoning, pp. 5-18.

$$
\begin{aligned}
& \text { 50 Uses, p. 7. } \quad{ }^{51} \text { Ibid., p. 8. } \quad 52 \text { Ibid., p. } 7 . \\
& 53 \text { Ibid., p. 104. } \quad 54 \text { Ibia., p. 7. } 210.255 .
\end{aligned}
$$
of his model to its application to micro-arguments. He does not discuss the potential application of his model to more complex macro-arguments.

$$
\begin{aligned}
& 56 \text { Ibid., p. 11, } 97 . \quad 57 \text { Tbid., p. } 97 . \\
& 58_{\text {Ibid., p. } 97, \text { 16-17. }}
\end{aligned}
$$

59 Tbid., p. 97. By the term "fact" Toulmin appears to mean an immediately verifiable or previously verified statement. Thus, direct sensory experiences as well as conclusions reached by habit or consensus involving correlations, signs, cause-effect chains and isomorphs among 
phenomena--all may be included as data. Toulmin does not specify how many facts may appropriately be classed as data with regards to a particular claim.

$$
60 \text { Ibid., p. 98. } 61_{\text {Ibid. }}
$$

62 Ibid., p. 105. Toulmin goes so far as to recommend the hypothetical form "If... (D), then... (C)" as a succinct and clear form for the statement of a warrant. He notes, however, that habits of speech are such that warrants are frequently combined in sentences with other elements, or they may be abbreviated, implied, or otherwise not immediately identifiable. For examples of warrant, see pp. 105, 111, 126, and 184.
63 Tbid., p. 100. ${ }^{64}$ Tbid., p. 120.
65 Ibid., pp. 120-121.

66 Ibid. Toulmin states that among warrant-using arguments are those which require only a single datum to support the claim. Further, he contends that only warrantusing arguments should be referred to as "inferences" because they are the only type which rely upon general rules to move from fresh data to new conclusions.

67 Example drawn from Gary Albertson and Mary Patrizzi, eds., Fire Mountain: The Eruptions of Mount St. Helens (Portland: Cathco Publishing Co., 1980).

$$
\begin{aligned}
& { }^{68} \text { Ibid., pp. 100-101. See also pp. 18-38. } \\
& 69 \text { Ibid., p. 83. }{ }^{70} \text { Ibid., pp. 101-102. } \\
& 7{ }^{1} \text { Ibid., pp. 101-102. } 7^{72} \text { Tbid., p. 103. } \\
& 73 \text { Ibid., p. 135. } 74 \text { Ibid., pp. 18-30. } \\
& 75 \text { Ibid., p. 30. }
\end{aligned}
$$

76 Toulmin, Human Understanding, pp. 165-168. See also, Toulmin et al. Reasoning, pp. 14-16, 195-202. It is assumed that Toulmin means roughly the same thing by the terms "field of argument," "rational enterprise," "discipline," and "forum of argument."

77Uses, p. 14. See Charles Willard, "Some Questions "About Toulmin's View of Argument Fields," and Ray McKerrow, "On Fields and Rational Enterprises: A'Reply to Willard," in Proceedings of the Summer Conference on Argumentation (July 26-29, 1979), eds. Jack Rhodes and Sara Newell 
(Falls Church: Speech Communication Association, 1980), 348-411, for a critical discussion of the field concept.

$78_{\text {Uses }}$, p. $15 . \quad{ }^{79}$ Ibid., p. 36, 103, 112.
$80_{\text {Ibid. }}$ p. 50 .
$81_{\text {According to McKerrow, "logical type is neither a }}$ function of arguers nor of disciplines (though there may be parallels in both instances). Instead, a field is a function of the objects or ideas named via language .... The 'steps' used in moving from one term to another in an inferential process call on different sorts of logical types, hence belong to different fields" (p. 402). Thus, in Uses Toulmin relies on a technical means of defining fields, one which draws from Gilbert Ryle's linguistic application of Russell's "theory of logical types." See Ryle, "Philosophical Arguments," in Collected Papers (London: Hutchinson and Co., 1971), II, 194-211; also Whitehead and Russell, Principia Mathematica.

${ }^{82_{\text {Uses }}, p . ~} 188$.

${ }^{83}$ Ibid., quoted, p. 147; see also p. 148.

${ }^{84}$ Reasoning, pp. 147-155.

${ }^{85}$ Ibid., p. 148, 150, 151, respectively.

86 Ibid. p. 155. 87 Ibid. p. 147. $\quad 88$ Ibid., p. 148.

${ }^{89}$ Uses, pp. 166-169, 188, 218.

90 Reasoning, p. 148.

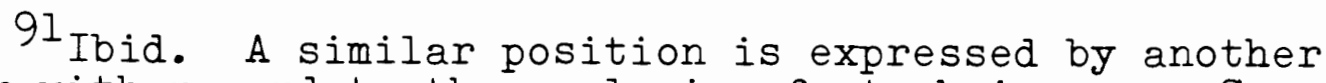
author with regard to the analysis of stock issues. See Robert P. Newman, "Analysis and Issues--A Study of Doctrine, " Central States Speech Journal, 13, No. 1 (Autumn, $1961), 43-54$.
92 Uses, p. 124.
93 Ibid., p. 205.
94 Ibid., p. 127.
${ }^{95}$ Ibid., pp. 126-127.

96 Toulmin, Human Understanding, pp. 24-29; Uses, pp. 253-259.

97 Uses, p. 253. 98 Kneale and Kneale, pp. 178-179.

99 Uses, pp. 178-179. 
100 Ibid., pp. 209-210. "Symbolic logic has so far been a domain of mathematicians. It grew from the soil of mathematics, it found its first successful applications in mathematics; and it remained accessible only to those who were trained in the mathematical technique." Hans Reichenbach, Elements of Symbolic Logic (New York: Macmillan Co., 1947), V. For another viewpoint, see Copi, pp. 245-28E.

${ }^{10}$ Toulmin goes on to qualify his position in the following way: if the field of argument is itself mathematical, then the applicability of a mathematical logic may be assumed. However, even in these fields, Toulmin challenges the degree to which any mathematical expression of probability can be very informative. See Uses, pp. 8993.

$$
\begin{aligned}
& 102 \text { Tbid., p. 147. } \quad{ }^{103} \text { Ibid., p. } 95 . \\
& 104 \text { Ibid., p. } 118 .
\end{aligned}
$$

105 Toulmin's analogy between logic and jurisprudence is not unique. While there is no acknowledged connection amongst the philosophers who have done so, some others have proposed a jurisprudential approach to the study of argumentation ard reasoning. See Ch. Perelmar and I. OlbrechtsTyteca, The New Rhetoric: A Treatise on Argumentation, trans. John Wilkenson and Purcell Weaver (Notre Dame: University of Notre Dame Press, 1969; originally published in French, 1958); and Rupert Crawshay-Williams, Methods and Criteria of Reasoning: An Inquiry into the Structure of Controversy (New York: The Humanities Press, Inc., 1957). While these works were published at about the same time as Uses, their differences of approach to the jurisprudential analogy are interesting.

$$
\begin{aligned}
& \text { I0E } E_{\text {Uses }}, \text { p. 7. 107 Ibid., p. 97. } 108 \text { Ibid., p. } 178 . \\
& 109 \text { Ibid., p. IEE. } 110_{\text {Ibid., p. } 254 .}
\end{aligned}
$$

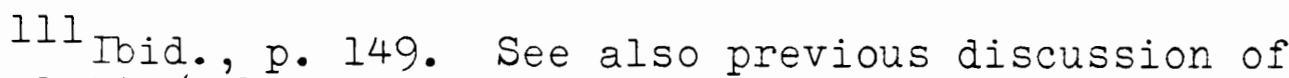
the analytic/substantial distinction in this study, pp. 5455 .

$$
112 \text { Uses, p. } 173 .
$$
no interchange with its environment." Stephen Littlejohn, Theories of Human Communication (Columbus: Charles E. Merrill Publishing Co. Inc., 1978), 30.

$$
114 \text { Uses, p. 127. } 115 \text { Ibid., pp. 107-109. }
$$




\section{$116_{\text {Uses }}$, pp. 147-154. 117 Toid., p. 147.}

118Ibid., pp. 148-149. Standard logical qualifiers have already been discussed in this study (see pp. 31-32). By "other sorts of connectives" Toulmin refers to such words as "most," "few," and "but" which are not uncommon in arguments but do not meet the standards of distribution necessary in formally valid arguments.

$$
\begin{aligned}
& 119 \text { Ibid., pp. 171-174. }{ }^{120} \text { Ibid., pp. 175-176. } \\
& 121 \text { Ibid., p. 117. } \\
& 123 \text { Ibid., p. 143. } \\
& 124 \text { Ibid., p. 134. For discussion of the principle of }
\end{aligned}
$$
the syllogism, see this study, pp. 28-35.

125 of the nature of "quasi-syllogisms," Toulmin writes "the conclusion.. - is only tentative, but in other respects the argument is exactly like a syllogism." Uses, p. 109. For further discussion of quasi-syllogisms, see Salmon, pp. 45-47.

$$
\begin{aligned}
& 126_{\text {Uses }}, \text { p. } 140 . \\
& 128 \text { Ibid., p. } 218 . \\
& 130 \text { Ibid., p. } 219 . \\
& 132 \text { Tbid., p. } 255 .
\end{aligned}
$$

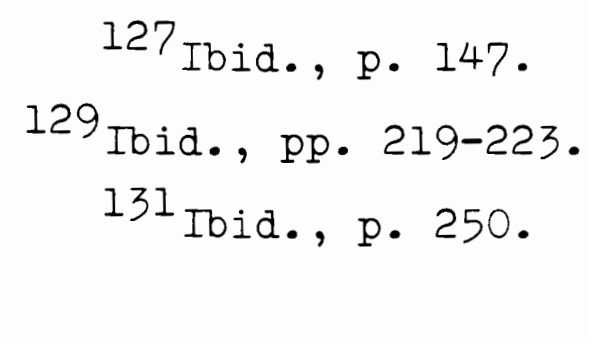


CHAPTER III

\section{CRITICISM OF THE TOULMIN MODEL FROM THE PERSPECTIVE OF FORMAI IOGIC:}

\section{A CONFLICT OF THEORETICAL}

\section{PERSPECT IVES}

Since the initial publication of Toulmin's concept of logic as "generalized jurisprudence," several expressions of the scholarly skepticism of formal logicians about the Toulmin approach have reached expression in journals of philosophy and speech communication. ${ }^{1}$ These largely negative criticisms of the Toulmin approach are the focus of this chapter. Major themes of criticism are discussed and their significance to the question of the potential usefulness of the Toulmin model to the area of speech communication are evaluated. The presentation which follows is divided into three sections. First, general criticisms of the Toulmin approach are examined. Second, specific criticisms of the Toulmin model are examined. Third, the criticisms of Toulmin's concepts from the perspective of formal logic are compared to Toulmin's perspective on the limitations and defects of formal logic, and a hypothesis is suggested which may explain the divergence of the two perspectives. The criticisms presented in this section are 
not meant to represent a complete survey of all the philosophical objections to the Toulmin approach which have been mentioned in articles; only the major, most frequently discussed themes of criticism are examined here in order that issues for subsequent investigation may be identified.

\section{GENERAL CRITICISMS OF THE TOUIMIN APPROACH}

Among the criticisms from formal logicians of the Toulmin approach four major themes have been identified. Critics charge that Toulmin's approach (I) is unoriginal, (2) is grounded in obsolete ideas, (3) does not represent an innovation in the field of logic, and (4) is unnecessarily broad in its implications for the field of logic.

\section{Toulmin's Approach is}

\section{Unoriginal}

If Toulmin's approach is unoriginal as critics have charged, then it must directly parallel or resemble the previously published work of other authorities. Several critics, notably Hardin, Korner, Casteneda, and Bird, point out that Toulmin is not unique among logicians seeking to develop a logic more applicable to practical argument, and that he appears to have derived many of his concepts from other philosophers. 2 Toulmin draws much from the works of Gilbert Ryle, J. I. Austin, R. M. Hare, J. T. Wisdom, H. I. A. Hart, and less directly from Ludwig Wittgenstein and David Hume. ${ }^{3}$ These and many other sources 
are cited by Toulmin. ${ }^{4}$ Thus, there can be no denial that some parts of Toulmin's discussion are derivative of other ordinary language philosophers. Since none of these critics have charged Toulmin with plagiarism, it is difficult to understand what difference to Toulmin's scholarship or the applicability of his approach the derivative nature of some of his ideas makes. Unless there is something wrong with the ideas which Toulmin has drawn from others (a position none of these critics take), the charge of unoriginality may be disregarded as of little consequence.

A more serious objection to Toulmin's ideas on the basis of their lack of originality is put forth by some critics to the effect that Toulmin accomplishes nothing more with his work than a relabelling or rediscovery of long established concepts from formal logic. Trent, for instance, compared the Toulmin model to the Ciceronian epicheireme which he describes as a supported enthymeme or an argument based on probability. 5 On this interpretation, the Toulmin model would be subject to the rules of formal validity just as the epicheireme is. 6 Along the same line, Hample contends that there exists little distinction between syllogistic logic and the Toulmin model if one "consider[s] backing and rebuttal as stock issues of stases which are applicable to the premises of any argument." 7 It may be significant that both Trent and Hample present these 
comparisons as part of arguments in favor of a reconsideration of the traditional procedures of formal logic. In the case of Trent, a unique interpretation of the epicheireme is proposed which combines some of Toulmin's terminology with syllogistic procedures and classifications. ${ }^{8}$ Hample, on the other hand, defends the syllogism for its simplicity and structural superiority to the Toulmin model. 9 Neither critic, in comparing the Toulmin model to a syllogistic form, attempts to reconcile Toulmin's concern with variations among field-dependent justification procedures with the field-invariant standards of formal validity. ${ }^{10}$ In other words, these critics apparently disregard Toulmin's epistemic concerns for relativism in arguments. For this reason, their comparisons appear to be poorly drawn.

Perhaps the best documented and most intriguing case made for Toulmin as a rediscoverer rather than an innovator is presented by Otto Bird. Bird details several resemblances between the functionally-defined elements of the Toulmin model, particularly warrant and backing, and the "topical maxim and difference" of medieval logic. ${ }^{11}$ The topics, which Bird says represent the field-dependent sources of proof in traditional formal logic, were in medieval times the object of extensive scholarly investigation. In modern textbooks of logic, they receive little attention. Bird concludes that at least some medieval logicians shared 
Toulmin's concern for field-dependent aspects of logic, and that "more has been done in the analysis of warrants and backings than Toulmin seems to realize."12 Bird does not discuss what has become of the medieval notions which he believes are echoed by Toulmin.

Comparisons such as those suggested by Trent, Hample, and Bird are interesting and suggest some directions future research might take. For example, the epicheireme apparently had great popularity among ancient Roman rhetoricians and yet was subsequently lost and since disregarded by logicians. 13 One wonders if the epicheireme was found by logicians to be too complex, or if some other inherent defect led to its eventual disuse. Similarly, assuming the relationship between the topics and Toulmin's model is more than just a resemblance, the history of topical maxim and difference may indicate something about potential strengths and limitations of the Toulmin model. Such historical research may shed light upon the current practices of logicians as well as implying revisions in those practices which may lead to the development of a more practical approach to logic.

With regard to the applicability of the Toulmin model to speech communication, charges that Toulmin's approach is unoriginal seem largely beside the point. Ancient and modern philosophers may have contributed directly and indirectly to Toulmin's concepts, and the extent of their 
influence is a matter which may be of interest to some current philosophers and historically-minded students of argumentation theory. However, what is central to the present study is the question of how useful a tool the Toulmin model provides to the critics and creators of arguments in comparison to the syllogism. In this light, any lack of originality of Toulmin's approach appears to be inconsequential.

\section{Toulmin's Approach is Grounded}

\section{in Obsolete Ideas}

Some critics charge that the categorical syllogism, the only logical form selected by Toulmin for discussion throughout The Uses of Argument, is not sufficiently representative of current practices of formal logicians. 14 Casteneda remarks that Toulmin's syllogistic focus indicates his disregard for "the progress of logic in the last 120 years."15 Hardin calls it "a regrettable oversimplification."16 Manicas suggests that this one aspect of Toulmin's discussion brings into doubt the overall value of Toulmin's hypothesis. 17 It may be significant that, among all of Toulmin's commentators, only these three rely upon the conventional notations of symbolic logic in their rebuttals to Toulmin's criticisms of the syllogism. 18

Toulmin may have limited his discussion to the categorical syllogism because it is traditionally offered in introductory logic textbooks as the simplest, most basic 
form of argument, and due to its singular premise and conclusion it has an obvious practical applicability which some more sophisticated forms have not. 19 Moreover, other forms of syllogisms are developed from or otherwise related to the basic form illustrated by the example "Socrates is a man, all men are mortal, therefore Socrates is mortal." Since Toulmin represents his approach as being fundamentally different from the traditional approach, his selection of the most basic kind of syllogism as a foil seems appropriate. Nevertheless, if the more current, sophisticated forms of logical analysis can be shown to eliminate the ambiguities of the syllogism, focus attention upon fielddependent sources of validity and provide practical procedures for demonstrating logical candidness, then the value of Toulmin's alternative approach would indeed come into doubt. However, it should be noted that none of the critics accusing obsolescence provide full support for their claims, that is, by showing the categorical syllogism to be obsolete and largely unrelated to current practices. A perusal of basic logic textbooks as well as textbooks in argumentation, debate, and rhetoric reveals that the categorical syllogism is still treated as fundamental; indeed, it is often the only form considered in speech communication texts in which formal logic is a subsidiary topic. 20 Whereas speech communication textbooks, if they mention logic at all, are likely to include discussion of 
categorical syllogisms primarily, what Toulmin says about this "obsolete" form may be of interest. Therefore, the charge that Toulmin's approach is founded on obsolete ideas, even if true, does not bear directly on its potential usefulness in the area of speech communication. 21

The Toulmin Approach Does Not Represent an Innovation in the Field of Logic

Those critics who charge that Toulmin's approach is not innovative include some who believe that formal logic is superior to Toulmin's approach and others who fail to see much difference between them. Both these critics insist that the syllogism is not so limited and ambiguous as Toulmin contends. For example, to Toulmin's claim that ambiguities in the major premise prevent the explication of matters of backing, Cooley responds by asking for "the identity of the individuals who restrict themselves in this way" implying that such logicians cannot be found. 22 Casteneda repeats this charge, stating emphatically that "no logician ever even hinted that major premises cannot have different supports or backings."23 Manicas and Simopoulos express similar criticisms. 24 In other words, according to these critics, the traditional approach is at least as good as, if not better than, the Toulmin approach. This is made clear in the final conclusions drawn by Cooley, Casteneda, and Simopoulos who agree that the Toulmin 
model may not in and of itself be faulty but it is not without problems and, even if those are solved, it does not change the ways in which arguments are criticized. 25

Whether the Toulmin model is inferior or superior to the syllogism as a tool of analysis is a matter of controversy. 26 It has already been shown that, while both share the same subject matter of argumentative discourse, the approaches of Toulmin and formal logicians vary in a number of significant ways. The critics who maintain that no important differences exist between them seem to presume that human reasoning itself operates syllogistically. 27 For a model of argument to be adequate, it must, therefore, do all that a syllogism does. 28 Because the Toulmin model is not designed to test or illustrate the structural consistency of parts of an argument (as discussed in chapter II), formal logicians feel it falls short of what is needed. For example, Cooley, Hardin, and Manicas each attribute Toulmin's sense of ambiguity in the major premise to his reliance on a peculiar terminology which fails to reflect traditional categories. 29 When compared to the parts of a syllogism which are as straightforward as the grammatical elements of the sentences they represent, Toulmin's functionally-defined elements seem ambiguous and difficult, if not impossible, to distinguish. Specific criticisms which follow from this view are discussed later in this chapter. 
If one presumes the usefulness and candidness of the syllogism as a tool for the analysis of arguments, no advantage can be realized by adopting distinctions which fail to reflect the "ideal" syllogistic elements. As Manicas rhetorically asks in reference to the categorical syllogism, "could the structure of this argument be any more candid than it now is?"30 According to this point of view, then, logic has reached a pinnacle of development; while it may be made more exacting through extension, no alteration of the basic assumptions and aims could improve it. In essence, the position of these formal logicians precludes the possibility of significant innovation in the field of logic; certainly they cannot accept Toulmin's approach which rejects much of the traditional view. 31 This posture taken by formal logicians may strike empirically-minded speech communication professionals as repugnant simply because it avoids what might be theoretical problems by considering them to be problems in the proper application of theory. In other words, the theory is maintained as acceptable while the process of application becomes increasingly complex as problems are encountered. Toulmin's effort is to simplify issues involving application by transforming the theory. This difference of approach to theory and application is part of a larger pattern of differences between Toulmin and formal logicians for which an explanation will be hypothesized in the final section of this chapter. 
Toulmin's Approach is Unnecessarily

Broad in its Implications for

the Field of Logic

As we have seen, the revolutionary tone of Toulmin's book disturbs some formal logicians who might otherwise find some of what he says worthy of consideration. Formal logicians do not believe the problems of formal logic to be so serious that a whole new approach needs to be pursued. 32 Further, they fail to see how Toulmin's model provides such a unique new approach.

At best, critics argue, some of the distinctions Toulmin makes may be usefully incorporated within the practices of formal logicians. However, there seems to be little agreement as to what these distinctions may be. For example, first, to Toulmin's division of probability into matters of force represented by modal qualifiers and criteria represented in warrant-backings, and second, to his discussion of the significance of field-dependent aspects of argument, Cooley contends that the conventional approach can be accommodated. 33 In contrast, Manicas argues that there are easier available solutions to the problems posed by Toulmin which are superior to adopting his questionable terminology. 34 Another reviewer, F. Will, is less skeptical than Manicas and finds many of Toulmin's discussions "interesting and illuminating." 35 Hardin, on the other hand, praises Toulmin's treatment of the relationship of logic and epistemology as well as his discussion of 
probability, while Korner calls the latter discussion "the least convincing in the book."36 Simopoulos and Casteneda prefer to dismiss Toulmin's approach entirely, agreeing that his distinctions, while interesting, are inconsequential and therefore deserving of no attention. 37 Cowan is more extreme, contending that Toulmin's approach is wrong in nearly every respect, but that the current thinking of formal logicians is equally misdirected--in a way almost antithetical to Toulmin's hypothesis. 38 Cowan's view represents a minority opinion, however, as most critics suggest that at least some aspects of what Toulmin proposes are worth further consideration, but not at the cost of sacrificing a 2300-year-old tradition. 39

Formal logicians, as previously noted, feel that formal logic provides an adequate tool for the analysis of arguments, and that major innovations are unnecessary if not impossible. Whatever ideas of Toulmin's seem promising can, in their view, be made a part of the practice of logicians within the conceptual framework which already exists. Moreover, much of what Toulmin offers as new and unique does not seem so to logicians who perceive resemblances to the parts of the syllogism or archiac forms related to it. Thus, to formal logicians who have published criticisms of The Uses of Argument, Toulmin's approach in general represents far less an advance in logic than Toulmin seems to believe. 
SPECIFIC CRITICISMS OF THE TOULMIN MODEL

Perhaps the single most controversial aspect of Toulmin's approach is his layout for the analysis of argument, the Toulmin model. Composed of functionally-defined rather than formal elements of argument, the Toulmin model is criticized by some formal logicians for (I) indistinguishability among its elements, (2) backing which cannot provide the justification which Toulmin believes is needed, (3) a questionable conception of data, and (4) an unexplained classification of some arguments as warrant-establishing. These charges are detailed in the following discussion along with their implications for the application of the Toulmin model to speech communication. Further issues about the Toulmin model which the writer believes to be crucial are discussed at the end of this section.

\section{Elements of the Toulmin Model}

\section{Are Indistinguishable}

Critics have charged that several crucial elements of the Toulmin model cannot be distinguished from one another. Specifically, the elements they find most difficult to distinguish are: warrant and data, warrant and backing, and data and rebuttal. On the basis of these alleged ambiguities, formal logicians have challenged the applicability of the model.

Warrant and Data. If warrant and data cannot be clearly distinguished, then not only does the useful 
applicability of the model come into doubt but its contrast to the categorical syllogism becomes less distinct. Several of Toulmin's critics feel uncomfortable with a distinction which, according to Toulmin, is not always possible to make on the basis of grammatical clues only. Hample, for example, states that "it seems odd that a distinction that is only sometimes apparent should be an essential part of a model designed to criticize all ordinary discourse." 40 He contends that without obvious grammatical indicators which are often absent in enthymemes, the distinction cannot be made. Manicas also doubts the usefulness of "linguistic clues" in distinguishing data from warrant since "grammatical transformations" must be performed in some cases to bring differences to light. 41 Even though such transformations are also necessary with the syllogism, Manicas doubts if the distinction can be applied to arguments which fail to fit the form of a syllogism with a singular and universal premise. 42 Because some arguments are formed with pairs of universal premises, Manicas counts the ambiguity between data and warrant among the limitations of the Toulmin model.

Other critics note that the functional differences themselves are difficult to keep separate. Casteneda finds the disjunctive choice between warrant and data oppressive especially because data seem limited to statements "about closed classes of objects." 43 Casteneda contends that this 
rules out as data common everyday statements about open or unlimited classes of objects as well as statements of prediction. Toulmin would count such statements as warrants, but Casteneda contends that they need not be "permissive" to be used in an argument. In other words, in Casteneda's view, to look only at the permissive function of a major premise is to restrict oneself to only a portion of the possible premises which may be taken into account with the syllogism. Taking Toulmin's distinction between data and warrant as a disjunctive limitation, Casteneda concludes that the Toulmin model is more restrictive and less applicable than the syllogism to practical argument.

Cooley, Cowan, and Manicas are all troubled by Toulmin's characterization of data as "categorical statements of fact" or "items of information." 44 They ask if warrants are not information--if they cannot be factual. Cooley notes that it seems to be up to the critic of argument whether statements of fact are to be classified as data (in which case they may affect a claim) or backing (in which case they affect the warrant). ${ }^{45}$ Cowan asks if a person unfamiliar with a particular warrant statement might not take it as "information," and thus data. 46 In other words, these critics are disturbed that Toulmin seems to imply that whether a statement is to be taken as factual and informative or authorizing and permissive depends upon the judgment of the person to whom the argument is made. Other 
distinguishing criteria noted by Toulmin--that data may be appealed to explicitly and warrants, implicitly--are dismissed by Cowan because they depend too much upon what the arguer thinks a respondent already knows or doesn't know about the subject of an argument and not so much upon the different functioning of the statements themselves. 47

In defense of Toulmin one might argue that he never claimed that such distinctions would be easy to make; on the contrary, he explicitly warns that functional differences are not always apparent in linguistic forms of statements given in argument. 48 Further, particular statements are seldom absolutely one thing or the other in practice. The same statement may be found to serve as data in one situation and warrant in another. 49 For example, depending upon the context, the statement "Abortion is immoral" may serve as a datum or a warrant. It may be a datum in this first argument: "(W) Immorality should be outlawed; therefore, (C) abortion should be illegal." On the other hand, it may be a warrant in this second argument: "(D) Ellen is pregnant but does not want the child; therefore, (C) she must either decide to keep the child or else put it up for adoption." It is conceivable that these arguments in which the same statement functions differently might occur together as separate units of proof in an anti-abortion message. This and other examples offered by Manicas and Casteneda may indeed be among the problematic cases Toulmin 
refers to in which the distinction is less than obvious. 50 However, the characterization of data as statements about "a closed class of objects" used by Casteneda to demonstrate the oppressive nature of Toulmin's distinction is itself more restrictive than any offered by Toulmin. 51 In addition, the hypothetical form "if $D$ then $C$ " into which warrant statements may normally be rewritten according to Toulmin does not imply "information" in the sense used by Cowan; rather it is their permissive function in connecting data to claim which is the salient feature of Toulmin's warrants. 52

Claims of the indistinguishability of data and warrant may come as a surprise to some speech communication professionals who have apparently found the Toulmin model useful in a number of research studies. 53 Considering the complexity of arguments in discourse as compared to textbook examples which are often constructed to demonstrate theoretical points, the potential effectiveness of the Toulmin model as a critical tool should not be quickly dismissed.

On the other hand, there is a casual quality to the definitive explanations Toulmin offers, especially of data. Operational definitions which might promote standards of application for the Toulmin model have yet to be developed. Such definitions are desirable, however, considering the varying interpretations which may be placed 
upon terms such as "information," "factual," "permissive," and "principles." To the extent that definitions of elements vary according to the different purposes and contexts of arguments in specific fields, illustrative examples which demonstrate such variations may help the analyst to make the necessary distinctions.

Warrant and Backing. Critics have claimed that warrant and backing cannot be clearly distinguished. This charge is largely a reiteration of that brought against the indistinguishability of warrant and data, to the effect that grammatical clues are not enough indication of differences. Cooley, Hample, and Manicas each challenge the distinction of backing from warrant on this basis. 54 Casteneda takes a different tack, using one Toulmin concept against another, suggesting "if we cannot get from any set of data to a conclusion without some warrant one naively wonders what sort of argument ' $D$, B; so $C$ ' can be." 55 In other words, according to Casteneda, either Toulmin is being inconsistent or backing may function as warrant at times, in which case the distinction between them seems a muddy affair.

Of the first of these charges, that grammatical indicators are an inadequate basis for distinguishing these elements, enough has been said. On the surface, Casteneda's charge seems more serious, but on closer examination it appears to be the result of a peculiar 
interpretation of Toulmin's position. As discussed in essay III of The Uses of Argument, the form "D, B; so C" is introduced in the context of analytic arguments and their special features. 56 One of these features which makes analytic arguments unique is that there is no significant difference between their warrants and their backings. In other words, while most practical arguments are substantial and require that their warrants be backed, only in analytic arguments are these functions unambiguously combined in major premises. 57 According to Toulmin, formal logicians have mistakenly idealized this unique analytic form, which is why formal logic has lost touch with its intended applications. Casteneda, in considering "D, B; so C" out of context, misses the point and presumes Toulmin to be in error. In short, just because a special class of arguments exists in which distinguishing warrant from backing is of no value does not mean that the same holds for arguments in general.

The distinction between backing and warrant is crucial to Toulmin's model, first because it represents one of the major innovations of the Toulmin approach, and second because without it the field-dependent sources of validity remain obscure. Toulmin's suggestions of how to distinguish backing from warrant are clearer than some of his other distinctions, perhaps because he is careful to explain them in terms of other more general distinctions 
on which they depend. Backings are, after all, not merely data-like statements offered in general support of a warrant. They are, in addition, representative of the criteria of an argument, one of its field-dependent aspects. 58 Thus, the function of backing is different from the other elements. To say that the distinction between warrant and backing is among Toulmin's clearest is not to suggest that it is beyond improvement. Toulmin has not helped critics of argument with the process of applying his distinctions. For instance, he fails to provide a set of clear procedures for testing statements to determine their functions, illustrations of well-backed warrants from various fields for comparison, or discussion of steps used in the criticism of argumentative discourse with the Toulmin model. Such matters are of major interest to argumentation students and scholars in speech communication who have had to develop their own interpretations. In subsequent chapters of this study, these various approaches to the Toulmin model are examined, along with a recent textbook coauthored by Toulmin. 59

Data and Rebuttal. Critics claim that data and rebuttal cannot be clearly distinguished. There is no element in the syllogism which corresponds to Toulmin's rebuttal. Apparently formal logicians believe that there is no need for any consideration of data which refutes to some degree a conclusion asserted in argument if the 
argument is presented in the unassailable form of an analytic syllogism. Formal logicians appear to find rebuttals difficult to make sense of and some argue that such an element is unnecessary and meaningless in a model of argument.

As has been shown, the element of rebuttal is concerned with the specification of possible exceptions to the applicability of the warrant to the particular case at hand. The probability which is represented by an abstract modal term as qualifier of a claim is exemplified and made concrete by what may be included as rebuttal. 60 To Toulmin, rebuttal is a way of acknowledging that no truth or principle is absolute and that all arguments compete within a field with alternative explanations. In other words, the rebuttal guides the critic's search for inconsistent data which are not part of the initial argument. Unknown factors which could affect the force or soundness of a claim are what the rebuttal is meant to specify.

Formal logicians appear to find the idea of rebuttal confusing. Hample, after long discussion, concludes that "the omission [on Toulmin's part] of a procedure for testing rebuttals leaves vague [sic] how the rebuttals work and how they generate qualifiers." 61 cooley similarly argues that more explanation is needed to establish how rebuttals serve to enlarge the area of support for a conclusion. 62 He also suggests that it would be simpler if 
rebuttals could be "manuevered out of the picture" by treating them as additional items of data which comment on or qualify other data. 63 Manicas thinks that there is no need to pay any attention to rebuttals at all since a warrant may itself imply exceptions, and the overall force of a claim will be the same whether or not a rebuttal is specified. 64 Further, he rejects rebuttals as matters of material validity which are more appropriately considered as separate arguments having to do with the truth of one of the premises of a syllogism. 65

At issue in the formal logicians criticism of rebuttal and its distinctiveness from data is the question of how complete one's data must be before a claim may properly be advanced. A syllogism is presumed to contain all of the relevant data in its premises. Likewise, according to Hample, Toulmin says the same of data in the Toulmin model, that it must be complete. 66 While it is true Toulmin considers that all of the relevant evidence to which one has access should be included in an argument, he does not say that it should be included as data as Hample implies. Toulmin makes a distinction which Hample does not acknowledge, differentiating a statement of data which bears directly on the question at issue from another kind of statement he terms "a second-order comment on our previous information" or a "statement about the nature of our data."67 It is this latter kind of statement which Toulmin 
implies ought to be included as rebuttal because it bears on the applicability of the warrant to the case at hand. Toulmin does not, as Hample states, suggest that such second-order comments be excluded from the model. 68 Hample and some other logicians seem to find this distinction between kinds of data difficult to grasp.

Indeed, Toulmin's distinction between information that is best considered data and that which is best considered rebuttal is not carefully described. Further clarification and exemplification would be appreciated by those who wish to apply the model without being hindered by, for example, having to consider what may be an infinite number of exceptions to an otherwise simple claim. But this need for further definition and illustration is not necessarily grounds for discarding rebuttal as an element of the Toulmin model.

Rebuttal, like backing, is one of the unique fielddependent aspects of the Toulmin model which makes it different from the traditional syllogism. Rebuttal gives the Toulmin model a more dynamic quality than it would have without it since it is the element which can reflect changing circumstances within a field or the discovery of new relevant evidence. Finally, a rebuttal which is judiciously conceived can potentially serve as an invaluable guide in the investigations of a critic or arguer. The rebuttal would appear to be an attractive feature of the 
Toulmin model for speech communication professionals concerned with practical argumentation.

In the case of each of the alleged ambiguities between warrant and data, warrant and backing, and data and rebuttal, it has been argued here that further clarification of definitions and the development of standardized procedures for their application are more desirable than a return to the static absolutism of the traditional approach. This opinion is supported by the applications which some in speech communication believe can effectively be made of the Toulmin model; these are discussed in chapter V. This is not to suggest that the Toulmin model is somehow the ideal way to view argument; as the remainder of this section will show, there are still important questions to be answered about some of the basic features of the model. For the purposes of analysis and comparison of rational procedures of various disciplines and as a basis for the criticism of conclusions asserted within a field, philosophical criticism notwithstanding, the Toulmin model has many attractive features which the syllogism lacks.

\section{Backing Cannot Provide}

Justification for

Arguments

Perhaps the charge most widely leveled by critics of the Toulmin model is this: backing for the warrant cannot provide justification for an argument. Instead it defines 
only the first step in an infinitely regressive set of supporting arguments. This idea is well represented by Cowan's statement:

- assuming justification to be what is required, we will need a justification of warrant (3) for our passage (2) to conclusion (1). But if this is the case, we will surely need a further warrant (4) to justify our passage from (2) and (3) to (1) and a further warrant (5) for passing from (2) and (3) and (4) to (1) and so on ad infinitum. 69

Toulmin presents the concept of backing with two qualifications meant to circumvent this objection. First, he introduces backing last among the six functional elements of his model, and he states "this form may not be final but it is significantly complex for the purpose of our present discussions." 70 This leaves the door open for modification of the model perhaps to allow for further justification of backings where necessary. ${ }^{1}$ Second, Toulmin specifies that in some cases backing need not be made explicit since the warrant is uncontested by the disputants. 72 Further, he states that if every warrant were challenged, no argument could ever begin, and he provides an illustration of how an infinite regress might result from infinitely successive challenges. 73 Ironically, several of Toulmin's critics refer to the illustrative passage to support their contention that this feature is a major weakness of the model. 74 The issue seems to involve not the "infinite regress" itself which Toulmin acknowledges as a possibility but the definition of where and in what argument rests. Formal 
logicians appear to view argument primarily as a product, a particular message, a linguistic artifact with a defined formal structure that can be evaluated on its own merits. Toulmin, on the other hand, is concerned with argument as a process involving interacting disputants using linguistic forms which represent various functions of argument. In other words, formal logicians appear to object to the infinite regression because it makes difficult any absolute determination of the soundness of an argument based solely on its form. After all, a form without limits is not subject to a complete analysis or evaluation. Thus, some formal logicians seem baffled by Toulmin's apparent satisfaction with backing as representative of justificatory criteria. For example, Cooley writes of Toulmin's examples of backing:

- . these illustrations . . have a remarkably casual quality. It is clear that nothing in the process of fixing the extent of evidential support is raising any philosophical queries in Mr. Toulmin's mind at this point. . . Toulmin has not erased evidential support as a factor in the situation but he seems to have convinced himself that when it is associated with backing rather than probability the old problems disappear.75

While the philosophical problems created by infinite regress are familiar to Toulmin, he believes that it represents a perversion of the process of practical argument. In the determination of the soundness of real-life arguments, the infinite regress problem is never a significant factor. 76 
Toulmin and formal logicians are clearly divided on this question of justification and backing. To formal logicians there can be no final justification for anything. 77 Hence, they conceive of logic as a matter of structural organization useful in the determination of inconsistencies in reasoning. For Toulmin, justification is possible to the extent that it is founded on the agreed upon historical achievements of rational investigators within their special enterprises. 78

\section{Toulmin's Concept of Data}

\section{is Questionable}

Perhaps no element is less discussed or illustrated by Toulmin than data. The data, assumed by Toulmin to provide the foundation of any argument, are described as "facts," "categorical statements of fact," and "information."79 He assumes that data must be found acceptable to the respondent if an argument is to proceed. 80 From this it may be inferred that data consist of those statements in which all parties to an argument share belief, perhaps as the result of separate supporting arguments through which the acceptability of such data is established. In this regard, Toulmin's model is similar to the syllogism-like minor premises which depend upon prior arguments for their material validity, data become established through prior arguments. 
Formal logicians have many questions about how statements become data and in what way they affect the force of a claim. Three issues about the nature of data emerge from the comments of critics of the Toulmin model. First, can data consist of multiple items of evidence or only single items such as those given in illustrations of arguments in The Uses of Argument? Second, can data be qualified in the same way that a claim is? Finally, should there be an element specifying support for data in manner similar to the way backing specifies support for a warrant? These issues are so intermeshed that to take a position on one of them is to imply answers to the others.

First, are data multiple or singular? This questior arises because nowhere in The Uses of Argument does Toulmin specify that multiple items of data may be included in an analysis using his model; all his diagrammatic examples rely on singular items of data. On the other hand, he does not specifically deny that multiple items may be used and his choice of the plural term "data" rather than the singular "datum" suggests that his concept of data may be more complex than his examples imply. The fact that he appropriately refers to a datum now and then supports this interpretation. 81

Hardin is uncomfortable with what appears to him to be Toulmin's ambivalence on this matter of multiple or singular items of data. Why, he asks, should data be 
limited to particular statements or statistical summaries. 82 Hample suspects that Toulmin "confines himself to singular data" in order to make them appear more distinct from warrants which are, by definition, general. $83 \mathrm{He}$ proposes that the restriction of data to particular statements be removed to make the Toulmin model more useful and more like the traditional approach. These critics, along with Manicas, interpret Toulmin as limiting data to particulars although such a restriction is not clear from Toulmin's discussion. 84

The second major concern of critics is the question of whether or not data may be qualified. Certainly if prior proofs provide the data statements for an argument, such previous data-claims are likely to carry a qualifier with them. Trent argues that Toulmin does not allow for qualification of data statements even though such a function would render the model more applicable. 85 After all, there are not so many absolute arguments on which we can rely for support; much practical argument is grounded in probabilities. Cooley's doubt about what counts as data and what as rebuttal is related to this question of the potential qualification of data. Some second-order comments about the nature of data may simply be qualifications, that is, statements of the degree of confidence one may have in the data. 86 On the other hand, Hample argues that not only should the claim be qualified but so 
should warrant and data. While this would complicate the Toulmin model, according to Hample it would also specify the sources of the force of a claim more clearly than a rebuttal. 87

Third, critics wonder why there is no element specifying support for the data in the Toulmin diagrammatic model. Cooley, Trent, and Manicas each argue that challenges to the reliability of data statements are a significant part of argument which Toulmin seems satisfied to overlook. 88 Trent claims that passing off responsibility of support for data to prior arguments "results in a fragmentation of the argument." 89 However, as Hample acknowledges, once one includes matters of support for the data, the same objections may be raised against this new element as are raised against backing, that it leads to an infinitely regressive chain of supportive arguments unless one arbitrarily specifies some acceptable level of justification. 90 The point of these critics' objections is that without some element which can address challenges made against data in argument, the diagrammatic model appears incomplete.

If Toulmin had been clearer in his discussion of the nature of data, these questions might never have arisen. However, the problem may involve more than data, perhaps stemming from a lack of clarity in his distinction between macro-arguments and micro-arguments. According to Toulmin, 
formal logicians have restricted themselves to microarguments. 91 Similarly, he introduces the Toulmin model in the context of micro-arguments, focusing on the sentenceby-sentence structure of arguments in order to demonstrate the comparative limitations and weaknesses of the syllogism. Thus, while the "finer, as-it-were physiological" structure of micro-arguments is well described, Toulmin does no more than hint at the "gross anatomical structure" of macro-arguments or how the line is specifically drawn between the two categories. 92 of macro-arguments, Toulmin implies that they consist of general phases of enquiry which begin with the identification of a problem and candidates for solution which must be considered and end with the selection of one of the solutions which, in light of evidence, appears best. 93 Elsewhere in The Uses of Argument Toulmin states that, whereas micro-arguments may reflect a mathematical analyticity when viewed in isolation, when returned to their larger, macroscopic contexts and considered in light of their applications, they become substantial. 94 In other words, according to Toulmin's implication, the usefulness of the diagrammatic model is not primarily at the level of microscopic analysis but at the level of practice involving substantial macro-arguments. Thus, while Toulmin does not discuss the mechanics of macroscopic analysis of arguments, he apparently intends the model to be applicable at either level. 
If Toulmin intends his model to be applicable not only at the level of individual sentences but also to extended discourse and the larger contexts of practical argumentation, then he must mean to consider multiple items of data. Indeed, it is doubtful that a philosopher so concerned with how language is used in argument would select the plural term "data" to indicate an exclusively singular element. Still, more than Toulmin's tacit endorsement of the concept of multiple items of data is needed for critics of arguments to be able to make good use of the Toulmin model. For instance, how are multiple items of data to be organized in relation to a claim? Are multiple warrants required to justify the movement from multiple items of data to a singular claim? Is the qualifier in some general way affected by the quantity of data? For the Toulmin model to be effectively applied to macro-arguments, answers will need to be developed for these questions.

Proposals to add a qualifier to the data, or warrant for that matter, are interesting but they have the potential to create confusion about the functional nature of the elements of the model. The modal qualifier which is added to a claim represents the qualification which accrues from the data in light of the strength and applicability of the warrant. Whether dividing the modal qualifier into several other elements reflecting various sources of qualification would add to the candidness or usefulness of the Toulmin 
model is not clear. Further research involving specific schemes of this nature, like Hample's, may eventually bring to light the comparative benefits and costs of this approach. At the present state of development of the Toulmin model, the addition of elements may serve to further confuse the issues of argument as much as clarify them. Further, the inclusion of an element of support for the data may supercede the need for explicit qualification of data, just as backing specifies the force a warrant may confer upon a claim.

The question of introducing an element to specify support for data raises some important theoretical questions. The consequences of such a proposal for the critic of argument are not clear. Proponents claim that such an addition presents a more complete picture of the challenges which may be brought against a claim. Because it is modeled after backing for warrant, an element specifying support for data may raise some of the same questions as those surrounding backing. For example, how does one distinguish statements of support for data from statements of data, backing, or rebuttal? Also, as previously mentioned, the infinite regress problem is as applicable to an element of support for data as it is to backing.

Inclusion of an element of support for data implies that it is sometimes practical to argue from data which are not believed by the audience. Requests for documentation 
of data may in practical situations be requests for something less than a complete enumeration of a line of argument leading up to the current controversy. Rather, such challenges to data may be requests for an explicit lemma (a tentatively accepted auxiliary argument). 95 Thus, an argument may be advanced at least tentatively without straining the patience of an audience, violating time limitations or other constraints of practical argument. Accordingly, an element of support for data may prove to be a practical modification of the model.

An element of support for data raises another issue regarding the assumptions it reflects about fields of argument. To use an analogy with kindred elements, warrants may require backing to make explicit their special acceptability within a field by indicating the degree to which they have become established as reliable principles of inference. Every field is thus conceived as consisting at any one time of warrants which are firmly established, warrants which have been rejected, and innovative warrants or hypotheses still in some degree of contention. The question is, does the inclusion of support for data imply the same kind of field-dependence for data as for warrant? Are we to conceive of fields as consisting of sets of data which are considered in varying degrees of establishment? Are some facts and information believed in all fields while others are found acceptable only in some fields or 
perhaps only in one field? Though Toulmin does not discuss these questions, the epistemological consequences of the inclusion of an element specifying support for data are intriguing. Assuming data may be looked at in this fielddependent way, one wonders if this commits us to a more completely relative view of reality, a position Toulmin warns against because of the paradoxes into which it leads. On the other hand, such epistemological issues are the concern of some current speech communication theorists who view rhetoric as epistemic, architectonic or "a way of knowing. "96

Finally, rhetorical implications of the Toulmin model are directly related to the issue of whether or not an element of support for data should be included as part of the model. As described by Toulmin, data are dependent upon the consent of the audience. That is, one cannot call data that which is challenged by the respondents to an argument; you have not the basis of an argument unless you have acceptable data on which to ground it. Others contend that some support for the data should be considered part of the argument. How this conflict may be resolved has implications for the application of the Toulmin model as a model for attitude change and persuasion. Can data be defined merely as whatever the audience may believe at the moment of presentation? Or are there field-invariant criteria for what is to be considered "fact" which need to be made 
explicit? Or, as suggested above, does each field have its own criteria for what can be taken as fact which should be reflected as part of the model? Further research and experimentation involving the practices of actual arguers may point towards definitive answers to these questions. However, the answers arrived at may depend upon the epistemological assumptions with which one begins as later discussion of the implications of conflicting theoretical perspectives will suggest.

\section{Warrant-Establishing Arguments}

Are Never Clearly Explained

Toulmin claims that one of the main distinctions between deduction and induction is that the first kind of argument relies on already-established warrants while the second is used to establish the reliability of particular warrants. The classification of arguments into those which are warrant-using and those which are warrant-establishing is not given much attention by Toulmin. 97 Nearly all of the examples presented by Toulmin involve warrant-using arguments which rely on a single datum, leaving in doubt the nature of the other kind. It is worth noting, too, that warrant-establishing arguments are the counterpart of induction--about which there is controversy among logicians. 98

The notion of warrant-establishing arguments is not a major component of Toulmin's approach and therefore has 
not merited much attention from commentators. However, two formal logicians have registered their objections to the concept. Cooley is surprised that Toulmin would simplify the inductive process to one of a successive testing of warrants. He concludes that the concept represents an obvious "slip" on Toulmin's part. 99 Casteneda is less severe, noting that "it is unfortunate that Toulmin neither discusses nor illustrates warrant-establishing arguments; so he leaves the relationships between $B$ and $W$ in the dark." 100

Speech communication professionals would have to agree that it is unfortunate that Toulmin was not clearer on this point. Specific questions which may be asked about warrant-establishing arguments include: does it make any difference to the way an argument is analyzed whether it is warrant-using or warrant-establishing and, if so, how? One solution is to assume that it makes no difference and the analysis will look the same. The claim will represent the yet-to-be-established warrant, data will include the records of various successive trials, and the warrant will assert the suitability of empirical testing to the establishment of general principles within the particular field. An example of a simple scientific argument analyzed in this manner appears in Figure 6. 
Because (D) in

successive trials the boiling point of water has been found to vary with altitude.
So, ( $Q$ ) it may be presumed as a general rule that the boiling point of water will vary with altitude.

Since (W) if in experimental

trials a specified variable

is found consistently to vary

in direct relation to changes

in another specified variable,

then it may be presumed that

the variables are correlated

and will vary together predictably.

Figure 6. One approach to the analysis of a warrant-establishing argument.

Another view is to assume that warrant-establishing arguments are analyzed differently than warrant-using arguments. For example, the tentative warrant may be stated as a warrant while the data include the controlled variables and the claim predicts a result. Then, every time the argument is found to successfully predict the results of an experimental trial, the backing for the tentative warrant becomes stronger and the warrant becomes slightly better established. If, as trials continue, no warrant can be devised which is more generally applicable, simpler, or otherwise more attractive to investigators, then the warrant may become established within the field. This "hypothetical-deductive" process in which the presumption of a warrant involves no contradiction of data or successive results represented by the claim is illustrated in Figure 7. 
(D) Given that all other factors are controlled and that water is heated until boiling at various specific altitudes below, at, and above sea level.
(C) The boiling point of water will be found to be lower than $112^{\circ} \mathrm{F}$. below sea level, $112^{\circ} \mathrm{F}$. at sea level, and higher than $112^{\mathrm{O}} \mathrm{F}$. above sea level.

(W) Since it may be presumed as a general rule that the boiling point of water will vary with altitude.

(B) On account of successive trials in which this has consistently been found to be the case.

Figure 7. A second approach to the analysis of a warrant-establishing argument.

Judging from Toulmin's discussion, it is this second approach to the analysis of warrant-establishing arguments which he has in mind. 101 Still one may legitimately wonder whether it makes any difference which approach to analysis one uses. While the second approach appears to draw attention to field-dependent features of an argument as specified in backing, the question of which approach is more useful or appropriate may prove inconsequential to the larger issue of the potential applicability to speech communication of Toulmin's approach. The distinction between warrantusing and warrant-establishing arguments is primarily useful in defining the relationship of Toulmin's approach to formal logic. 


\section{Other Crucial Issues Regarding}

the Toulmin Model

There are several lines of criticism which have not been explored by Toulmin's critics but may be of interest to users of the Toulmin model in speech communication. This writer believes there are three additional areas which merit investigation: the appropriateness of a retrospective approach, the relationship of the Toulmin model to the syllogism, and the alleged irrelevance of field-invariant aspects of argument.

First, while Toulmin's case in favor of a jurisprudential model is persuasive, it requires that one view argument as a retrospective process. In other words, for Toulmin an argument begins with the assertion of a claim. Is this the only way an argument may be produced in practice? Might not the claim be the last thing made clear to the arguer himself through the discovery and organization of reasons? The model may provide a useful tool with which arguments can be analyzed, functions compared, and justification procedures evaluated according to the relevant criteria of the applicable fields. However, it is not clear how or if the model can help a critic deal with argument as an interactive process in which people engage independently or in various communication networks. It does not appear to be the only useful way to view argumentation. 102 
Does the use of the Toulmin model make the syllogism obsolete? Toulmin appears to reject the approach of formal logicians and argues that his model provides a more candid and applicable tool for the analysis of practical arguments. Of the syllogism and formal validity, he says only that they apply in certain limited systems of calculus like pure mathematics, and that the matters of linguistic consistency which they describe are prerequisite to any rational consideration of arguments. He does not, however, dismiss them entirely. Should the syllogism be considered a complementary model which deals with prerequisite linguistic matters of stating an argument clearly, a task Toulmin recognizes is beyond the scope of his model?

Finally, Toulmin devotes most all of his attention to the field-dependent aspects of argument which he contends have all but been ignored by formal logicians. Does this mean that there are no field-invariant aspects of argument worthy of consideration? What then becomes of the study of fallacies, general forms of reasoning and other field-invariant notions long associated with argumentation? Are such matters to be considered as irrelevant to argument analysis as Toulmin believes formal validity to be? Or can these field-invariant aspects of argument be reconciled with his approach? More basically, how are specific fields to be clearly distinguished and how absolute is the dichotomy between field-invariance and field-dependence in practice? 
These questions, in addition to the previously discussed issues of needed clarifications and possible modifications of the diagrammatic model, provide some directions research may usefully take with regard to this approach to argument. In subsequent chapters, some of the efforts of speech communication writers to deal with these issues are discussed. In the remainder of this chapter, a hypothetical relationship is explored between the kinds of criticisms Toulmin and formal logicians make of each others' approaches and the divergent theoretical perspectives in which they appear to be rooted.

\section{DIFFERENCES OF THEORETICAL PERSPECTIVES}

As we have seen, in advancing his attack upon traditional notions of logic Toulmin proceeds from novel assumptions and moves towards unconventional aims. His practical orientation and analysis of argumentative functions are in sharp contrast to formal logicians' idealism and structural focus. Given the fundamental nature of these differences and Toulmin's professed intention to "draw the fire of others," it is perhaps not surprising that his proposals have met with philosophical antipathy. 103 Indeed, it would be more surprising to find formal logicians working towards Toulmin's aims: to provide justification for claims, to explicate support for premises and to explore the elements of argument beyond their formal consequences. As has been 
shown, many formal logicians believe that such matters are, at best, beside the point of logical analysis. Much of the criticism directed against Toulmin's approach by formal logicians suggests a hypothesis that Toulmin and formal logicians are operating in different frames of reference, from divergent theoretical perspectives. In this section of chapter III, the apparent contrasts between their theoretical perspectives are explored.

\section{Ideal vs. Practical Aims}

Perhaps no greater or more consequential distinction exists between the theoretical perspectives of Toulmin and formal logicians than their divergent aims. Formal logic provides a standard toward which creators and critics of argument may strive. The best arguments are those which conform to the criteria of the analytic syllogism. Further, the syllogism serves as a critical structure, useful in discovering errors and weaknesses in arguments. It is the goal of formal logic to ensure that argumentative discourse is given credence only when it meets the rigorous standards of formal validity. In other words, the aims of formal logic are prescriptive and evaluative, defining an ideal model and criteria for the proper organization of statements given in arguments.

Toulmin, on the other hand, is interested in argument as it is practiced. Practical arguments may include claims which fall short of rigid standards of formal logic and yet 
are found to be useful in the fields to which they apply. Because of this, Toulmin emphasizes the process by which claims in general are justified in various fields of argument. The functionally-defined elements of his model are meant to provide a frame of reference for the comparison of justification procedures in different fields. How knowledge becomes established or disestablished within a field of thought and how various fields differ or are similar in their justification procedures are issues of practical argument with which Toulmin's revised logic is intended to deal. In other words, his aims are descriptive and comparative, providing a language and model which directs and focuses a critic's observations of the practice of argument.

Formal logicians' prescriptive-evaluative aims are to Toulmin's descriptive-comparative aims much as the treatment of disease is to the investigation of its causes. While there is overlap in the subject matter, the problems and procedures of each approach are likely to be different.

\section{Absolute vs. Relative}

Assumptions

Another area where the different theoretical perspectives and aims of Toulmin and formal logicians are reflected is in their different assumptions about the nature of truth. Formal logicians have generally assumed truth to be an absolute, timeless, and universal feature of reality. For instance, the proper combination of premises is assumed by 
formal logicians to define a domain of entailment within which any and all necessary, valid conclusions will be found. The combined premises, then, imply an absolute relationship among terms with which an asserted conclusion must be consistent to be valid. Thus, formal logicians' approach to argument is to designate a connection between correctly-reasoned conclusions and the truths from which they are derived. This is accomplished through an absolute structure, the syllogism. If an argument can be successfully recast into one of the limited number of predefined acceptable syllogistic structures, it can be considered formally valid and its conclusion a candidate for truth. Other arguments will be judged fallacious and ruled out of formal logicians' considerations. In other words, a prescriptive-evaluative logic of argument defines absolute procedures for determining absolutely what follows from a combination of two propositions taken to represent true concepts.

Toulmin's approach involves more relative notions of truth. 104 His concept of practical argument involves the relative probabilities of competing conceptions within a field of inquiry. Some fields, like pure geometry, involve closed systems of calculi to which the absolute assumptions of formal logic may be appropriate. 105 However, in most fields of practical argument, according to Toulmin, claims cannot be judged according to absolute standards of truth. 
Instead they must be judged in terms of the justifications available for them within their fields of application. More importantly, the elements of argument are themselves defined not in terms of any absolute structure but by their functions in relation to a particular claim. In essence, claims and the arguments of which they are a part are not found by Toulmin to be true or false, but are instead judged to have some degree of applicability within a field of competing concepts. In other words, a descriptivecomparative logic of argument relies on relative procedures of justification to determine degrees of relative probability.

Formal logicians assume that what is most important in an argument is the potential correctness or truth-value of the conclusion. They may wonder, "can this argument be somehow transformed into an unassailable, ideal type?" Practitioners of the Toulmin approach assume that what is most important in an argument is the degree of probable applicability of a claim within a particular field. They may ask, "how justifiable is this claim when compared to similar claims of like type made within this field of argument?" and also question the justification procedures themselves. The assumptions and procedures maintained by formal logicians and Toulmin are as different as their aims. 
Geometric Structure Vs.

Jurisprudential

Functions

The centrality of geometric structure to formal logic and jurisprudential function to Toulmin's approach represents a third manifestation of difference in theoretical perspectives. He contends that an argument depends for its soundness on the kind of justification offered in support of a claim asserted. This justification is conceived as deriving from the combined functions of the elements of an argument. He assumes that the justification of assertions is the primary function served by arguments and it is to this that all other functions are subordinate and dependent. 106 Toulmin's concept of the phases, functions, and justificatory purpose of argument is based on an analogy which likens logic to jurisprudence, arguments to lawsuits. 107

Formal logicians charge that Toulmin is unclear in what is meant by "jurisprudence" in his comparison and therefore that "justification" is equally undefined. In contrast to Toulmin, formal logicians determine the soundness of an argument by applying the structural standards of the syllogism. If an argument is found to exhibit a formally valid structure, then it is considered by formal logicians to be soundly reasoned. This difference of attitude toward the structure and functions of an argument is further evidence of a difference in theoretical perspectives of Toulmin and formal logicians. 
Perhaps Toulmin could have been clearer in his description of what is meant by the "jurisprudential analogy," although he does make several attempts to explain himself. 108 Chiefly he draws comparisons between logical argument and jurisprudence focusing on (1) the presence of disputants to a claim, (2) the phases of a dispute leading to its settlement, (3) the sorts of propositions or elements of an argument bearing upon the soundness of claims in general, and (4) the differences among kinds of criteria for soundness and the contexts from which they derive.

Given the quasi-geometric structure of the formally valid syllogism discussed in chapter III, it should not be surprising that some formal logicians find Toulmin's inattention to structural features of argument disturbing and unclear. 109 To them, anything less than the perfection of the analytic ideal is likely to seem uncertain and perhaps confusing. 110 Formal logicians question the clarity of Toulmin's jurisprudential analogy, citing multiple varieties of jurisprudence discoverable in history and across cultures as well as the complexity of jurisprudential procedures. 111 They request that he discuss in more depth what he means by the term "jurisprudence" and that he rely less upon the everyday expression "court of reason" as an explanation. 112 Further, they wonder why he fails to provide in-depth examples of legal reasoning and thus specify the paradigmatic qualities of legal reasoning. 113 Cooley speculates that Toulmin, in his 
enthusiasm for discovering the "key mistake" made by formal logicians, too easily embraces a corresponding key solution; however, philosophical wrangles of the type which bother Toulmin are seldom so easily resolved. 114

Field-Invariant vs. Field-

Dependent Features of Argument

The difference in theoretical perspectives of formal logicians and Toulmin appears to be a factor in the disagreement over the significance of his field-dependent features of argument. It will be recalled that formal logicians are concerned with those aspects of argument which are universal and timeless. These field-invariant features are the focus of formal logic and the concern for formal validity. Toulmin, on the other hand, claims that a large proportion of real-life arguments with which people must deal rely for their logical candidness upon criteria drawn from various fields of application. In other words, to determine the soundness of a claim, one must know not only the data from which it is drawn but also principles which are operative in a given field. Field-dependent features are, then, central to his approach.

Formal logicians contend that the notion of fielddependent sources of validity is a weakness of Toulmin's approach because it limits a critic to arguments within his special areas of expertise. The general applicability 
which logicians claim for formal logic is absent, they say, from his model. Manicas, among others, believes that Toulmin is proposing that logicians become lexicographers, recording all the acceptable warrants which may apply in various contexts. 115 Given the breadth of possible arguments among various fields, such a collection of warrants would be enormous if not infinite. Formal logicians instead concern themselves with field-invariant features of argument which are broadly generalizable.

Toulmin, on the other hand, argues that a logic cannot be considered practical if it is divorced from its particular applications. It is his practical orientation which leads him to attend to field-dependent features of arguments. He writes, "questions about the acceptability of arguments have in practice to be understood and tackled in a context."116

Toulmin's aims conflict with those of formal logicians. Formal logicians, in seeking to evaluate and improve arguments in general, emphasize field-invariant features. Toulmin, in seeking to describe and compare justification procedures, emphasizes field-dependent features of argument in practice.

Eormal Validity vs. Justification

Finally, the divergent perspectives of formal logicians and Toulmin is reflected in the respective products 
of the two approaches to logical analysis. Formal logic produces a determination of formal validity or its converse. Toulmin's model produces a description of some degrees of justification for assertions.

Toulmin generally avoids the term "validity" in reference to his approach, perhaps because to do so would cause confusion with the more restrictive concept of "formal validity." He prefers to discuss the "soundness" of reasoning or the "logical candidness" of an argument. 117 His critics find this notion of logical candidness at once too broad and too unconnected with traditional formal validity. Says Cooley of Toulmin, "he wants to broaden the subject [of logic] so that it covers every case where conclusions are backed by reasons of one sort or another, not merely those in which the result follows analytically. "1l8 $\mathrm{He}$ is correct; Toulmin is interested in clarifying the functions of statements used in argument to justify conclusions. To formal logicians who judge arguments according to the structural relations of their propositions, Toulmin's functional focus seems peculiar and unclear.

Toulmin uses the jurisprudential analogy in part to make clear what he means by justification. Not surprisingly, formal logicians expressing doubt about clarity of the first concept are equally unhappy with the second. Justification is what Toulmin asks of sound reasoning. To him, logic is representative of "standards of achievement 
which a man, in arguing, can come up to or fall short of, and by which his arguments can be judged."119 In other words, he believes the rules of logic should provide critical guidelines for the determination of soundness in reasoning by examining the ways conclusions are justified. Justification, then, refers to the defensive function which arguments are meant to supply for assertions. More importantly, the concept of justification is introduced by Toulmin specifically to exclude from consideration any other purposes for which argument might be used. Other than to say it could be argued that the justificatory function is more important than other kinds of purposes arguments may serve, a position he is clearly in sympathy with, this limitation of his discussion is nowhere defended. 120

Some critics of Toulmin contend that he does not demonstrate that he has solved the problem of how arguments are justified. They believe he has merely relocated the problem through his relabelling of the parts of the syllogism, and so does not clearly solve it. Cowan, among others, believes that Toulmin is seriously remiss in the matter of justification:

Surely it is not enough to say that this [the Toulmin model] is the sort of procedure we call "justification" and that is all there is to it. This would leave justification a wholly empty ceremony. If justification is what is needed for a sound argument, how is one to know when he has reached it? What does a 
critic of argument look for? These are questions the formal logicians wish Toulmin would answer more clearly. He is quite explicit in what he means by backing for the warrant, the main justificatory feature of his model. Yet to formal logicians this is not enough. They seem uncomfortable with less than absolute rules for and less than universal sources of justification. From the theoretical perspective of formal logicians, such concrete standards appear to be mandatory.

Linear vs. Systems Perspectives:

A Meta-Theoretical Context

Throughout the preceding analysis, several differences in the theoretical perspectives of Toulmin and formal logicians have been examined. It may be helpful at this point to step back from the specific approaches to logic and place these differences into a meta-theoretical context. It is the opinion of this writer that the formal logicians' approach to logic reflects a linear theoretical perspective while Toulmin's approach reflects a systems perspective. This fundamental difference of theoretical perspective may affect all levels of observation, description, and evaluation engaged in by theorists. In addition, this difference of perspectives may account in part for the depth of disagreement with and occasional misapprehension of Toulmin's approach by his formal logician critics. 
According to Bennett, theories of communication are roughly classifiable into three kinds of perspective: linear, systems, and process. ${ }^{122}$ These perspectives are conceived as existing along a continuum defined first by varying degrees of absolutism-relativism in the structures and functions of a theory and, second, by varying degrees of interaction assumed to exist among defined elements.

Theories marked by the highest degree of absolutism in descriptions of structures and functions represent a linear perspective. The interaction assumed to exist among the immutable elements in linear theories is a limited, one-at-a-time, one-directional chain of events. An example of a communication theory which typifies the linear perspective is David Berlo's "S-M-C-R" diagrammatic model of the communication process. 123

Theories of communication which are less absolute in their descriptions of structures and functions as well as more complex in the interactivity of their elements represent a systems perspective. The term "systems perspective" is derived from General System Theory, a body of concepts presumed to be applicable to systems in any field. ${ }^{124}$ A systems perspective views the structures and functions of a phenomena as relative, that is, as a product of the interdependent relationships among elements. In other words, the assumption of bi-directional interaction among elements and possible change in their relationships 
is viewed as potentially more meaningful than the independent description of the parts of the system. The whole effect of a system is considered greater than the sum of its parts. An example of a communication theory which typifies the systems perspective and contrasts with Berlo's linear diagrammatic model is the model of the process of communication rule acquisition developed by Watzlawick, Beavin, and Jackson. ${ }^{25}$ The openness of structures, relativity of functions, and complex interactions described in theories based upon the assumptions of a systems perspective contrast with the static structures, causal functions, and deterministic interactions discussed in theories based upon assumptions of a linear perspective.

With this linear/systems meta-theoretical context as a frame of reference, we can return to the previously noted differences between the two approaches to logical argument under consideration here. Our contention is that formal logicians are working with theoretical aims and assumptions quite different from Toulmin's. Therefore, the criticisms to which his concepts have been subjected by formal logicians cannot be very surprising. It may be a conflict between a linear and systems perspective of the same phenomena. 126 In addition to the generally negative and in some cases caustic responses his approach has received from formal logicians which have already been discussed, two further examples should serve to illustrate this hypothesis. 
Differences Regarding Structure and Functions. Structures and functions are interpreted and evaluated differently by formal logicians and Toulmin. As linear theorists, formal logicians view function as an aspect of structure. For example, formal validity is a structural matter, determined by evaluating the relationships between terms in the premises of a syllogism and terms in the conclusion. If the relationship of terms is found to meet criteria specifying their number, distribution, quality, and existential import, then the syllogism may be considered formally valid. In a formally valid syllogism, the truth-value of the conclusion is considered a function of the structural relationship of the elements of the verified premises. Thus, for formal, logicians the structure and functions of an argument can be made no more candid than when stated as a formally valid syllogism.

Toulmin contends that a logic focusing on structural matters is misdirected. He argues that with a mere "shuffling of parts of the premises and rearranging them" the formal validity of nearly any syllogistic conclusion can be demonstrated. ${ }^{127}$ Toulmin, adopting more of a systems perspective, is interested in the functions of propositions within their fields of application. To him, structure is a separate, prerequisite consideration having to do with consistency in the use of language. To determine the soundness of arguments, Toulmin proposes a pattern for the layout of 
arguments for analysis which represents the functional roles played by the elements of arguments. Rather than represent some universal structure in his model, he presents an organizational device to aid critics of arguments. His model represents the functions of statements given in arguments and their relative impact upon one another with regards to the justifiability of a claim. The justification of argument is to the Toulmin model what formal validity is to the syllogism.

Manicas, among others, takes great pains to establish that Toulmin is virtually without support among logicians in his quest for the justification of arguments. ${ }^{128}$ Formal logicians are unconcerned with the justification of deductive conclusions. In response to Toulmin's charge that the "principle of the syllogism" is inadequate warrant to serve as field-invariant justification for analytic syllogisms, Manicas writes "of course it is; but whoever said that it did that job?"129 He continues:

No one so far as I can see considered these principles [of the syllogism] as functioning as warrants in Toulmin's sense. . . The principle was not employed to justify moves from premises to conclusions, but rather was thought of as a generalization of all syllogistic argument. The perfect syllogism (Barbara) needs no justification. 130

In others words, Toulmin's notion of the justificatory functions of argument is to formal logicians an inadequate substitute for structural standards of formal validity. Thus, they seem unwilling to comprehend how an argument can 
be made any more candid than through syllogistic analysis. While Toulmin emphasizes the relative functions of elements of argument and their relationships to justification, formal validity can be precisely determined.

\section{Differences Regarding Interactivity Among Elements.}

In addition to differences over structures and functions, a similar difference apparently arising from the contrasting theoretical perspectives involves the degree of interactivity assumed to exist among the elements of argument. Formal logicians, consistent with a linear perspective, presume that propositions function in a linear causal way. The structure and function of terms within propositions are predetermined by the rules of grammar which are not considered a province of logic. However, when premises are placed in syllogistic combination with each other, they may "cause" a conclusion. A conclusion is conceived by formal logicians as the outcome or result of the major and minor premise. For instance, if one knows that all men are mortal and that Socrates is a man, then one must arrive at the conclusion that Socrates is mortal. This onedirectional, additive relation which "causes" a conclusion is the basis for formal validity. It is also one reason why inductive arguments are taken by formal logicians to be formally invalid; true conclusions can be derived only from true universals and not the other way around. Thus, the assumption of absolute, linear-causal interaction 
among elements reduces the concerns of formal logicians to matters of structure. The functions of elements are predetermined by mules of grammar and by this linear-causal assumption.

In contrast to formal logicians, Toulmin pays little attention to structural matters which he considers prerequisite details having to do with the internal consistency and comprehensibility of linguistic expressions used in argument. Instead, he focuses on the functions of the parts of an argument in context to determine the justifiability of a claim. While all the elements of an argument are defined by Toulmin in terms of some claim, the relationships among them are presumed to be more complex than linear. Elements are conceived as affecting each other mutually: warrant affecting what may be taken as data; backing affecting warrant as well as potential rebuttals; and all affecting the qualifier. This amounts to a bidirectional interactivity, a feature consistent with a systems perspective.

In summary, a number of criticisms formal logicians make of the Toulmin approach appear to be due to their different theoretical assumptions. The linear perspective of formal logicians assumes an absolute structure, causal functioning, and prescriptive-evaluative aims. The systems perspective of Toulmin assumes structural relativity, bi-directional interaction among functionally-defined 
elements and descriptive-comparative aims. Fundamental disagreements about the nature of argument and the goals of the critic of argument are likely to be unresolvable unless the theoretical perspectives and the assumptions they imply can be reconciled.

\section{SUMMARY}

In this chapter criticisms made of the Toulmin approach have been examined and their consequences for speech communication evaluated. In addition, a hypothetical explanation has been explored which attributes to a fundamental divergence of theoretical perspectives the negative responses of formal logicians to Toulmin's approach.

Four general criticisms of the Toulmin approach have been identified: that it is unoriginal, grounded in obsolete ideas, unrepresentative of an innovation in logic, and unnecessarily broad in its implications for logic. These charges have been found to be not particularly salient to the question of the potential applicability of the approach to the area of speech communication.

Less easily dismissed for their implications than general criticisms of the Toulmin approach are criticisms specific to the Toulmin model. Formal logicians have charged that (I) several elements of the model, including warrant, backing, data, and rebuttal, are indistinguishable from each other; (2) backing cannot provide justification 
for arguments; (3) the concept of data as discussed by Toulmin is questionable; and (4) warrant-establishing arguments are not clearly explained. With regard to (1), (3), and (4) it has been found that in several cases Toulmin's style of definition and illustration lend themselves to ambiguous interpretations, although not so much as the critics have charged. It is concluded that, while there may be a need for clarification of some points, this does not argue for a rejection of the model as critics have contended. Instead, it is noted that the model appears to have several promising features, among them qualification of claim, specification of rebuttal and explication of backing for justification, which may be attractive to speech communication professionals. Issues regarding the nature of data and warrant-establishing arguments are identified as areas where further research may prove useful. The remaining criticism, (2), is considered of interest only as partial evidence for the hypothesis developed in the final section of the chapter.

To explain the negative response of formal logicians, the following hypothesis has been suggested: formal logicians and Toulmin draw their assumptions and aims from divergent theoretical perspectives. Two perspectives are discussed, the linear perspective associated with formal logic and the systems perspective associated with Toulmin's approach to argument. Linear theories tend to attribute 
all significant qualities of a phenomenon to independently defined elements which, when added together in a linear sequence, create particular effects. Such a perspective is represented by these features of formal logic: ideal aims; absolute assumptions; and an emphasis of geometric structure and field-invariant aspects of argument for the purpose of determining formal validity. In contrast, systems theories tend to view elements and relationships among elements as significant factors and posit synergistic outcomes from certain changes in relationships. Further, such changes or interactions are presumed to be complex rather than one-directional. Such a perspective is represented by these features of Toulmin's approach: practical aims, relative assumptions, and emphasis of jurisprudential functions and field-dependent aspects of argument for the purpose of describing justification procedures. Both formal logicians and Toulmin may be unduly harsh in their negative assessments of each other's approaches due to this apparent paradigmatic conflict.

The critical issues and divergent theoretical perspectives discussed in this chapter are referred to in the analysis of speech communication textbook presentations of the Toulmin approach in the next two chapters. 
$1_{\text {Uses }}$, p. 7. Only published criticism from the perspective of formal logic is referred to here. See pp. 7-9 of this study for a description of selection procedures and citation of articles selected. For criticisms of the Toulmin approach from a constructivist-interactionist sociological perspective, see Charles Willard, "On the Utility of Descriptive Diagrams for the Analysis and Criticism of Arguments, "Communication Monographs, 43, No. 4 (November, 1976), 308-319; "Argument as Non-Discursive Symbolism," Journal of the American Forensic Association, 14, No.? (Spring, 1978), 187-193; "Some Questions About Toulmin's View of Argument Fields," Proceedings of Summer Conference on Argumentation (July 26-29, 1979), eds. Jack Rhodes and Sara Newell (Falls Church: Speech Communication Association, 1980). See also responses to Willard: Brant Burleson, "On the Analysis and Criticism of Arguments: Some Theoretical and Methodological Considerations," JAFA, 15, No. 1 (Winter, 1979), 137-147; Charles Kneupper, "On Argument Diagrams," JAFA, 14 , No. 2 (Spring, 1978), 181-186; Ray McKerrow, "On Fields and Rational Enterprises: A Reply to Willard," PSCA (July 26-29, 1979).

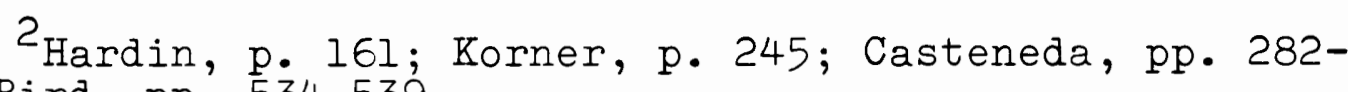
283; Bird, pp. 534-539. $230-232$.

3 For specific citations, see Uses, pp. 260-261, 252,

${ }^{4}$ See Uses, p. vii; note also the sixty-four references in his index of proper names, p. 263.

5rent, p. 254. ${ }^{6}$ See chapter II, pp. 35-38.

7 Hample, p. 8. $\quad 8$ Trent, p. 259. 9 Hample, pp. 2-9.

$10_{\text {While }}$ Trent appears to ignore field-dependence entirely, Hample inexplicably refers to it as one of the most powerful ideas in Uses--apparently unaware of any inconsistency between field-dependent criteria and standards of formal validity. See Hample, pp. 8-9.

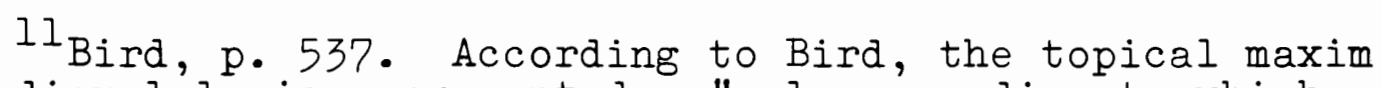
in Medieval logic represented a "rule according to which one can make an inference," and the topical difference represented "the 'matter' from which the Maxim is composed." As an example of each, Bird offers these: "Of whatever the species is predicated, so is the genus" (Topical Maxim); and 
"'Man' is related to 'animal' as species to genus" (Topical Difference).

$$
12_{\text {Bird, p. } 539 .}
$$

13 Rhetorical theorists have referred to the epicheireme. See for example, Clark, p. 120.

${ }^{14}$ Among others, Cooley (pp. 305-307) claims that Toulmin has misinterpreted what other philosophers are doing and therefore Toulmin's criticisms of the work of Kneale, Strawson, and Carnap are unsound. However, because they do not bear directly upon concepts related to the Toulmin model, these criticisms are considered beyond the scope of the present study.

${ }^{15}$ Casteneda, p. 281. 16 Hardin, p. 161.

17 Manicas, p. 87.

18 Symbolic logic may be the development of the last 120 years to which Casteneda refers.

19 Uses, pp. 107-108.

20 See for example, Copi, pp. 181-244; Charles Mudd and Malcolm Sillars, Speech: Content and Communication, 3rd ed. (New York: Thomas Crowell Co., 1975), 153-154; Dominic LaRusso, Concepts and Skills of Oral Communication, 2nd ed. (Dubuque: Wm. C. Brown Co. Publishers, 1973).

${ }^{21}$ By the same token, other advances in the theory of logic may be found to be useful in speech communication. 22 Cooley, p. 310. $\quad 23$ Casteneda, p. 284.

24 Manicas, p. 86; Simopoulos, p. 97. Besides claims of ambiguity in the major premise and lack of attention to matters of backing, formal logicians take issue with Toulmin's tests of analyticity. See Hardin, p. 162; Cowan, pp. 36-38; Cooley, p. 303.

25 Cooley, pp. 314-315, 318-319; Casteneda, p. 292; Simopoulos, pp. 97-98; see also Manicas, p. 89.

${ }^{26}$ Articles by Hample, Trent, and Lewis take positions on this question. p. 91 .

27 See Korner, p. 427; Casteneda, p. 292; Manicas, 
${ }^{28}$ Sara Newell, "Making Sense of Argumentation Theory," paper presented at the Western Speech Communication Assoc. Convention, Portland, Oregon, February 1980, p. 6.

${ }^{29}$ Cooley, p. 319; Hardin, p. 161; Manicas, p. 87.

$30_{\text {Manicas, p. } 87 .}$

31 one senses in reading these critics that there is considerable resentment of the "revolutionary" tone of Toulmin's hypothesis. Note especially the titles and character of articles by Casteneda, Manicas, Cooley, and Cowan.

32 See Cooley, p. 297; Manicas, p. 94; Casteneda, p. 279 .

33 Cooley, p. 300.

$$
34 \text { Manicas, p. } 87 .
$$

35Will, p. 401. 36 Hardin, p. 163; Korner, p. 426.

37 Simopoulos, p. 98; Casteneda, p. 292.

38 Cowan, pp. 27-28.

39 Formal logic, which began with Aristotle, c325 B.C.

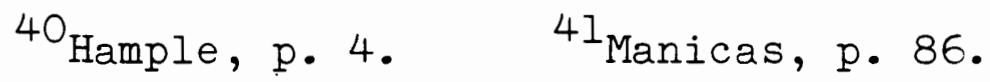

42 Mortenson and Anderson, pp. 72-73.

${ }^{43}$ Casteneda, pp. 281-282. By "closed class of objects" Casteneda appears to be referring to the kind of limited, measurable class representedby Toulmin's example involving "Roman Catholics" and "Swedes." See Uses, pp. 131-141.

${ }^{44} \underline{\text { Uses }}$, p. 105, 98 ; Manicas, p. 86.

${ }^{45}$ Cooley, p. 314. ${ }^{46}$ Cowan, p. 30. ${ }^{47}$ Ibia.
${ }^{48}$ Uses, p. 99.
${ }^{40}$ See note 11 in Manicas, pp. 88-89; Casteneda, pp. 281-282.

$51_{\text {Uses }}$, p. $97,100,105 . \quad 52$ Ibid., p. 98.

${ }^{53}$ See Arthur Claude Hastings, "A Reformulation of the Modes of Reasoning in Argumentation" (Ph.D. dissertation, Northwestern University, 1962); Adele Levine Lenrow, "A Toulmin Analysis of the Argumentation Patterns in Selected 
Speeches of Joseph Kennedy, John Kennedy, Robert Kennedy, and Edward Kennedy" (Ph.D. dissertation, Columbia University, 1971); Neil Howard Phillips, "The 1976 Presidential Debate: A Toulmin Analysis of the Personality Issues" (Masters thesis, University of Houston, 1978); Raymond Joseph Heidt, "Stephen Toulmin's Argument Model as a Critical Device for Speech" (Masters thesis, University of Pacific, 1973); Robert Gordon Smith, "The Arguments Over Abolition Petitions in the House of Representatives in December, 1835: A Toulmin Analysis" (Ph.D dissertation, University of Minnesota, 1962); Jimmie Douglas Trent, "Stephen E. Toulmin's Argument Model as an Instrument for Criticism of Forensic Speeches" (Ph.D. dissertation, Purdue University, 1966); Holt Vandercook Spicer, "Stephen Toulmin's Functional Analysis of Logic and Ethics and its Relation to Rhetoric" (Ph.D dissertation, University of Oklahoma, 1964).

${ }^{54}$ Cooley, pp. 314-315; Hample, p. 2 ; Manicas, p. 85.

${ }^{55}$ Casteneda, p. 283.

57 Tbid., pp. 126-127.

59 Toulmin, et al., Reasoning.

$61_{\text {Hample, }}$. 7 . 62 Cooley, p. 310.

${ }^{64}$ Manicas, pp. 84-85. 65 Tbid., p. 85.

66 Hample, pp. 5-7.

67Uses, p. 140. By "nature of data" Toulmin appears to be referring to the confidence or force with which data is introduced.

${ }^{68}$ Compare Toulmin's comments on p. 140 of Uses with Hample's analysis of the same on $p .5$ of his article.

${ }^{69}$ Cowan, p. 34.

$70_{\text {Uses, }}$ p. 104 .

${ }^{71}$ In Reasoning, no such modifications are noted.

$72_{\text {Uses }}$ p. 106.

74 Besides Cowan, see Hample, p. 7; Casteneda, p. 284 ; and Manicas, p. 86.

75cooley, pp. 302-303. 
76 See will, p. 420. For a formal logician's discussion of the problem of infinite regress, see $S_{\text {. F. Barker, }}$ The Elements of Logic (New York: McGraw-Hill Co., 1965), 22f.

77 Cowan, p. $34,43$.

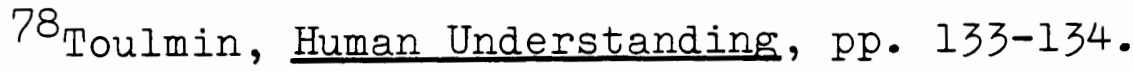

79 Uses, p. 97, 105. 80 Tbid., p. 97.

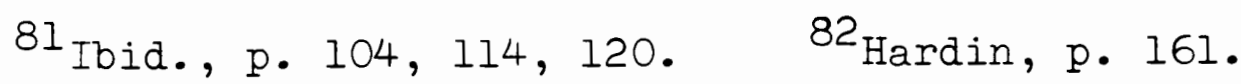

${ }^{83}$ Hample, p. 6. $\quad{ }^{84}$ Manicas, p. 87.

${ }^{85}$ Trent, pp. 255-256.

${ }^{86}$ Cooley, p. 310 (see note 13). $\quad 87$ Hample, p. 8. ${ }^{88}$ Cooley, p. 303; Trent, pp. 255-256; Manicas, p. 86. ${ }^{89}$ Trent, p. 256. 90 Hample, p. 7 .

$91_{\text {Uses }}$, p. 94. 92 Ibid.

93 Ibid., pp. 5-22, 94.94 Tbid., p. 210.

95 Ibid., pp. 106-107. Toulmin's discussion of lemmas has to do with their role as backing for warrants. However, there is no apparent reason why they could not also be relied upon as support for data.

96 See Robert Scott, "On Viewing Rhetoric as Epistemic," Central States Speech Journal, 18 (February, 1967), 9-17.

97 Uses, p. 120, 135.

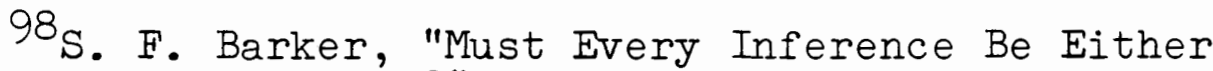
Deductive or Inductive?" in Philosophy in America, ed. W. Alston (Ithaca: Cornell University Press, 1967), 5873. See also Henry Kyburg and Ernest Nagel, eds., Induction: Some Current Issues (Middleton: Weslyan University Press, 1963).

${ }^{99}$ Cooley, p. 344.

$101_{\text {Uses }}$, p. 184.

103 Uses, p. 1 .
100 Casteneda, pp. 283-284. 102 Newell, pp. 19-22. 
104 Human Understanding, pp. 52-54, 68-84, 98-102. According to Toulmin, the relativistic perspective of R. G. Collingwood deserves more sympathy than it has received in philosophical circles. The U.s.es of Argument is seen as a move in that direction. Uses, p. 258 .

$$
\begin{aligned}
& { }^{105}{ }_{\text {Uses }}, \text { pp. 205-210. } \\
& 107_{\text {Tbid. }} \text { Ibid. p. } 7.7,12 . \\
& 108 \text { Ibid., pp. 7-8, 15-16, 41-43, 96, 141-142. } \\
& 109 \text { Ibid., p. 249. } 110_{\text {Korner, pp. } 425-426 .}
\end{aligned}
$$

111 Ibid., p. 427. See Toulmin's comment on the same point, Uses, p. 42 .

112 Cooley, p. 318. See Uses, p. 8, 40.

113 Cooley, p. 314, fn. 21 .

${ }^{114}$ Cooley, p. 318. Toulmin has yet to publish any direct response to specific criticisms of his hypothesis, other than to reaffirm his position in the prefaces to the paperback edition of Uses, p. viii, and Human Understanding, pp. vii-viii. Examples of legal reasoning presented in the more recent publication, Reasoning, may satisfy Cooley's request for illustrations, but it is doubtful the illustrators will answer Cooley's objections to the jurisprudential analogy.

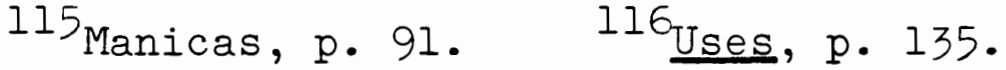

$$
\begin{aligned}
& 117 \text { Ibid., pp. 8-9. } \quad{ }^{118} \text { Cooley, p. } 297 . \\
& 119_{\text {Uses }}, \mathrm{p} .8 .
\end{aligned}
$$$$
\text { 120 Ibid., p. 12. See also Human Understanding, }
$$

pp. 307-313.

\section{$121_{\text {Cowan, p. } 31 .}$}

122 Milton Bennett, "The Relationship of Communication Perspectives," paper, Portland State University, 1977. Process perspectives are not discussed in this study as they are not germane to either Toulmin's or formal logicians' approaches to argument. For another approach to metatheoretical classification, see B. Aubrey Fisher, Perspectives on Human Communication (New York: Macmillan Co., 1978). Fisher's "mechanistic" and "interactional" perspectives correspond roughly to Bennett's "linear" and "systems" perspectives respectively. 
${ }^{123}$ David Berlo, The Process of Communication (New York: Holt, Rinehart and Winston, 1960), 24. For criticism of the linear nature of Berlo's diagrammatic model, see David H. Smith, "Communication Research and the Idea of Process," Speech Monographs, 39, No. 3 (August, 1972), 175-176.

\section{${ }^{124}$ Littlejohn, pp. 29-53. \\ 125 Pragmatics of Human Communication (New York:}

W. W. Norton and Co., Inc., 1967), pp. 23-71.

126 For a process perspective on argumentation, see any of Willard's writings, especially "The Epistemic Functions of Argument: Reasoning and Decision-Making from a Constructivist/Interactionist Point of View," JAFA, 15 (Winter, 1979), 169-191; and "The Epistemic Functions of Argument, Part II," JAFA, 15 (Spring, 1979), 211-219.

127 Uses, p. 118. As might be expected, Manicas and others object to this view of formal validity. See Manicas, pp. 89-90. Cowan, on the other hand, while disagreeing with Toulmin's interpretation of the significance of the point, supports Toulmin's view that "every argument is at least potentially a valid deductive argument." Cowan, p. 43.

128 Manicas, p. 88 .

129 Ibid. See also discussion of the "principle of the syllogism" in Uses, p. 130; and this study, chapter II.

$130_{\text {Manicas, p. } 88 .}$ 


\section{CHAPTER IV}

\section{TEXTBOOK REPRESENTATIONS OF THE TOULMIN}

\section{APPROACH: INTERPRETATIONS OF SPEECH COMMUN ICATION PROFESSIONALS}

That the Toulmin model has had an impact upon speech communication is undeniable; what kind of impact this has been is the subject of this and the next chapter. In addition, the impact of speech communication upon the Toulmin approach is evaluated and areas of potential development suggested. In light of criticisms and questions about Toulmin's approach discussed in chapter III, what interests us here are these questions: which of the innovations of Toulmin's theoretical approach are maintained by textbook writers and which have been ignored?; how have the Toulmin diagrammatic model, terminology, and definitions been represented, altered, or extended in textbook discussions and illustrative examples?; to what extent is the Toulmin model presented in textbooks in isolation of or in conjunction with discussions of the syllogism? The answers to these questions are based on selected speech communication textbooks which have helped to disseminate the Toulmin model.

In this chapter, textbook representations of the Toulmin approach are examined, compared, and evaluated in 
five areas: (1) theoretical basis of the Toulmin approach, (2) the Toulmin diagrammatic model, (3) terminology and definitions of the model, (4) illustrative examples of the model, and (5) treatment of the syllogism in conjunction with the Toulmin model. As shall be seen, the theoretical bases discussed in textbooks relate most directly to those general criticisms of the Toulmin approach discussed in chapter III while the representations of the diagrammatic model, terminology, and definitions in textbook discussions and illustrative examples relate to specific criticisms of the Toulmin model. Further, the diversity of interpretations of the Toulmin approach presented in textbooks may be an effect of the various theoretical perspectives held by speech communication professionals.

\section{THEORETICAL BASES OF THE TOUIMIN APPROACH AS REFLECTED IN SPEECH COMIUNICATION} TEXTBOOKS

In addition to introducing a model of argument more complex than the syllogism, The Uses of Argument is controversial for the view of argument it defends, identified in this study as approximating a systems perspective. The theory involves field-dependent sources of soundness, substantive argumentative claims based in relative probabilities rather than absolute certainties, and a rejection of idealized static notions of truth in favor of practical evolving concepts. To what extent are these innovative 
features of his theoretical approach to logic reflected in speech communication textbooks? If speech communication treatments of the model are meant to preserve the major innovations of his theory, they should reflect in some explicit manner the features of these innovations. In other words, we should expect to find in textbook discussions of the model some reference to (1) the field-dependent sources of soundness in argument, (2) the probable nature of substantive claims, and (3) the relative, time-bound changeability of substantive arguments. The explicit absence of these features or the implicit contradiction of them would indicate that the model as applied by speech communication professionals is something quite distinct from that suggested by Toulmin.

\section{Field-Dependent Sources}

\section{of Soundness}

As we have seen, according to Toulmin the justifiability of a claim depends not upon universal standards of truth but upon criteria that are derived from fields or contexts of argument. In this sense, the logical assessment of an argument may only be performed by a person knowledgeable in a field, an expert in the subject matter of the argument. I Field-dependent aspects of argument are central to the design and purpose of his model. Yet, with one exception, none of the twelve textbooks on oral communication examined in this study so much as mentions the 
distinction between field-dependence and field-invariance or its significance for evaluating the soundness of argument. 2 Some textbooks appear to substitute audience analysis procedures for a consideration of field-dependent standards. 3 The authors of these textbooks on oral communication do not appear to believe as Toulmin does that familiarity with the concept of field-dependence is essential for the useful application of the Toulmin model.

It can be said that textbooks on argumentation and debate are the only ones surveyed that do not ignore the role of field-dependent sources of soundness in argument. 4 Windes and Hastings imply the notion of field-dependence in their discussion of evidence. ${ }^{5}$ The second edition of Decision by Debate includes a brief discussion of fields of argument and extends the concept to include interpersonal and situational factors. 6 In other words, in addition to the ideational dimensions of fields discussed by Toulmin, Ehninger and Brockriede include as part of a field the setting of an argument, communication channels used, and personalities and emotional states of the arguers. Rieke and Sillars have integrated the concept of field-dependence into their discussion of the Toulmin model and data while devoting whole chapters to argument within various fields.? Toulmin, Rieke, and Janik in their textbook on reasoning go even further, making the differences among fields the central theme of their 
textbook. ${ }^{8}$ Some other argumentation textbooks do not discuss fields at all, notably the first edition of Decision by Debate, both editions of Mills' Reason in Controversy, Bettinghaus in Perspectives on Argument (Miller and Nilsen eds.), and Freeley's Argumentation and Debate. ${ }^{9}$

Does the apparent disregard for Toulmin's fielddependence by some authors signify a rejection of that aspect of his approach to argument? Not necessarily. It may be that what speech communication writers have done is to reinterpret the concept to fit their interests and desire for a model of argument which elucidates the rhetorical functioning of arguments. Bradley, for example, characterizes the Toulmin model as a "rhetorical-logical model."10 While it has been noted that Toulmin's notion of fields of argument may be thought of as a way of speaking about different expert audiences consisting of sets of listeners with authority to judge claims within special fields, some writers appear to conclude that the notion may as well be applied to general audiences. For example, Bettinghaus contends:

Toulmin claims that the elements he discusses are those which are persuasive in argumentation... Arguments so constructed [via the Toulmin model]

will be generally acceptable to audiences. Further, these authors emphasize that the "appearance of logic is important in persuasion, but the actual use of logic is much less so."12 Scheidel makes similar comments 
in both of his textbooks. ${ }^{13}$ Thus it appears that for many speech communication writers who discuss the Toulmin model, there is no practical distinction between a "field" and a "popular audience." It has even been suggested that "the standards for judging the acceptability of data (evidence) and the validity of arguments may vary from field to field, or from person to person."14 Arnold states that the model is useful in helping a critic determine the "rhetorical validity" of an argument which he defines as "a critic's estimate of the psychological credibility of 'Argument $A$ ' as its 'judges'--the listeners--probably viewed the matter." 15

If speech communication textbook writers have not ignored field-dependence, they have more often than not reinterpreted the concept to emphasize the rhetorical dimensions of argument. This shift in emphasis from a linguistic-conceptual focus to a rhetorical or persuasive focus, though not explicitly identified as such, represents an extension of Toulmin's theory of argument. ${ }^{16}$ A major consequence of this development is the apparent expansion of the general applicability of the Toulmin model. Warrant and backing, once thought to depend upon a field of argument, may instead be conceived as originating in members of the audience in a manner analagous to the propositions of an enthymeme. Instead of evaluating claims according to some criteria established within a field of thought, an 
argument would be evaluated with an eye to psychological and sociological variables arising out of the particular audience and situation. In sum, the soundness of an argument becomes equivalent to its persuasive success, that is, whether it gets the desired response from the targeted listeners. Such a situational view of argument is surely far more relative than Toulmin ever intended to promote. 17 Whether it is more useful to abandon all pretensions of objectivity in logical argument and focus instead on subjective variables as those who have tacitly denied or expanded the field-notion have done is a matter deserving of careful debate. Indeed, such a debate has apparently ensued. Scholarly concern for how the terms "argument," "persuasion," and "logic" should be defined and distinguished is evident in recent publications. 18

Several writers use the Toulmin model to illustrate general forms of argument which may be viewed as fieldinvariant although they are not discussed in such terms. These treatments are discussed in chapter $V$ as applications of the Toulmin model to field-invariant forms.

Among those writers who discuss the field-dependent/ field-invariant distinction, there seems to be broad disagreement as to what the boundaries and features of fields are or should be. Rieke and Sillars believe that little if any injustice is done to the field-notion by translating it into an audience-centered view as is done implicitly by 
other writers previously discussed. 19 Ehninger and Brockriede in the second edition of Decision by Debate argue in favor of an expanded view of fields to include "the ideational, the situational, and the interpersonal."20 Toulmin, Rieke, and Janik defend a more limited view of fields or, as they call them, "forums" of argument:

Just because the kinds of issues raised in each forum are of such different sorts, the procedural organization of the resulting discussions is correspondingly different, and the manner in which claims and arguments have to be presented and defended also differs. These variations from forum to forum are not a mark of rhetorical subtlety or dishonesty but a direct consequence of the functional differences between the needs of the enterprises concerned, for example, law or science, business or medicine.2l [Emphasis added.]

They go on to say that arguments from different forums cannot be compared except in the broadest way. 22 The point is that little agreement exists as to what fields of argument may be even among those authors who feel the concept is important enough to merit explicit discussion.

The issue of field-dependent sources of soundness in arguments is apparently far from resolved among speech communication professionals. Many have ignored the notion of field-dependence, apparently finding that it is not crucial for an understanding of argument. This position is not unlike that of formal logicians and may be an indication of the degree to which their linear perspectives and attendant assumptions and aims are shared by speech communication textbook writers. Other writers have 
implicitly redefined the field notion to redirect the focus of the Toulmin model to the rhetorical dimensions of argument and so raising important definitional if not epistemological questions. Some have proposed expansions of the field-notion which are as yet untested. One might conclude, then, that Toulmin's notion of field-dependence has not been an important or influential factor in the impact of his approach on the area of speech communication.

The Probable Nature of

Substantive Claims

Probability is another innovative feature of the Toulmin approach to argument. 23 It involves the notion that most practical arguments are substantial, involving claims which entail relative degrees of probability rather than the absolute certainty implied by syllogistically demonstrable conclusions. As with the concept of fielddependence, the notion of probability in arguments has received little emphasis in textbooks on oral communication while receiving greater emphasis in textbooks on argumentation and debate.

Only one of the twelve oral communication textbooks surveyed makes prominant mention of the probable nature of most argumentative conclusions as discussed by Toulmin. 24 Most of these authors explicitly introduce the element of the Toulmin model most closely associated with the notion of probability, the qualifier. However, McCroskey, Terris, 
Verdeber, and, in their first edition, Wilson and Arnold omit the qualifier from their diagrammatic models and one must infer from the examples offered whether or not these authors believe that probable or qualified claims can be the result of a sound argument. 25

It is uncertain whether the obscuring or omission of probability from explanations of argument in textbooks on oral communication reflects a genuine disagreement with the concept or merely an attempt by authors to avoid explanatory complications. Either way, an explanation of argument which fails to introduce a student to the concept of probability and ignores the element of qualifier would appear to be little different in this respect from a syllogistic approach and consequently may serve as tacit confirmation of the linear theoretical assumptions of formal logic. On the other hand, textbooks on oral communication which introduce the element of qualification as part of their diagrammatic models clearly imply the probable nature of substantive arguments. While Toulmin's notion of probability in argument differs in some respects from notions of probability traditionally associated with the enthymemes of rhetorical arguments, these differences are perhaps too technical to merit specific discussion in textbooks on oral communication. In other words, a treatment of the role played by qualifiers in arguments may well be 
all that is needed by way of explanation of Toulmin's notion of probability in substantive arguments.

Textbooks on argumentation and debate surveyed have been found in general to provide greater emphasis to the notion of probability than textbooks on oral communication. Bettinghaus, in Miller and Nilsen, refers to the Toulmin model as a "probability model." 26 Even Windes and Hastings, who do not introduce the qualifier element in their treatment of the Toulmin model, discuss probability. 27 Freeley does not discuss probability but introduces a qualifier. 28

It may be argued that argumentation textbooks provide greater attention to probability as well as other specifics of the Toulmin approach than do oral communication textbooks because the focus of their subject is narrower and, therefore, more attention can be afforded such matters. Even so, what is notable here is not the differences in the extent to which probability is treated in different classes of speech communication textbooks, but that in some texts it does not appear at all. Toulmin devotes large portions of The Uses of Argument to the establishment of a unique view of the role of probability in arguments. From the number of pages he devotes to each, one might presume that Toulmin is more concerned with his special view of probability than he is with the layout of arguments which has received so much more attention in speech communication 
textbooks. 29 of course, both concepts are innovative features of his approach to argument.

Yet, as we have seen, speech communication writers generally grant little emphasis to the notion of probability, some choosing to omit it altogether. One possible explanation for this may be that, to students of rhetorical theory, the introduction of probability into the logic of argument does not seem innovative. To the contrary, it may be this feature which is most familiar and attractive to speech communication professionals. 30 As mentioned before, Aristotle introduced the notion of argument from probabilities in the Rhetoric in the form of enthymemes. 31 Like the enthymeme, the Roman epicheireme involves argument from probabilities, as discussed in chapter II. Some writers have commented upon similarities between the Toulmin model and these traditional forms of rhetorical syllogism. For example, Scheidel half apologizes for the resemblance of the Toulmin model to the epicheireme, while McCroskey appears to feel that it is too much like the syllogism of formal logic and therefore suggests revisions to make the model more enthymematic. 32 so the role of probability in argument suggested by Toulmin may seem a less noteworthy feature to those with a background in rhetorical theory than it does to formal logicians to whom he has addressed his theory. In other words, while it may be a crucial feature of the Toulmin approach, some rhetorically-oriented 
writers appear to believe that probability is a commonplace that does not merit special explanation in speech communication textbooks.

Relativistic Assumptions

About the Nature of

Argument

In addition to field-dependence and probability, another theoretical base of the Toulmin approach involves its relativistic assumption. In contrast to the universal, timeless absolute conclusions of formal logic, the soundness of a claim is assumed by Toulmin to be relative over time to the available data and historical developments within a field. In addition, the elements of the structure of an argument are defined by him according to how each functions in relation to a particular claim. Finally, as previously discussed, claims are assessed according to their relative probabilities. Relativism, as opposed to absolutism, is fundamental to Toulmin's conception of argument. Other than the relativism implied by field-dependence and probability, matters already discussed, the relative nature of the Toulmin approach is for the most part not reflected in speech communication textbooks.

Of the twelve oral communication textbooks surveyed, only one, Speech Communication in Human Interaction by Scheidel, dwells at any length on the "flexibility" of the Toulmin model in contrast to the Aristotilian model, the 
syllogism. 33 Scheidel points out that logic itself is an example of a growing, changing field in which the Toulmin model represents but one--and not the final--modification. Other textbooks surveyed focus on individual arguments which may be presented within a speech and do not comment on the relativity of arguments over time or across cultural boundaries.

Textbooks on argumentation more frequently discuss the relativistic nature of argument than do oral communication textbooks. It would appear that Brockriede and Ehninger, in emphasizing the "dynamic" relationship of data, warrant, and claim, mean to draw attention to the relativistic nature of argument as found in Toulmin. 34 In the second edition of Decision by Debate, these same authors present a detailed discussion of "argument as a corrective method" emphasizing the tentative nature of all claims. 35 The tentative nature of claims as opposed to the static conception of syllogistic conclusions in formal logic is discussed in several contexts by Rieke and Sillars. 36 Toulmin, Rieke, and Janik are perhaps the most emphatic about the importance of relativity in arguments. Pointing out that standards of judgment will "inevitably vary in time or differ according to context and circumstances of judgment," these authors discuss the problems of criticizing argument in light of their "historical variability."37 Other authors imply or obliquely refer to the static and inflexible 
nature of the syllogism as compared to the Toulmin model, but their discussions leave in doubt the degree to which relativity plays a role in argument. 38 Both Mills and Freeley appear to ignore the relativistic implications of the Toulmin approach. 39

At least one textbook uses the Toulmin model primarily because of its relativistic assumptions. Condon and Yousif, in An Introduction to Intercultural Communication select the Toulmin approach to help illustrate cultural variety in argumentation. 40

Writers of oral communication textbooks, perhaps because their focus is on the role of an argument in one particular audience setting, fail to discuss the relativism of claims over time. In essence, the static nature of the syllogism is not necessarily a problem for those concerned with argument in speech design. However, some writers of argumentation textbooks seem to exhibit more concern for relativism in argument than writers of oral communication textbooks. They recognize that one of the advantages of the Toulmin approach is its emphasis of the tentative or controversial nature of claims established in arguments and how the introduction of new evidence may affect the evaluation of them. It may be significant that the authors who do not mention Toulmin's relativistic assumptions emphasize that the formal validity of an argument cannot be demonstrated with his model. They each 
present the syllogism to assist the critic in this regard. 41 Thus, it may be that we are observing a split between speech communication writers who favor the systems theoretical perspective of argument which appears to be reflected in Toulmin's approach and those who adhere to the more linear theoretical perspective of formal logicians.

THE TOULMIN DIAGRAMMATIC MODEL AS REPRESENTED IN SPEECH COMMUNICATION TEXTBOOKS

The Toulmin model and variations of it are widely published and quite familiar within speech communication. First introduced in the third essay of The Uses of Argument, "The Layout of Arguments," the Toulmin diagrammatic model has since been borrowed, interpreted, truncated, extended, and redesigned by various writers in speech communication. 42 The nature of these various visual representations is our concern here, especially with regard to the effect which each diagrammatic alteration may have on the potential applicability and comprehensibility of the Toulmin model.

of the twenty-seven editions of speech communication textbooks examined, only two were found to include both a diagram and terminology matching Toulmin's in The Uses of Argument. ${ }^{43}$ All other textbooks exhibit diagrammatic models which vary from Toulmin's layout in their visual relationships, identified elements, or terminology. Of these texts, fourteen present a standard diagram consisting of six elements and the same visual relationship between 
warrant, data, and claim as represented by Toulmin. 44 Seven other textbooks present truncated diagrams in which the layouts are simplified through the omission of one or more elements, while three present extended diagrams in which the layout is expanded to include new elements or relationship among elements. ${ }^{45}$ Three textbooks included diagrams which are both truncated and extended versions of the Toulmin layout. ${ }^{46}$ Variations in terminology are discussed later in this chapter.

\section{Standard Diagrams}

The diagrammatic model presented by Toulmin consists of six elements representing the functions of sentences used in arguments and the relationships of these functionally-defined elements are illustrated with a horizontal arrow between data and claim and some vertical lines extending downward from warrant to backing and qualifier to rebuttal. This model is illustrated in Figure 3 in chapter II, p. 4l. To be considered a standard diagram a model must at least include all six functionally-defined elements of the Toulmin layout and preserve the same visual relationship among the data, warrant, and claim.

With regard to the standard diagrams represented in textbooks, three kinds of alterations are noted: lineal, directional, and configural. Lineal relationships are those illustrated by lines which connect the elements. 
Directional relationships are those illustrated with arrowheads on the lines between elements. Configural relationships have to do with the overall pattern of visual display of the elements.

The most common deviation from Toulmin's layout is the lineal relation of warrant and rebuttal. This first appeared in the article by Brockriede and Ehninger in Quarterly Journal of Speech and was subsequently repeated with different terminology in their first edition of Decision by Debate. 47 See Figure 8 .

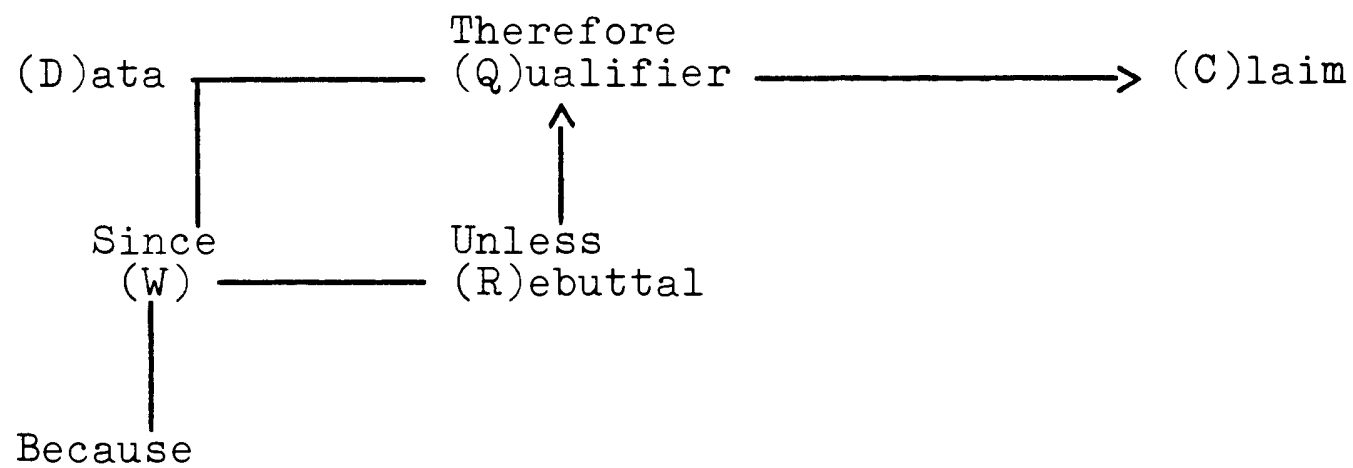

(B) acking

Figure 8. The Toulmin model according to Brockriede and Ehninger, 1960.

Other authors, for example Bryant and Wallace, Minnick, Bettinghaus in Miller and Nilsen, Freeley, and Hastings in Mills' first edition of Reason in Controversy, have also drawn a line connecting warrant and rebuttal or reservation in their diagrammatic models. 48 Like Brockriede and Ehninger's diagrammatic model in Figure 8, most of these 
diagrams connect $\mathrm{R}$ to both $\mathrm{W}$ and $\mathrm{Q}$ or $\mathrm{C}$, creating kind of a "square of proof." Among the textbooks examined, Hasting's diagram is alone in connecting $R$ only to $W .49$ In his second edition, Mills omits the line between $W$ and $R$ entirely, returning to a more standard representation of the Toulmin layout. 50

Minnick not only connects $W$ to $R$ but inexplicably introduces a line connecting support for warrant to conclusion. Further, he alters the line connecting $W$ to the arrow between evidence and conclusion so that it begins at the line between $W$ and $R$ and snakes its way directly to the conclusion. These alterations are illustrated in Figure 9.51

Evidence: Conclusion:

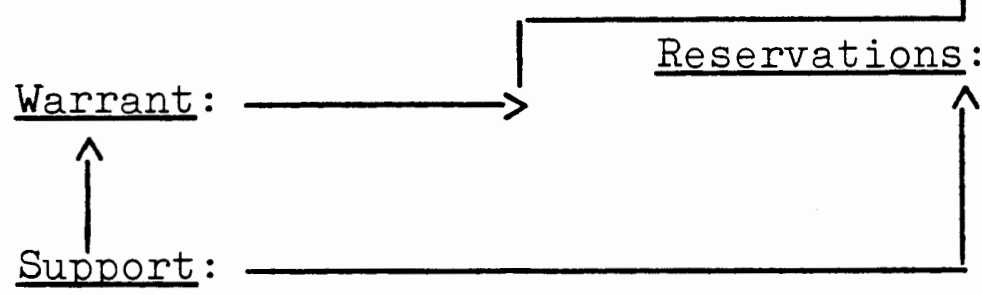

Figure 9. The Toulmin model according to Minnick.

Minnick's modifications of the standard diagram appear to add nothing in the way of clarification of the relationships among elements. It is possible that Minnick intended this diagram to apply only in the case of the particular 
argument he illustrates with it; however this is uncertain because Minnick offers no explanation or alternative diagram.

The significance of lineal linkages of $W$ to $R$ is not altogether clear. However, it is evident from the novel configuration introduced by Toulmin, Rieke, and Janik that they consider such a link inessential if not a distortion of the role of rebuttals in arguments. Their diagram, representing the only modification of configural relationship proposed in textbooks presenting standard diagrams of the Toulmin model, maintains Toulmin's original lineal relationships while making visually inappropriate any conception of a link between $W$ and $R$. According to these authors, "given grounds, $\underline{G}$, we may appeal to warrant, $\underline{W}$ (which rests on backing, $\underline{B}$ ), to justify the claim that $\underline{C}--$ or, at any rate, the presumption (프) that $\underline{\mathbf{C}}-$-in the absence of some specific rebuttal or disqualification ( $\underline{R})$." 52 This diagrammatic model which precludes the configural relationship of $W$ and $R$ appears in Figure 10 . 
The accumulated experience of meteor-

B ologists in the North Temperate Zone indicates that

In these latitudes, passage of a cold

W front is normally followed after a few hours by clearing, cooler weather.

This evening the wind has veered around from SW toward NW; the rain has nearly stopped; there are local breaks in the clouds--all signs indicating the passage of a cold front.

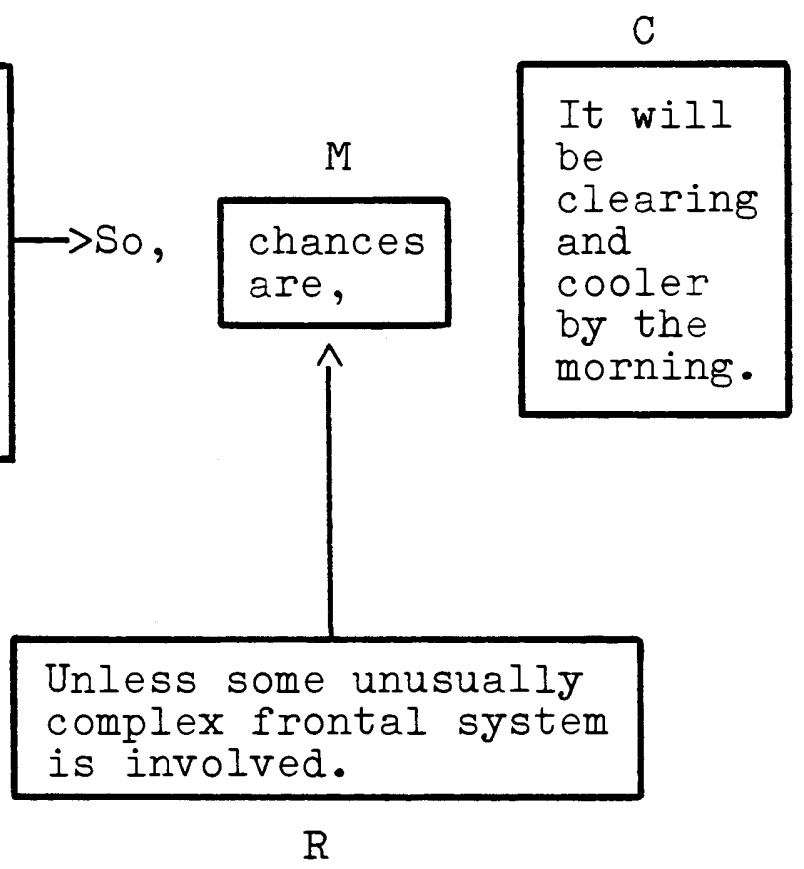

"G" represents "grounds" or data.

Figure 10. An illustration of an argument analyzed in terms of the Toulmin model according to Toulmin, Rieke, and Janik. 
Unlike other writers, Toulmin, Rieke, and Janik claim that rebuttal is only used in conjunction with a particular modal qualifier. 53 Those writers linking $W$ and $R$ offer more general recommendations for its use. 54 Thus it appears that the presence, absence, or difference of linear connectedness of rebuttals to other elements of the Toulmin model may be related to differences in definition and suggested use of these elements. Variations of definitions and terminology are discussed later in this chapter.

Directional relationship, illustrated with arrowheads on lines between elements in diagrammatic models, are frequently presented in variations of standard diagrams. It will be recalled that only one such directional relation is illustrated in Toulmin's original layout, the arrow representing the movement from data to claim. Apparently Toulmin intended the arrow to represent the function of the warrant itself. 55 The significance of arrows indicating directional relationships is that each may imply a supportive, causal, or temporal interaction between elements. Toulmin uses the arrow to indicate that a claim depends upon data for foundation or support, and that the warrant functions as an incidental explanation of the justification for the movement from data to claim. As he states:

We may symbolize the relation between the data and the claim in support of which they are produced by an arrow, and indicate the authority for taking the step from one to the other by writing the warrant immediately below the arrow. . . As this 
pattern makes clear, the explicit appeal in this argument goes directly back from the claim to the data relied on as foundation. 56

Thus, his arrow is not intended to imply that one reasons in only one direction, namely from the data with which one begins to a claim at which one arrives. Rather, the arrow symbolizes the interactive relationship between data and claim regardless of the direction or sequence of one's inferential process. 57

What speech communication writers intend by the arrows many of them have added to lines in their diagrammatic models is not clear. To Toulmin's single directional relation, Bettinghaus in Miller and Nilsen adds an arrow on the vertical line connecting $R$ to $Q$ as is shown in Figure 11.58 Such an arrow also appears in Freeley's diagrammatic model, parallel to a downward arrow which has been made of the vertical line connecting $W$ to the arrow between $D$ and $C$ as shown in Figure 12.59 By this downward arrow, Freeley may mean to illustrate that one moves from data to claim on one level and from data through warrant and rebuttal to claim on a deeper level. Blankenship shows a similar loop made more explicit by an additional arrow from $W$ to $R .60$ Interpreted as a visual representation of the deepening levels of argument to which challenges to a claim and warrant will take an argument, these downward arrows appear to be roughly consistent with Toulmin's explanation of the progressive phases of argument. 61 


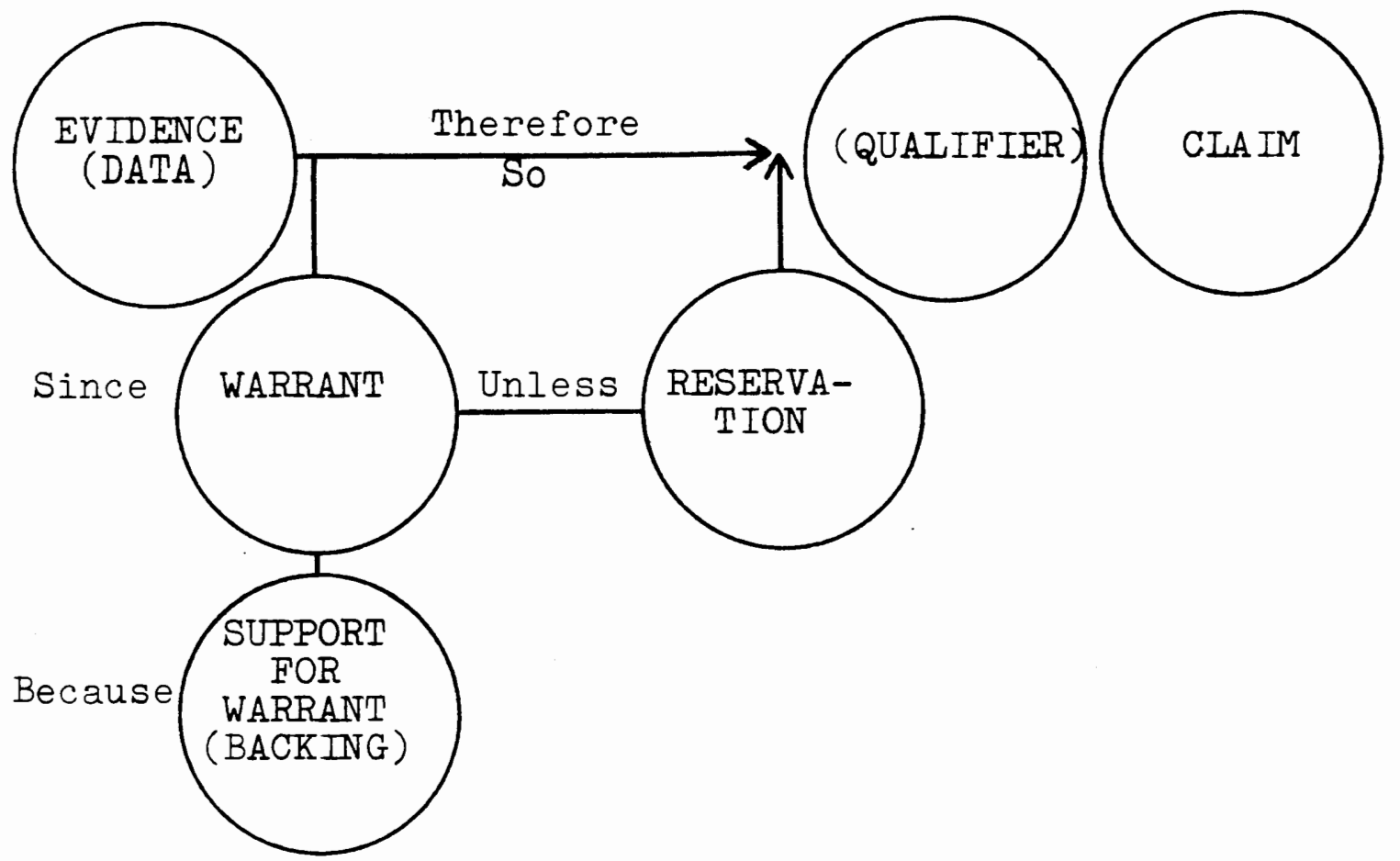

Figure 11. The Toulmin model according to Bettinghaus in Miller and Nilsen.

(D) ata

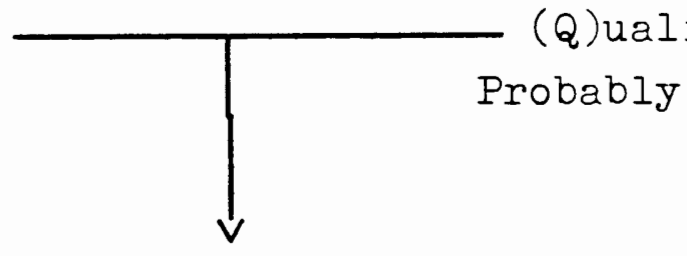

Since
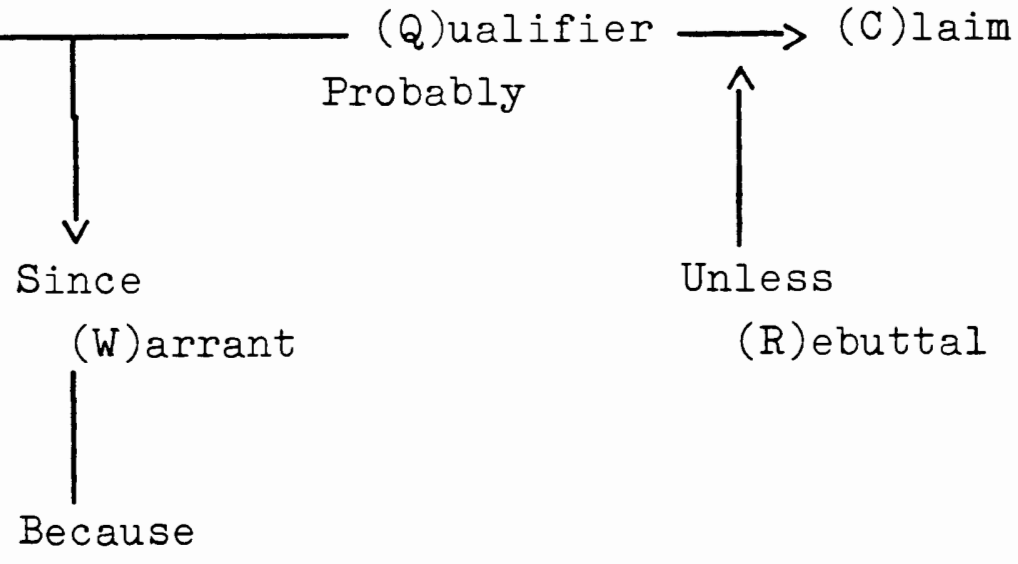

Unless

(R)ebuttal

(B)acking

Figure 12. The Toulmin model according to Freeley. 
Bradley curiously places arrowheads on each of the lines in his diagrammatic model, most of them pointing away from the directional line from evidence to claim as shown in Figure 13.62 What one is to make of Bradley's arrows is difficult to guess. Perhaps he means to illustrate that an examination of the relationship of evidence and claim leads one deeper into the argument, to warrant, reservation and, eventually, backing for warrant. Thus, his downward arrows may mean something similar to the downward arrows of Bettinghaus and Freeley already discussed. However, like Minnick who also places arrows on each of the lines in his diagrammatic model as illustrated in Figure 9, Bradley fails to explain the meaning of his arrows. It is possible that the arrows have no particular meaning for Bradley or Minnick.

Evidence:

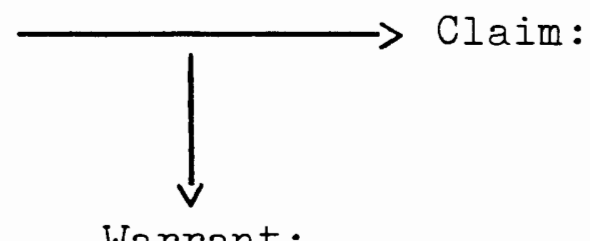

Warrant:

$$
\downarrow
$$

Backing for Warrant:

Figure 13. The Toulmin model according to Bradley.

In short, the directional relationships indicated by arrows which have been added to Toulmin's layout by some 
speech communication writers are subject to interpretation. The significance of these alterations may be that they do not agree, are not explained, and therefore, contribute little more than an increased potential for misunderstanding. Linear, directional, and configural modifications which are presented in several standard diagrams also are found in truncated and extended variations of the Toulmin model. Truncated diagrams of the Toulmin model presented in speech communication textbooks are discussed next.

Truncated Diagrams

Truncated models are those which omit one or more elements of the standard diagram of the Toulmin model. None of the three basic elements of the Toulmin layout-claim, data, and warrant--are omitted by any author of the surveyed speech communication textbooks. Backing, rebuttal, and qualifier are by individual authors selectively omitted. Indeed, in two textbooks a Toulmin diagram is presented which omits all three of these secondary elements, giving the model the appearance of "a syllogism lying on its side."63 One author, Gary Cronkhite, who presents a diagram which is both truncated and extended, borrows only the three basic elements of the model on which to build his extension. 64 None of these authors discusses the syllogism; their truncated Toulmin diagrams are presented in isolation. 
Other truncated models come in various combinations. Wilson and Arnold in their first edition and, more recently, Ehninger have included backing or support for warrant while omitting qualifier and rebuttal. 65 Terris relies on rebuttal while omitting qualifier and backing. 66 Similarly McCroskey, who both truncates and extends the Toulmin model in his diagram, omits backing and qualifier. 67 Another extended and truncated version of the Toulmin model, this one introduced by Condon and Yousif, omits both backing and reservation. 68 Wilson and Arnold in their fourth edition, Ehninger and Brockriede in their second edition, and Blankenship each exclude only the backing from their diagrammatic models. 69 So, among speech communication textbook writers who have in one way or another simplified the standard diagram of the Toulmin model for their presentations, which elements are thought to be most essential appears to be a matter of contention.

It is interesting to note the changes over time in the diagrammatic models presented by Wilson and Arnold, and Ehninger and Brockriede. Wilson and Arnold, who have in some way modified their presentation of the Toulmin model with every new edition of their textbook, have gradually added elements originally excluded and finally eliminated backing which is one of the four elements with which they began. 70 No explanation for these modifications is provided in their textbooks. Ehninger and Brockriede have 
introduced some directional arrows to their diagram which perhaps indicates a changing emphasis in their thinking, as a comparison of their original diagram in Figure 8 to their more recent diagram in Figure 14 shows. 71

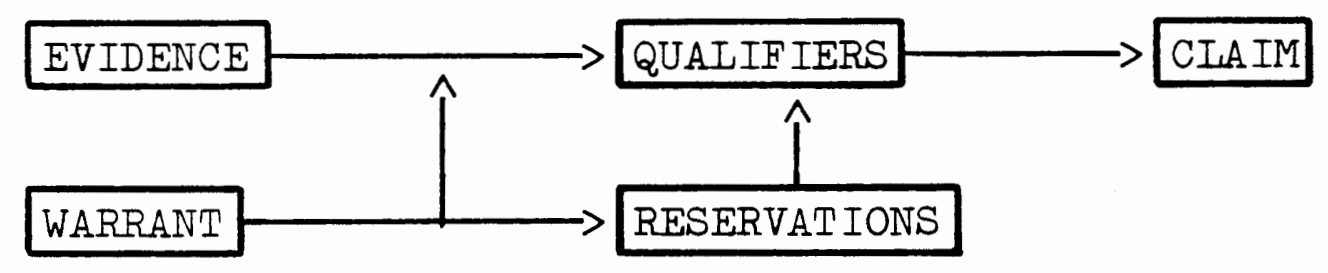

Figure 14. The Toulmin model according to Ehninger and Brockriede, 1978.

The roles played by reservations and qualifiers seem visually more central in this newer conception of Ehninger and Brockriede's diagram of the Toulmin model. However, this diagram seems more complex than others examined thus far; even a close reading of their text fails to make clear how the evidence-qualifiers relationship is affected by the warrantreservations relationship or how warrant affects reservations. Ehninger and Brockriede imply that support for the warrant has been ruled out for the same reason that evidence requires no element of support: namely, both evidence and warrant are subject to support through separate units of proof. 72 In other words, separate arguments are needed to support evidence and warrant just as separate arguments are required to establish the truth of the major and minor premise of a syllogism. Why the connection between warrant 
and reservations, an innovation apparently attributable to these authors, has been given greater emphasis is uncertain. The advantages of truncated models may be their simplicity, the ease with which they can be presented briefly in a text and, presumably, comprehended by a learner. In addition, such models focus attention on elements and relationships of greatest interest to the individual textbook authors. For instance, because of the constraints of academic debate such as time limits and audience bias, authors of textbooks on debate may not be especially concerned with teaching students how to perform a fully developed analysis of an argument. 73 In other words, a truncated model may be viewed by some textbook authors as of more immediate pedagogical value than a standard diagram of the Toulmin model.

\section{Extended Diagrams}

The standard Toulmin diagrammatic model has not only been truncated in a variety of ways; it has also been extended, by having new elements or relationships added to it. Such extended diagrams are offered by speech communication textbook writers apparently as improvements intended to increase the applicability of the model in general and in particular to certain common forms of argument to be discussed in chapter $V$. 
Those who propose extensions appear to be especially aware that arguments, as they occur in discursive forms, are seldom as simple or neat as Toulmin diagrams. Some elements, warrants for instance, may not be explicitly stated while an abundance of other items may be included in discourse which are the elements of separate arguments or not aspects of argument at all. The point is, in order to deal with the natural complexity of argumentative discourse, several writers have suggested more complex structures and extensions of the Toulmin model. Not coincidentally, the three most common proposals for extensions of the standard diagram--regarding the inclusion of multiple data, chains of reasoning, or support for the data--are directly related to issues raised by Toulmin's critics about potentiallimitations or defects of the Toulmin layout as discussed in chapter III.

As has been discussed, Toulmin's explanation of data in The Uses of Argument leaves room for doubt as to whether he intends an analysis of an argument to include multiple items of data as the word implies or only a single item as many have interpreted him to mean. Regardless of what Toulmin's initial intentions may have been, it is in connection with the element of data that most extensions have been proposed. Toulmin, Rieke, and Janik, for example, clearly imply in their diagrams and illustrations that 
multiple data items are permissible in conjunction with an individual claim and warrant. 74 However, they do not amplify on the mechanics of this feature; thus, it is difficult to determine what difference this modification makes to the process of analysis. Bettinghaus and Book et al. both present diagrams illustrating the use of multiple data items in various forms of argument. 75 For example, both textbooks present extended diagrams which graphically illustrate the role of multiple data in a single argument, as shown in Figure 15.76 While these diagrams represent patterns of presentation, arguments as they may appear in discourse, they presume that in some cases a single warranted claim may require several items of data to be valid. In addition to the deductive and probabilistic patterns, Bettinghaus presents two other "general patterns of proof," termed "functional" and "genetic."77 Even more complex than the patterns illustrated in Figure 15, these patterns resemble some of the general forms of argument discussed in chapter $V$. 


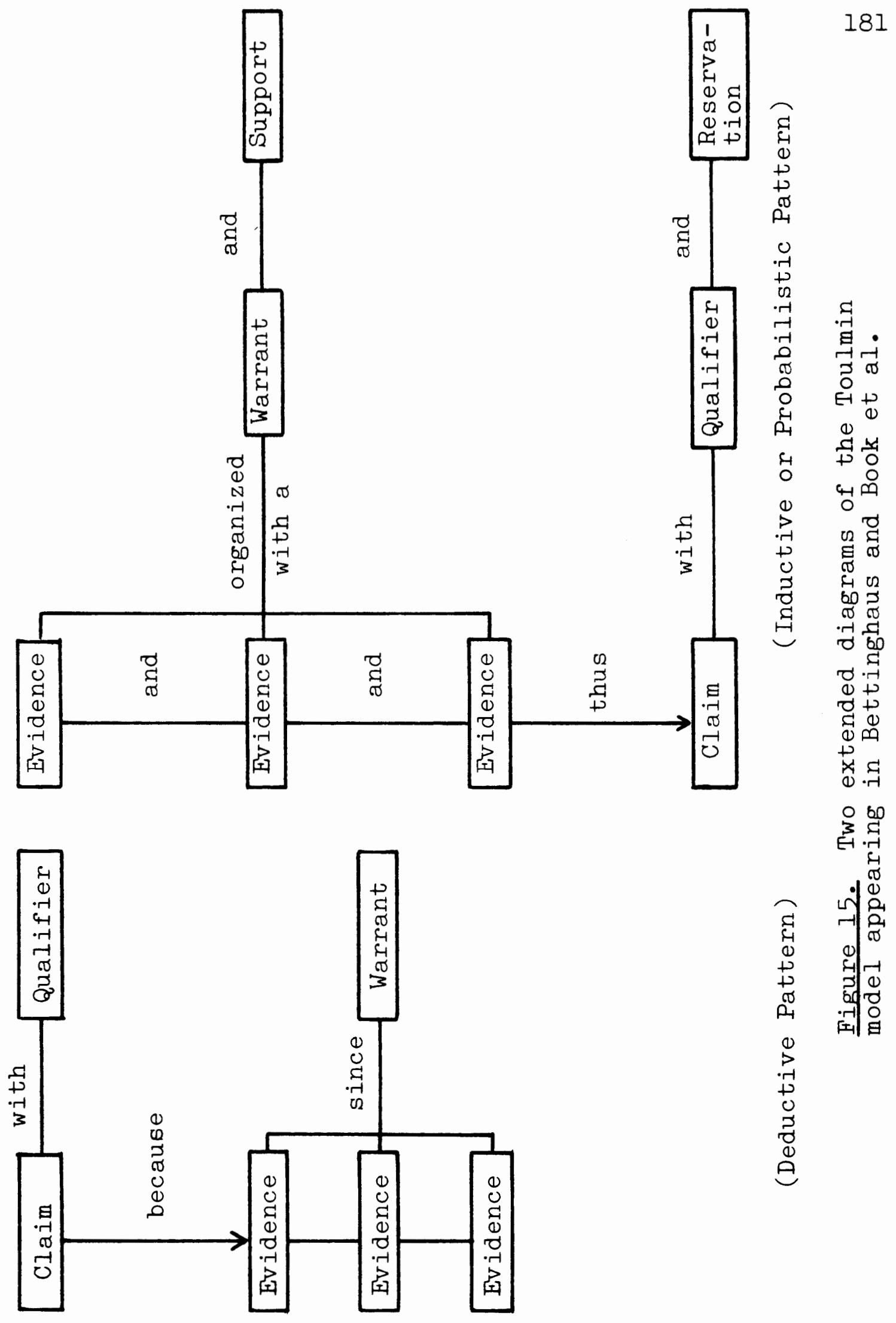


Another extension apparently related to the application of the Toulmin model to arguments in discourse or macro-arguments is the diagramming of chains of reasoning. Many authors follow Toulmin's suggestion that if data are challenged, a preliminary argument must be presented to establish the reliability of the data. Some have presented diagrammatic models which illustrate various ways in which arguments may be chained together to support a conclusion. 78 Ehninger and Brockriede identify two patterns according to which individual units of proof may be combined to build a case or macro-argument. 79 Likening arguments to electrical circuits, the two structures are termed "series and parallel circuits" by Ehninger and Brockriede and are diagrammed as shown in Figure 16.80 By comparison to a standard diagram of the Toulmin model, these extended diagrams representing chains of reasoning look very complex as is shown by the illustration of a "chain argument" presented by Book et al. which appears in Figure 17. The complexity results from the number of related claims, sets of data, and warrants which are involved in the diagramming of a lengthy argument. It would appear that the candidness which analysis with the Toulmin model is meant to provide a critic might be lost in some of these complex diagrams of chains of reasoning. 81 


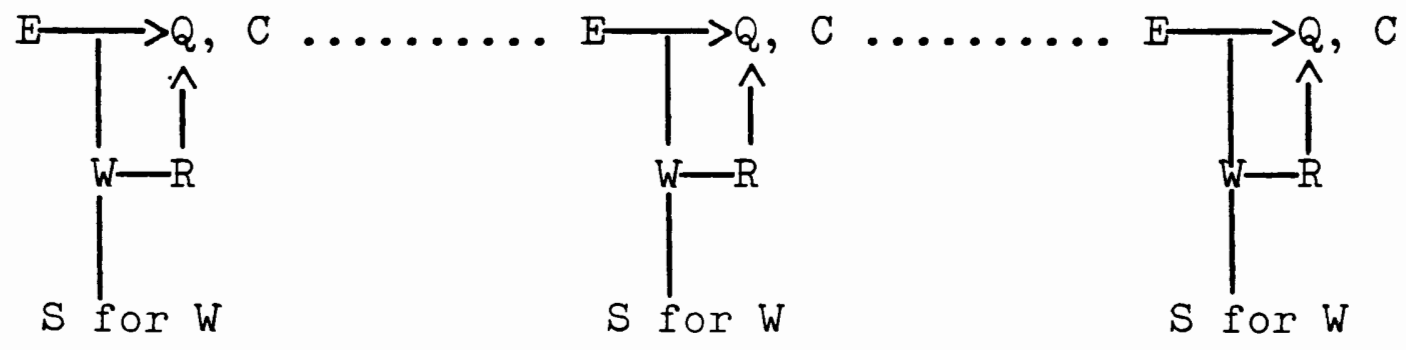

(Series Circuit)

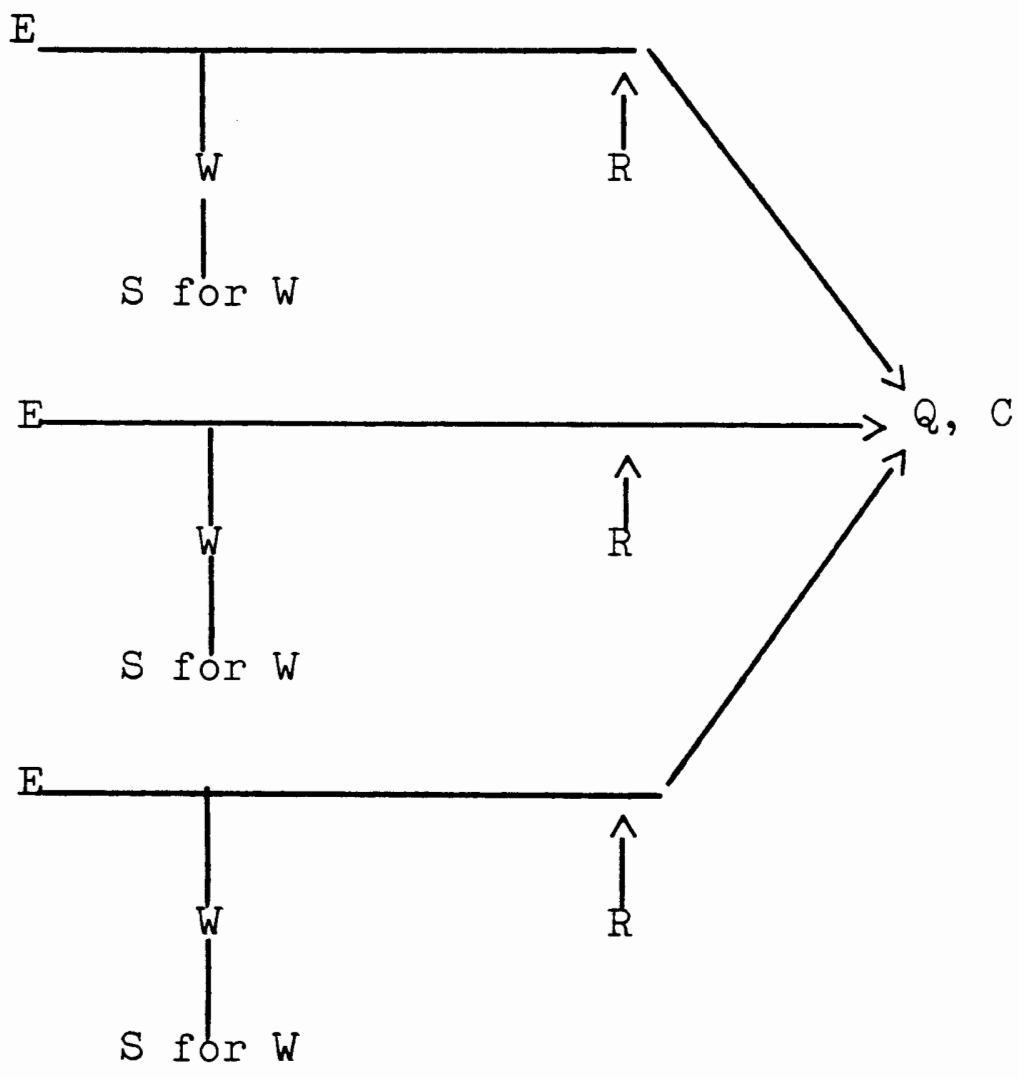

(Parallel Circuit)

Figure 16. Extension of the Toulmin diagrammatic model to chains of reasoning according to Ehninger and Brockriede, 1963. 


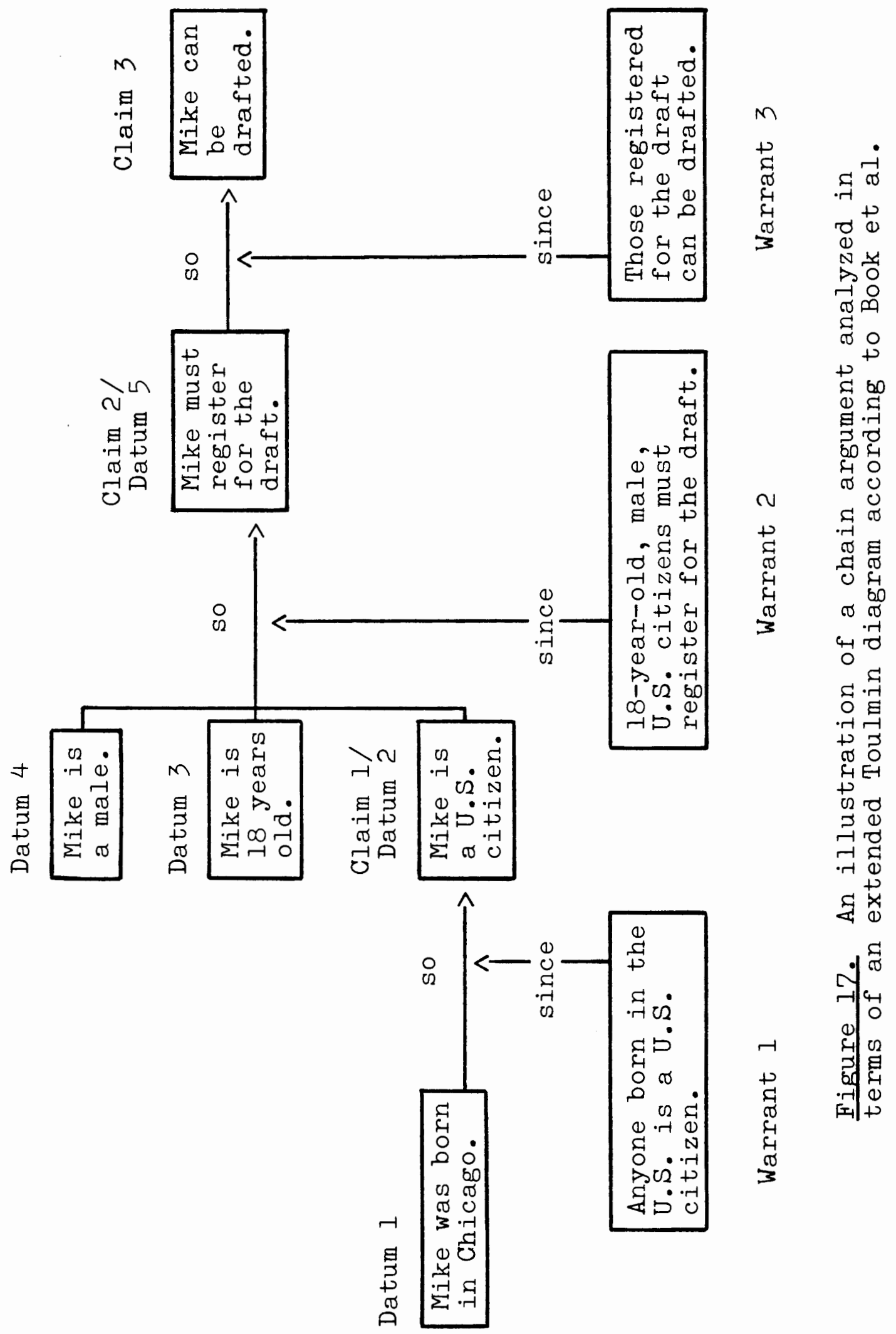


A different approach to the problem of specifying the reliability of statements given as data in argumentative discourse is suggested by Rieke and Sillars. In their diagrammatic model they include a seventh element, related to data in a manner which parallels the relationship of backing to warrant, which serves to specify support for the data. 82 The new element is termed "support for data" while the element of data is termed "assertion of data." In all other respects, their model resembles a standard Toulmin diagram. Condon and Yousif introduce a similar element related to data but for a different purpose: to separate raw data, as in statements of fact based upon direct observation, from what they term "evidence," as in statements of interpretation of selected data. This distinction is introduced to draw attention to the cultural relativity of what is taken as evidence for assertions by comparison to phenomenal reality which is assumed to be more universal. 83 Others have proposed that an element representing support for data be introduced into the Toulmin diagram. ${ }^{84}$ Thus, the introduction of a seventh element of argument, linked to data and serving a function which parallels that of backing for the warrant, has emerged independently from several sources and deserves further examination.

In addition to diagrammatic models which are extended to accommodate modifications in the concept of data, there are two other extensions which deserve mention here. 
First, there is McCroskey's "model of the enthymeme which employs terms set forth by Toulmin as labels for its parts."85 This model is unique in that its configural layout is entirely different from a standard Toulmin diagram, implying very different relations among elements than conceived by Toulmin. Also, its fourth element, reservations, may be appended to any and all of the three basic elements, claim, warrant, and data, as shown in Figure 18. McCroskey's diagram is simpler than the standard Toulmin diagram, having fewer parts and implying no directional relationships. In addition, the reservation is intended to represent a general modifier or screen which may serve to invalidate any of the three legs of an argument.
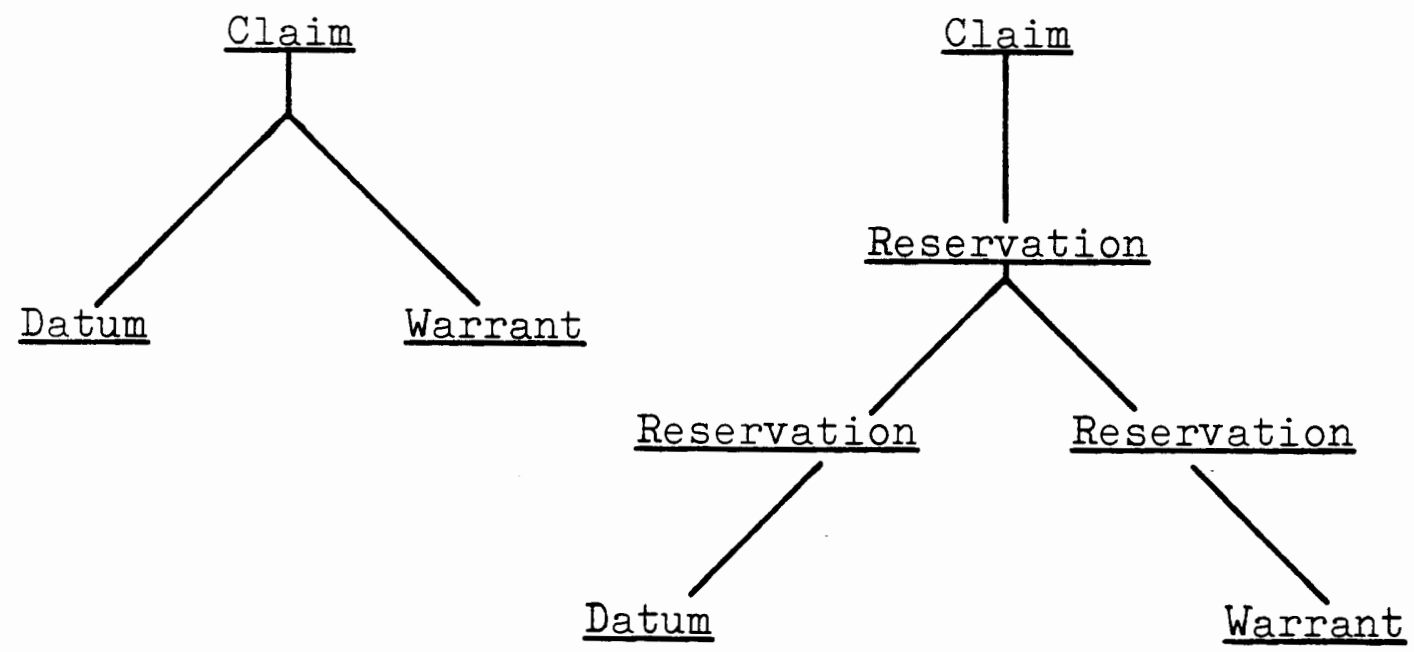

Figure 18. Two versions of the extended Toulmin diagram proposed by McCroskey as a model of the enthymeme. 
While McCroskey entitles his discussion of this model "A Psychological Model of Argument," there are as many references to classical distinctions and Aristotle as there are references to psychological concepts or research studies. It appears that McCroskey has in mind a synthesis of old and new ideas, a hybrid model which combines Aristotle's enthymeme, Toulmin's layout, and psychological theories applicable to persuasion. However, his model appears to have more in common with the syllogism than it does with Toulmin's model despite the use of some of Toulmin's terminology. 86 Thus, the extent to which McCroskey's model may represent an extension of the Toulmin approach rather than a return to formal logic is in doubt. It is interesting that in an earlier publication, McCroskey proposed that the Toulmin model be used in Basic Speech Communication courses in several ways. 87 McCroskey has abandoned the Toulmin model more recently because, he says, "the model's usefulness for communicators is severely limited" due to the fact that it is based in logical rather than rhetorical considerations. 88

A second notable extended diagram of the Toulmin model has been proposed by Cronkhite. Cronkhite combines the Toulmin model with a model of attitude change. Of the potential applicability of the Toulmin model to persuasion theory, Cronkhite writes: 
If the Toulmin model is used to encompass an entire argument, it has an obvious shortcoming: both the data and warrant may require support and may, in effect, become claims in new units of proof. If this modification is made [that of allowing for chains of support]. . the Toulmin model appears to have great utility inn describing a part of the process of persuasion. 89

Using only the three basic elements of the Toulmin model and suggesting that any questionable data or warrants be viewed as the claims of preliminary arguments, Cronkhite proposes that we distinguish data-claims from warrantclaims. In addition, the overall macro-argument is centered upon a major attitudinal or behavioral objective, termed an "object concept." The object concept represents the final endpoint or goal of all the chains of arguments leading up to it. Cronkhite also discusses "motivational concepts" which represent the stimuli for an attitude change involving the object concept. In other words, in persuasion, arguments are used to establish claims of relationship between particular motives and object concepts. For instance, if one who is motivated by greed (motivational concept) is confronted with an opportunity to invest in large amounts of silver (object concept) and can be convinced through a series of arguments that there is a relationship between the act of silver investment and a satisfaction of greed (claim of relationship), then a behavior change is likely to result. 90 Cronkhite has developed mathematical formuli to represent the degree to 
which each of these elements must be present for change to occur. 91 While this quantification of the elements involved in persuasion is the more important aspect of Cronkhite's extended model, he also presents a diagrammatic model which appears in Figure 19. In short, according to Cronkhite persuasion may be described in terms of the establishment of asserted claims of relationship between motivational and object concepts through the use of chains of data-claims and warrant-claims presented as arguments. While this extended diagrammatic model is inventive in its combination of a psychological theory with an epistemological one, it suffers from an extreme and seemingly infinite potential for complexity. The universe of concepts which may bear upon a single change in attitude could easily fill a book. Thus, the value of such a model probably should be judged in terms of its qualities as theoretical explanation and its use in quantitative prediction. As a descriptive analytic tool, Cronkhite's extended diagrammatic model appears to be cumbersome, to say the least. 
Motivational

Concept \#2b

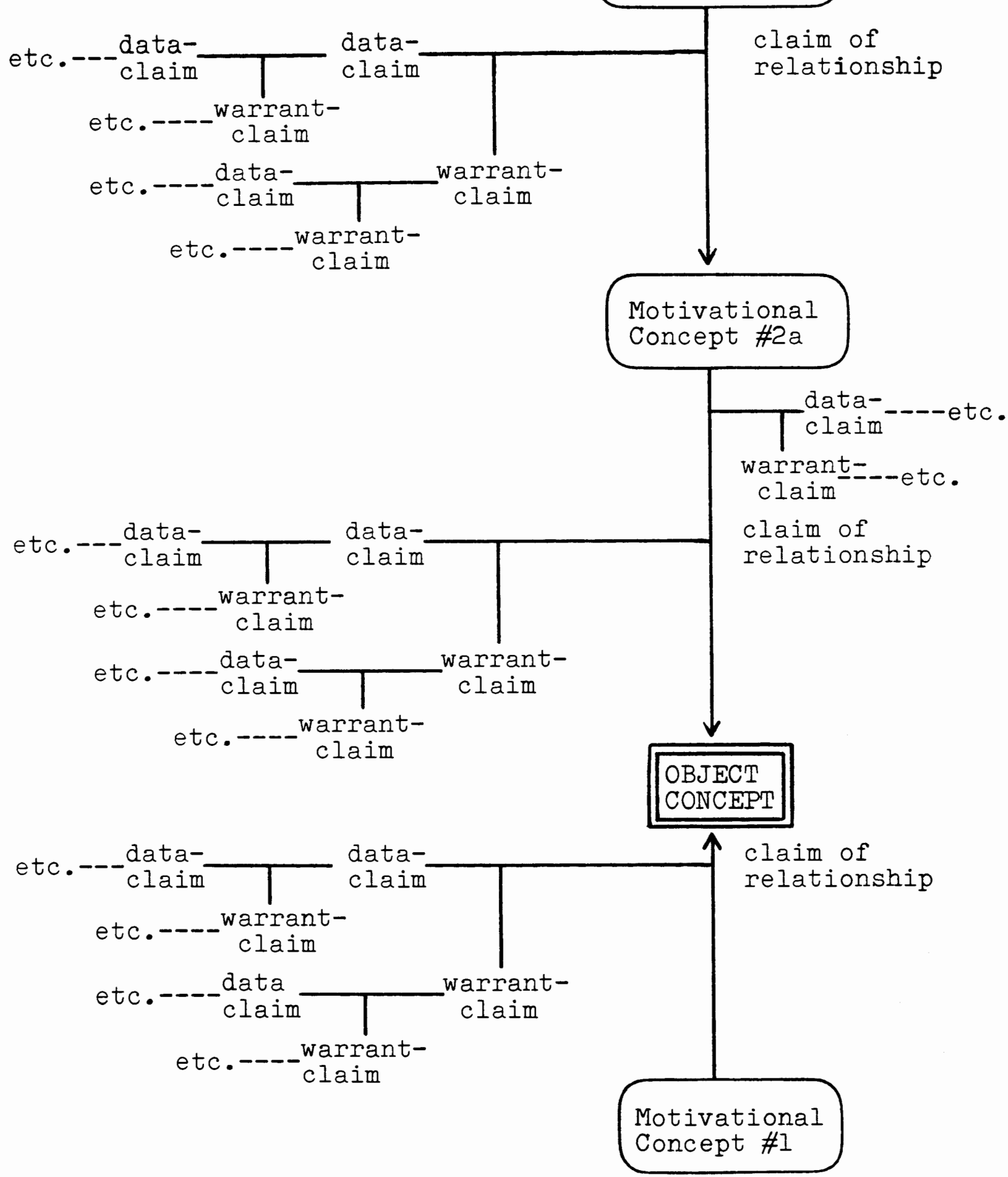

Figure 19. An extended Toulmin diagram proposed by Cronkhite as a model of persuasion and attitude change. 
To their credit, speech communication textbook writers who have proposed extended Toulmin diagrams by developing and specifying support for data may have increased the usefulness of the model by providing at least tentative solutions to some of the problems posed by critics of the Toulmin model. In addition, attempts by McCroskey and Cronkhite, among others, to find connections between Toulmin's approach and psychological theories current in speech communication are positive developments which may eventually result in a refinement of Toulmin's diagrammatic model. 92 On the other hand, it is not at all clear that the major modifications proposed by extenders of the Toulmin diagram have resulted in a conceptually superior, more candid or applicable model of argument. Some of the extensions are marked by a complexity which may threaten the comprehensibility and applicability of the model. Empirical investigation may be helpful in establishing the descriptive and predictive values of extended models which, on the surface, seem promising. 93

\section{TERMINOLOGY AND DEFINITIONS OF THE TOULMIN MODEL AS REPRESENTED IN SPEECH COMMUN ICATION TEXTBOOKS}

There are some significant differences in the terminology and definitions of the elements of variations of the Toulmin model presented in speech communication textbooks. Modifications of terminology and definitions may 
serve as an indication of which aspects of Toulmin's approach are maintained and which have undergone adjustment to the field of speech communication. While some subtle shifts of meaning or emphasis presented in a textbook or two may possibly indicate nothing more than the unique perspectives of individual authors, an overall pattern of change in the textbooks surveyed may signal the directions of theoretical development which the Toulmin approach is undergoing in the hands of speech communication professionals.

\section{Modified Terminology}

In general, the elements of the Toulmin model are identified either in the terms supplied by Toulmin or in those first used by Ehninger and Brockriede in the first edition of Decision by Debate. Twelve of the twenty-seven textbook editions surveyed were found to present roughly the same terminology introduced by Toulmin in The Uses of Argument while all the rest were found to use Ehninger and Brockriede's terminology or some combination of Toulmin's and Ehninger and Brockriede's terms. The definitions associated with these terms vary little with regard to claim, warrant, and qualifier but more frequently with regard to data or evidence, backing or support for warrant, and rebuttal or reservations. Of course, as discussed in the previous section, not all textbooks treat all of these 
elements. What differences appear to exist, and their consequences for the applicability of the Toulmin model, are discussed here.

As will be recalled, in The Uses of Argument Toulmin uses six terms to refer to the elements of his diagrammatic model: claim (C), data (D), warrant (W), qualifier (Q), rebuttal ( $R$ ), and backing ( $B$ ). Occasionally he uses other terms as if they are synonymous with these, for example, "conclusion" for C, "grounds" or "information" for D, "inference-license" for W, "probability term" and "modal qualifier" for $Q$, "conditions of exception" for $R$, and "assurances" or "grounds . . supporting a warrant" for B. 94 Ehninger and Brockriede first published their adaptation of the Toulmin model using Toulmin's terminology for each of the six elements of argument. 95 However, in Decision by Debate some substitute terms were introduced by these authors who explain their move in this manner:

We have departed in several instances from Toulmin's terminology in favor of traditional language. . . . [However] no traditional terms say gdequately what Toulmin means by warrant and claim. 96

Therefore, they maintained the terms warrant, claim, and qualifier while using "evidence" for D, "reservations" for $R$, and "support for warrant" for B. Presumably, these substitute terms are more widely recognized and understood within speech communication than Toulmin's originals. 
One wonders if Ehninger and Brockriede had motives other than their stated intention to preserve the more familiar traditional language. Their shift makes some sense in the case of substituting the term evidence for data. While evidence may have a somewhat broader meaning than implied by Toulmin's characterization of data as "statements of fact," the difference does not seem likely to affect the functional role of the element in the Toulmin model and, as Ehninger and Brockriede contend, evidence is perhaps better recognized in speech communication than data. 97 However, they must have had another reason for substituting the term "reservations" for rebuttal. Rebuttal is a term better known in speech communication than reservations, the meaning of which is less obvious. Perhaps these authors intended to avoid the confusion between this element of argument and that aspect of academic debate referred to by the term "rebuttal." Still, one wonders why they did not select one of Toulmin's substitute terms, namely, "conditions of exception" or even "exceptions," which seem to be clearer and more precise to this writer than the term reservations. Finally, as regards their term "support for warrant," one can only wonder how this is any more traditional or clearer than Toulmin's "backing."

Semantics aside, the adapted terminology of Fhninger and Brockriede is used as well by many other writers of 
speech communication textbooks. Nine textbook editions rely strictly upon Toulmin's terms while three others vary somewhat from Toulmin. 98 Seven textbook editions use only Ehninger and Brockriede's terminology. 99 Eight textbook editions are found to include some combination of Toulmin's, Ehninger and Brockriede's, and their own terminology. 100 Thus, the elements of the Toulmin model are referred to by various labels supposedly representing the same concepts. Despite the good intentions of Ehninger and Brockriede in using terms which are supposedly more traditional and clearer, the profusion of different terms used in various textbooks may create as many opportunities for confusion as for clarification. If the concepts to which the terms refer are indeed synonymous, then these alternative terminologies appear to be superfluous.

\section{Definitions of Elements}

More important than the terms used to label elements are the meanings for which they stand. Do variations in terminology also represent variations in the definitions and explanations of the elements of the Toulmin model? To find the answer to this question by surveying the content of textbooks is complicated by the differences in depth among the various treatments of the Toulmin model. A number of the textbooks considered here include only cursory definitions and explanations of the elements and their 
functions. Some of these textbook explanations of the elements of the Toulmin model are no longer than a paragraph or two while others only imply definitions through illustrations. 101 students and instructors in speech communication exposed to the Toulmin model only through such cursory textbook presentations must infer how elements may be distinguished and used in practice. Even textbooks which treat the Toulmin model at some length, for instance, Decision by Debate by Ehninger and Brockriede, often define each element differently depending upon which fieldinvarient form of argument it happens to be classifiable as. In spite of these complications, it is possible to assess the clarity and degree of unanimity of definitions for each of Toulmin's elements across textbooks.

Claim. In speech communication textbooks, a claim is generally defined as any assertion, proposition, statement, or conclusion in which a communicator wishes to induce belief, that is, to get an audience to accept as true. 102 While several authors conceive of claim as identical to the "conclusion" of a syllogism, Ehninger and Brockriede explicitly differentiate the two on the grounds that conclusions are the endpoints of an argument, but claims may serve as intermediate steps in a series of related units of proof which may lead to a final conclusion.103 What Ehninger and Brockriede imply about the 
role of claims in a lengthy argument, no other author explicitly denies: the Toulmin model is properly applicable to macro-arguments as well as micro-arguments. ${ }^{104}$ This position would appear to be a reasonable shift from Toulmin's apparent focus upon micro-arguments to include macro-arguments in that speech communication is more often than not concerned with lengthy argumentative discourse rather than the sentence-by-sentence structure of single arguments.

There are other minor variations among types of definitions and explanations offered of claim, but these appear to be of little consequence to the applicability of the Toulmin model to speech communication. 105

Qualifier. As with claims, there is apparently general agreement among speech communication textbook writers as to the definition and role of qualifiers. A qualifier is generally defined as a word or phrase which serves to limit the degree of force, cogency, certitude, reliability, strength, or probability of a claim. 106 However, there are variations in the expressed sources of qualification. Some writers identify the strength or probability of the warrant as the source of qualification of a claim. ${ }^{107}$ Others state that qualifiers are the result of qualified data or warrants. 108 
Arnold states that qualifiers are always the outgrowth of conditions of rebuttal. 109 Some writers discuss the persuasive value of including qualifiers in arguments. 110

The concept of qualified warrants and qualified data implied by some authors as the source of the qualifier of a claim raises the question of whether such subordinate qualifiers can usually be represented as independent elements of argument in an extended Toulmin diagram. No author says as much, but the potential value of such an extension is undetermined. Ill

In sum, while these differences in the assumed sources of qualification may be quite significant to the theoretical assumptions of Toulmin's approach particularly with regard to distinction between data and warrants, they appear to have little direct impact upon the function of qualifiers in the Toulmin model. Thus, it is judged that speech communication textbook writers agree as to the nature of qualifiers and the role they play in arguments. Warrant. There appears to be general agreement among authors of speech communication textbooks surveyed as to the nature of warrants and their function in arguments. Warrants are conceived as general, hypothetical statements which serve as justificatory links connecting data to claim. Some authors emphasize in their explanations that the warrant is the element most likely to be implied rather than explicitly stated in an argument. ${ }^{112}$ other 
than Condon and Yousif who liken them to value-orientations, warrants are frequently associated by textbook writers with assumptions held by an audience. ${ }^{113}$ As noted elsewhere, the field-dependent nature of the content of warrants is mentioned in only four textbooks. ${ }^{114}$ One textbook clearly introduces audience related standards as warrants. 115

Other than these differences and with the exception of some authors who apply the Toulmin model to field-invariant forms of argument, there appears to be considerable agreement about the nature of warrants. 116

Data or Evidence. In the matter of data, there is an important difference among authors, a difference which may be related to the shift in terminology introduced by Ehringer and Brockriede. Data, less carefully defined than other elements, are in general conceived as specific facts, opinions, reasons, or anything else given as "evidence" in support of some claim. ${ }^{117}$ Toulmin, Rieke, and Janik introduce the term "grounds" as a substitute for data, defining them as "statements specifying the particular facts about a situation relied on to clarify and make good the previous claims."1l8 However, all but one of the speech communication textbook writers who uses the term evidence and two of those presenting extended Toulmin diagrams who use the term data emphasize the relation of this element to audience beliefs. 119 That is, while all writers appear to agree that data are given as true, some place special 
emphasis on the notion that any information believed by an audience may serve as evidence (or data). In fact, Ehninger and Brockriede present only two conditions which a statement must meet in order to qualify as evidence: it "must be believed by the listener or reader" and "some principle of reasoning must warrant the connection between a bit of information and some claim."120 In other words, if an audience accepts it as true and if a warrant can be found to connect it to the claim, then it may be judged to be evidence. Thus, in general, writers employing the term data conceive of this element as consisting of statements of fact about a particular situation, while those employing the term evidence tend to emphasize the believability of such statements to the members of a particular audience.

Defining data primarily in terms of its believability to some audience may aggravate a problem alleged to exist by some critics of the Toulmin model: specifically, how data statements are to be differentiated from warrant statements. If a key characteristic of both data and warrant statements is, according to speech communication textbooks, that they must be believed by an audience, this differentiates them only from the claim and not from each other. To say that the warrant is a general statement connecting the data to a claim is helpful, but how different is this from the traditional distinction between major and minor premises of a syllogism ${ }^{121}$ It is possible that 
speech communication writers who define data in terms of audience believability are inadvertantly binding themselves to the traditional syllogistic categories while employing Toulmin's or, more frequently, Ehninger and Brockriede's terminology. The point is, a failure to distinguish the functions of data and warrant may result in an obscuring of the justificatory, certifying role of the warrant in argument. Unless both the relative, field-dependent nature of warrants and the established, factual, field-invariant nature of data statements can be maintained, the Toulmin model may lose its essential character. By defining data and warrant in such a way that both are dependent upon the particular beliefs of an audience, speech communication textbook writers present the Toulmin model as something of an elaborated syllogism, potentially with all of the trappings of absolutism, a geometric notion of validity and ambiguity in the functions of its parts.

In sum, these differences between the definitions of data and evidence presented in speech communication textbooks may be symptomatic of a distrust for or misunderstanding of some of the unique features of the Toulmin model in comparison to the syllogism. Or, as suggested previously, such differences may be a reflection of the different theoretical assumptions held by speech communication textbook writers. Whatever their source, these differences among definitions of data, subtle as they may be, 
are considered of serious consequence to the potential applicability of the Toulmin model in speech communication. Rebuttal or Reservations. Another of the unique features of the Toulmin model is the element termed rebuttal or reservations. There seems to be a concensus of opinion as to what the role of rebuttal in an argument is, but less agreement as to the proper conditions for its use. Rebuttals, it is generally agreed, have to do with the conditions or circumstances of exception to a claim. Several authors say nothing more about this element. ${ }^{122}$ Thus, it is possible for students or instructors using such textbooks to see rebuttals as anything from existing or potential counter arguments to specifications of the sources of qualification of a claim. Freeley's defirition hardly brings matters into any sharper focus by stating that "rebuttal (R) indicates exceptions, limitations, special conditions, counter argument or counter evidence which may refute the claim, discount it, or restrict or qualify it in some way."123 This definition leaves in doubt when a rebuttal is called for and when, if ever, it is not.

Several authors suggest the relationship between qualifier and rebuttal. ${ }^{124}$ Ehninger and Brockriede discuss three roles which reservations may play in an argument: they may eliminate the claim altogether, specify circumstances under which the claim would not hold, or specify circumstances which may affect the qualifier used in 
conjunction with the claim. ${ }^{125}$ To Ehninger and Brockriede, then, reservations are used only in certain special situations for rhetorical effect. Toulmin, Rieke, and Janik concur that rebuttals are used to indicate "extraordinary or exceptional circumstances" and present an even more limited view of when such rebuttals are properly used in argument. 126 These authors claim that rebuttals apply only in cases of presumptive argument. In other words, a rebuttal is not appropriate when the modal qualifier modifies the strength of a claim, as in the adjectives "certainly" and "probably," but is appropriate when the qualifier means that the claim is only so under certain conditions, as in "presumably" true. 127 This is a more exacting definition of the term rebuttal and the conditions for its use than is generally found in speech communication textbooks. In sum, rebuttals are less precisely defined in speech communication textbooks than other elements thus far considered. While some authors contend that they should be included, like qualifiers, for their persuasive support of a claim, others imply that they serve only to specify weaknesses in the claim, or even to eliminate all support for a claim. 128 This imprecision in definition leaves unsettled the issue or whether or not rebuttals can ever be used independently of qualifiers. Indeed, some definitions leave uncertain the distinctiveness of rebuttal and qualifier from each other. 
Backing or Support for Warrant. An imprecision similar to that in definitions of rebuttal occurs in definitions of backing and support for warrant making possible multiple interpretations of this element. Backing is termed by some textbook writers "support for warrant" and one writer, Scheidel, is satisfied to say nothing more about it. 129 Most writers describe backing as additional argument to help establish or make more credible the warrant itself. It is unclear whether such additional argument may consist of one item of data or several units of proof. 130 Ehninger and Brockriede in the first edition of Decision by Debate state that support for warrant may consist of a complete unit of proof, a group of acceptable standards for evaluating the warrant, or the assertion of a relation between a doubtful feature of the warrant with a valued concept or principle believed by listeners. ${ }^{131}$ Ehninger says virtually nothing about this element while, as noted previously, in the second edition of Decision by Debate Ehninger and Brockriede drop all references to support for warrant, replacing them with oblique references to shared "frame of reference" or common ground. 132 In other words, according to Ehninger and Brockriede, warrants are supported by audience-beliefs, established in previous units or circuits of proof. McCroskey expresses a similar view, arguing that prior arguments or chains of reasoning must be used to "verify" warrants. 133 
Toulmin, Rieke, and Janik present a more precise but limited view of backing than is found in other textbooks. They contend that backing consists of generalizations explicating the "body of experience relied on to establish the trustworthiness" of a warrant. ${ }^{134}$ Backing, they say, is used to demonstrate that the warrant, first of all, is sound or generally reliable and, second, is applicable to the case at hand. This explanation is unique in that it implies increasing generality as one moves from data to warrant to backing, and it introduces as a matter of backing the relevance of a warrant--a matter which Toulmin originally associated with rebuttal. Although it is difficult to determine exactly what some speech communication textbook writers believe backing to be, Toulmin, Rieke, and Janik's description appears to be significantly different from most. Diversity amongst speech communication textbook definitions of the elements of Toulmin's model may in part be due to the tendency of most writers to overlook his innovative theoretical bases and, consequently, the degree to which his perspective differs from the traditional approach of formal logic.

THE TOULMIN MODEL AS REPRESENTED BY ILLUSTRATIVE EXAMPLES IN SPEECH COMMTUN ICATION TEXTBOOKS

In addition to the theoretical explanations, diagrams, definitions, and terminology with which the Toulmin model is 
presented in speech communication textbooks, it is also illustrated by illustrative examples. These are of two kinds, invented and discursive. Invented examples are those apparently constructed by writers to demonstrate particular points. Included as invented examples are those which appear to be purely the products of creative imagination and those which appear to be based upon or adapted from some actual argumentative discourse which is not specifically cited. Discursive examples are those drawn directly from the texts of particular public speeches or published essays. 135

Of the textbook editions surveyed, twenty present invented examples while four present discursive examples. 136 Three other textbooks were found to include examples of each kind. 137 In general, the textbooks which include the greatest number of different illustrative examples are those which present several field-invariant forms of argument and provide at least one example per form represented. ${ }^{138}$ An exception to this is the textbook by Toulmin, Reike, and Janik which, while providing no diagrammed illustrations of field-invariant argument forms, includes far more illustrative examples than any other textbook examined. 139 However, nine of the textbooks examined were found to include no more than two illustrative examples of the Toulmin diagram. 140 speech communication textbook writers tend to favor invented over discursive examples and range from briefly illustrated to heavily illustrated. 
A comparison of examples from several different textbooks indicates the strengths and weaknesses of each type of illustrative example. Invented examples, like Toulmin's discussion of the case of Harry, the alleged Bermuda national, have the advantage of being clear and to the point. ${ }^{141}$ That is, they are constructed to fit the concept being illustrated. Several of the textbooks replicate Toulmin's examples or present close imitations of them. ${ }^{142}$ The disadvantage of invented examples is their artificiality: they are perhaps too neat and therefore atypical of real arguments encountered in discourse. For instance, Ehninger and Brockriede's example, shown in Figure 20, regarding the effects of an increase in the price of oil is so simple that it boggles the imagination to create a situation where such an assertion would be a matter for argument. ${ }^{143}$ The same criticism, of course, can be applied to almost any invented example. 


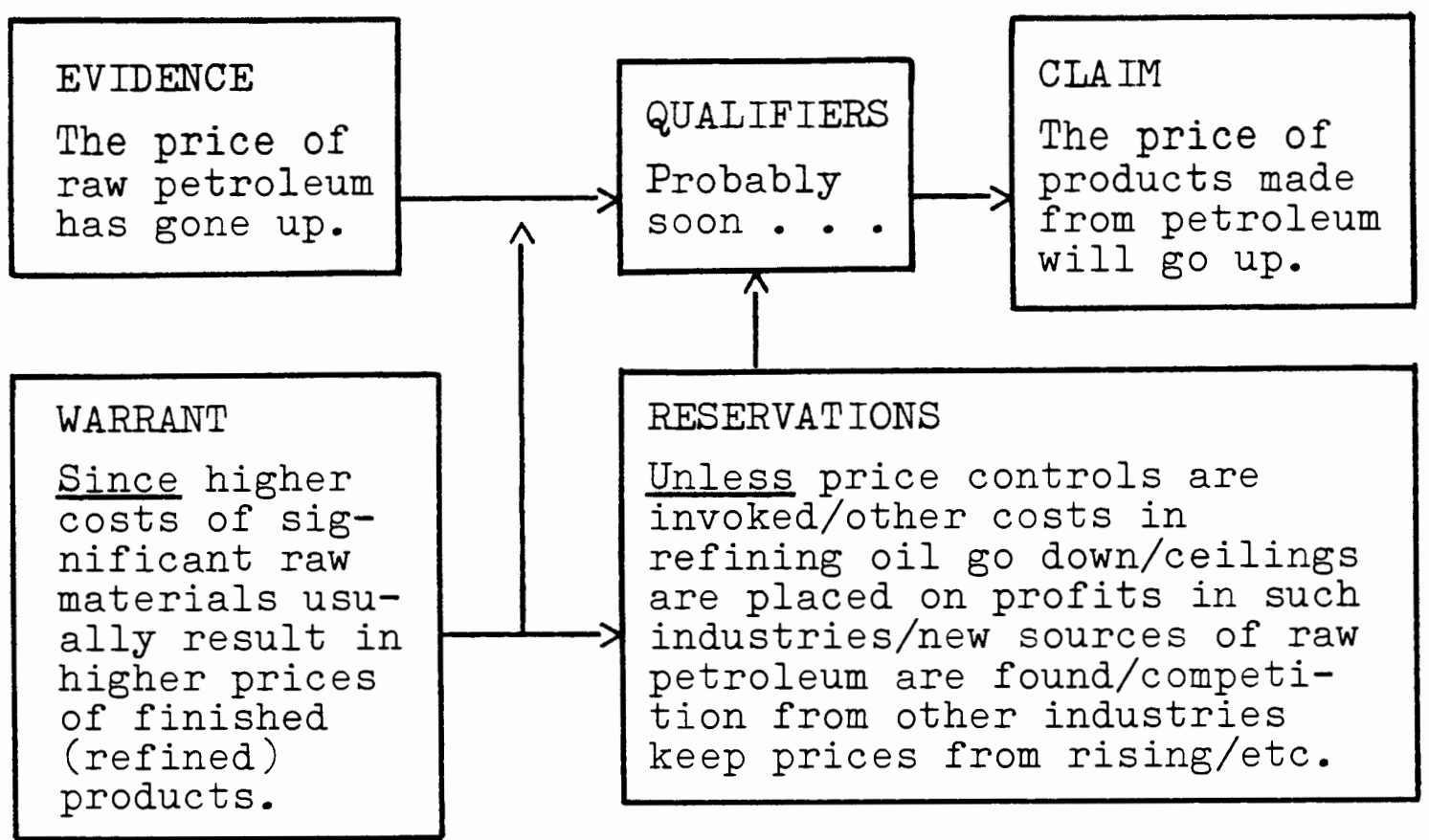

Figure 20. An illustrative example of the Toulmin model presented by Ehninger and Brockriede, 1978.

Discursive examples are rarely too simple and have the advantage of illustrating not just a completed Toulmin analysis, but also the difference between the argument as it appears in its actual context and as analyzed in terms of the Toulmin model. Frequently, translation and extrapolation of the actual text is required before analysis can begin; such hidden steps are usefully displayed by some authors using discursive examples. 144 on the other hand, such explanations may suffer from their length, complexity, and the fact that arguments in which all six elements of the Toulmin model are explicitly demonstrated are difficult to find. Because both kinds of illustrative examples 
appear to have inherent strengths and weaknesses, an ideal solution would be to include both in a textbook presentation. Yet, as noted before, few textbooks present such a combination of illustrative examples.

Another problem with examples worth noting in passing is the frequency with which invented examples mimic categorical syllogisms in their use of data and warrant. That is, they rely upon a generalization which resembles a major premise and a single datum which resembles a minor premise. Consider this solitary illustration of the Toulmin model of argument presented in a textbook by Bryant and Wallace, shown in Figure 21. Except for the inclusion of subsidiary elements, backing, reservation, and qualifier, this argument appears to have the form of a categorical syllogism. Similar quasi-syllogistic examples in which a general rule is used as warrant for drawing a conclusion based on a single datum may be discovered in nearly all of the textbooks in which invented examples are used to illustrate the Toulmin model. 
/E/ Prices are

going up

/R/ Rising prices are a sign of inflation

/B/ The more

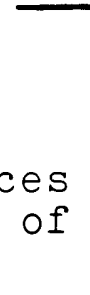

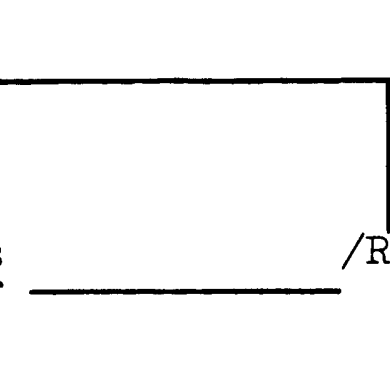

/Res/ Unless productivity keeps pace with price increases, etc.

/Q/ There is some danger of inflation

Professor $X$ says wages will continue to rise. Etc.

"R" represents "reasons" or warrants

Figure 21. An illustrative example of the Toulmin model presented by Bryant and Wallace.

Finally, there are some cases in which examples are offered that appear to be poorly conceived or in error in terms of the definitions of elements presented. For instance, Ehninger and Brockriede appear to go astray of their own general definitions of the elements of argument in their illustration of "classification" which appears in Figure 22. In discussing the characteristics of argument from classification, Ehninger and Brockriede assert that the evidence in a classification is a generalization. However, if one ignores that admonition and instead relies on their previously established definitions of the elements, then a different, significantly simpler analysis becomes possible to the effect that (E) Russia is a totalitarian state, since (W) a majority of totalitarian states can 
usually make fast crisis decisions, therefore, (C) Russia can [(Q) probably] make fast crisis decisions. In order to make their example fit their theoretical category, Ehninger and Brockriede have apparently confused $E$ with $S$ for $W$, and W with E. Rieke and Sillars appear to have similar problems with an illustrative example, as do Toulmin, Rieke, and Janik in their handling of questions of law. 146
(E) A majority of totalitarian states can usually make fast crisis decisions.
Therefore, (C) Russia can [(Q) probably] make fast crisis decisions.

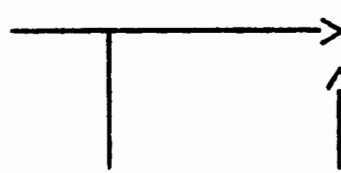
$\hat{\imath}$

Since (W) what is usually-Unless (R) Russia does true of a majority of totalitarian states is probably true of a partic- decisions. ular totalitarian state, viz. Russia. not share the attribute of making fast crisis<smiles>C=C</smiles>

Because ( $S$ for W) Russia is a totalitarian state/ the totalitarian class is reasonably homogeneous and its attributes relatively stable and predictable.

Figure 22. An illustrative example of the Toulmin model presented by Ehninger and Brockriede, 1963.

In short, there appear to be weaknesses in illustrative examples used in textbook presentations of the Toulmin model. 


\section{DISCUSSION OF THE SYLIOGISM IN SPEECH COMMUN ICATION TEXTBOOKS PRESENT ING THE TOULMIN MODEL}

One of the issues raised by critics of the Toulmin model and discussed in chapter III is whether the Toulmin model constitutes an adequate substitute for the syllogism as a structure useful in the analysis of arguments. Whether the Toulmin model is best conceived as an alternative or complement to the syllogism is, as yet, an unresolved matter. However, speech communication textbook writers imply their positions on this point by their treatment or omission of the syllogism in conjunction with their discussion of the Toulmin model of argument.

In general, the Toulmin model is just as likely to be presented in conjunction with an exposition of the syllogism as it is in isolation. Ironically, among textbooks in oral communication, there are some which purport to present concepts from our rhetorical heritage, such as the one by Wilson and Arnold, in which the Toulmin model has apparently replaced the syllogism, while other textbooks claiming a concern for more modern perspectives, such as Scheidel's, compare the Toulmin model with the syllogism and note the benefits and costs of each approach. 147 Thus, it is not simply a matter of historically-minded authors featuring the Toulmin model, as one might expect. 
Similarly, authors of argumentation and debate textbooks are far from unanimous in their treatment of the categorical syllogism in conjunction with the Toulmin model. For instance, in their pioneering article in which they introduced the Toulmin model to speech communication, Brockriede and Ehninger reflect much of the tone and content of The Uses of Argument, including a favorable comparison of the Toulmin model to the syllogism. ${ }^{148}$ However, by the time their first textbook was published three years later, Ehninger and Brockriede apparently no longer felt any need to justify their preference for the Toulmin model in that they chose to include only the slightest reference to "the rules, moods, and figures of syllogisms. "149, These authors and, incidentally, Toulmin in collaboration with others have removed the syllogism entirely from consideration in recent publications. ${ }^{150}$ Mills in the first edition of Reason in Controversy takes a similar course and presents only the Toulmin model as interpreted by Hastings. ${ }^{151}$ For reasons not at all clear, Mills dropped the chapter by Hastings for his second edition, severely shortening the discussion of the Toulmin model, while at the same time redeeming the syllogism. ${ }^{152}$ Like Mills, Freeley has updated his widely-used textbook to include both the syllogism and Toulmin's model. ${ }^{153}$ Both models are also presented in two other recent textbooks, one by Rieke and Sillars, the other edited by Miller and Nilsen. 154 
Nothing in the preceeding discussion should suggest that those textbooks which treat both the syllogism and the Toulmin model are superior to those in which only the Toulmin model is discussed. What can be inferred from the variety of approaches to the Toulmin model regardless of the general purposes of given textbooks, is that some authors present the Toulmin model as a self-sufficient approach to the analysis of arguments while, in contrast, others present it in conjunction with the categorical syllogism, perhaps implying more clearly the developing nature of the theory of argument. 155 Thus, these speech communication textbook writers appear by their discussions of the Toulmin model and the syllogism to be ambivalent or in disagreement as to the status of each model in speech communication.

\section{SUMMARY}

Five aspects of textbook representations of the Toulmin model were examined in this chapter: (1) theoretical bases, (2) diagrammatic models, (3) terminology and definitions, (4) illustrative examples, and (5) discussions of the syllogism.

With regard to innovative theoretical bases of the Toulmin approach, there appear to be differences between the extent to which they are treated in textbooks devoted to oral communication as opposed to textbooks devoted to 
argumentation and debate. In general, oral communication textbooks tend to overlook the field-dependent sources of soundness, the probable nature of substantive claims, and the relativistic assumptions about the nature of argument on which the Toulmin model is based. On the other hand, argumentation and debate textbooks more frequently attend to these features although only three can fairly be credited with giving some recognition to all three concepts. 156 The most complete treatment of Toulmin's theoretical bases is found in a textbook coauthored by Toulmin himself. 157 Thus, the influence of Toulmin's innovative theoretical bases on speech communication textbook writers is far from overwhelming and definitely not uniform. Whether this indicates that speech communication professionals by and large reject Toulmin's overall approach, fail to understand it, or simply find it easier to adapt it to their own purposes remains unclear.

There is, a great deal of variety found in diagrammatic representations of the Toulmin model in speech communication textbooks. While few textbooks replicate the original six-part model presented by Toulmin in The Uses of Argument, most textbooks offer modified diagrams, ranging from the overly simple, which seem to obliterate all that differentiates the Toulmin model from the syllogism, to the incredibly complex which seem difficult to comprehend and apply. Several of the extended diagrams 
presented involve some expansion of the data element through the explication of multiple data, chains of argument, or the addition of an element representing support for data. However, if any single adaptation or modification of the Toulmin model is gaining in popularity or authority, it is not apparent from the textbooks examined for this study. What is perhaps most surprising is that in spite of all this diversity of interpretations, modification, and development, all of these diagrammatic models are associated with Toulmin.

The terminology and definitions of the elements of the Toulmin model as presented in speech communication textbooks indicate several things. First, the modified terminology introduced by Ehninger and Brockriede, while it has gained some degree of popularity, appears to be superfluous, potentially confusing, and probably related to differences among authors in the definition of data. Second, despite other differences, there appears to be general agreement among textbook writers as to the nature of and roles of each of three elements, claim, warrant, and qualifier. Third, speech communication writers agree on the applicability of the Toulmin model to macro-arguments and that the standards of argument are a reflection of the audience to whom a claim is addressed and are not necessarily dependent upon established fields of argument. Fourth, rebuttals and backing are less precisely defined by nearly all speech 
communication textbook writers than are the other elements of the Toulmin model. This may explain why some authors choose to omit these elements from their diagrammatic models. The variety of interpretations of some elements seems to indicate that the Toulmin model is being adapted and developed by speech communication textbook writers in a number of different ways. As in the case of diagrammatic representations, the differences among definitions and terms do not appear to be convergent.

Of illustrative examples used in textbook presentations of the Toulmin model, it may be concluded that the tendency of most writers to favor invented examples over discursive ones has led to some problems. First, many invented examples illustrate arguments with primary elements which resemble syllogistic premises, perhaps obscuring some of the unique features of the Toulmin approach. Second, some invented examples appear to have errors in them which may be the result of too much attention to theoretical categories and interests of textbook writers and too little attention to arguments as they occur in practical situations. This is not to suggest that most textbook writers distort or confuse the Toulmin model in their examples, but only that there are inconsistencies presented in some textbooks which may be attributable to an inattention to discursive examples. Ideally, both discursive and invented examples would be used in a presentation of the Toulmin model. 
Finally, it is noted that some authors present the Toulmin model in conjunction with a discussion of the syllogism while others present the Toulmin model in isolation. This is further evidence of a problem suggested by some of the criticisms of the Toulmin model discussed in chapter III, to the effect that the nature of the relationship between the two models, whether alternative or complementary, is as yet undetermined.

In short, the Toulmin approach is diversely interpreted in speech communication textbooks and, in some cases, there appears to be confusion regarding some innovative features of the Toulmin model. This diversity and confusion may be related to the hypothesized conflict of theoretical perspectives between formal logicians and Toulmin. Speech communication writers draw theories, models, and methodologies from many other disciplines apparently with little regard for their associated theoretical perspectives. Accordingly, concepts drawn from alternative theoretical perspectives including "linear" and "systems" may be freely interpreted and presented as if compatible, while their inconsistent assumptions and aims are not examined. Thus, the eclectic nature of speech communication may be a contributing factor to the diversity of interpretations of the Toulmin approach. 
The various interpretations of the Toulmin model has led to a variety of suggested applications by the writers of speech communication textbooks. These are discussed in chapter V. 
${ }^{1} u_{\text {ses }}$, p. 8, 14-15, 37-38, 40, 212, 218, 257. See also, McKerrow in Proceedings . . , eds. Rhodes and Newell, p. $401 f$.

${ }^{2}$ Erwin Bettinghaus, Message Preparation: The Nature of Proof (Indianapolis: The Bobbs-Merrill Co., 1966); Jane Blankenship, Public Speaking: A Rhetorical Perspective, 2nd ed. (Englewood Cliffs: Prentice-Hall, Inc., 1972); Cassandra Book et al., Human Communication: Principles, Contexts, and Skil Is (New York: St. Martin's Press, Inc., 1980); Bert Bradley, Fundamentals of Speech Communication: The Credibility of Ideas, 2nd ed. (Dubuque: Wm. C. Brown Co. Pub., 1978); Donald Bryant and Karl Wallace, Fundamentals of Public Speaking, 4th ed. (New York: Appleton-Century-Crofts, 1969); Wayne Minnick, The Art of Persuasion, 2nd ed. (Boston: Houghton Mifflin Co., 1968); James McCroskey, An Introduction to Rhetorical Communication, 2nd ed. (Englewood Cliffs: Prentice-Hall, Inc., 1972); Thomas Scheidel, Persuasive Speaking (Indianapolis: The Bobbs-Merrill Co., 1967); Speech Communication and Human Interaction (Glenview: Scott, Foresman and Co., 1972); Walter Terris, Content and Organization of Speeches

(Dubuque: Wm. C. Brown Co. Pub., 1968); John Wilson and Carroll Arnold, Public Speaking as a liberal Art, lst-4th eds. (Boston: Allyn and Bacon, Inc., 1964, 1968, 1974, 1978); Rudolph Verdeber, The Challenge of Effective Speaking, 3rd ed. (Belmont: Wadsworth Pub. Co., 1976).

${ }^{3}$ See for instance, Book et al., pp. 85-86.

${ }^{4}$ Erwin Bettinghaus, in Perspectives on Argumentation, eds. Gerald Miller and Thomas Nilsen (Chicago: Scott, Foresman and Co., 1966); Douglas Ehninger and Wayne Brockriede, Decision by Debate (New York: Dodd, Mead and Company, Inc., 1963); Decision by Debate, 2nd ed. (New York: Harper and Row, Pub., 1978); Douglas Ehninger, Influence, Belief, and Argument: An Introduction to Responsible Persuasion (Glenview: Scott, Foresman and Co., 1974); Arthur Hastings, in Reason in Controversy, by Gien Mills (Boston: Allyn and Bacon, Inc., 1964); Gien Mills, Reason in Controversy, 2nd ed. (Boston: Allyn and Bacon, Inc., 1968); Richard Rieke and Malcolm Sillars, Argumentation and the Decision Making Process (New York: John Wiley and Sons, Inc., 1974); Stephen Toulmin, Richard Rieke, and Allan Janik, An Introduction to Reasoning (New York: Macmillan Pub. Co., Inc., 1979); Russell Windes and Arthur Hastings, Argumentation and Advocacy (New York: Random House, Inc., 1965).

5 Windes and Hastings, pp. 105-150. 
Ehninger and Brockriede, Decision by Debate, 2nd ed., pp. 91-92. This text is hereafter referred to in notes as "Ehninger and Brockriede, 2nd ed."

7 Rieke and Sillars, p. 17, 229-301.

8 Reasoning, pp. 14-16, 195-337.

9 Ehninger and Brockriede, lst ed., pp. 98-99, 101 , 105-106; Hastings in Mills, Reason in Controversy, pp. 125148 (hereafter referred to in notes as "Hastings in Mills, lst ed."); Mills, Reason in Controversy, 2nd ed., p. 16, 110-111, 184-185" (hereafter referred to in notes as "Mills, 2nd ed."); Bettinghaus in Perspectives on Argumentation, eds. Miller and Nilsen, pp. 146-155 (hereafter referred to in notes and text as "Bettinghaus in Miller and Nilsen"); and Austin J. Freeley, Argumentation and Debate, 3rd ed. (Belmont: Wadsworth Publishing Co. Inc., 1971), 142-147.

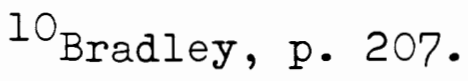

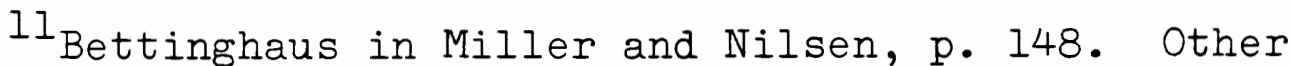
authors lend support to this position; see Arnold, p. 50, and David Shepard, "Rhetoric and Formal Logic," WS, No. 4 (Fall, 1966), 241-247. p. 61 .

12 Bettinghaus in Miller and Nilsen, p. 147; Arnold,

13 Scheidel, Persuasive Speaking, p. 39; Speech Communication in Human Interaction, pp. 206-207 (hereafter referred to in notes as "Scheidel, Human Interaction").

${ }^{14}$ Book et al., p. 77 ; there is no explanation of the mechanics of this procedure of analysis which assumes the standards of argument to depend in some way upon the beliefs of individual lay-persons.

${ }^{15}$ Arnold, p. 54.

16 One wonders if Toulmin would be more inclined to consider this a distortion of his approach.

17 Toulmin, Human Understanding, p. 67; see also emerging process perspectives on argumentation represented by any of the essays of Charles Willard already cited.

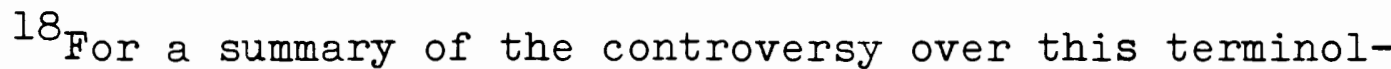
ogy of argumentation and rhetoric, see Joseph Wenzel, "Perspectives on Argument," in Proceedings . . . . , eds. Rhodes and Newell, pp. 112-113. 
${ }^{19}$ Rieke and Sillars, p. 19.

20 Ehninger and Brockriede, 2nd ed., pp. 92-95.

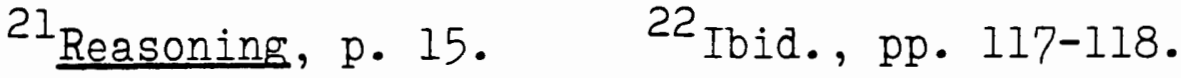

${ }^{23}$ See chapter II, especially p. 45 and pp. 53-54.

24 Bradley, p. 207.

25McCroskey, pp. 83-87; Terris, pp. 28-33; Verdeber, pp. 185-186; Wilson and Arnold, lst ed., p. 139 .

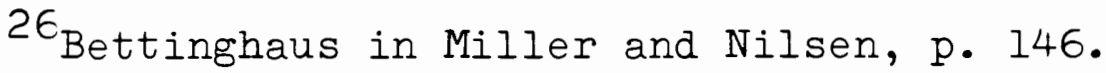

27 Windes and Hastings, p. 159.

28 Freeley, p. 143, 144.

29 Uses (on probability), pp. 44-93, 100-102, 151-154, $169-177, \frac{188-210 ;}{18}$ (on layout of arguments), pp. 94-145, 175, 184.

30 According to Brockriede and Ehninger, among the advantages of the Toulmin model is that is provides for "the establishment of claims which are no more than probable." "Toulmin on Argument: An Interpretation and Application," QJS, 46, No. 1 (February, 1960), 46. Yet this point was subsequently omitted from Enninger and Brockriede, lst ed.; their simplified list of the advantages of the Toulmin model does not mention probability, pp. 98-99.

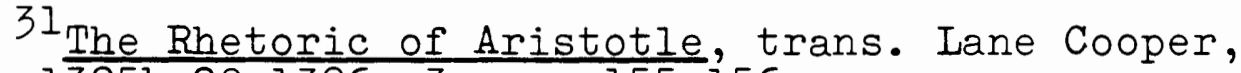
II.22, 1395b.20-1396a.3, pp. 155-156. p. 84 .

${ }^{32}$ Scheidel, Persuasive Speaking, p. 28; McCroskey,

33 Scheidel, Human Interaction, p. 206.

34 Brockriede and Ehninger, "Toulmin on Argument," p. 46 .

35 Ehninger and Brockriede, 2nd ed., pp. 27-30.

36 Rieke and Sillars, pp. 15-16, 76, 266-270.

37 Reasoning, pp. 127-135.

38 See for instance, Bettinghaus in Miller and Nilsen, p. 147. 
39Mills, 2nd ed., pp. 110-111, 184-185; Freeley, pp. 142-147.

${ }^{40}$ Condon and Yousif, pp. 214-231; personal communication with Condon, Portland State University, 12 November 1977.

${ }^{41}$ Bettinghaus, pp. 108-110; Bettinghaus in Miller and Nilsen, p. 148; Freeley, p. 144.

42 Uses, pp. 94-145.

${ }^{43}$ Arrold, pp. 51-52; Gulley, pp. 114-116.

${ }^{44}$ Bradley, pp. 200-2ll; Bryant and Wallace, p. 360; Minnick, p. 146; Scheidel, Persuasive Speaking, p. 36; Human Interaction, p. 205; Ehninger and Brockriede, lst ed., p. 107; Hastings in Mills, p. 127; Mills, 2nd ed., p. 1ll; Reasoning, p. 78; Bettinghaus in Miller and Nilsen, p. 148; Freeley, p. 144; Arnold, p. 51; Golden et al., p. 176; Gulley, p. 116 .

45 Truncated: Blankenship, p. 179; Terris, p. 31 ; Wilson and Arnold, lst ed., p. 139; Verdeber, p. 186; Ehninger and Brockriede, 2nd ed., p. 47; Ehninger, p. 14 ; Windes and Hastings, p. 158; Extended: Bettinghaus, p. 109, Book et al., pp. 87-88, 90-91; Rieke and Sillars, p. 77 .

${ }^{46}$ Cronkhite, pp. 84-88; Condon and Yousif, pp. 214218; McCroskey, pp. 87-88.

47 Brockriede and Ehninger, "Toulmin on Argument," p. 45; Ehninger and Brockriede, lst ed., p. 107.

48 Bryant and Wallace, pp. 359-360; Minnick, p. 148 ; Bettinghaus in Miller and Nilsen, p. 148; Freeley, pp. 144147; Hastings in Mills, p. 127.

${ }^{49}$ Hastings in Mills, p. 127.

50 Mills, 2nd ed., pp. 110-11l.

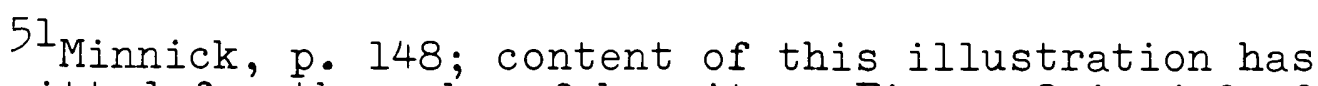
been omitted for the sake of brevity. Figure 8 is judged to constitute a standard diagram because, while it is not illustrated, the qualifier is emphasized in Minnick's discussion.

52 Reasoning, p. 78. 
${ }^{53}$ Reasoning, p. 76.

${ }^{54}$ McCroskey, pp. 105-108; Ehninger and Brockriede, 2nd ed., pp. 44-46.

55 Uses, pp. 99-100. $\quad 56$ Ibid., p. 99.
57 Ibid., p. 104.

58 Bettinghaus in Miller and Nilsen, p. 148. See also a similar arrow in Toulmin, Rieke, and Janik's diagrammatic model illustrated in Figure 9.

59 Freeley, p. 144; content of this illustration has been omitted for the sake of brevity.

60 Blankenship, p. 176.

$6_{\text {See Uses, }}$ pp. 97-104.

62 Bradley, p. 208; content of this illustration has been omitted for the sake of brevity.

63Verdeber, pp. 185-186; Windes and Hastings, pp. 157158. This characterization appears in Brockriede and Ehninger, "Toulmin on Argument," p. 53.

${ }^{64}$ Cronkhite, p. 85.

${ }^{65}$ Wilson and Arnold, lst ed.,p. 28; Ehninger, pp. 1314.

66 Terris, pp. 28-33. $\quad 67$ McCroskey, p. 88.

${ }^{68}$ Condon and Yousif, pp. 214-218.

69 Wilson and Arnold, 4th ed., pp. 131-138; Ehninger and Brockriede, 2nd ed., pp. 40-47; Blankenship, pp. 177-178.

70 Wilson and Arnold, 1st ed., pp. 139-142; 2nd ed., pp. 154-159; 3rd ed., pp. 113-117; 4th ed., pp. 131-138.

${ }^{71}$ Ehninger and Brockriede, 2nd ed., p. 47; content of this illustration has been omitted for the sake of brevity.

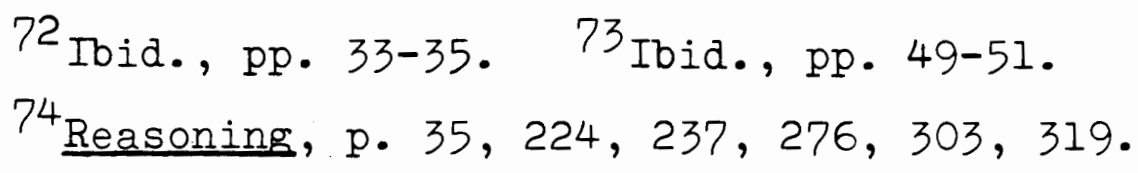


75 Bettinghaus, p. 104, 109; Book et al., p. 79, 8691.

76 The "deductive pattern" is exactly as represented in Bettinghaus, p. 109; the "inductive pattern" is exactly as represented in Book et al., p. 91. Differences between the diagrams in these two textbooks are so slight that one suspects they may be due only to printer's errors.

77 Bettinghaus, p. 109.

78 Ehninger and Brockriede, 1st ed., pp. 234-240; 2nd ed., pp. 188-191; Reasoning, p. 238; Cronkhite, p. 87; Book et al., p. 87; Rieke and Sillars, pp. 87-88.

79 Ehninger and Brockriede, 2nd ed., p. 34.

80 Ehninger and Brockriede, Ist ed., p. 234. (In their 2nd edition diagrams presented are identical except for the exclusion of "support for warrant.")

${ }^{81}$ It should be noted that special procedures for dealing with chains of inference not subject to analysis with a single syllogism have been developed by formal logicians. Termed "sorites," these chains of reasoning may consist of any number of premises and be expressed enthymematically, resulting in a complexity which makes analysis a more involved process. See Copi, pp. 228-231, for a description of analysis procedures used in dealing with sorites.

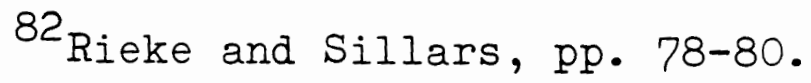

${ }^{83}$ Condon and Yousif, p. 216.

${ }^{84}$ See Trent, Heidt, and Francis Gibson, "The Nature and Elements of Reasoning," in Critical Inquiry and Speech Communication, manuscript (Portland State University, 1975).

85 McCroskey, p. 84. ${ }^{86}$ Ibid., pp. 100-101.

87 McCroskey, "Toulmin and the Basic Courses," ST, 14, No. 2 (March, 1965), 91-100.

88 McCroskey, p. 84. ${ }^{89}$ Cronkhite, p. 45.

90 Ibid., pp. 85-87; Cronkhite's "object concept" and "motivational concept" correspond to Fishbein's "attitude concept" and "motivational stimulus," respectively. 
${ }^{91}$ Cronkhite, pp. 88-91.

92 Gary D'Angelo, "A Schema for the Utilization of Attitude Theory Within the Toulmin Model of Argument," CSSJ, 22 (Summer, 1971), 100-109; Bae Keun Cha, "The Toulmin Model of Argument and Cognitive Consistency: A Search for the Foundations of Logical Proof," Ph.D. dissertation (Kent State University, 1972).

93 Bettinghaus in Miller and Nilsen, p. 148. ${ }^{94}{ }_{\text {Uses }}$, p. $97 ; 11,101,127-128 ; 98,112 ; 92,101$; 103,112 . p. 46 .

${ }^{95}$ Brockriede and Ehninger, "Toulmin on Argument,"

96 Ehninger and Brockriede, lst ed., p. 99.

97 The term "evidence" does not appear to be any more precise than the term "data"; thus it fails to answer any of the critics' criticisms of this element discussed in chapter III.

$98_{\text {Book et al., pp. 78-89; Scheidel, Persuasive }}$ Speaking, p. 36; Terris, pp. 28-33; Wilson and Arnold, Ist ed., p. 139; Arnold, p. 51; Cronkhite, p. 45; Brockriede and Ehninger in Golden et al., p. 176; Hastings in Mills, pp. 126-127; Freeley, p. 143; Condon and Yousif, p. 214, 217 ; Verdeber, pp. 185-186; Reasoning, p. 78 .

99 Ehninger and Brockriede, 1st ed., p. 107; 2nd ed., p. 47; Ehninger, p. 14; Rieke and Sillars, pp. 77-78; Bettinghaus, pp. 149-151; Blankenship, pp. 170-171, 178179; Minnick, p. 146.

100 Bradley, pp. 208-211; McCroskey, pp. 84-87; Scheidel, Human Interaction, p. 205; Gulley, pp. 114-il6; Milis, 2nd ed., p. Ill; Bryant and Wallace, p. 360; Windes and Hastings, pp. 157-159.

${ }^{101}$ See for example Blankenship, pp. 170-171; Bryant and Wallace, p. 360; Minnick, p. 146; Scheidel, Persuasive Speaking, p. 36; Human Interaction, pp. 204-205; Arnold, pp. 51-52; Freeley, p. 143; Verdeber, pp. 185-186; Wilson, and Arnold, lst ed., p. 139.

102 Bettinghaus, pp. 104-105; Book et al., pp. 78-79; Ehninger, p. Il; Ehninger and Brockriede, 2nd'ed., pp. 404l; Bettinghaus in Miller and Nilsen, p. 179; Rieke and Sillars, p. 77; Reasoning, pp. 30-32. 
103 Blankenship, pp. 170-171; Bryant and Wallace, p. 360; Wilson and Arnold, lst ed., p. 139; Brockriede and Ehninger in Golden et al., p. 176; Ehninger and Brockriede, lst ed., p. 99; 2nd ed., pp. 40-4i.

104 Bettinghaus in Miller and Nilsen, p. 148, suggests that this is a major shift from Toulmin's approach. See also Bettinghaus, p. 105.

105 Some books define claims purely in terms of linguistic factors having to do with the relationship of statements to their referential realities, others in terms of their audience-belief functions. See Bradley, pp. 208209; Book et al., pp. 78-79; Bettinghaus, pp. 104-105; Wilson and Arnold, lst ed., p. 139; and Arnold, pp. 51-52.

106 For typical examples, see Book et al., pp. 87-89; Ehninger and Brockriede, Ist ed., pp. 106-107; 2nd ed., p. 46; Arnold, p. 52.

107Freeley, p. 143; Gulley, p. 115; Book et al., pp. 87-89.

108 Ehninger and Brockriede, Ist ed., pp. 106-107; 2nd ed., p. 46; Bradley, p. 210; Reasoning, pp. 69-75; Toulmin, Rieke, and Janik view modal as always present but not always explicit in argument.

\section{${ }^{109}$ Arnold, p. 52.}

110 See for example, Bettinghaus in Miller and Nilsen, p. 151; and Bettinghaus, pp. 107-108.

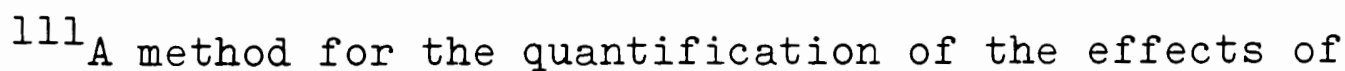
such qualifiers has been suggested; see Michael Sproule, "Assessing Validity in Rhetorical Argument: A Definition and Application," paper presented at the Speech Communication Association convention, December, 1975 (ERIC \#EDI19249). See also John Reinard and Rodney Reynolds, "An Experimental Study of the Effects of Toulmin's Pattern for Argument Development on Attitude Change," paper presented at the Western Speech Communication Association convention, San Francisco, November, 1976, and the article by Feezel, already cited.

112 See for example Hastings in Mills, p. 126; Book et al., pp. 84-85; Verdeber, pp. 185-186.

113 Bettinghaus, pp. 105-106; Book et al., pp. 84-85; McCroskey, p. 85. 
114 Ehninger and Brockriede, 2nd ed.; Rieke and

Sillars; Reasoning; Brockriede and Ehninger in Golden et al.

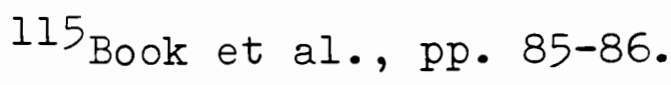

116 There are differences in the manner in which warrants are phrased by various authors who apply the Toulmin model to field-invariant forms of argument. See chapter V.

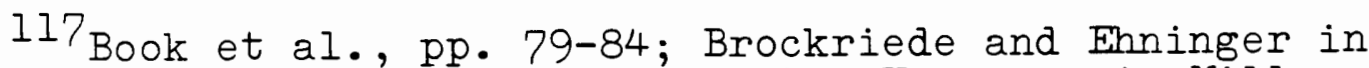
Golden et al., p. 176; Freeley, p. 143; Hastings in Mills, p. 126; Verdeber, pp. 185-186; and Scheidel, Persuasive Speaking, p. 36.

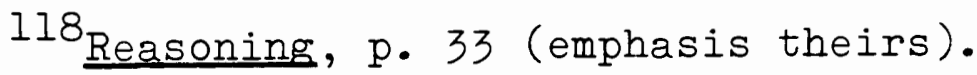

119 Bettinghaus, p. 104 , is the exception; McCroskey, pp. 85-86, Rieke and Sillars, p. 77, are the extenders.

120 Ehninger and Brockriede, lst ed., pp. 99-100.

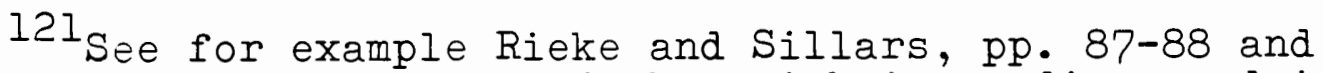
compare to the definitions of the epicheireme discussed in chapter II.

122 Blankenship, pp. 178-179; Scheidel, Persuasive Speaking, p. 36; Book et al., pp. 87-89; Minnick, p. 146; Wilson and Arnold, 3rd ed., p. 114; Rieke and Sillars, p. 78; Bradley, p. 210 .

123 Freeley, p. 143.

124 Arnold, pp. 51-52; Brockriede and Ehninger in Golden et al., p. 176; Ehninger and Brockriede, lst ed., p. 106; 2nd ed., pp. 44-46; Reasoning, pp. 75-78.

125 Ehninger and Brockriede, lst ed., p. 106; 2nd ed., pp. 45-46.

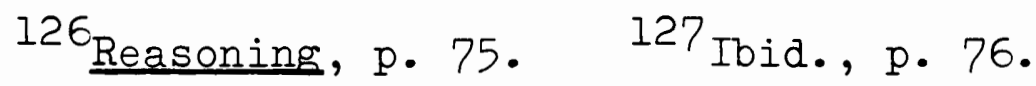

128 Minnick, p. 146; Bryant and Wallace, p. 360 ; McCroskey, pp. 86-87; Bettinghaus in Miller and Nilsen, p. 151 .

${ }^{129}$ Scheidel, Human Interaction, p. 204.

130 Brockriede and Ehninger in Golden et al., p. 176; Minnick, p. 146; Freeley, p. 143. 


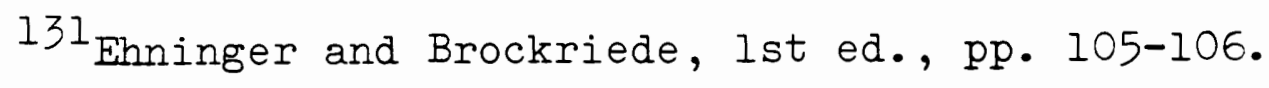
p. 25.

132 Ehninger, p. 14; Ehninger and Brockriede, 2nd ed.,

133 Mc Croskey, pp. 99-100.

${ }^{134}$ Reasoning, pp. 57-58.

135 Several textbooks, for instance Reasoning and Ehninger, include discursive examples as exercises for practice but do not present completed Toulmin diagrammatic analyses of these discursive examples.

$136_{\text {For }}$ invented examples only, see Bettinghaus; Book et al.; Bryant and Wallace; McCroskey, Scheidel, Persuasive Speaking and Human Interaction; Terris; Cronkhite; Brockriede and Ehninger in Golden et al.; Gulley; Verdeber; Ehninger and Brockriede, lst and 2nd eds.; Ehninger; Hastings in Mills; Mills, 2nd ed.; Windes and Hastings; Reasoning; Bettinghaus in Miller and Nilsen; Freeley. For discursive examples, see Blankenship; Minnick; Wilson and Arnold; Arnold.

137 For textbooks presenting both kinds of illustrative examples, see Rieke and Sillars; Condon and Yousif; Bradley. Textbooks by Toulmin, Rieke, and Janik, and Bettinghaus both include some illustrative examples which resemble discursive examples but neither provides adequate citations; therefore, these textbooks are listed with those which include only invented examples.

138 Ehninger and Brockriede, lst and 2nd ed.;

McCroskey; Book et al.; Rieke and Sillars; Blankenship;

Bradley; Bettinghaus; Verdeber; Hastings in Mills; Windes and Hastings. See chapter V.

${ }^{139}$ See Reasoning, p. 35, 46-52, 59-61, 72, 77-78, 87$89,159-161, \frac{164,177}{164} 276,274,280,301,303,315,317$, $319,321,324,328,329$.

${ }^{140}$ Condon and Yousif, p. 323; Bettinghaus in Miller and Nilsen, pp. 151-153; Terris, pp. 28-33; Gulley, pp. 114117; Scheidel, Persuasive Speaking, pp. 36-37; Human Interaction, p. 205; Wilson and Arnold, lst ed., pp. 138-142; 2nd ed., pp. 154-159; 3rd ed., pp. 112-116; 4th ed., pp. 131138; Minnick, pp. 147-148; Arnolda, pp. 54-64.

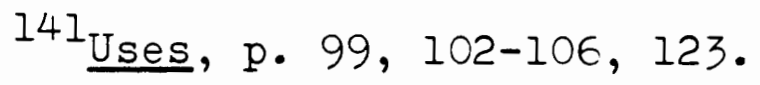


142 See for example Scheidel, Persuasive Speaking, p. 36; Human Interaction, p. 205; Rieke and Sillars, p. 78; Book et al., p. 38; Gulley, pp. 114-117.

143 Ehninger and Brockriede, 2nd ed., p. 47. The same example appears in a slightly different form in Ehninger and Brockriede, lst ed., p. 127, as well as in McCroskey, p. 67, and Bryant and Wallace, p. 360 .

${ }^{144}$ See especially Arnold, pp. 54-64; Minnick, pp. 147148; Bradley, pp. 210-2ll; Wilson and Arnold lst ed., pp. 138142; 2nd ed., pp. 154-159; 3rd ed., pp. 112-116; 4th ed., pp. $131-138$.

${ }^{145}$ See Ehninger and Brockriede, lst ed., pp. 98-107.

146 Rieke and Sillars, p. 79; Reasoning, p. 210.

147 See Wilson and Arnold, Ist ed., pp. 137-143;

Scheidel, Human Interaction, pp. 204-207.

${ }^{148}$ Brockriede and Ehninger, "Toulmin on Argument," pp. $46-47$.

149 Ehninger and Brockriede, lst ed., pp. 98-99.

${ }^{150}$ Ehninger and Brockriede, 2nd ed.; Reasoning.

${ }^{15}{ }^{1}$ Hastings in Mills, pp. 125-148.

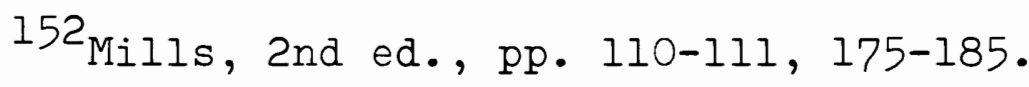

153 Freeley, 3rd ed., chapter 9.

${ }^{154}$ Rieke and Sillars, p. 278; Bettinghaus in Miller and Nilsen, p. 147.

${ }^{155}$ See Scheidel, Human Interaction, p. 206.

156 Ehninger and Brockriede, 2nd ed.; Rieke and Sillars; and Reasoning.

157 Reasoning. 
CHAPTER V

APPLICATIONS OF THE TOULMIN MODEL: UTILIZATION BY SPEECH COMMUNICATION PROFESSIONALS

Throughout this study the issue of potential applications of the Toulmin model to speech communication has been raised. In this chapter, suggested applications found in speech communication textbooks are discussed and evaluated. Three general kinds of applications are suggested in textbooks: the Toulmin model may be useful ( 1 ) in the analysis, classification, and exemplification of differences among field-invariant categories of argument, (2) as a theoretical construct applicable to concepts and arguments of specific fields relevant to speech communication, and (3) in the analysis, construction, and criticism of rhetorical discourse. In the course of discussing these suggested areas of application, other possibilities not fully explored in speech communication textbooks will be submitted.

\section{APPLICATIONS OF THE TOULMIN MODEL TO FIEID-INVARIANT CATEGORIES OF ARGUMENT}

About general categories of argument such as "generalization," "sign," and "cause-effect," Toulmin makes two points: first, they represent field-invariant basic 
assumptions which may underlie the warrants of arguments; and second, like other field-invariant aspects of argument, such categories are largely irrelevant to that upon which the soundness of an argument rests--field-dependent criteria as represented by backing. ' The field-invariant/ field-dependent distinction is at the heart of Toulmin's view of argument categories and their significance.

As has been shown, many of the writers of speech communication textbooks do not explicitly maintain the fieldinvariant/field-dependent distinction or its consequences in the same way as Toulmin. Further, several of these writers propose that the Toulmin model be applied in the analysis, classification, and exemplification of fieldinvariant as well as field-dependent aspects of argument. The nature of this proposed application offers clues as to the degree of difference between speech communication textbook writers and Toulmin with regard to the potential value of his model in the analysis of general forms of argument. Is such an application an irrelevant exercise as Toulmin asserts or a valuable tool as some speech communication textbooks suggest? Discussion of this issue is divided into four parts: (1) the nature and scope of textbook treatments of general categories of argument, (2) the rhetorical approach of Ehninger and Brockriede and their followers, (3) the empirical approach of Hastings to the 
reformulation of general categories of argument, and (4) an evaluation of conflicting orientations to general categories of argument and the role of basic assumptions in this application of the Toulmin model.

\section{Textbook Treatments of General}

\section{Categories of Argument}

Of twenty-seven textbook editions surveyed, fourteen were found to present analyses of general categories of argument exemplified in terms of the Toulmin model. ${ }^{2}$ Arguments are frequently categorized in speech communication textbooks under various headings, such as "forms of argument," "types of reasoning," "patterns of proof," and "classifications of warrant." 3 In this study, they shall be referred to as "general categories of argument." While these textbook treatments have much in common, their differences tend to be confusing. Mills has observed that such classifications are seldom in agreement with each other or clear as to upon what they are based. ${ }^{4}$ Mills argues that the bases of categorization must be clarified and systematically applied if the forms of argument are to be a help to students in the construction or criticism of arguments. 5 To this end he presents his own "eclectic system of classifying arguments" which in no way relies upon the Toulmin model. 6

Writers of speech communication textbooks presenting the Toulmin model offer a variety of solutions to the 
problem of the analysis of general categories of argument. Ehninger and Brockriede were first to propose that the Toulmin model be used as the basis for an analysis of general forms, and their approach appears to have influenced several subsequent textbook writers. Hastings has presented an empirically-based reformulation of the general categories in terms of the Toulmin model. Both of these approaches are discussed later. However, despite minor differences in terminology and definitions presented, nearly all of the schemes are found to include the following categories: causation, sign, generalization, analogy, and classification.? Several other general forms are mentioned in speech communication textbooks, but only these five are frequently represented. However, the significance of these five apparently agreed upon forms is questionable, for as Toulmin, Rieke, and Janik argue, "it turns out not to be possible to give an exhaustive or formal account of all the possible types of argument . . [ [and] many of the types listed here merge into one another and are hard to distinguish sharply from one another." 8 It appears that applying the Toulmin model to the analysis, classification, and exemplification of general categories of argument has not resulted in an end to the confusion observed by Mills. 
A Rhetorical Approach: Ehninger

and Brockriede and Their

Followers

While the various categorizations of general forms of argument are subject to criticism on several grounds, what is of most interest here is the role of the Toulmin model in such schemes. Ehninger and Brockriede were the first to find the Toulmin model to be "suggestive of a system for classifying artistic proofs." 9 Their work is significant because of the influence it appears to have had upon the work of several subsequent writers.

Ehninger and Brockriede's approach has four features which indicate their reliance upon the Toulmin model in categorizing general forms of argument. First, they rely upon the concept of warrant to differentiate between an inartistic and an artistic proof: if to accept the data as true is to accept the claim as true, then an argument is judged inartistic; on the other hand, if the warrant is "the crucial element . . and its function is to carry the data to the claim," then the proof is judged artistic. 10 Second, the Toulmin model is viewed as applicable to each of the three modes of proof of classical rhetorical theory. ${ }^{11}$ The authors offer substitute terminology--substantive, motivational, and authoritative proofs--for the traditional logos or appeal to reason, pathos or appeal to emotions, and ethos or appeal of a speaker's character, respectively. 12 While all three are analyzed with Toulmin 
diagrams, the most detailed analyses presented are of the categories of substantive proof. Third, the authors suggest that analysis of an argument in terms of the Toulmin model can facilitate the identification of the general category to which the argument belongs. Their initial presentation implies that each unit of proof may be analyzed with a single Toulmin diagram representing one or the other general categories of argument. This contention has more recently been revised; the authors currently view the process of analysis as highly complex, often requiring multiple diagramming of the same argument from different perspectives. 13 Fourth, in presenting their detailed aralyses of substantive, motivational, and authoritative proofs, these authors imply that their categories represent field-invariant forms of argument. 14

The most significant of the four features of the rhetorical approach for our discussion is that which bears upon what Toulmin says about general categories--that they are field-invariant. Several of Ehninger and Brockriede's illustrations seem to indicate field-dependence rather than field-invariance. The net result is that one cannot determine from Ehninger and Brockriede's presentation whether or not their categories are more field-dependent or field-invariant. Clear criteria by which the distinction can be made are never presented. 
Several subsequent textbook writers follow the rhetorical approach of Ehninger and Brockriede, although none pursue it with the same depth and detail. In textbooks by Blankenship and McCroskey, and to a lesser degree Bettinghaus, Bradley, Freeley, Rieke and Sillars, and Verdeber, one can recognize Ehninger and Brockriede's major categories as well as some of their terminology and style of illustration. Despite many differences in depth and content among these treatments, all have at least one important feature in common with the approach of Ehninger and Brockriede: none presents an explicit or coherent explanation of the nature of field-invariance or of the basic assumptions said by Toulmin to underlie the general categories of argument. Ehninger and Brockriede and their followers appear to confuse field-dependence and fieldinvariance in presenting their categorization of general forms of argument.

Ehninger and Brockriede have at different times published three presentations of the general categories of argument. 15 Overlooking for the moment differences among these treatments, the categories which have been presented by Ehninger and Brockriede are these: cause-effect, effectcause, generalization, classification, parallel case, analogy, statistics, motivational, and authoritative. ${ }^{16}$ The authors appear to believe each of these categories to be field-invariant for they preface their discussion of them 
in Decision by Debate, lst edition, with a quote from The Uses of Argument in which Toulmin describes fieldinvariance. ${ }^{17}$ Moreover, their verbal discussion of each category of proof implies field-invariance; almost no attention is given to field-dependence in arguments as discussed by Toulmin.

Despite the implication of field-invariance in the general categories of argument discussed by Ehninger and Brockriede, their analysis and exemplification of arguments in some categories creates doubt as to their invariant nature. Only generalization, and potentially analogy, parallel case, and authoritative proof seem from their examples to be more field-invariant than field-dependent. Other categories discussed by Ehninger and Brockriede are either unclear or apparently more field-dependent than field-invariant. Followers of Ehninger and Brockriede, while altering some terminology and consolidating some of the categories also imply the field-invariance of their general categories without clearly or explicitly demonstrating it through examples presented. ${ }^{18}$

The most clearly field-invariant of the general categories of argument discussed by Ehninger and Brockriede is generalization. This is because it is the only form of proof in which these authors explicate an underlying fieldinvariant assumption which is the basis of a content-free warrant statement. They state "because a class, by 
definition, exhibits a certain uniformity, the warrant assumes that what is true of the items forming the sample is also true of other members of the class not included in the sample." 19 While the assumption is identified in this case, in all other examples of forms of proof, these authors define the warrant only in terms of what it "states" or "asserts."20 In their example of generalization shown in Figure 23, Ehninger and Brockriede use a warrant which, while somewhat ambiguous in its phrasing as to whether or not its authority is dependent upon the field of international relations, parallels the field-invariant assumption. 21 Further, while the rebuttal is fielddependent, the support for warrant is field-invariant in nearly all respects. Thus, more than in any other category of argument exemplified by Ehninger and Brockriede, the field-invariant nature of the warrant in generalization is apparent. Some followers of these authors similarly imply the field-invariance of warrants in proofs by generalization in examples. Blankenship's example of generalization appears in Figure 24.22 Unlike Ehninger and Brockriede, Blankenship phrases her warrant like a basic assumption--completely devoid of any content which is specific to the case at issue. Regardless of whether warrants as stated in each of the examples in Figures 23 and 24 are representative of basic assumptions or poorly phrased warrants, they are apparently independent of the particulars of the content of statements 
of evidence and claim. So long as the warrant of an argument states a principle not directly derived from or dependent upon an appropriate field of argument, it may be judged to be field-invariant.

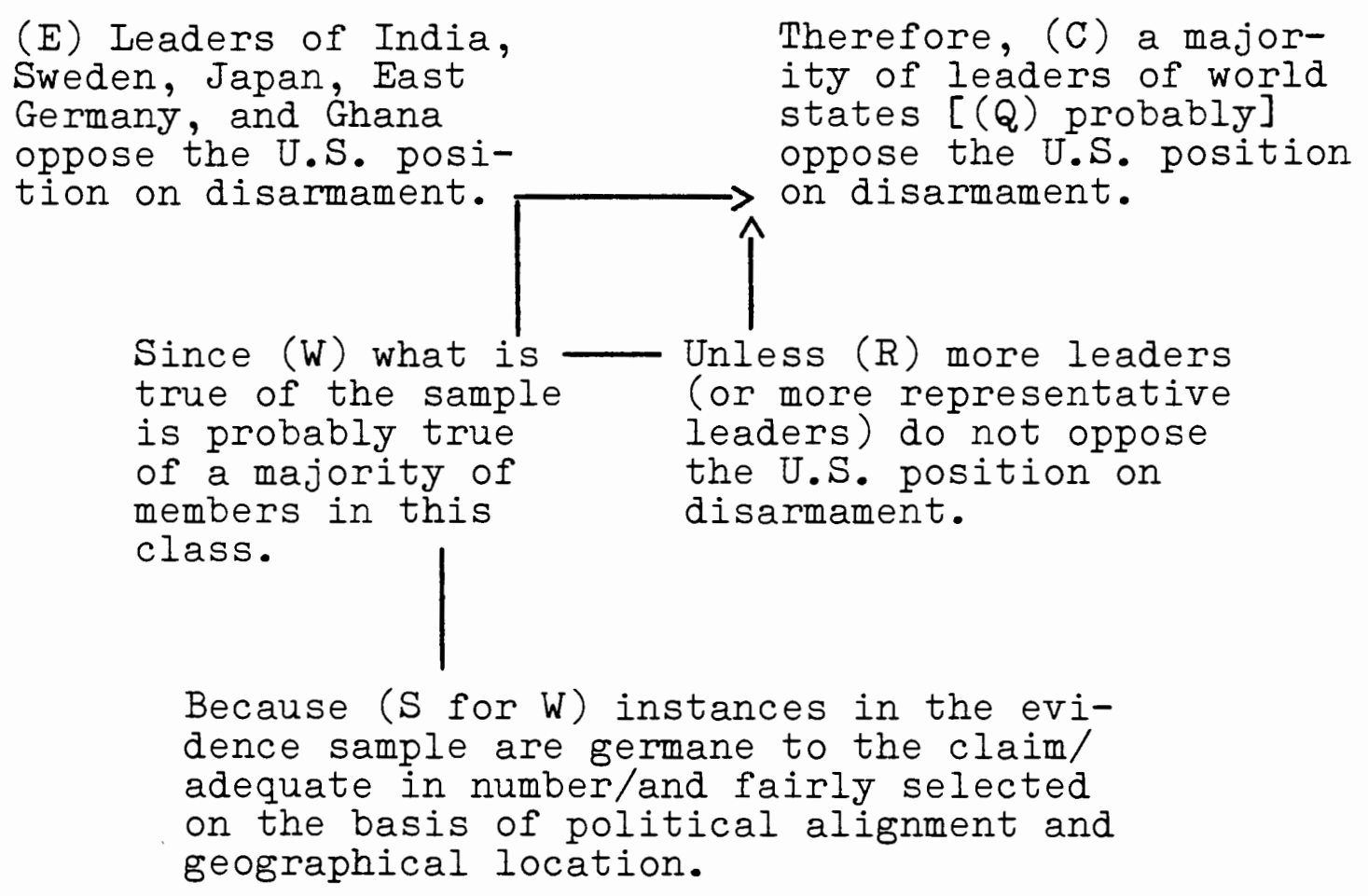

Because ( $S$ for $W$ ) instances in the evidence sample are germane to the claim/ adequate in number/and fairly selected on the basis of political alignment and geographical location.

Figure 23. An illustrative example of proof by generalization according to Ehninger and Brockriede, 1963. 
E. "The people of

the U.S. individ-

ually could not

have developed

the Tennessee

Valley. Collec-

tively, they could have"

"Seventeen million

Americans who live over 65 on an average social security check of about $\$ 78$

a month--they're not able to sustain themselves individually, but they can sustain themselves through the social security system"

$\longrightarrow$ C. $\begin{aligned} & \text { Therefore, in } \\ & \text { cases where } \\ & \text { individual } \\ & \text { action is } \\ & \text { ineffective, } \\ & \text { then national } \\ & \text { governmental } \\ & \text { action will be } \\ & \text { effective }\end{aligned}$

Therefore, in cases where individual action is ineffective, then national governmental action will be effective

W. Since what is

true of a selected sample is probably true of the majority of members in its class

Figure 24. An illustrative example of proof by generalization according to Blankenship.

In no other category of argument but generalization is the matter of a field-invariant underlying assumption so clearly expressed by Ehninger and Brockriede or their followers. Warrants, said by these authors to be "hypothetical and content-free," are almost never phrased this way in examples. More often than not, the warrant used in an example is tied to backing drawn specifically from the field of argument in which the claim applies. In some 
cases, such as the examples of analogy, parallel case, and authoritative proof, the warrants themselves appear to be subject to translation or rephrasing that will render them clearly content-free and field-invariant. Such translations would be likely to increase the candidness of examples by explicating the underlying assumptions and presenting a warrant phrased in a form immediately generalizable to arguments in other fields. In other words, the warrants could be rephrased as abstract field-invariant assumptions. However, Ehninger and Brockriede and their followers do not provide such translations. Further, the support for warrant offered in examples of analogy, parallel case, and authoritative proof is field-dependent thus giving rise to doubts as to whether Ehninger and Brockriede believe these categories of argument to be of a field-invariant nature. 23 of the potential field-invariance of argument from classification, even less may be said with certainty because this category appears to be confused and possibly the result of an error in analysis or illustration. 24 The remaining categories, cause-effect, effect-cause, and sign, appear from the examples of warrant and backing in each case to be more field-dependent than field-invariant. In order to assess the soundness or strength of the warrants in these categories, one must investigate issues which are applicable to only one field. 25 see for instance their example of effect-to-cause proof in Figure 25.26 In this case not 
only is the warrant inextricably bound to the content of the data and claim statements, neither is anything of a general nature said or asked of causation in the support for warrant. There is no hint of the underlying fieldinvariant assumption.

(E) Russia keeps a large number of divisions under arms.
Therefore, (C) Russia is (Q) probably demonstrating aggressive mot motivation.
Since (W) nations that keep a large number of divisions under arms often do so because of aggressive motivation. $\hat{\imath}$

Unless ( R) Russia keeps a large number of divisions under arms for national defense/internal security/ stimulation of the economy/etc.

Because ( $S$ for $W$ ) Expert $X$ reports that a large number of divisions under arms almost always indicates aggressive intent/a large sample of instances exist in which aggressive motivation caused the arming of large numbers of divisions/ etc.

Figure 25. An illustrative example of effectcause proof according to Ehninger and Brockriede, 1963.

Similarly, followers of Ehninger and Brockriede use field-dependent arguments to exemplify causal and sign arguments. For instance, consider the example of sign argument presented by Blankenship, as shown in Figure 26.27 As in Ehninger and Brockriede's examples, the warrant in 
Blankenship's example is phrased in terms of the particulars of the evidence and claim. No support for warrant or basic assumption is stated to help us judge whether this argument is field-dependent or field-invariant. Thus, the asserted field-invariance of this category is not at all obvious. The role of signs in the warrant seems less important than potential backing from the fields of international politics or military strategy. It may be concluded from this and other examples presented by followers of Ehninger and Brockriede that the field invariance of the categories of argument and the assumptions which underlie their warrants are far from explicit and less than candid. There is, therefore, reason to doubt that Ehninger and Brockriede and their followers share Toulmin's sense of the cruciality of the fieldinvariant/field-dependent distinction to the assessment of soundness of arguments.

E. There exist in Cuba "large, long-range, and clearly offensive weapons of sudden mass destruction"

W. Since the buildup of offensive weapons by one nation constitutes

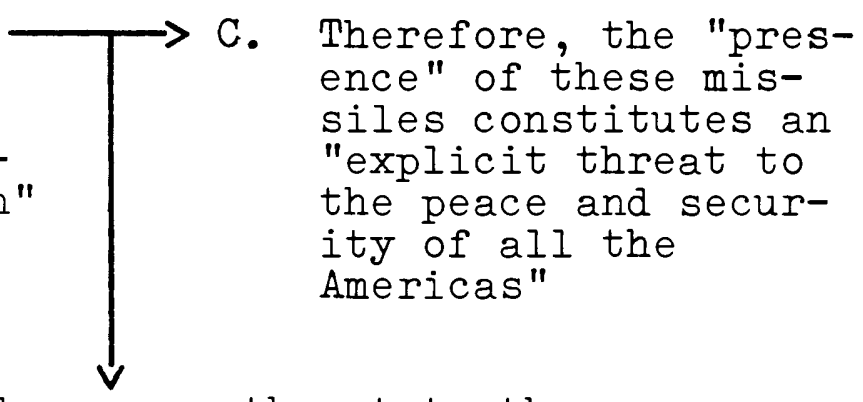

a threat to the security of other nations

Figure 26. An illustrative example of sign proof according to Blankenship. 
In summary, proponents of the rhetorical approach believe that the Toulmin model can usefully be applied in the analysis and exemplification of general categories of argument. At the same time, they fail to acknowledge Toulmin's objection that such inquiries into field-invariant aspects of argument are irrelevant, to clearly identify field-invariant basic assumptions underlying the warrants of each category, or present clear criteria by which an argument in field-invariant form may be readily distinguished from an argument in field-dependent form. ${ }^{28}$ The major contribution of Ehninger and Brockriede and their followers appears to be their suggestion of the potential of the Toulmin model in this application to general categories of argument. However, solutions to the problems created by such a move are still to be determined.

\section{An Empirical Approach: Arthur}

Hastings' Reformulation of

General Categories of

Argument

Another writer who uses the Toulmin model to elucidate the differences among various general categories of argument is Arthur Hastings. ${ }^{29}$ Hastings claims to have reformulated the general forms of argument into categories which more accurately reflect the practices of actual arguers than do traditional categories. 30 Unlike Ehninger and Brockriede who extrapolate from the traditional categories of classical rhetorical theory, Hastings draws from his empirically-based 
doctoral research in which he performed Toulmin analyses of over 250 examples of arguments from various fields of discourse. 31 Based upon his results, Hastings has identified nine categories of argument--five commonly used "major methods" and four less commonly used "further methods." 32 While Hastings' method of defining his categories differs from that used by Ehninger and Brockriede, many of the categories recognized in the two approaches appear to be roughly the same. 33 One important difference between the rhetorical and empirical approaches is the precision with which the warrant is phrased in the latter. While the rhetorical approach focuses primarily on the characteristics of the warrant as a basis for the categorization of an argument, Hastings' empirical approach examines the relationship between data and claim in order to develop an accurate warrant statement. Thus, while the rhetorical approach presumes the nature of evidence and claim in every category to be roughly the same, Hastings is precise in describing differences in the kind of content in the data-statements and the kind of conclusions asserted in the claim-statements for each category. 34

With regards to field-invariance and field-dependence, Hastings' treatment of the general categories of argument suffers from some of the same defects as the rhetorical approach. Hastings implies that his categories represent field-invariant aspects of argument and even offers a 
content-free statement of the warrant for each category. 35 Further, what Hastings refers to as rebuttal amounts to a different set of field-invariant questions which may be used to test the strength of arguments in each category. 36 Although Hastings does not explicitly discuss or identify assumptions which may underlie warrants in each category of argument, in most cases such assumptions may be inferred from the general statements of warrant, rebuttal questions, and related discussions. 37 In Windes and Hastings, differences among arguments in different fields--in effect, field-dependent aspects of argument--are discussed in connection with evidence. 38 Thus, to Hastings it appears that field-dependence is a matter of evidence, field-invariance a matter of the classification of warrants. That this division more closely resembles the distinction between material and formal validity of formal logic than it does Toulmin's field-dependence and field-invariance does not appear to be a problem for Hastings.

In spite of a strong implication of field-invariance in Hastings' reformulated categories, the examples of arguments presented as illustration for each category tend to support a field-dependent interpretation. Hastings draws his examples from real discourse and, despite having "been rephrased for purposes of clarity and illustration," they frequently do not include explicit warrants. 39 Where warrants are cited, they are phrased in a content-bound 
manner which obscures any field-invariant features they may have, a problem made worse by Hastings' inattention to matters of backing that would provide clues to whether an argument should be judged field-invariant or field-dependent. For example, Hastings presents the following illustration of argument from cause to effect:

Recognition of Communist China (D) would harm our relations in Asia (C) because we would be retreating once more from the Communists $(W)$. We have said we are going to defend Formosa against Communist Chinese attack, but if we abandon the island of Formosa, the effect on the Asians would be that we were afraid (W). 40

Hastings then goes on to summarize the warrant in two different ways: "In recognizing Communist China the United States would lose other nations' respect" and, elsewhere, "when nations do not maintain consistent policies other nations do not respect them." 41 Neither warrant, not even the more general statement, would have much applicability outside of the field of international diplomacy. Further, it is unclear what field-invariant basic assumption regarding cause and effect would underlie each of the different versions of the warrant statement in this example. The content-bound nature of the warrant-statements and the undefinability of the basic assumptions in Hastings' examples of arguments from different categories contradict his implication of the field-invariance of his categories, at least in practice. 
In summary, Hastings' main contributions are his empirically-based approach, developing categories from a study of actual arguments in various fields, and his precision in defining the warrant of an argument in terms of the form of the relationship between data and claim. The empirical approach is promising in that it is consistent with Toulmin's practical aims, and it may potentially bring to light the extent to which it is possible or useful to analyze arguments in terms of field-invariant categories. Further, it may provide a method for examining the differences in the forms of argument used in different fields, that is, the field-dependent aspects of argument. However, at present Hastings' approach provides little in the way of criteria by which the distinction between fielddependence and field-invariance may be maintained. While Hastings' approach appears to be superior in other respects to the rhetorical approach of Ehninger and Brockriede, both approaches appear to begin with the assumption that all arguments may be usefully categorized according to some field-invariant scheme. The reliability of this assumption is challenged by Toulmin and remains undemonstrated by these speech communication textbook writers. 
Conflicting Orientations to the

General Categories of Argument

and the Role of Field-

Invariant Basic

Assumptions

As has been shown, there appears to be a sharp difference between Toulmin and some speech communication textbook writers as to the significance of general categories of argument and the applicability of the Toulmin model to such categories. This difference appears to be related to the distinction between field-invariance and field-dependence and how it is interpreted in discussions and examples of general categories of argument. Ehninger and Brockriede, their followers, and Hastings all endorse the application of the Toulmin model in the analysis and exemplification of general categories. In doing so, these authors suggest various definitions and procedures which they believe will facilitate this application of the Toulmin model. While acknowledging that this move represents an expansion of Toulmin's approach to argument, these authors do not make clear their position on Toulmin's field-dependent orientation. Moreover, they do not address the field-invariant/ field-dependent distinction, nor do they clearly identify the "deeper assumptions or mules" which embody common features among warrants of arguments within each general category. In other words, these authors appear to believe that argument is best viewed from a field-invariant standpoint and that the general categories of argument may 
usefully serve as field-invariant criteria. The question is, can this field-invariant orientation to argument analysis be reconciled with Toulmin's position that fieldinvariant standards will be largely irrelevant to arguments in particular fields?

To say with certainty that these approaches can or should be reconciled is more than the evidence of this study justifies. Clearly, further investigation is warranted. Nevertheless, a first step toward resolving this apparent conflict might be, as Mills has suggested, to clarify the bases of categorization, in this case by identifying the assumptions which underlie the warrants of arguments within each category. Confusion as to the nature of these assumptions has been a consistent feature of the textbook treatments of general categories of argument. Just what are the underlying assumptions of these categories of argument and to what extent may they be viewed as field-invariant?

One interpretation as to what these assumptions may be is offered by a rhetorical theorist, Carroll Arnold, who chooses not to present an analysis of general categories of argument. He argues that such general categories are derived from cultural orientations of the arguer and the audience:

Westerners habitually look for causes to explain things as effects and they look for effects because they believe there are causes. They also look for similarities that authorize comparative conclusions and for examples that allow generalizations. When 
we hear such connection-asserting, conclusionauthorizing relationships explicitly offered as reasons, we do not just put labels on them-"causal," "analogical," "inductive," etc.--nor do we analyze them for technical validity. If we respond to such reason giving by reasoning, we follow in thought along the "logical" pathway the speaker proposed (or some other), but we do so for our own reasons, not for the sake of the "logical" form the logos had. 42

In other words, for all members of a particular society-in this case, Western society--arguments in these recognized forms are likely to have force regardless of their fields of application. A similar view is expressed by Condon and Yousif who argue for an analysis of general forms of argument which recognizes the differences in the "epistemic structures" of various cultures. 43 Thus, general categories of argument may be conceived as culturallydependent as well as field-invariant within a culture. This interpretation suggests that the field-invariant/fielddependent distinction may be overly simple if not a false dichotomy. 44

It seems probable that Toulmin's charge of the irrelevance of field-invariant criteria is appropriate in the most highly evolved and clearly delineated disciplines such as the older branches of philosophy and the physical sciences. The arguers in such fields argue from common assumptions which are the product of their indoctrination to the history, goals, and justification procedures of various fields. 45 In those situations where a shared 
context or sense of common problems and techniques prevails, any field-invariant or universal criteria may be superfluous. The issues of argument in a field like physics are likely to be more precisely defined and specific than can be resolved by recourse to common-sense principles of causality such as those embodied in the warrants of a general category representing "causal argument." In such a case, Toulmin's charge of the irrelevance of field-invariant standards seems appropriate.

Field-invariant criteria are more likely to apply in situations where no common assumptive base exists, as in arguments among lay-persons or among experts from different fields. In defending research in techniques of genetic engineering, a biochemist must argue differently to colleagues than to a minister or to an investigating comittee of congress. The difference is not just a matter of rhetorical strategy: it is a problem of arriving at a common basis for linking data to claims and conclusions. Where no field is available from which warrants may be drawn, then whatever shared assumptions may exist among the arguers provide the only available basis for argument. 46 However, the conclusion that field-dependent criteria may not be the only relevant kind does not compel us to presume what Toulmin implies about shared assumptions-that they are either field-dependent or field-invariant. To the contrary, it is conceivable that such assumptions 
may be independent of fields and still other than absolute or universal truths. Just as each field has an associated set of unique shared assumptions, so might each interpersonal relationship, small group, mass audience, culture, or species. Thus, one may conceive of relative "levels" or types of rational assumption which may underlie the criteria relied upon in practical arguments. Toulmin's apparent bias in favor of field-dependence is not ample justification for disregarding other potential useful bases for rationality.

The importance of the question of field-invariant vs. field-dependent criteria should not be underemphasized. In a world which is becoming increasingly reliant upon instantaneous information and communication links among individuals and groups despite traditionally recognized geographical, historical, cultural, and national boundaries, the study of similarities and differences in justification procedures worldwide is vital. ${ }^{47}$ A failure to recognize how different assumptions about argument interact with each other when representatives from differing cultures--the United States and an Islamic republic, for example--negotiate their political differences can lead to disasterous results. 48

What is needed, then, is a clearer characterization of the field-invariant assumptions which may underlie the warrants of arguments in each general category. For 
example: What are the assumptions of each category? To what degree are they isolable from one another? To what extent do they differ in force in their soundest forms? To what extent do they differ in range of applicability to arguments of different fields? Once these assumptions are made explicit, the ways in which they may interact with field-dependent sources of soundness will require exploration. For example: should both field-dependent and fieldinvariant criteria be applied to the same argument simultaneously or, if not, should field-dependent criteria be thought of as a special category of argument in and of itself? Should either field-invariant or field-dependent criteria be thought to predominate? Which context variables, if any, should be considered in determining which criteria are more appropriate--the field in which the issue develops? the nature of the arguers? the content or substance of the arguments? the phrasing of the arguments? Overall, these problems would be easier to resolve if speech communication professionals were harmonious in their epistemological assumptions. Formal logicians and Toulmin clearly differ as to their assumptions regarding the nature of truth; yet, this is a matter about which no single position appears to predominate in the field of speech communication. Thus, there is a need for clarification of the comparative merits of many epistemological issues, including absolutistic vs. relativistic assumptions, in 
terms of the various aims, interest areas, and methods of speech communication.

Pending exploration and resolution of the issues discussed above, there appears to be no reason why the Toulmin model cannot be applied in the analysis and exemplification of categories of argument as it can to arguments in general and arguments from particular fields of inquiry. However, the rhetorical and empirical approaches are, in the opinion of this writer, unsatisfactory in their present state of development because they introduce several problems while failing to take clear positions on some of the theoretical bases of the Toulmin approach. 49

APPLICATIONS OF THE TOULMIN MODEL TO SPECIFIC FIELDS RELEVANT TO SPEECH COMMUNICATION

Several special applications of the Toulmin model to areas of theory and fields associated with speech communication have been suggested in textbooks and other publications. By "special applications" we mean to exclude for later discussion the most frequently discussed use of the Toulmin model, as a tool of analysis of arguments in general. Special applications to fields relevant to speech communication include the application of the Toulmin model to (1) theories which bear on speech communication, (2) fields of argument which may be the subject of communication research, and (3) particular communication settings. 
This brief survey is in no way exhaustive of the possibilities; rather it is meant to reflect some of the specific applications which have begun to be explored by some writers.

The Toulmin Model in Theories

\section{Bearing on Speech}

Communication

As has been indicated in the preceding chapter, the Toulmin approach as interpreted by some speech communication textbook writers is useful as a model of persuasion as much as it may be useful as a model of logic. The elements of the model tend to be conceived by these writers as relative to the beliefs of an audience and the superiority of the Toulmin model to the syllogism is considered its inclusion of certain rhetorical factors, such as qualifiers and rebuttals, that have persuasive impact not recognized in a syllogism. Thus, because the Toulmin model may take into account audience factors as well as message factors, it has an impact on rhetorical theory. In particular, the Toulmin model appears to be more consistent than the syllogism with emerging views of rhetoric as a way of knowing. It is in this regard--as representative of an "epistemic" view of rhetoric--that the Toulmin model is introduced in the textbook by Golden, Berquist, and Coleman, The Rhetoric of Western Thought. 50 
As discussed in chapter III, there have been some attempts to merge Toulmin's approach to argument with psychological theories of attitude change. Cronkhite's extended diagrammatic model is the result of a blending of Toulmin's concepts with Martin Fishbein's attitude theory. 51 Bae Keun Cha has examined the relationship of Toulmin's approach to various consistency theories and Gary D'Angelo has suggested a schema which places various aspects of attitude theory, as developed by Hovland and Janis, McGuire, Festinger, Sherif, Sherif and Nebergall, among others, within the Toulmin model. 52 Such attempts as these to apply the Toulmin model to theories in psychology and other fields related to speech communication are provocative and should be encouraged.

So far as is known to this writer, Condon and Yousif are alone in applying the Toulmin model to intercultural communication theories. However, the epistemic dimensions of the Toulmin approach would appear to be as applicable to other areas as they are to intercultural and rhetorical communication. For example, the Toulmin model may have applications to theories of interpersonal communication, particularly interpersonal perception, acquaintanceship, and conflict resolution; organizational communication, as subsequent discussion of "management" as a field of argument will suggest; and oral interpretation, in the analysis of emotional content implicit in poems or other 
forms of literature. 53 These applications are among the more creative possibilities for applying the Toulmin model to theories related to communication.

The Toulmin Model and Fields

Subject to Speech

Communication

Research

Potentially any field of argument may be subject to the researches of argumentation theorists and other speech communication professionals. However, some fields have received special attention in textbooks and other publications as being particularly suitable for study with the Toulmin model. For example, the field of politics, including government and international diplomacy, has dominated the illustrative examples presented in textbooks. While none treats political argument as having special features which differentiate it from argument in general, the applicability of the Toulmin model to the analysis of arguments found in the speeches of government representatives and other political leaders is implicit in most textbook presentations of the Toulmin model. The fields discussed below are explicitly mentioned in some textbooks.

Law. There have been many articles and at least one book written on the application of the Toulmin model to legal arguments. 54 Especially noteworthy is the work of 
Gottlieb who, in The Logic of Choice, presents an extension of the Toulmin model to meet the special demands of analysis of legal argumentation. 55 His model is shown in Figure 27. While this extension of the Toulmin model is too complex to be explained here, a brief look at it reveals that extensive modifications have been made in the standard diagram: new elements representing inference (I) and future consequences (CD, CSI) have been added, no qualifier is included because legal pronouncements always represent absolute decisions, and rebuttal and backing have been redefined as seven new elements representing the arguments both for and against a particular legal judgment ( $I, L^{\prime}, \mathbb{I N}, I N^{\prime}, P, P^{\prime}, F^{\prime}$ ). Such an extensive redesign of the Toulmin model raises a question: does application of the Toulmin model within any special field of argument require that the model be modified to meet the needs of that field? Or has Gottlieb simply introduced a new model which is more his own than it is Toulmin's? 


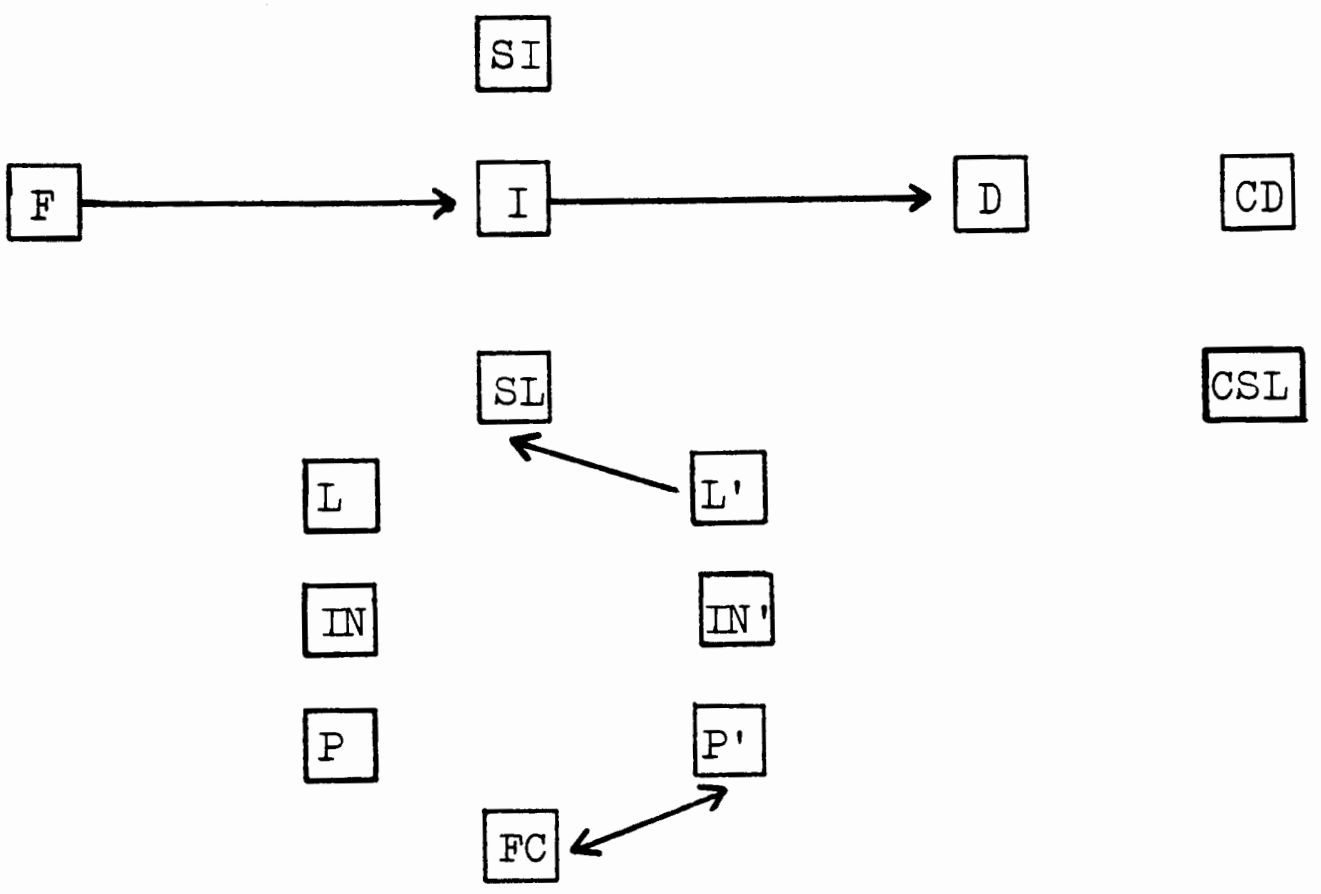

$F=$ the facts on record

$I=$ the process of selecting the material facts and reasoning from the material facts to the required or desired conclusion.

$D=$ the decision.

SI = statement about the process of inference.

SI = formulation of the rule governing the case.

$I=$ the preexisting rules and procedures ultimately selected for SI.

IN = the canons for the construction of rules and the techniques for using precedents.

$P=$ the purposes and interests contemplated by $I, \mathbb{I N}$, and SL.

$L^{\prime}=$ the preexisting rules and precedents competing with $I$. $I^{\prime}=$ the canons for the construction of rules and the techniques for using precedents competing with $\mathbb{N}$.

$P^{\prime}=$ the purposes and interests competing with $P$.

FC = preexisting commitment to weigh the competing purposes and interests in favor of $\mathrm{P}$ whenever a conflict arises.

$C D=$ foreseeable consequences of the decision.

CSL = foreseeable range of application of the formulated rule (SL) in other cases.

Figure 27. Gottlieb's extended version of Toulmin's diagrammatic model. 
Explanations of legal argumentation also appear in three speech communication textbooks in which the Toulmin model is presented: Rieke and Sillars; Toulmin, Rieke, and Janik; and Windes and Hastings. 56 Because the Toulmin model is drawn from an analogy with jurisprudence, the applicability of the model to arguments from the legal field seems quite appropriate.

Science, Medicine, and Technology. Scientific arguments are discussed in two textbooks in which the Toulmin model is presented. 57 While many arguments in science, medicine, and technology involve the use of warrants already established, scientific arguments are frequently warrantestablishing which means that the role of backing in a Toulmin analysis may be somewhat different than in other fields. 58 While the Toulmin model would appear to provide a valuable tool for the analysis and description of scientific paradigms and their epistemological implications, there is little in the textbooks surveyed to indicate that the Toulmin model is being used for this purpose.

Ethics. Toulmin, Rieke, and Janik discuss the special features of ethical arguments in terms of the Toulmin model. 59 Another writer, Joseph Wenzel, has suggested an application of the Toulmin model to value claims in argument. 60 Although his ideas draw as much from Toulmin's Reason in Ethics as they do from The Uses of Argument, his 
suggestions represent a potentially useful application for the Toulmin model. 61

Other Fields. Other fields related to speech communication which have been mentioned in textbooks presenting the Toulmin model include history, the arts, and management. 62 Here as in previously discussed fields the Toulmin model is identified as having potential in the identification and description of special features of these fields and yet very little research appears to have been done which uses the Toulmin model in this way.

If speech communication textbooks are any indication of what applications the Toulmin model is being put to by speech communication researchers, it appears that very little has been done thus far to develop the applicability of the model to special fields which may be the subject of speech communication research. While potential application to fields such as politics, law, science, and ethics have been referred to in a few textbooks, how much of this potential can be realized remains to be seen. Most textbooks discuss only the general applications to which the Toulmin model may be put, as discussed in the final section of this chapter.

The Toulmin Model in Particular

\section{Communication Settings}

The Toulmin model at one time or another has been associated with all but one of the commonly discussed 
communication settings: intrapersonal, dyadic, small group, speaker-audience, and mediated communication. In most textbooks, the Toulmin model has been discussed as a tool for the analysis and evaluation of arguments in oral rhetoric either in a speaker-audience or presentational dyadic setting--in other words, a public speech or academic debate. ${ }^{63}$ Gulley introduces the Toulmin model as an aid to discussion in small decision-making groups. ${ }^{64}$ At least two textbooks discuss the Toulmin model in connection with arguments used in written communication aimed at mass audiences, particularly journalism and scholarship. ${ }^{65}$ However, no textbook surveyed was found to associate the Toulmin model with mediated settings such as broadcast messages. While each of the above referred to applications of the Toulmin model in a particular setting may be significant in its own right, they all seem to be based on the implicit assumption that the Toulmin model is valuable at the level of intrapersonal communication. In fact, most of the applications of the Toulmin model which have been suggested and are discussed in this chapter have to do with critical thinking, effective decision-making, or applied reasoning. The Toulmin model is seen by most fundamentally as a tool useful in the evaluation of ideas and the connections among them. It is this assumption about the value of the Toulmin model which seems to have led to its adoption by so many speech communication textbook writers. 
After all, among the goals of the Speech Communication Association are "encouraging and developing instructional programs for . . effective decision-making, . . critical analysis of persuasive messages, . . use of ideas and arguments supported by the evidence." 66 In addition, a recent survey of Basic Speech Communication courses at American colleges and universities indicates that more than fifty-five percent of basic courses with a public speaking orientation and nearly forty-four percent of those with a combination of public speaking, interpersonal, and group communication orientation devote a significant amount of time to the teaching of reasoning. 67 Over ninety percent of the basic courses surveyed are taught with one or the other of these formats. Thus, it may fairly be concluded that the teaching of reasoning is an important aspect of speech communication instruction. As a model of the rational aspects of intrapersonal communication, the Toulmin model may fill a need in our discipline.

In summary, the Toulmin model has been associated in speech communication textbooks with applications in nearly every communication setting. However, it is at the level of intrapersonal communication, as a model of reasoning or rational thinking that most speech communication professionals appear to locate the primary value of Toulmin's approach. Because intrapersonal communication is presumed to be a part of every other communication setting, the 
applicability of the Toulmin model does not appear to be limited to one setting or another; potentially, it may be applicable to all. In other words, general applications of the Toulmin model discussed in the final section of this chapter have been found to be pertinent to all communication settings except perhaps mediated communication.

APPLICATIONS OF THE TOULMIN MODEL TO RHETORICAL DISCOURSE IN GENERAL

Toulmin's layout was intended to serve as a "pattern of analysis," a way of describing "the operation of arguments sentence by sentence" to clearly display the sources of soundness. 68 Most speech communication textbook writers surveyed propose that the Toulmin model be used in the analysis of arguments and, as noted above, as a paradigm of the reasoning process. These writers appear to agree that the Toulmin model may be suitable for the analysis of rhetorical discourse from any field. However, these writers appear to differ as to whether Toulmin's pattern of analysis is primarily descriptive or evaluative, concerned with sentence by sentence or overall organization, helpful in dealing with the products or the process of argumentation. In some cases, such differences are subtle and possibly attributable to the special purposes of particular textbook presentations of the Toulmin model. However, these differences are worth considering because they are indicative of the 
breadth of suggested applications of the Toulmin model to rhetorical discourse among those speech communication textbook writers who agree with Toulmin's view of the model as a tool of analysis.

Two kinds of applications of the Toulmin model to rhetorical discourse in general are discussed: (1) in rhetorical criticism, retrospective analysis for the evaluation of arguments; and (2) in inventio and dispositio, the first two canons of rhetoric, prospective analysis for the development and organization of arguments in a message.

The Toulmin Model in Rhetorical

Criticism

As discussed in chapter II, Toulmin limited his discussion in The Uses of Argument, hence the applicability of his model, to retrospective arguments brought in justification of assertions. Some textbooks remain bound to this limitation by emphasizing the retrospective analysis of arguments for their description and evaluation. Toulmin, Rieke, and Janik introduce the Toulmin model first as a descriptive device and second as an aid to the critical evaluation of arguments. 69 They focus on the products of argumentation, arguments already in verbal form, and they make no explicit comments concerning how a descriptive analysis can be useful in message design. 70 In their view, the model provides the means of evaluation: identification of the purposes and elements of an argument, explication of 
the force and structure of an argument, and opportunities for clear comparisons within and among fields as well as across history. ?1

Arnold, like Toulmin, Rieke, and Janik, is concerned with the products of argumentation and their retrospective analysis. Analysis of an argument in terms of the Toulmin model is seen by Arnold as one step in the overall process of rhetorical criticism. ${ }^{2}$ The model is conceived of as an aid to determining the role of arguments, if any, in a speech, the manner of persuasion, the degree of controversiality for a particular audience of parts of a message and the specific force of the verbal content of a sentence, paragraph, or the overall message of a speech. 73

The authors discussed above, as well as Cronkhite, and Condon and Yousif, give primary emphasis to the descriptive value of the Toulmin model in retrospective analysis. In all other textbooks surveyed, the authors stress the evaluative aspect of analysis, particularly as it pertains to the process of message design. Only Blankenship and Scheidel present the Toulmin model as a description of the process of argument at all, and along with Minnick and Bryant and Wallace, these authors emphasize its role in the "analysis of decision-making in speech communication. "74 In the brief presentations made by each of these authors, it is uncertain just how a student can usefully apply the Toulmin model to his decision-making in speech preparation. 
Other speech communication textbook writers are also less than clear on this point, but many appear to presume the applicability of the Toulmin model in the retrospective analysis and evaluation of arguments without specifically discussing procedures of this application. Further, they appear to view the model as equally applicable in the retrospective and prospective analysis of arguments. Gulley claims that the Toulmin model is better suited than other models to problem-solving group discussion "for laying out arguments, both for expressing a line of reasoning quickly in the group situation and also for testing arguments others have advanced."75 Similarly, Rieke and Sillars identify the Toulmin model as "an analytical device that could be used before or after the actual written or oral argument is prepared (or after it has been heard). "16 In other words, according to these authors the Toulmin model is not limited to its application in the retrospective analysis of arguments.

Ehninger and Brockriede are perhaps most explicit in pointing out the usefulness of the Toulmin model in detecting deficiencies in proofs before, during, and after a debate as well as in lending assistance to the debater in assembling reasonable proofs and organizing them into circuit-like structures for presentation. 77 Their enthusiasm for the "anytime" applicability of the Toulmin model appears to have been eroded somewhat by comments from readers of the first 
edition of their textbook, for in their second edition, Ehninger and Brockriede express a more qualified conception of the usefulness of the model in message design. They state:

We want to make explicit and emphatic our opinion that the Toulmin model has little utility in creating proofs. Its value lies in criticizing them--before, during and after a debate.78 Again, in another place, they state:

The Toulmin model is not a scheme for building units of proof but for criticizing them; nevertheless, persons may view topoi [that is, fieldinvariant or field-dependent warrant forms] as "places to look for help in criticizing rationales for units of proof. 79

Thus, at least in the context of its application in academic debate, these authors emphasize the critical functions of the Toulmin model. One may use the model to retrospectively analyze ones own or anothers proposed or expressed arguments to assess their strengths and weaknesses; however one may not use the model prospectively to develop or organize arguments for a message.

The Toulmin Model in Inventio and Dispositio

As the preceding discussion indicates, whether or not it is stressed in their textbook presentations, the use of the Toulmin model in the description and evaluation of already verbalized arguments is apparently recognized by speech communication textbook writers. Ehninger and Brockriede emphatically deny that the model has a prospective 
application, that is, they deny that it may be used in the creation of proofs. However, there are some writers who propose primarily prospective applications for the Toulmin model.

The prospective applications mentioned in speech communication textbooks generally involve one or both of the first two canons of rhetoric. These are: inventio, concerned with the selection of materials to be used in a message, determining which proofs a speaker or writer should use; and dispositio, concerned with the organizational structure of a message and the arrangement of proofs within it. 80

Except for textbooks discussed in the previous section, most textbooks surveyed were found to recommend that the Toulmin model be utilized in the construction and testing of arguments to be used in a message. This appears to be the primary application explicitly discussed in speech communication textbooks. Bettinghaus in Miller and Nilsen presents a step-by-step list of instructions regarding how to construct an argument using each of the elements of the Toulmin model. 81 Other authors are less precise about the procedures to be used. 82 Bradley argues that the Toulmin model is helpful as a guideline for students who wish their messages to possess an aura of credibility which sound argument generates. 83 Thus, while none deny the value of 
the Toulmin model in reptrospective analysis, some writers stress its prospective function in inventio.

Some speech communication textbook writers, for example, Book et al., and Bradley, argue that the only prospective use of the Toulmin model is in inventio. 84 Bradley states "It is not a plan for organizing a speech nor even necessarily a plan for organizing an argument in a speech." 85 This position is in direct contrast to other writers who contend that the Toulmin model may be useful in dispositio, that is, "helpful to the communicator in organizing his materials into formal argumentative units for presentation to an audience. "86 Bettinghaus in Miller and Nilsen carries this position further, suggesting "that the model is also applicable to the organization of the entire speech."87 Writers who do not express specific positions on this issue appear to be primarily concerned with the use of the Toulmin model to ensure that arguments chosen by a student for use in speeches meet minimum criteria of rationality. 88

Thus, there appears to be some disagreement about the suitability of the model in dispositio as a plan for the organization of an argument or a chain of arguments for presentation in a message. At the same time, many writers agree that the Toulmin model may be helpful in inventio to help a student create arguments. These prospective applications of the Toulmin model to the first two canons of 
rhetoric represent an extension of Toulmin's approach which is limited to retrospective analysis of arguments.

\section{SUMMARY}

Three kinds of applications for the Toulmin model have been examined in this chapter: to (1) field-invariant categories of argument, (2) specific fields relevant to speech communication, and (3) rhetorical discourse in general.

The Toulmin model has been used in the exemplification and analysis of differences among general categories of argument despite Toulmin's view of the irrelevance of such field-invariant aspects of argument. Two different approaches to this application of the Toulmin model are Ehninger and Brockriede's rhetorical approach and Hastings' empirical approach to the classification of general categories of argument. While each approach appears to have its strengths and weaknesses, neither addresses the conflict this application of the Toulmin model creates with theoretical bases of the Toulmin approach, in particular, his field-dependent orientation. It is concluded that the Toulmin model may prove useful in the exemplification and analysis of general categories if some acceptable means of distinguishing field-invariance and field-dependence can be devised and if the field-invariant assumptions which underlie the warrants in each general form can be explicitly 
defined. Further, it is suggested that several useful distinctions may be obscured by the concept of fieldinvariance. Investigation of these issues would be facilitated by a clarification of the epistemological assumptions of the field of speech communication.

The Toulmin model has been applied in textbooks to special fields of argument relevant to speech communication. Attempts have been made to integrate Toulmin's approach with current rhetorical theory, psychological theories of attitude change, and intercultural communication theory. The model has been applied in textbooks to arguments in special fields such as politics, law, science, and ethics. Further, the model has been associated with nearly every commonly discussed communication setting. Perhaps the most widely recognized specific application of the Toulmin model is as a model of rational thinking or the process of reasoning. In speech communication textbooks, the Toulmin model is more often applied to rhetorical discourse in general than it is to any specific field of argument. Two kinds of application are discussed: the more common is as a tool of rhetorical criticism used in the retrospective analysis and evaluation of arguments; also mentioned in some textbooks is the use of the Toulmin model in the prospective analysis of arguments in inventio or dispositio, that is, the creation and organization of arguments for presentation in a message. There is some disagreement as to whether the 
second of these applications is a sound idea. However, most speech communication textbook writers appear to agree with Brockriede and Ehninger's initial assessment of the Toulmin model that "as a means of describing and testing arguments" the Toulmin model is superior to and "provides a practical replacement" for the syllogism of formal $\operatorname{logic.} 89$ 
Chapter 5--Notes

${ }^{I_{\text {See }}}$ this study, chapter II, pp. 51-53.

2 Brockriede and Ehninger in Golden et al., pp. 178180; Ehninger and Brockriede, lst ed., pp. 125-167; 2nd ed., pp. 73-91; Hastings in Milis, pp. 128-147; Windes and Hastings, pp. 159-188; Ehninger, pp. 67-81; Freeley, pp. 145147; Rieke and Sillars, pp. 80-87; Reasoning, pp. 147-155; Bettinghaus, pp. 109-110; Blankenship, pp. 171-177; Bradley, pp. 211-223; McCroskey, pp. 89-99; Verdeber, pp. 186-193.

3 See Mills, 2nd ed., p. 186. "Reasoning" types may be found in Bradiey, Freeley, and Verdeber. "Proof" patterns may be found in Bettinghaus, Ehninger and Brockriede, lst ed., and Hastings in Mills. "Warrant" classifications are found in Blankenship, Ehninger and Brockriede, 2nd ed., and McCroskey. Other writers use "argument" forms or other headlines.

$$
\begin{aligned}
& { }^{4} \text { Mills, 2nd ed., pp. 185-188. } \\
& { }^{5} \text { Ibid., p. 188. } \\
& { }^{6} \text { Ibid., p. } 191 . \\
& \text { Each of these five categories appears in at least }
\end{aligned}
$$
eleven of the fourteen textbooks examined; the first three forms appear in all textbooks treating general categories of argument. Causation is assumed to include both cause/ effect and effect/cause arguments which are in some textbooks treated as independent categories. Similarly, analogy is assumed to include both figurative and literal analogies, also sometimes treated independently. Classification includes "definition" or "deductive" arguments which both depend upon the relationship of classes of phenomena.

8 Reasoning, p. 155 .

9 Brockriede and Ehninger, "Toulmin on Argument," p. 47.

${ }^{10}$ Tbid.; see also Ehninger and Brockriede, lst ed., p. 125.

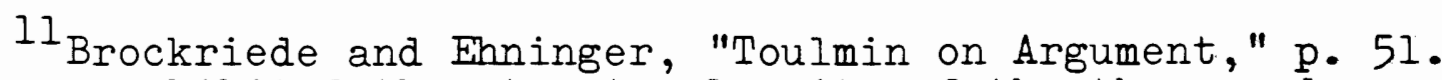
"We have exhibited the structural unity of the three modes of proof by showing how they may be reduced to a single invariant pattern using argument as a unifying construct."

12 Corbett, p. 50 . 
13 Ehninger and Brockriede, 2nd ed., p. 91; "any unit of proof can be defined and diagrammed predominantly as an analogy, an authoritative proof or a motivational proof; but its assessment by arguers, opponents and judges will be made best by recognizing that in most instances (if not all) several warrants have to be taken into account (even though Toulmin's layout is not complex enough to handle all of them in one diagram)."

${ }^{14}$ Ehninger and Brockriede, 2nd ed., p. 92. These authors compare these general categories of argument to Aristotle's "general topoi" which are field-invariant, that is, applicable to all arguments. While they acknowledge the existence of "special topoi" which they view as equivalent to Toulmin's field-dependent sources of soundness, their analyses are focused upon the field-invariant categories.

15 Respectively, "Toulmin on Argument," now in Golden et al., and Decision by Debate, Ist and 2nd editions.

16 "Statistics" appears only in the lst edition of Decision by Debate, pp. 148-154. Because it has appeared in no subsequent textbook, it will not be discussed here as a category of proof.

17 Ehninger and Brockriede, p. 125.

18 The degree to which field-invariant assumptions are implied by the followers of Ehninger and Brockriede varies, yet none provide a clear explanation of field-invariant assumptions or examples which illustrate them. The collective result of these presentations is confusing. Textbooks by Bettinghaus, Freeley, and Rieke and Sillars include examples of warrants which appear to be field-dependent. See Freeley, p. 145. On the other hand, Bradley, Ehninger, and Verdeber imply field-invariance for all of their categories of argument and reinforce this implication by supplying field-invariant tests or questions. See Bradley, pp. 212-220; Ehninger, pp. 80-81; Verdeber, pp. 187-191. Still there are no references to field-invariant assumptions which underlie the warrant nor any examples which are clearly consistent with this notion.

$$
\begin{aligned}
& { }^{19} \text { Ehninger and Brockriede, 1st ed., p. } 134 . \\
& 20 \text { Ibid., p. 127, 129, 132, 139, 143, 145, 159, } 163 .
\end{aligned}
$$

See also McCroskey, p. 98, who refers to an assumption but unclearly. 
${ }^{21}$ Ehninger and Brockriede, lst ed., p. 135.

22 Blankenship, pp. 173-174. The discursive example is drawn from the transcripts of the Nixon-Kennedy presidential candidate's debate of 26 september 1960.

23 Ehninger and Brockriede, lst ed., p. 139, 143, 159.

24 Ibid., p. 145. Similar questions may be raised about motivational proof, pp. 163-165. Rieke and Sillars, pp. 78-88, and Ehninger, pp. 73-79 appear to make other errors of analysis and exemplification.

25 Ehninger and Brockriede, 1st ed., p. 127, 132, 143, $163,165$.

26

Ibid., p. 129.

27Blankenship, p. 173. This discursive example is drawn from a transcription of John F. Kennedy's "Cuban Missile Address."

${ }^{28}$ For an approach which identifies field-invariant assumptions and discusses their relationship with warrants in each category of argument, see Gibson, unpublished manuscript.

29 Hastings' work appears in two textbooks: Mills, lst ed., pp. 125-148; Windes and Hastings, especially pp. 157-189. His work has apparently not generated the kind of following which Ehninger and Brockriede's has.

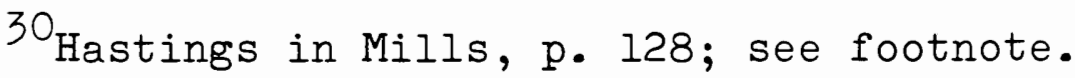

31 Arthur Hastings "A Reformulation of the Modes of Reasoning in Argumentation, " Dissertation Abstracts, 23 (1962), 4016A (Northwestern University).

32 This ranking reflects the frequency with which he found such forms being used in his sampling of arguments from various fields. In Windes and Hastings, ten categories of argument are identified, some of them different than the nine categories of his dissertation and Mills' lst edition.

\section{Hastings' nine categories are: argument from}

(1) example to a descriptive generalization, (2) criteria to a verbal classification, (3) definition to characteristics, (4) sign to unobserved event, (5) cause to effect, (6) circumstantial evidence to hypotheses, (7) comparison, 
(8) analogy, and (9) authority or testimony. In Mills, lst ed., p. 142, Hastings refers to (4) as "observed effect to an unobserved cause." In Windes and Hastings, p. 162, a new category is added, "characteristics to a value judgment (by criteria of value)", while other categories are relabeled and (2) and (4) are apparently replaced by a catchall category, "other processes of reasoning." See pp. 159-185.

${ }^{34}$ On the other hand, Hastings pays relatively little attention to the secondary elements of the Toulmin model-backing, rebuttal, and qualifier.

146 .

35 Hastings in Mills, p. 129, 131, 133, 137, 140, 145, 146.

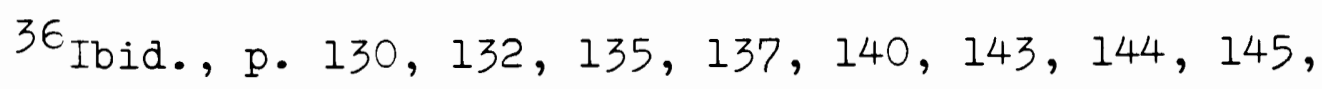

37 See, for instance, the description of the warrant in argument from circumstantial evidence to a hypothesis, Hastings in Mills, p. 144.

38 Windes and Hastings, pp. 104-150.

${ }^{39}$ Hastings in Mills, p. 129.

40 Ibid., p. 133. ${ }^{41}$ Ibid., p. 134,133 respectively.

42 Arnold, pp. 61-62.

${ }^{43}$ Condon and Yousif, pp. 228-230.

${ }^{44} \mathrm{~A}$ multiplicity of standards may be applicable to any particular argument. Some may draw their authority from a specific field, others from a cultural-orientation and, perhaps, others which are inherent in universal features in the structure of human language. While this view somewhat complicates what may be implied by "standards of argument," it also provides a middle ground between the field-invariant orientation of formal logicians and, apparently, some speech communication textbook writers and the field-dependent orientation of Toulmin.

${ }^{45}$ Human Understanding, pp. 378-380.
${ }^{46}$ Ibid., pp. 395-411. What Toulmin terms nondisciplinary activities and would-be disciplines fit this category where a common assumptive base is unavailable. Toulmin might consider rational argument in such areas unlikely if not impossible. 
47 See L. S. Harms, Intercultural Communication (New York: Harper and Row, 1973), for an intriguing prospectus of the implications of recent technological developments in communication.

${ }^{48}$ See Marilyn Matelski, "Khomeini's Argument for His Islamic Republic: A Relationist Perspective," paper presented at WSCA annual convention, Portland, Oregon (February, 1980).

49 Other approaches to the practical analysis of general categories of argument may be found in the previously cited work of Rupert Crawshay-Williams, Methods and Criteria of Reasoning, and Francis Gibson, "Critical Inquiry and Speech Communication," manuscript, Portland State University.

50 Golden et al., pp. 173-175, 182.

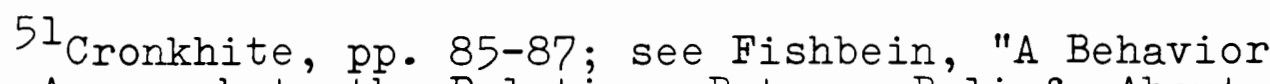
Theory Approach to the Relations Between Beliefs About an Object and the Attitude Toward the Object," in Readings in Attitude Theory and Measurement, ed. Martin Fishbein (New York: John Wiley and Sons, Inc., 1967). Reynolds.

52 Bae Keun Cha; D'Angelo; see also Reinard and

53 Application of the Toulmin model in the analysis of literature for oral interpretive performance was suggested to me by Francis Gibson in a seminar on the teaching of oral interpretation, Portland State University, 1977.

${ }^{54}$ See Jerie Pratt, "The Appropriateness of a Toulmin Analysis of Legal Argumentation," Speaker and Gavel, 7, No. 4 (May, 1970), 133-137; Richard Crable, "Models of Argumentation and Judicial Argument, "JAFA, 18, No. 1 (Winter, 1976), 113-120; David Rabin, "Gottlieb's Model of Rule-Guided Reasoning: An Analysis of Griswold v. Connecticut," JAFA, 15, No. 2 (Fall, 1978), 78-90; Don Abbott, "The Jurisprudential Analogy: Argumentation and the New Rhetoric," CSSJ, 25 (Spring, 1974), 50-55; Gidon Gottlieb, The Logic of Choice: An Investigation of the Concepts of Rule and Rationality (New York: Macmillan Co., 1968), especially pp. 169-171.

55 For a review of this work, see Charles Willard, "In Print," review of The Logic of Choice by Gidon Gottieb, JAFA, 15 (Fall, 1978), $\frac{124-132 .}{132}$ 


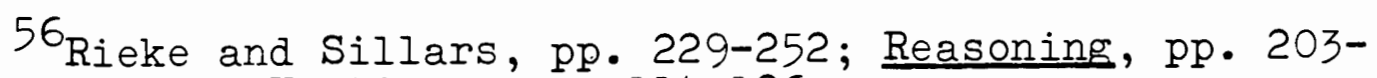
227; Windes and Hastings, pp. 114-126.

57 Reasoning, pp. 229-263; Windes and Hastings, pp. 126-137.

58 Reasoning, p. 251.

59 Toid., pp. 309-337.

60 Joseph Wenzel, "The Contributions of Argumentation to a Rhetoric of Values," ERIC (December, 1975), \#ED 123679.

${ }^{6 l_{\text {See }}}$ also Holt Spicer, "Stephen Toulmin's Functional Analysis of Iogic and Ethics and Its Relation to Rhetoric," Dissertation Abstracts, 25 (1964), 2105A (University of Oklahoma).

62 For "history," see Windes and Hastings, pp. 106-114; for "the arts," Reasoning, pp. 265-285; for "management," Reasoning, pp. 285-307; and Vicky Bradford and Larry Bradford, "The Executive as Arguer: Teaching Argumentation in a Major Industry," paper presented to WSCA annual convention, Portland, Oregon (February, 1980).

63 Application of the Toulmin model to speakeraudience settings is discussed in textbooks by Bradley, Verdeber, Bettinghaus, and McCroskey. Application of the Toulmin model to academic debate is discussed in Fhninger and Brockriede, 1st and 2nd editions; Mills, 1st and 2nd editions; Freeley; and Rieke and Sillars, especially pp. 277-301.

64 Gulley, p. $113 f$.

65 Windes and Hastings, pp. 137-150; Rieke and Sillars, pp. 255-275.

${ }^{66}$ Speech Communication Association Administrative Committee, SPECTRA, 16, No. 1 (February, 1980), 9.

67 Reported in Communication Education, 29 , No. 1 (January, 1980), 1-3.

68 Uses, pp. 94-95.

${ }^{69}$ Reasoning, p. 23, 105, 121.

70 Ibid., pp. 16-18. 
${ }^{71}$ Reasoning, "Part II," pp. 105-135.

72 Arnold, pp. 49-50. $\quad 73$ Ibid., pp. 61-64.

${ }^{74}$ Scheidel, Human Interaction, p. 206; Blankenship, pp. 170-171; Minnick, pp. 146-148; Bryant and Wallace, pp. 359-360.

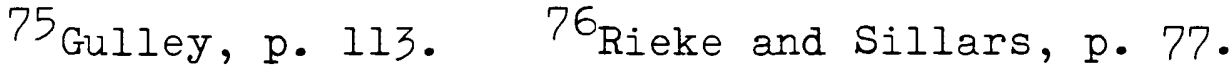

77 Ehninger and Brockriede, 1st ed., pp. 98-99, 238240.

${ }^{78}$ Tbid., 2nd ed., p. 49. $\quad 79$ Tbid., p. 44.

80 Clark, pp. 69-83.

${ }^{81}$ Bettinghaus in Miller and Nilsen, pp. 149-151.

${ }^{82}$ See for instance Book et al., p. 89.

83 Bradley, p. 207.

${ }^{84}$ Book et al., p. 89; Bradley, p. 207.

85 Bradley, p. 207. $\quad 86$ Bettinghaus, p. 103.

87 Bettinghaus in Miller and Nilsen, p. 148.

${ }^{88}$ See Freeley, Mills 1st and 2nd editions, Verdeber, Wilson and Arnold, Windes and Hastings, and McCroskey. ${ }^{89}$ Brockriede and Ehninger in Golden et al., p. 177. 


\section{CHAPTER VI}

\section{CONCLUSION}

Just as it was Toulmin's intention in The Uses of Argument not to solve problems but to draw attention to them, so the purpose of this study has been to survey the development of the Toulmin model as applied to speech communication and formulate questions which it is hoped will lend impetus and direction to subsequent research. In this chapter the major findings of this study are summarized followed by a discussion of main issues and implications for further research.

\section{SUMMARY OF MAJOR FINDINGS}

Major findings are presented here in four parts, each representative of a main line of inquiry, chapter division, and answer to one of the general questions toward which this study has been directed:

In what ways may the Toulmin approach be viewed as an innovation in the field of logic? To what extent and in what ways has the Toulmin model been developed through exposure to philosophical criticism? To what extent and in what ways has the Toulmin model been developed through interpretation by speech 
communication professionals? What effect has development of the Toulmin model had upon its various potential applications to speech communication?

The conclusions drawn in the following are based upon an analysis first of published criticisms of the Toulmin approach and second of selected speech communication textbook discussions of the Toulmin model.

Formal Logic and the Toulmin Approach

In chapter II, the Toulmin approach is compared to formal logic. Both are in general concerned with an assessment of the soundness, truth-value, or acceptability of assertions in argument. However, the specific assumptions, aims, and patterns of analysis of the two approaches differ. The Toulmin model may be viewed as an innovation in the field of logic because it is designed to accomplish the same general ends while avoiding the limitations of formal logic and the syllogism.

Characterized in earlier discussion as a linear theoretical perspective, formal logic is founded on the assumption that there is an absolute structure to reality such that sound conclusions may properly be inferred from true propositions, much as quantities are calculated in mathematics or geometry. The specific aim of analysis in formal logic is the determination of formal validity which may be considered tantamount to truth. The model for analysis 
used in such determinations is the syllogism, actually a set of rules governing the relationship of meaningful elements of sentences linked in an argument. Toulmin criticizes formal logic for its idealized assumptions, irrelevant aims, and simplistic model used in analysis--all which he believes contribute to the impracticality of applying formal logic to arguments in general.

The Toulmin approach to logical argument represents an attempt to avoid the limitations of formal logic with the aim of developing a more practical and applicable logic. Characterized in earlier discussion as a systems theoretical perspective, the Toulmin approach assumes a world of relative probabilities, the strength and soundness of which are subject to description and comparison in a manner analogous to jurisprudential procedure. The specific aim of the Toulmin approach is the candid description of methods of justification used in an argument and the degree of force associated with each justification. The model for analysis in terms of which justificatory arguments can be described is the Toulmin model. More complex than the syllogism, the Toulmin model distinguishes the elements of an argument according to their functions--drawing attention to several previously neglected features of argument.

Perhaps the most significant innovative aspect of the Toulmin model is that it may be used to describe the degree of strength or soundness of arguments which, 
according to the rules of the syllogism, may be judged formally invalid and therefore unsound. This is possible because the Toulmin model relies on criteria which are field-dependent, that is, specific to well-defined fields of inquiry. Formal logic on the other hand, relies on field-invariant criteria, that is, universal principles which are applicable to arguments in any field at any time. The Toulmin approach derives the broad applicability and practicality claimed for it primarily from this distinction between field-dependent and field-invariant criteria and its groundedness on the former.

Accordingly, the Toulmin approach may be said to represent an innovation in the field of logic. While sharing the same general goal as formal logic, the Toulmin approach differs in its assumptions, specific aims, model used in analysis, and criteria. These innovations are aimed at increasing the practical applicability of logic to substantial as well as analytic arguments.

Criticisms of the Toulmin Approach: Implications for Development of the Toulmin Model

In chapter III, principally philosophical criticisms are surveyed to determine what weaknesses, limitations, or difficulties may be inherent in the Toulmin approach. Critical claims regarding the Toulmin approach in general 
and the Toulmin model specifically are summarized and found to reflect the nearly unanimous skepticism of philosophers schooled in formal logic. These consistently negative responses support a hypothesis that the difference between formal logicians and Toulmin is deeper than a disagreement over Toulmin's innovative proposals; rather the difference may be indication of a conflict in their fundamental theoretical perspectives. Available supports for this hypothesis are examined.

General Objections to Toulmin's Approach. Formal logicians have four general objections to Toulmin's approach: (1) his ideas are unoriginal, derived from other modern logicians; (2) his concepts of formal logic are obsolete; (3) his proposals are not innovative, but essentially the same as current practices; and (4) his proposals are too innovative, discarding essential and useful features of formal logic. With regard to the effect of these criticisms on the development of the Toulmin model, there are two reasons why these objections may be judged inconsequential so far as speech communication is concerned. First, these objections are contradictory--they cannot all be true. Apparently, while agreeing that the Toulmin approach is unacceptable, formal logicians as a whole do not agree as to why this is so. Their rejection of the Toulmin approach is therefore suspect. At best no conclusion can be drawn from such controversial criticism. 
Second, none of these general objections by itself constitutes sufficient grounds for rejection of the Toulmin approach. One may grant its unoriginality, obsolescence, lack or excess of innovation without affecting the potential usefulness of applicability of the Toulmin approach to speech communication. Investigation of the philosophical implications of the Toulmin approach should not end in these four general objections, for they appear to leave the matter unsettled. Additionally, because none of them appears to affect the potential applicability of the Toulmin approach to speech communication, they may be judged inconsequential to the present study.

Specific Objections to Toulmin's Model. Formal logicians present several specific objections to the pattern of analysis proposed by Toulmin, the Toulmin model. Briefly, the primary objections are: (1) several of Toulmin's functionally-defined elements, notably data, warrant, and backing, cannot be reliably distinguished; (2) backing cannot provide any real justification because there can be no final justification in logic, only an infinitely regressive chain of justificatory arguments; (3) the concept of data as discussed by Toulmin is questionable; and (4) one cannot know for certain what Toulmin means by the phrase "warrantestablishing argument." Each of these objections has direct bearing on the potential applicability of the Toulmin 
model and the directions its development may usefully take. These are discussed below.

1. Two main conclusions may be drawn from objections regarding the distinguishability of elements of the Toulmin model. First, Toulmin never claimed that functional elements may be easily distinguished; however, his failure to offer precise definitions and illustrative examples of arguments in various fields has tended to leave room for confusion. Especially in the cases of data, warrant, and backing, Toulmin has only hinted at the relative degrees of generality associated with each, and he never compares their essential features in a manner which would clarify the distinctiveness of each element. Such clarification would increase the practical applicability of the model. Second, formal logicians on the whole seem to object to the delineation of nearly every functional element for which there is no counterpart in the syllogism--the innovative features of the Toulmin model. Some speech communication writers do not appear to encounter the same difficulties as formal logicians in distinguishing the differing functions of, for example, warrant and backing or data and rebuttal. While it may be granted that functionally-defined elements are not as obviously distinct as the linguistically-defined elements of the syllogism, this is not to suggest that Toulmin's elements cannot be reliably distinguished. If the bases for making such distinctions can be made clearer and 
more precise perhaps through the development of specific procedures of definition and the selection of illustrative examples drawn from discourse, then this objection may be disregarded.

2. Formal logicians object to Toulmin's apparent satisfaction with backing as representative of justification in argument. They argue that any resort to separate assurances such as the criteria in backing constitutes not justification but a separate argument--the first in an infinitely regressive chain of arguments. In other words, there can be no real justification for anything, according to formal logicians. While this objection may have a sound philosophical basis, Toulmin contends that it has no relevance to argument as practiced in human affairs. If there could be no practical justification, then there would be no rational basis for choosing from among alternative conclusions. Yet in every field there exists some systematic basis for making choices.

As implied by earlier discussions of the conflict between linear and systems theoretical perspectives, the crux of the problem is this: formal logicians and Toulmin mean different things when they use the term "justification." To Toulmin, justification refers to the fielddependent criteria resorted to when the soundness of a warrant is challenged, in other words, "backing." To formal logicians, justification refers to field-invariant 
criteria which are universal and absolute. Toulmin might agree with formal logicians who conclude that there can be no final or absolute justification for an argument. In human affairs, however, criteria which are at least temporarily acceptable within a special field are commonly resorted to as justification for arguments. It is doubtful that many formal logicians would accept this interpretation of justification.

The source of this objection to Toulmin's backing appears on the surface to be a semantic difference over the term "justification." This may only be symptomatic, however, of deeper theoretical differences. More to the point, the two concepts of justification need not be viewed as mutually exclusive, and therefore this objection does not present any obstacle to the potential applicability of the Toulmin model to speech communication.

3. Formal logicians raise a number of questions about data for which Toulmin presents no explicit answers. First, may data include multiple items as the term implies or is the Toulmin model only applicable in arguments based on a single datum? Second, are data subject to qualification; that is, wouldn't the candidness of the model be increased if modal qualifiers were appended to the data as well as to the claim in arguments where the data are less than absolute? Third, along the same lines, wouldn't the candidness of the model be increased if there was an 
independent element specifying support for data in the same way that backing specifies support for the warrant? Although not emphasized by formal logicians, it is apparent that each of these questions results from a confusion over the size and complexity of arguments to which the Toulmin model may be applied. Toulmin discusses only microarguments which yield most easily to analysis and involve only single items of data. Yet he nowhere explicitly prohibits or advises against applying the model to more complicated arguments as they may occur, for example, in rhetorical discourse. On the other hand, neither does he discuss procedures for the analysis of extended arguments which frequently involve multiple and qualified items of data as well as complex linkages among micro-arguments and major claims. Thus, formal logicians appear to have identified some significant issues concerning the nature of data. How and if these issues may be resolved is a matter of direct consequence to the applicability of the Toulmin model to speech communication.

4. The nature of warrant-establishing arguments is never clearly explained by Toulmin, as some formal logicians have indicated. While the concept of warrantestablishing vs. warrant-using arguments appears to be introduced by Toulmin merely to make a point about the nature of induction and deduction, it is unfortunate that Toulmin is not clearer on this point. There are at least 
two ways to interpret how a warrant-establishing argument may be analyzed in terms of the Toulmin model. It may be that either interpretation is adequate, although this determination will depend upon further investigation. This objection to the Toulmin model is, however, judged relatively inconsequential in that it appears that arguments may be analyzed with the Toulmin model regardless of any determination of whether they are warrant-using or warrantestablishing.

Other issues which receive only the passing attentions of formal logicians may be raised about the Toulmin model. For instance, Toulmin's assumption that argument is best viewed retrospectively may be challengeable. Aren't there practical situations in which argument functions prospectively, that is, when claims are discovered through the creative application of warrants to data? Whether the Toulmin model would be applicable to such cases is uncertain. Further, the relationship of the Toulmin model to the syllogism remains unsettled. According to Toulmin, formal logic and the syllogism are inherently limited if not defective, and should therefore be discarded in favor of his more candid practical approach. Yet, if the two approaches differ so much as to their aims and assumptions they need not be viewed as incompatible. Certainly the question of whether or not the Toulmin model represents an alternative or complement to the syllogism is an important one. 
Finally, Toulmin's assumption that field-invariant aspects of argument are irrelevant to that upon which the soundness of argument depends may be the single most controversial feature of his approach. More than any other, it is this assumption which separates Toulmin from formal logicians. The question is to what extent may field-invariant aspects of argument be considered irrelevant? Unless one is prepared to discard them entirely as Toulmin seems to suggest, their role in the analysis of argument is uncertain. Many formal logicians and, as it turns out, speech communication textbook writers choose not to disregard them. The relationship of field-invariant and field-dependent aspects of argument and the relevance of each to the soundness of an argument is an important matter for further investigation. An Hypothesis: Conflicting Theoretical Perspectives. An obvious conclusion about the responses of formal logicians to Toulmin's innovative proposals is that they have been vigorous and almost unanimously negative. One explanation for this might be that Toulmin's approach is indeed without merit. Occasionally a weak theory or poor idea will gain popularity in a particular field; perhaps this is the case with the Toulmin model in speech communication. On the other hand, the near total disagreement expressed by formal logicians regarding Toulmin's view of the nature of logical argument and the values of analysis suggests another hypothesis: Toulmin and formal logicians are not 
working within the same theoretical perspective. To formal logicians, logical argument has an absolute structure involving elements which function in a causal, deterministic manner. Such assumptions are consistent with a linear theoretical perspective. In contrast, Toulmin assumes the structure of logical argument to be more relative, evinced by the bi-directional interaction among its functionallydefined elements. Such relativism is consistent with a systems theoretical perspective. The difference in the fundamental assumptions of these theoretical perspectives would at the very least inhibit the comprehensibility of Toulmin's approach to formal logicians--and vice versa.

Moreover, the differences in theoretical perspectives are not limited to the contrasting assumptions of Toulmin and formal logicians; their specific aims diverge as well. To formal logicians, the aims of logical analysis of argument are both prescriptive and evaluative--contributing to the preservation of a standard against which all arguments may be judged. However, Toulmin's aims are both descriptive and comparative. His retrospective approach to logical analysis is designed to provide the conceptual tools necessary to explain the epistemological functions of argument and the role played by arguments in the evolution of ideas. In other words, to Toulmin it is not the preservation of a standard but the documentation of changing standards which is of greatest interest. Accordingly, he adheres to a 
systems theoretical perspective which is flexible enough to facilitate his purpose. The deterministic, linear theoretical perspective of formal logicians would appear to be inadequate to the tasks Toulmin has in mind.

Just as Toulmin's objections to formal logic seem most sensible when viewed from a systems perspective, so it is that formal logicians' objections to the Toulmin approach seem more sensible when viewed from a linear perspective. This explanation of the gulf between Toulmin and formal logicians is pertinent to the question of applicability of the Toulmin model to speech communication in that among speech communication professionals are both systems and linear theorists.

Interpretations of Speech Communication

Professionals: Implications for

Development of the Toulmin

Model

In chapter IV are presented the results of a survey of twenty-seven speech communication textbook editions in which the Toulmin model is discussed. How Toulmin's innovative approach is represented in these textbooks and what that may indicate about the interpretations of speech communication professionals is the focus of this discussion. Five features of these presentations are discussed: (1) theoretical bases of the Toulmin approach; (2) the Toulmin diagrammatic model and variations; (3) terminology and definitions of the elements of the Toulmin model; (4) illustrative examples of arguments analyzed with the Toulmin model; and (5) 
discussions of the syllogism in conjunction with presentations of the Toulmin model. In general, speech communication textbook writers have appropriated the Toulmin model for their own purposes regardless of the objections of formal logicians to the Toulmin approach. However, the various attempts to develop the model have led to wide diversity of interpretations and apparent disagreements regarding many features of the Toulmin model.

Theoretical Bases. The theoretical bases of the Toulmin approach are in general poorly represented in speech communication textbooks. As might be expected, argumentation and debate textbooks embody more of these concepts than do oral communication textbooks. Nevertheless, in most cases theoretical bases of the Toulmin model are either explicitly absent or implicitly contradicted in textbook presentations. Only a few textbooks are found to discuss the significance of field-dependent sources of soundness, the probable nature of substantive claims, and other relativistic assumptions of the Toulmin approach.

An apparent consequence of the poor representation of theoretical bases of the Toulmin approach is the confusing diversity of interpretations it promotes. For example, the distinction between field-invariance and field-dependence is ignored in most textbooks. However, in several textbooks the notion of field-dependent criteria appears to have been substituted with a rhetorical concept--audience-dependent 
criteria. Similarly, probability and other relativistic aspects of the Toulmin approach are seldom discussed, lending support to an absolute and static view of argument more in harmony with the linear perspective of formal logic than the systems perspective of the Toulmin approach.

On the basis of the foregoing it may be concluded that many speech communication textbook writers diverge from the Toulmin approach by failing to acknowledge his theoretical assumptions. Whether the resulting diversity of interpretations should be considered distortions or developments of the Toulmin model probably depends upon one's theoretical perspective.

Diagrammatic Model and Variations. The Toulmin model as represented in textbooks is not a single, recognizable construct but actually a number of models which vary in their complexity, structure, and definitive characteristics. Diagrammatic models appear to come in three varieties: standard, consisting of Toulmin's six elements in roughly their original configuration; truncated, consisting of fewer than six elements; and extended, consisting of more than six elements or presuming more elaborate relationships among elements than in a standard diagram.

Few standard diagrammatic models are presented in speech communication textbooks. Most authors present some sort of truncated diagram of the Toulmin model, omitting one or more of its innovative features. Indeed, some 
diagrams are so truncated so as to resemble syllogisms on their sides with major premise, minor premise, and conclusion simply relabelled as warrant, data, and claim, respectively. Extended diagrams, on the other hand, generally emphasize innovative features of the Toulmin model by adapting it to complex forms of argument. Most extended diagrams appear to provide various answers to some of the questions posed by formal logicians. Notably, extended diagrammatic models exemplify the applicability of the Toulmin model to macro-arguments, involving chains of interacting warrants and claims. In addition, some extended diagrams involve the explication of multiple items of data in support of a single claim as well as the inclusion of new elements such as qualifiers appended to the data and elements indicating support for data.

On the whole, diagrammatic models presented in speech communication textbooks constitute a confusing assortment, even though nearly all of them are at least partially attributed to Toulmin.

\section{Terminology and Definitions of Elements. Just as} there is diversity in interpretations of Toulmin's diagrammatic model, so is there also diversity in interpretations of definitions of the elements. While the concepts represented are ostensibly the same, some authors use substitute terminology to refer to the elements of the Toulmin model. More significant than differences in terminology are 
differences in definitions of the elements themselves. According to speech communication textbooks: (a) claim is generally conceived as applying to both macro-arguments and micro-arguments; (b) qualifier and warrant are generally defined roughly as Toulmin suggests; (c) the term data is defined differently by different authors, some emphasizing its factual specificity, others emphasizing its credibility to a particular audience; (d) rebuttal is defined roughly the same by all, but there appears to be disagreement as to the conditions for its use; and (e) backing, its nature and conditions for use, is not clearly defined in most cases. Most variations in definitions are subtle; however, overall there is a lack of precision and clarity in textbook definitions of the elements.

It may be significant that the imprecision of definition to which formal logicians have objected in Toulmin's writing is also characteristic of presentations of the Toulmin model in speech communication textbooks. In other words, speech communication textbook writers have not contributed to a needed clarification of Toulmin's terms. They may have added new opportunities for confusion with their various definitions. As previously suggested, this diversity of definitions may be related to the apparent failure of many writers to recognize the extent to which Toulmin's theoretical perspective differs from that of formal logicians. 
Illustrative Examples. Two kinds of illustrative examples characterize textbook presentation of the Toulmin model: invented, including arguments created or freely adapted from discourse to suit the needs of the presentation; and discursive, arguments drawn from specifically cited public speeches or published essays. Most textbooks are found to include only a minimal number of invented examples. Few present discursive examples and even fewer present both kinds of illustrative examples. Some of the invented examples are found to illustrate quasi-syllogistic arguments which do not have features that may be distinctively displayed with the Toulmin model. In some instances, the illustrative examples presented appear to be in error-inconsistent with verbal explanations of the Toulmin model.

Ideally, textbook presentations would include illustrative examples of both kinds, invented and discursive. In this way confusion as to the nature of the elements might be avoided and procedures of analysis might be made clearer. In any case, illustrative examples which are limited to syllogistic arguments or are inconsistent with verbal explanations are bound to be detrimental to the clear transmission of Toulmin's innovative approach. Discussion of the Syllogism. It cannot be determined from speech communication textbook presentations of the Toulmin model whether it is conceived as an alternative or complement to the syllogism. In general, the Toulmin model 
is as likely to be presented in isolation as it is in conjunction with the syllogism. Thus, there appears to be some ambivalence or disagreement about the relative status of each model of logical analysis in speech communication.

Application of the Toulmin Model as

Suggested in Speech Communication

Textbooks

In chapter $V$, proposed applications of the Toulmin model are discussed. It has been suggested by speech communication professionals that the Toulmin model is applicable to: (1) the analysis and exemplification of fieldinvariant categories of argument; (2) specific fields relevant to speech communication; and (3) rhetorical discourse in general. As with other aspects of speech communication textbook presentations already discussed, the interpretations of speech communication professionals are diverse and often in disagreement on finer points. Overall, however, writers who present the Toulmin model tend to be optimistic about its applicability to speech communication. General Categories of Argument. Some authors have utilized the Toulmin model in the analysis and exemplification of general categories of argument. Two approaches are found in textbooks: one introduced by Ehninger and Brockriede which has developed a following within speech communication relates the Toulmin model to concepts drawn from classical rhetorical theory; another, introduced more 
recently by Hastings, draws its reformulated general categories from an empirical study of the frequency with which they occur in actual arguments. The two approaches appear to overlap at many points, including the assumption that general categories are field-invariant and that the Toulmin model is useful in describing them.

While Toulmin apparently agrees that general categories are field-invariant, his field-dependent orientation which is based on the assumption that field-invariant features of argument are irrelevant is clearly inconsistent with attempts to apply the Toulmin model to general categories of argument. Neither the rhetorical nor the empirical approach addresses the issue of field-invariance vs. field-dependence. No clear criteria for distinguishing field-invariant from field-dependent aspects of argument are identified; neither are the basic assumptions which underlie each of the general categories explicitly identified. Thus, the confusion which has long surrounded the subject of general categories of argument has apparently not much been reduced by this proposed application of the Toulmin model.

The field-invariant/field-dependent distinction may be the source of some of the controversy about general categories of argument; it is, perhaps, a false dichotomy. It has been suggested that general categories of argument are not absolute universals as implied by the term 
"field-invariant," they may instead be culturally-based assumptions about justification. Though they may be superceded by more exacting criteria drawn from a specialized field as Toulmin suggests, cultural assumptions may in many circumstances provide the only available logical criteria for an argument. Therefore, Toulmin's view to the contrary, general categories of argument conceived as cultural assumptions may be relevant to analysis. Such a reconciliation between the positions of Toulmin and proponents of the application of the Toulmin model to general categories may only be accomplished through a clarification of the fieldinvariant/field-dependent distinction and the development of clear criteria--the identification of basic assumptions-for each general category or form of argument. Overall, there is a need for clarification of the epistemological assumptions of the field of speech communication; this might expedite attempts to resolve the issues regarding the nature of field-invariant assumptions.

Specific Fields Relevant to Speech Communication. In textbooks and other publications, applications to theories from relevant fields, special fields subject to speech communication research and various communication settings have been proposed. The Toulmin model has been related to rhetorical theory, psychological theories of attitude change, and intercultural communication theory as well as to specific fields such as politics, law, science, and ethics 
among others. Further, it has been associated with arguments in nearly all of the commonly discussed communication settings.

Field-specific applications represent the direction of theoretical development Toulmin appears to have hoped his approach would undergo. At present, all of these applications are fairly young and their usefulness is undetermined. It is possible that as each special field interprets the Toulmin model any number of unique variations may be developed, each suited to its field of application. The Toulmin model appears to have potential value in a number of fields and communication settings. How much of this potential will be realized remains to be seen.

Rhetorical Discourse in General. Most of the textbooks surveyed advocate the application of the Toulmin model in the analysis and determination of soundness of the arguments of rhetorical discourse in general. Two kinds of application are discussed: retrospective analysis as in rhetorical criticism, and prospective analysis as in inventio and dispositio, the construction and arrangement of arguments in a message. Some take the position that the model may be used both retrospectively and prospectively as a paradigm of rational argument. The only clear disagreement appears to be between those authors who explicitly advocate the use of the Toulmin model in dispositio as a plan of organization and those who argue specifically 
against such an application. The differences between proponents of the retrospective and prospective applications of the Toulmin model may result from differences between the two kinds of textbooks surveyed--argumentation and debate textbooks on the one hand and oral communication textbooks on the other. The point is that the model is being utilized in both ways in speech communication textbooks. Generally, writers who present the Toulmin model appear to believe that it is superior to the syllogism as a means of describing and testing the soundness of arguments.

In summary, a wide range of applications have been suggested for the Toulmin model by speech communication professionals, nearly all of them based on the assumption that the Toulmin model is representative of the process of reasoning. Whether the Toulmin model will achieve the optimistic potential applications suggested for it by speech communication professionals depends upon the extent to which presently unresolved issues are addressed in subsequent research. Without attempts to examine and hopefully resolve issues surrounding the application of the Toulmin model in speech communication, the current trend towards increasingly diverse and competitive interpretations of the Toulmin model may continue, thus furthering the general confusion apparently associated with the Toulmin approach. 
SUGGESTIONS FOR FURTHER RESEARCH

This study represents an attempt to document the evolution and current state of theoretical development of Toulmin's approach to the study of argument. Through this review and analysis of salient literature, many issues have been identified which bear upon the potential applicability of the Toulmin model in speech communication. These issues comprise the major findings presented in the preceding summary. Further research appears to be justified in a number of areas.

While areas for future investigation have been alluded to throughout this study, for the benefit of subsequent researchers they are here collected and presented in an order which emphasizes their interrelatedness. These issues involve: (1) an apparent conflict of theoretical perspectives; (2) confusion regarding the nature of fields of argument; and (3) confusion regarding the nature of the Toulmin model. Several research questions related to each general issue are suggested.

\section{Conflict of Theoretical}

\section{Perspectives}

One explanation for the vastly different positions advocated by formal logicians and Toulmin is that they are working within conflicting theoretical frames of reference. It appears that formal logicians in general conform to the aims and assumptions of a linear perspective and that 
Toulmin's views in general conform to the aims and assumptions of a systems perspective. The significance of this apparent conflict of theoretical perspectives is that it provides a basis for answering questions about the relative usefulness of formal logic and the Toulmin approach in speech communication, such as "Which approach or combination of the two approaches best suits the goals and methods of speech communication? Moreover, what are the goals and methods of speech communication in this context? Because speech communication is an eclectic field comprised of theorists working within various theoretical perspectives, it may be that both approaches to logical argument may have a useful role to play in studying different aspects of discourse or interpersonal behavior. Specifically, which approach may be most useful for which purpose is a subject for further investigation.

Another important consequence of the conflicting theoretical perspectives is the determination of the relationship in speech communication of the syllogism and the Toulmin model. Currently, textbooks may present either, both, or some combination of the two models; authors apparently do not agree as to which may be the more useful and candid tool for the analysis of arguments. Three possible relationships appear to be possible between these two models: alternative, in which one or the other is determined to be superior in most important respects or for the 
greater number of applications; complementary, in which the different values of each approach are identified and their respective domains of application determined; or synthetic, in which the most valuable elements of each approach are combined in a new model which is superior to both. Some of the proposed truncated and extended diagrammatic models which appear in textbooks imply different authors' preferences as to the most useful features of each approach. However, there is almost no published empirical support for any one of the above relationships. Therefore, what is needed, in addition to the clarification of underlying theoretical assumptions, is comparative testing of the two models--preferably on real arguments drawn from discourse. In this way relative values indicating degrees of reliability, precision, intelligibility, and applicability can be determined.

\section{Confusion Regarding the} Nature of Fields

Many aspects of the Toulmin approach appear to require clarification and more precise definition. One of these is the nature of fields of argument and, consequently, the field-invariant/field-dependent distinction. Basically there is confusion as to what may properly be considered a field and how apparently similar, overlapping, or related fields--such as psychology, sociology, social-psychology, and speech communication--may be distinguished. Some 
authors appear to believe that any human enterprise, no matter how diffuse its activities, may be usefully conceived as a field in Toulmin's terms. Others suggest that some human enterprises qualify as fields while others may not, and still others may be somewhere in between. Because the criteria which the Toulmin model is designed to explicate are field-dependent, what may or may not be usefully conceived as a field is of primary importance. Indeed, the very nature of what constitutes "justification," hence backing, depends upon how fields are defined.

Some aspects of argument are field-dependent according to Toulmin, while others are field-invariant. How these two types of aspect are to be distinguished is a matter of confusion. Further, in this study it is suggested that the distinction itself may be misleading--a false dichotomy. The field-dependent half of the dichotomy is only as clear as the concept of fields of argument may be; the fieldinvariant half may have obscured within it any number of potentially useful distinctions such as culture-dependence, group-dependence, dyad-dependence, person-dependence, or even species-dependence. Any one of these hypothetical constructs may prove useful in describing a source of justification resorted to by some arguer in some formm of argument or another. Unless the field-invariant/fielddependent dichotomy can be more carefully defined, broken down into other distinctions, or linked with deeper 
underlying theoretical differences, it will remain a source of confusion in the analysis of arguments.

In this study it has been suggested that fieldinvariant forms of argument may more easily yield to observation if viewed as culturally-dependent assumptions about justification. This view may provide a bridge between the study of argument as an interpersonal or linguistic phenomenon to its epistemic role in intercultural communication. Further, if culturally-dependent assumptions can be more precisely defined, they may provide a more agreeable basis for the classification of general categories of argument than any other thus far proposed.

Returning to the subject of field-dependence, the extent to which justification procedures in various fields actually differ from one another, as Toulmin has claimed, has yet to be determined. Perhaps because the boundaries which separate one field from the next have been so resistant to definition, comparative analyses of arguments in different fields have yet to be performed. Yet this is one of the primary purposes for which the Toulmin model was intended: the description and comparison of justification procedures and their evolution in various fields of inquiry. Finally, Toulmin's claim that field-invariant aspects of an argument have no relevance to its soundness or strength appears to be the source of some disagreement and confusion among writers of speech communication textbooks. 
Apparently there are many who disregard this fundament of Toulmin's approach. On the basis of the conclusions summarized earlier, it appears possible that Toulmin may have overstated his case. The extent to which analyses of fieldinvariant aspects of argument are relevant and useful to a determination of the soundness and strength of argument is a matter for further investigation. If it can be shown that a failure to attend to field-invariant features such as the basic assumptions according to which arguments may be classified into general categories reduces the degree to which an analysis is candid and complete, then some revision in Toulmin's position is in order. It would be most helpful if comparative studies were made of both fieldinvariant and field-dependent analyses of a variety of arguments.

\section{Confusion Regarding the Nature} of the Toulmin Model

Given a clarification of paradigmatic differences discussed above then there is the need for clarification of many of Toulmin's concepts, particularly the elements of the Toulmin model. Formal logicians have criticized Toulmin's initial presentation of his concepts for their lack of clarity; some critics have hinted that Toulmin failed to be more precise because his concepts themselves are ambiguous and self-contradictory. While speech communication textbook writers appear to be untroubled by this 
alleged lack of clarity, neither have they presented any more precise definitions. Thus, there is confusion about several concepts related to the Toulmin model which must be reduced if the model is to be made reliably applicable.

One source of imprecision in definitions of the elements is ambiguity about the scope of applicability of the Toulmin model. The model is obviously applicable to microarguments, the smallest and simplest units of argument. However, there is disagreement about its suitability to the analysis of more complex extended arguments as they might appear in discourse. As a result, some authors present modified, extended diagrams based upon the Toulmin model which adapt it to common complex forms. Others suggest that the model may be applied to longer, more complex arguments if only one specifies the acceptability of multiple data, adds an element to indicate support for data, or links several diagrams together indicating a chain of arguments leading to a conclusion. Each of these maneuvers is meant to make the Toulmin model more easily applicable to macroarguments. Whether any of them is necessary and, if so, which is the most candid and least problematic is a matter requiring clarification.

Of the elements of the Toulmin model it is suggested that all could be more precisely defined, that is, described in such a way that students can learn to reliably distinguish each element from the others without confusion or 
undue disagreement. Judging from textbook definitions, the procedures for performing such reliable analyses have jet to be developed. Questions regarding the nature of data have been discussed as contingent upon the applicability of the Toulmin model to macro-arguments. About rebuttals, there is confusion about their limits, conditions for use, and relationship to other elements, in particular, qualifiers, and warrants. This confusion has apparently led some writers to omit this element entirely, and others to include as rebuttals every conceivable counterargument that can be listed. Either interpretation of rebuttal seems to restrict the ease with which the Toulmin model may be applied.

Perhaps the element about which the greatest disagreement exists is backing. Supposedly representative of the rational criteria by which an argument is justified, the definition of this element is uniquely dependent upon the definition of the term "field," because according to Toulmin backings are field-dependent. Consequently, confusion over the nature of fields has apparently led some writers to define backing in terms of the credulity of the immediate audience regarding the topic of argument. Others have omitted this element from their diagrammatic versions of the Toulmin model, thus circumventing the difficulty of arriving at a precise definition. By doing so, they cause their versions of the Toulmin model to be more syllogistic 
by making warrants, like major premises, dependent for support upon prior arguments. The integrity of the Toulmin approach is dependent upon the potential development of less drastic solutions than omission to the problem of defining elements of the Toulmin model.

Finally, there is some confusion as to the limits of applicability of the Toulmin model. Some writers follow Toulmin's suggestion that his approach is restricted to the retrospective analysis of justificatory arguments. What kinds of arguments are not justificatory is not clear. Neither is it clear whether the model has any prospective applications, although some speech communication textbook writers advocate such uses.

Further, there is disagreement among proponents of prospective applications as to whether or not the Toulmin model has any value as an organizational pattern. Issues such as these should be resolvable through the development of more precise definitions which stand up to the practical test of reliability in practice as well as comparing the effectiveness of the Toulmin model in prospective applications with other approaches to inventio and dispositio.

\section{LIMITATIONS OF THE PRESENT STUDY}

Besides the practical limitations of availability of resources and time, this study has been limited by its metatheoretical nature. In other words, the data base from 
which conclusions have been drawn consists of the writings of theorists about the writings of a theorist about theories of argumentation. There has been relatively little opportunity to move from the abstract to the concrete, from concepts of practical argument to a consideration of actual examples of arguments. Thus, most of this study has remained in the abstract--relating concepts to concepts and seldom to that which the concepts represent. This was necessary because the author could not find in the literature of the Toulmin approach any single source in which issues concerning the applicability of the Toulmin model to speech communication were formulated. It was concluded that until issues drawn from the history of theoretical development of the Toulmin approach could be formulated, no concrete investigation of the model itself could proceed. It is hoped that this work may provide a foundation for more concrete and focused investigations of the Toulmin model which may follow. While this meta-theoretical inquiry may serve as a starting place, the issues raised here can only be resolved by research which has as its data-base the intended concerns of the Toulmin approach--practical arguments drawn from various fields of argument. However, this research must proceed from a clear understanding of the possible epistemological differences underlying the traditional syllogistic approach and Toulmin's approach to argument. 


\section{A SELECTED BIBLIOGRAPHY}

Abbott, Don. "The Jurisprudential Analogy: Argumentation and the New Rhetoric," Central States Speech Journal, 25 (Spring, 1974), 50-55.

Albertson, Gary, and Patrizzi, Mary, eds. Fire Mountain: The Eruptions of Mount St. Helens. Portland: Cathco Publishing Co., 1980 .

Anderson, Barry. The Compleat Thinker. Portland State University, 1978.

Anderson, Ray Iynn. "Argumentation and Rhetoric," Speaker and Gavel, 4, No. 2 (January, 1967), 36-41.

Aristotle. The Rhetoric of Aristotle. Translated by Lane Cooper. New York: Appleton-Century-Crofts, Inc., 1960 .

Prior Analytics. Translated by A. J. Jenkinson. In The Basic Works of Aristotle. Edited by Richard Mckeon. New York: Random House, 1941.

Posterior Analytics. Translated by G. R. G. Mure. In The Basic Works of Aristotle. Edited by Richard Mckeon. New York: Random House, 1941.

Arnold, Carroll. Criticism of Oral Rhetoric. Columbus: Charles E. Merrill Publishing Co. Inc., 1974.

Barker, Stephen. "Must Every Inference Be Either Deductive or Inductive" in Philosophy in America. Edited by W. Alston. Ithaca: Cornell University Press, 1967. The Elements of Logic. New York: McGraw-Hill Publishing Co., 1965.

Barzun, Jacques, and Graff, Henry. The Modern Researcher. New York: Harcourt Brace and World, Inc., 1957.

Bateson, Gregory. Mind and Nature. New York: E. F. Dutton Publishing Co., 1979.

Bennett, Milton. "The Relationship of Communication Perspectives," paper, Portland State University, 1977. 
Berlo, David. The Process of Communication. New York: Holt, Rinehart and Winston, 1960.

Bettinghaus, Erwin. Message Preparation: The Nature of Proof. Indianapolis: Bobbs-Merrill Co. Inc., 1966. "Structure and Argument," in Perspectives on Argumentation. Edited by Gerald Miller and Thomas Nilsen. Chicago: Scott, Foresman and Co., 1966.

Bird, Otto. "The Re-Discovery of the Topics: Professor Toulmin's Inference-Warrants, " Mind, 70 (Octboer, 1961), 534-539.

Bitzer, Lloyd. "Aristotle's Enthymeme Revisited," Quarterly Journal of Speech, 45, No. 4 (December, 1960), 399408.

Black, Max. Critical Thinking. Englewood Cliffs: PrenticeHall, 1942 .

Blankenship, Jane. Public Speaking: A Rhetorical Perspective. 2nd ed. Englewood Cliffs: Prentice-Hall, Inc., 1972.

Book Cassandra et al. Human Communication: Principles, Contexts, and Skills. New York: St. Martin's Press, Inc., 1980 .

Bradford, Vicky, and Bradford, Larry. "The Executive as Arguer: Teaching Argumentation in a Major Industry," paper presented to Western Speech Communication Association annual convention, February, 1980, Portland, Oregon.

Bradley, Bert. Fundamentals of Speech Communication: The Credibility of Ideas. 2nd ed. Dubuque: Wm.C. Brown

Brembeck, Winston. Review of The Uses of Argument by Stephen Toulmin. Quarterly Journal of Speech, 44, No. 2 (October, 1958), 358-359.

Brockriede, Wayne, and Ehninger, Douglas. "Toulmin on Argument: An Interpretation and Application," Quarterly Journal of Speech, 46, No. I (February, 1960), 44-53.

Bryant, Donald, and Wallace, Karl. Fundamentals of Public Speaking. 4th ed. New York: Appleton-CenturyCrofts, 1969. 
Burleson, Brant. "On The Analysis and Criticism of Arguments: Some Theoretical and Methodological Considerations," Journal of the American Forensic Association, 15 (Winter, 1979), 137-147.

"On the Foundations of Rationality: Toulmin, Habermas, and the A Priori of Reason," Journal of the American Forensic Association, 16 (Fal1, 1979), 112127 .

Casteneda, Hector Neri. "On a Proposed Revolution in Logic," Philosophy of Science, 27 (July, 1960), 279292 .

Cha, Bae Keun. "The Toulmin Model of Argument and Cognitive Consistency: A Search for the Foundations of Logical Proof." Ph.D. dissertation, Kent State University, 1972.

Clark, Donald. Rhetoric in Greco-Roman Education. New York: Columbia University Press, 1972.

Cohen, M. R., and Nagel, Ernest. An Introduction to Logic and Scientific Method. New York: Harcourt, Brace and World, Inc. 1934.

Condon, John, and Yousif, Fathi. An Introduction to InterCultural Communication. Indianapolis: Bobbs-Merrill Company, Inc., 1975.

Cooley, I. C. "On Mr. Toulmin's Revolution in Logic," Journal of Philosophy, 55 (March, 1959), 297-319.

Copi, Irving. Introduction to Logic. 4th ed. New York: Macmillan Publishing Co. Inc., 1972.

Corbett, Edward. Classical Rhetoric for the Modern Student. 2nd ed. New York: Oxford University Press, 1971.

Cowan, J. I. "The Uses of Argument--An Apology for Logic," Mind, 73 (January, 1964), 27-45.

Cox, Gerald. Review of An Introduction to Reasoning by Toulmin, Rieke, and Janik. Southern Speech Communication Journal, 45, No. I (Fall, 1979), 104-106.

Crable, Richard. "Models of Argumentation and Judicial Argument," Journal of the American Forensic Association, 12, No.1(Winter, 1976), 113-120. 
Crawshay-Williams, Rupert. Methods and Criteria of Reasoning: An Inquiry into the Structure of Controversy. New York: The Humanities Press, Inc., 1957.

Cronkhite, Gary. "The Enthymeme as Deductive Rhetorical Argument," Western Speech, 30, No. 2 (Spring, 1966), $129-134$.

Persuasion: Speech and Behavioral Change. Indianapolis: Bobbs-Merrill Company, Inc., 1969.

D'Angelo, Gary. "A Schema for the Utilization of Attitude Theory Within the Toulmin Model of Argument, " Central States Speech Journal, 22 (Summer, 1971), 101-109.

Delia, Jesse. "The Logic Fallacy, Cognitive Theory, and the Enthymeme: A Search for the Foundations of Reasoned Discourse," Quarterly Journal of Speech, 56, No. 2 (April, 1970), 140-148.

Durant, Will. The Story of Philosophy. New York: Simon and Schuster Publishing Co., 1926; reprinted 1961.

Ehninger, Douglas, and Brockriede, Wayne. Decision by Debate. 2nd ed. New York: Dodd, Mead and Company, Inc., 1978; lst ed., 1963.

Ehninger, Douglas. Influence, Belief, and Argument: An Introduction to Responsible Persuasion. Glenview: Scott, Foresman and Co., 1974.

Feezel, Jerry. "The Mystery of the Epicheireme," Western Speech, 31, No. 2 (Spring, 1967), 109-115.

"A Qualified Certainty: Verbal Probability in Arguments," Communication Monographs, 41 (November, 1974 ), 348-356.

Fisher, Walter. "Uses of the Enthymeme," Speech Teacher, 8, No. 3 (September, 1964), 187-203.

Fishbein, Martin, ed. "A Behavior Theory Approach to the Relations Between Beliefs About an Object and the Attitude Toward the Object," in Readings In Attitude Theory and Measurement. New York: John Wiley and Sons, Inc., 1967 .

Gibson, Francis. "The Nature and Elements of Reasoning," in "Critical Inquiry and Speech Communication." Manuscript, Portland State University, 1975. 
Gibson, James et al. "The Basic Course in Speech at U.S. Colleges and Universities: III," Communication

Education, 29, No. 1 *January, 1980), 1-9.

Gottlieb, Gidon. The Logic of Choice: An Investigation of the Concepts of Rule and Rationality. New York: Macmillan Co., 1968.

Gulley, Halbert. Discussion, Conference and Group Process. 2nd ed. New York: Holt, Rinehart and Winston, Inc., 1968.

Hample, Dale. "The Toulmin Model and the Syllogism," Journal of the American Forensic Association, 41 (November, 1974), 348-356.

Hardin, C. I. Review of The Uses of Argument by Stephen Toulmin. Philosophy of Science, 26 (April, 1959), $160-163$.

Harms, I. S. Intercultural Communication. New York: Harper and Row, 1973.

Harrington, Elbert. Rhetoric and the Scientific Method of Inquiry, A Study of Invention. Boulder: University of Colorado Press, 1948.

Hastings, Arthur. "A Reformulation of the Modes of Reasoning in Argumentation," Dissertation Abstracts, 23 (1962), 4016A, Northwestern University.

Review of Decision by Debate by Ehninger and Brockriede. Journal of the American Forensic Association, 1, No. 1 (January, 1964), 34-36.

"Reasoning Processes" in Reason in Controversy, by Glen Mills. Boston: Allyn and Bacon, Inc., 1974.

Heidt, Raymond. "Stephen Toulmin's Argument Model as a Critical Device for Speech." M.A. thesis, San Jose State College, 1968.

Hill, Forbes. Review of Decision by Debate by Ehninger and Brockriede. Journal of the American Forensic Association, 1, No. 1 (January, 1964), 36-38.

Informal Logic Newsletter, 2, No. 3 (June, 1980), 19.

Janis, Irving, and Frick, Frederick. "The Relationship Between Attitudes Toward Conclusions and Errors in Judging Logical Validity of Syllogisms," Journal of Experimental Psychology, 33 (1943), 73-77. 
Kaplan, Abraham. The Conduct of Inquiry. San Francisco: Chandler Publishing Co., 1964.

Kneale, William, and Kneale, Martha. The Development of Logic. London: Oxford University Press, 1962.

Kneupper, Charles. "On Argument Diagrams," Journal of the American Forensic Association, 14 , No. 2 (Spring, 1978), 181-186.

Korner, S. Review of the Uses of Argument by Stephen Toulmin. Mind, 68 (July, 1959), 425-427.

Kruger, Arthur. Modern Debate: Its Logic and Strategy. New York: McGraw-Hill Co., 1960.

Kyburg, Henry, and Nagel, Ernest. Induction: Some Current Issues. Middleton: Weslyan University Press, 1963.

Lamb, Catherine. "Exploring the Common Ground of Rhetoric and Logic," ERIC (1978), ED 162-309.

Larson, Barbara. "Method in Rhetorical Criticism: A Pedagogical Approach and Proposal," Central States Speech Journal, 28 (Winter, 1977), 295-301.

LaRusso, Dominic. Concepts and Skills of Oral Communication. 2nd ed. Dubuque: Wm. C. Brown Co. Publishers, 1973.

- The Shadows of Communication. Dubuque: Kendall/ Hunt Fublishing Co., 1977.

Lefford, Arthur. "The Influence of Emotional Subject Matter on Logical Reasoning," The Journal of General Psychology, 34 (1946), 127-151.

Lenrow, Adele. "A Toulmin Analysis of the Argumentation Patterns in Selected Speeches of Joseph Kennedy, John Kennedy, Robert Kennedy and Edward Kennedy, "Dissertation Abstracts International, 32 (1971), 4804A, Columbia University.

Lewis, Al. "Stephen Toulmin: A Re-Appraisal," Central States Speech Journal, 23 (Spring, 1972), 48-55.

Littlejohn, Stephen. Theories of Human Communication. Columbus: Charles E. Merrill Co., 1978.

Manicus, Peter. "On Toulmin's Contribution to Logic and Argumentation, "Journal of the American Forensic Association, 3 (September, 1966), 83-94. 
Marsh, Pat. "A Model for Arguing Directive Propositions," Journal of the American Forensic Association, 6 (Winter, 1969), 1-11.

Matelski, Marilyn. "Khomeini's Argument for His Islamic Republic: A Relationist Perspective," paper presented at Western Speech Communication Association annual convention, February, 1980, Portland, Oregon.

Mill, John Stuart. A System of Logic. 1843; reprinted New York: Longmans, Green and Co., 1941.

Mills, Glen. Reason in Controversy. Boston: Allyn and Bacon, Inc., 1964; 2nd ed., 1968.

and Hugh Petrie. "The Role of Logic in Rhetoric," Quarterly Journal of Speech, 54, No. 3 (October, 1968), $260-267$.

Minnick, Wayne. The Art of Persuasion. 2nd ed. Boston: Houghton Mifflin Co., 1968.

Morgan, John, and Morton, James. "The Distortion of Syllogistic Reasoning Produced by Personal Convictions," The Journal of Social Psychology, 20 (1944), $39-59$.

Mortenson, C. D., and Anderson, R. L. "The Limits of Logic, "Journal of the American Forensic Association, 7 (Spring, 1970), 71-78.

Mudd, Charles. "Enthymeme and Logical Validity," Quarterly Journal of Speech, 45 (December, 1959), 413.

and Sillars, Malcolm. Speech: Content and Communication. 3rd ed. New York: Thomas Crowell Co., 1975.

McBath, James. Review of Decision by Debate by thninger and Brockriede. 2nd ed. Journal of the American Forensic Association, 16 (Summer, 1979), 64-65.

Mc Croskey, James. "Toulmin and the Basic Course," Speech Teacher, 14 (March, 1965), 91-100.

2nd e $\frac{\text { An Introduction to Rhetorical Communication }}{\text { d. Englewood Cliffs: Prentice-Hall Inc., }}$ ig72.

McKeon, Richard, ed. The Basic Works of Aristotle. New York: Random House, 1941. 
McKerrow, Ray. "On Fields and Rational Enterprises: A Reply to Willard," in Proceedings of the Summer Conference on Argumentation. Edited by Jack Rhodes and Sara Newell. Falls Church: Speech Communication Association, 1980.

Newell, Sara. "Making Sense of Argumentation Theory," paper presented at Western Speech Communication Association annual convention, February, 1980, Portland, Oregon.

Newman, Robert. "Analysis and Issues--A Study of Doctrine," Central States Speech Journal, 13, No. I (Autumn, 1961), 43-54.

O'Keefe, Daniel. Review of An Introduction to Reasoning by Toulmin, Rieke, and Janik. Journal of the American Forensic Association, 16 (Fall, 1979), 143-145.

Parson, Donn. Review of An Introduction to Reasoning by Toulmin, Rieke, and Janik. Journal of the American Forensic Association, 16 (Fall, 1979), 145-147.

Perelman, Chaim, and Olbrechts-Tyteca, I. The New Rhetoric: A Treatise on Argumentation. Translated by John Wilkenson and Purcell Weaver. Notre Dame: University of Notre Dame Press, 1969.

Phillips, Neil. "The 1976 Presidential Debate: A Toulmin Analysis of the Personality Issues." M.A. thesis, University of Houston, 1978.

Polanyi, Michael. The Study of Man. Chicago: University of Chicago Press, 1959.

Pratt, Jerie. "The Appropriateness of a Toulmin Analysis of Legal Argumentation," Speaker and Gavel, 7, No. 4 (May, 1970), 133-137.

Quine, W. V. O. Methods of Logic. 3rd ed. Iondon: Routledge Publishing Co., 1952.

Quintilian. Institutes of Oratory. Translated by H. Butler. Cambridge: Harvard University Press, 1921, II.

Rabin, David. "Gottlieb's Model of Rule-Guided Reasoning: An Analysis of Griswold v. Connecticut," Journal of the American Forensic Association, 15, No. 2 (Fall, 1978), 78-90.

Reichenbach, Hans. Elements of Symbolic Logic. New York: Macmilian Co., 1947. 
Reinard, John, and Reynolds, Rodney. "An Experimental Study of the Effects of Toulmin's Pattern for Argument Development on Attitude Change," paper presented at Western Speech Communication Association annual convention, 1976, San Francisco, California.

Rhodes, Jack, and Newell, Sara, eds. Proceedings of the Summer Conference on Argumentation. Falls Church: Speech Communication Association, 1980.

Rieke, Richard, and Sillars, Malcolm. Argumentation and the Decision Making Process. New York: John Wiley and Sons, Inc., 1974.

Ryle, Gilbert. "Formal and Informal Iogic," in Essays on Rhetoric. Edited by Dudley Bailey. New York: Oxford University Press, 1965.

"Philosophical Arguments," in Collected Papers by Ryle. London: Hutchinson and Co., 1971, II.

Salmon, Wesley. Iogic. Englewood Cliffs: Prentice-Hall, Inc., 1963.

Sapes, William. "Selected Arguments of Richard Nixon as Analyzed on the Toulmin Model." M.A. thesis, University of Pacific, 1973.

SCA Administrative Committee. SPECTRA, 16 (February, 1980), $1-3$.

Scheidel, Thomas. Persuasive Speaking. Indianapolis: Bobbs-Merrill Co., 1967.

Speech Communication and Human Interaction.

Glenview: Scott, Foresman and Co., 1972 .

Scott, Robert. "On Viewing Rhetoric as Epistemic," Central States Speech Journal, 18 (February, 1967), 9-17.

Shepard, David. "Rhetoric and Formal Logic," Western Speech, 30, No. 4 (Fall, 1966), 241-247.

Sillars, Malcolm. "Audiences, Social Values, and the Analysis of Argument," Speech Teacher, 22 (November, 1973), 291-303.

Simpoulos, J. Ch. Review of The Uses of Argument by Stephen Toulmin. Hibbert Journal, 57 (1958), 96-98. 
Smith, David. "Communication Research and the Idea of Process," Speech Monographs, 39, No. 3 (August, 1972), 175-176.

Smith, Robert. "The Arguments Over Abolition Petitions in the House of Representatives in December, 1835," Dissertation Abstracts, 24 (1962), 897, University of Minnesota.

Smith, Ted III. Review of An Introduction to Reasoning by Toulmin, Rieke, and Janik. Communication Education, 29, No. 2 (May, 1980), 210.

Spicer, Holt. "Stephen Toulmin's Functional Analysis of Logic and Ethics and its Relation to Rhetoric," Dissertation Abstracts, 25 (1964), 2105, University of Oklahoma.

Sproule, Michael. "Assessing Validity in Rhetorical Argument: A Definition and Application, " paper presented at the Speech Communication Association annual convention, 1975, in ERIC, ED 119-249.

Terris, Walter. Content and Organization of Speeches. Dubuque: Wm. C. Brown Co. Publishers, 1968.

Toulmin, Stephen. Reason in Ethics. Cambridge: Cambridge University Press, 1950.

The Philosophy of Science: An Introduction. London: Hutchinson and Co. Ltd., 1953.

The Uses of Argument. Cambridge: Cambridge University Press, 1958.

Foresight and Understanding: An Enquiry into the Aims of Science. New York: Harper and Row, Publishers, Inc., 1963.

- Human Understanding: The Collective Use and Evolution of Concepts. Vol. I. Princeton: Princeton University Press, 1972.

, Rieke, Richard, and Janik, Allan. An Introduction to Reasoning. New York: Macmillan Publishing Co., Inc., 1979.

Trapp, Robert. "Toward a Person-Centered Theory of Argument," paper presented at Western Speech Communication Association annual convention, February, 1980, Portland, Oregon. 
Trent, Jimmie. "Stephen E. Toulmin's Argument Model as an Instrument for Criticism of Forensic Speeches," Dissertation Abstracts, 27 (1966), 552A, Purdue University.

"Toulmin's Model of Argument: An Examination and Extension," Quarterly Journal of Speech, 54 (October, 1968), 252-259.

Wason, P. C., and Johnson-Laird, P. N. Psychology of Reasoning: Structure and Content. Cambridge: Harvard University Press, 1972.

Watzlawick, Paul, Beavin, Janet, and Jackson, Don. Pragmatics of Human Communication. New York: W. W. Norton and Co. Inc., 1967.

Wenzel, Joseph. "The Contributions of Argumentation to a Rhetoric of Values," ERIC (December, 1975), ED 123697.

"Perspectives on Argument," in Proceedings of the Summer Conference on Argumentation. Edited by Jack Rhodes and Sara Newell. Falls Church: Speech Communication Association, 1980.

Whately, Richard. "Elements of Rhetoric," in The Rhetoric of Blair, Campbell and Whately. Edited by James Golden and Edward P. J. Corbett. New York: Holt, Rinehart and Winston, Inc., 1968.

Whitehead, Alfred North, and Russell, Bertrand. Principia Mathematica. Cambridge: Cambridge University Press, 1927.

Will, F. Review of The Uses of Argument by Stephen Toulmin. The Philosophical Review, 69 (1960), 399-403.

Willard, Charles. "On the Utility of Descriptive Diagrams for the Analysis and Criticism of Arguments," Communication Monographs, 43, No. 4 (November, 1976), 308-319.

"Argument as Non-Discursive Symbolism," Journal of the American Forensic Association, 14 , No. 2 (Spring, 1978), 187-193.

Review of The Logic of Choice by Gidon Gottlieb. Journal of the American Forensic Association, 15 (Fall, 1978), 124-132. 
"Propositional Argument Is to Argument What Taiking About Passion Is to Passion, "Journal of the American Forensic Association, 16 (Summer, 1979), 21-28.

"Some Questions About Toulmin's View of Argument Fields," in Proceedings of the Summer Conference on Argumentation. Edited by Jack Rhodes and Sara Newell. Falls Church: Speech Communication Association, 1980.

Wilson, John, and Arnold, Carroll. Public Speaking as a Liberal Art. Boston: Allyn and Bacon, Inc., 1964; 2nd ed., 1968; 3rd ed., 1974; 4th ed., 1978.

Windes, Russell, and Hastings, Arthur. Argumentation and Advocacy. New York: Random House, Inc., 1965.

Woodworth, Robert, and Sell, Saul. "An Atmosphere Effect in Formal Syllogistic Reasoning," Journal of Experimental Psychology, 18 (1935), 451-460.

Verdeber, Rudolph. The Challenge of Effective Speaking. 3rd ed. Belmont: Wadsworth Publishing Co., 1976. 